IMISCOE Research Series

Peter Scholten

Han Entzinge

Rinüs Penninx

Stijn.Verbềek Editors
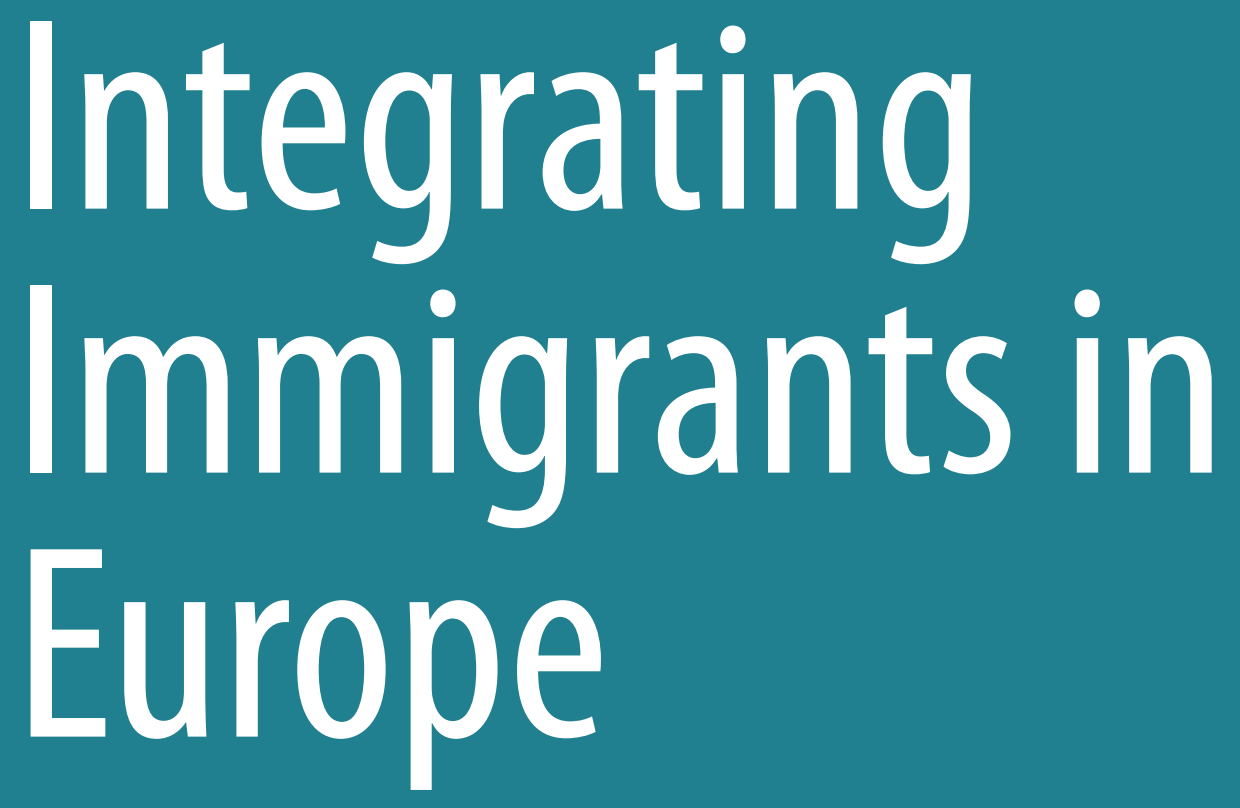

Research-Policy Dialogues

IMISCOE

Springer Open 


\section{IMISCOE Research Series}


This series is the official book series of IMISCOE, the largest network of excellent research on migration and diversity in the world. It comprises publications that present empirical and theoretical research on different aspects of international migration. The authors are all specialists, and the publications are rich source of information for researchers and others involved in international migration studies.

The series is published under the editorial supervision of the IMISCOE Editorial Committee, which includes leading scholars from all over Europe. The series, which contains more than eighty titles already, is internationally peer reviewed. This ensures that the books published in this series continue to present excellent academic standards and scholarly quality. Most of the books are available in open access.

For information on how to submit a book proposal, please visit: http://www. imiscoe.org/publications/how-to-submit-a-book-proposal.

This book is published in Open Access with support of the Volkswagen Foundation.

More information about this series at http://www.springer.com/series/13502 
Peter Scholten • Han Entzinger • Rinus Penninx Stijn Verbeek

Editors

\section{Integrating Immigrants in Europe}

Research-Policy Dialogues

黛 Springer Open 


\section{Editors}

Peter Scholten

Department of Public Administration

Erasmus University Rotterdam

Rotterdam, Netherlands

Rinus Penninx

Institute for Migration and Ethnic Studies

University of Amsterdam

Amsterdam, Netherlands

\author{
Han Entzinger \\ Department of Sociology \\ Erasmus University Rotterdam \\ Rotterdam, Netherlands
}

Stijn Verbeek

Education Council of the Netherlands

(Onderwijsraad)

The Hague, Netherlands

Stijn Verbeek was previously associated with Erasmus University Rotterdam
ISSN 2364-4087

IMISCOE Research Series

ISBN 978-3-319-16255-3

DOI 10.1007/978-3-319-16256-0
ISSN 2364-4095 (electronic)

ISBN 978-3-319-16256-0 (eBook)

Library of Congress Control Number: 2015941153

Springer Cham Heidelberg New York Dordrecht London

(C) The Editor(s) (if applicable) and The Author(s) 2015. The book is published with open access at SpringerLink.com.

Open Access This book is distributed under the terms of the Creative Commons Attribution Noncommercial License, which permits any noncommercial use, distribution, and reproduction in any medium, provided the original author(s) and source are credited.

All commercial rights are reserved by the Publisher, whether the whole or part of the material is concerned, specifically the rights of translation, reprinting, reuse of illustrations, recitation, broadcasting, reproduction on microfilms or in any other physical way, and transmission or information storage and retrieval, electronic adaptation, computer software, or by similar or dissimilar methodology now known or hereafter developed.

The use of general descriptive names, registered names, trademarks, service marks, etc. in this publication does not imply, even in the absence of a specific statement, that such names are exempt from the relevant protective laws and regulations and therefore free for general use.

The publisher, the authors and the editors are safe to assume that the advice and information in this book are believed to be true and accurate at the date of publication. Neither the publisher nor the authors or the editors give a warranty, express or implied, with respect to the material contained herein or for any errors or omissions that may have been made.

Printed on acid-free paper

Springer International Publishing AG Switzerland is part of Springer Science+Business Media (www. springer.com) 


\section{Foreword}

This book is the outcome of a truly European exercise. It all started in May 2008 with a conference called 'Research-Policy Dialogues on Migration and Integration in Europe', held at the University of Twente, organised by Peter Scholten, the first editor of this book, who was based at Twente at the time, and Rinus Penninx. This conference was co-sponsored by the IMISCOE Research Network, and some of its contributors decided to continue their joint activities in this field in a special research group under the IMISCOE umbrella. They were all intrigued by the vast differences between European countries in the use of scientific knowledge in policymaking and in the patterns of communication between academic researchers and policymakers when it comes to analysing the impact of immigration and migrant integration. Peter Scholten and Rinus Penninx invited several speakers at the Twente conference to transform their paper into a book chapter. Updated versions of these chapters are included in the present volume.

In addition to this, a research proposal was developed by some of the members of the research group. The proposal primarily aimed at gathering more empirical evidence on the functioning of the research-policy nexus in the field of immigrant integration in several EU countries as well as in the EU as such. The proposal was called 'Science-Society Dialogues on Migration and Integration in Europe', abbreviated DIAMINT. It was accepted for funding by the Volkswagen Foundation in Hanover under its programme 'Science, the Public and Society'. The DIAMINT project was carried out between September 2011 and September 2013, under the supervision of Han Entzinger of Erasmus University Rotterdam, and Peter Scholten, who had moved meanwhile to that university. Stijn Verbeek, also at Erasmus University, contributed significantly to both the contents and the organisation of the project. The theoretical design of the present volume as well as most of its chapters constitutes the final report of the DIAMINT project. The project, and the IMISCOE Standing Committee of which the project was part, has also produced a considerable number of journal articles and other output, of which a list appears elsewhere in this book (see Appendix II).

As the editors of this book we wish to thank the Volkswagen Foundation, the IMISCOE Research Network and the University of Twente for their generous 
support that has enabled us to carry out this project over the past years. Our sincere thanks also go to all authors who have contributed to this volume. It has been a real challenge to work with so many colleagues of so many different backgrounds, but in the end all deadlines have been met! Of course, our thanks also go to all those who agreed to being interviewed for the DIAMINT project. Without their valuable expert observations this project would never have produced such insightful outcomes on research-policy dialogues over so many years and in so many different settings.

Last but not least, our thanks go to those who have contributed to the production of the present volume (see Appendix I for biographies of all contributing authors). We would like to thank several persons and organisations in particular. First, Dr. Alistair Hunter, who was not only a much appreciated colleague in the UK DIAMINT team, but who, as a native speaker of English, also took an essential role in the final editing of the book manuscript. Secondly, we would like to thank the VolkswagenStiftung for making the DIAMINT project possible, and for their support for publishing this book in Open Access. Finally, we owe a lot to the anonymous reviewers of an earlier version of this book. Their valuable comments have been much appreciated. Needless to say that the responsibility for the book rests with us as editors as well as with the authors of the individual chapters.

Peter Scholten Han Entzinger

Rinus Penninx

Stijn Verbeek 


\section{Contents}

1 Research-Policy Dialogues on Migrant Integration in Europe: A Conceptual Framework and Key Questions

Peter Scholten, Han Entzinger, and Rinus Penninx

Part I Forms and Functions of Research-Policy Dialogues

2 Cultures of Knowledge Use in Policymaking: The

Functions of Research in German and UK Immigration Policy......

Christina Boswell

3 Migration Statistics in Europe: A Core Component of Governance and Population Research

Albert Kraler, David Reichel, and Han Entzinger

4 The Coproduction of National Models of Integration:

A View from France and the Netherlands

Christophe Bertossi, Jan Willem Duyvendak, and Peter Scholten

5 Consultative Commissions and the Rethinking of Integration Policies in the Netherlands and Germany: The Blok Commission and the Süssmuth Commission Compared ... Jan Schneider and Peter Scholten

6 European Cities in Search of Knowledge for Their Integration Policies

Rinus Penninx

7 EU Policymaking and Research: Case Studies of the Communication on a Community Immigration Policy and the Common Basic Principles for Integration

Sandra Pratt 
8 Speaking Truth to Power? Why Civil Society, Beyond Academia, Remains Marginal in EU Migration Policy

Ann Singleton

Part II Research-Policy Dialogues in the European Union and Seven of Its Member States

9 Research-Policy Dialogues in Austria Maren Borkert

10 Research-Policy Dialogues in Italy Tiziana Caponio

11 Research-Policy Dialogues in Germany Friedrich Heckmann and Delia Wiest

12 Research-Policy Dialogues in the Netherlands Stijn Verbeek, Han Entzinger, and Peter Scholten

13 Research-Policy Dialogues in the United Kingdom Alistair Hunter and Christina Boswell

14 Research-Policy Dialogues in Poland Mikołaj Pawlak

15 Research-Policy Dialogues in Denmark Martin Bak Jørgensen

16 Research-Policy Dialogues in the European Union Andrew Geddes and Marthe Achtnich

\section{Part III Comparison and Conclusions}

17 Research-Policy Dialogues on Migrant Integration in Europe: Comparison and Conclusions

Peter Scholten, Han Entzinger, and Rinus Penninx 


\title{
Chapter 1 \\ Research-Policy Dialogues on Migrant \\ Integration in Europe: A Conceptual \\ Framework and Key Questions
}

\author{
Peter Scholten, Han Entzinger, and Rinus Penninx
}

\subsection{Introduction}

Europe has become 'a continent of immigration' in the course of the last half century, and European societies have experienced growing ethnic and cultural diversity (Okolski 2012). Recognition of the necessity to devise migrant integration policies in light of these facts has been uneven in time and place (Penninx 2013). For example, in a number of cases integration policies were first formulated at the city level rather than the national level. Since the turn of the century, however, most European states have developed some form of integration policy; after 2003, the European Union (EU) also entered this increasingly multi-level field of policy.

These local, national and EU governmental actors have often made great efforts to collect and develop the knowledge and expertise required to understand integration processes and to control and steer these. Such knowledge may be collected from existing sources or, if the required knowledge is not available, it may be solicited from the research world. It may be used for different purposes: to give policies a sound conceptual basis, to develop policy instruments and measures, or to monitor and evaluate policies.

\footnotetext{
P. Scholten $(\bowtie)$

Department of Public Administration, Erasmus University Rotterdam, P.O. Box 1738, 3000 DR Rotterdam, Netherlands

e-mail: p.w.a.scholten@fsw.eur.nl

H. Entzinger

Department of Sociology, Erasmus University Rotterdam, P.O. Box 1738, 3000 DR Rotterdam, Netherlands

R. Penninx

Institute for Migration and Ethnic Studies, University of Amsterdam,

Nieuwe Achtergracht 166, 1018 WV Amsterdam, Netherlands

(C) The Author(s) 2015

P. Scholten et al. (eds.), Integrating Immigrants in Europe,

IMISCOE Research Series, DOI 10.1007/978-3-319-16256-0_1
} 
In this context, the social sciences have played an important role in shaping public understanding of immigrant integration processes, and in many cases also in shaping government policies. When this started to happen and the way in which this took place, however, varies from one country to another, and from city to city. The specific role of social scientists in shaping policies also varies greatly: in some cases researchers have been quite active both in the scientific process of formulating the content of policies and in the political process of getting policies established. In other cases, social scientists have distanced themselves, or have been kept at a distance, from policymaking. Between these two positions many variations also exist.

Scientists may have influenced policies, but the reverse may also be the case: policymakers may play a role in shaping the production of knowledge. Policymakers may solicit the knowledge they wish to have in many ways and with varying degrees of scientific freedom for researchers.

Major differences exist between European countries in the way relations between policy and research on immigrant integration have evolved. Nowadays, however, a feature common to many European countries is that the body of scientificallybased knowledge on immigrant integration has increased substantially, while at the same time public authorities seem to have become less interested in making use of the assembled knowledge. The current relationship between migration research and policymaking seems to have led to a certain disenchantment about researchpolicy dialogues. Although the idea of 'evidence-based policymaking' has gained wide recognition discursively, strong evidence also exists that politicians and policymakers often use scientific research for symbolic rather than instrumental purposes (Boswell 2009). Clearly, in parallel with the increasing politicisation of the field, earlier optimism about the value of academic expertise in guiding rational societal steering has yielded to a growing cynicism about the validity of research and the credibility of researchers (Scholten and Verbeek 2014).

At the same time, various scholars have indicated their disenchantment about the policy-driven orientation of research in this area and the lack of theoretical development in this research field (Favell 2003; Bommes and Thränhardt 2010). They see this as an effect of the intense contacts between researchers and policymakers that have existed in several countries. Critics have coined the term 'methodological nationalism' to describe research fields where choice of topics, questions to be answered, conceptual and theoretical approaches, and the sources to be used largely depend on political and policy framing by national governmental actors (Wimmer and Glick Schiller 2002). This, in turn, has led to a call for more independent, theory-driven and (international) comparative research (Penninx et al. 2006).

This book aims to develop deeper insights into how research and policymaking in the field of migrant integration have developed historically and how this interrelationship plays out in the strongly politicised climate of opinions on migration in Europe. We do this firstly by developing a conceptual frame for analysis of research-policy dialogues (in this introductory chapter). This is followed by a comparative analysis of empirical cases in the rest of the book: Part I presents comparative case studies of different forms of dialogues and their functions, while Part II systematically analyses the development of research-policy dialogues in 
seven national cases, as well as at the EU level. In Part III (Chap. 17) we compare the main findings of this book and try to find answers to the hypotheses formulated in this introductory chapter.

\subsection{Conceptualising Research-Policy Dialogues}

For the purpose of this book, research-policy dialogues are defined broadly as all forms of interaction between researchers and policymakers in the domain of immigration and immigrant integration. The term 'dialogues' is used to refer to the reciprocal nature of research-policy relations; we are not just looking at how research is used in policymaking, but also how the policy context and the dialogues influence research (in size, orientation and content: the production of knowledge). In addition, the term 'dialogues' is meant to capture the very diverse forms that research-policy relations may take. In some cases, research-policy dialogues evolve around a strongly institutionalised research-policy nexus, for instance through formal research or advisory committees. In other cases research-policy dialogues are much less institutionalised and take more informal and indirect forms, for example through personal networks, through the media, or through other ad-hoc channels.

Since we intend to study research-policy dialogues empirically, we do not sharply define at the outset what counts as 'research' or 'knowledge' within these dialogues. In fact, establishing what type of research or knowledge is produced and communicated in research-policy dialogues is an interesting empirical question. For instance, whether quantitative or qualitative-conceptual research is produced and used tells us something about the nature of the research-policy dialogue that is taking place. Conversely, the policy side of these dialogues is not monolithic either. Research and knowledge can be in demand at different locations and at different levels of government (national, regional, local, supra-national) for different purposes (policy development, implementation, evaluation or political debate). This has consequences for what is defined as relevant knowledge (which will be discussed in more detail in Sect. 1.2.3).

In our analytical approach we distinguish three aspects of research-policy dialogues. First, we will explore and analyse the concrete structures of researchpolicy dialogues (dialogue structures). These are the formal, and also the informal, arrangements through which knowledge is exchanged, and through which decisions on knowledge production and the relevance of knowledge for policy, are communicated. Secondly, we will look at cultures and practices of knowledge utilisation in policy processes (knowledge utilisation). Here we take the perspective of policymakers and analyse what role is assigned to researchers and what function is attributed to knowledge and research. Thirdly, taking the perspective of researchers, we will look at cultures of knowledge production in the field of migration research itself (knowledge production).

These three aspects of research-policy dialogues have been dealt with separately in the migration literature. In the area of dialogue structures, for example, Florence 


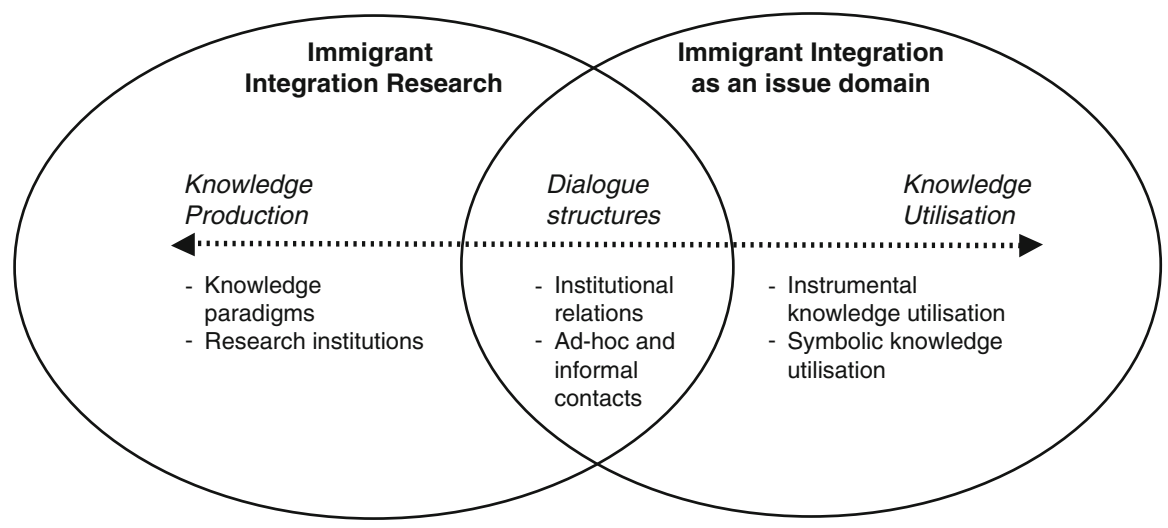

Fig. 1.1 The three main aspects of research-policy dialogues and their interrelationship: this book's conceptual model

and Martiniello (2005), Geddes (2005), Penninx (2005), Scholten (2011a), and Thränhardt and Bommes (2010) have written variously about channels of communication in research-policy dialogues, such as research institutes, advisory bodies, expert committees and more informal networks. Boswell (2009) has focused on knowledge utilisation. The impact of policy on knowledge production has been treated by Favell (2003), Thränhardt and Bommes (2010), Vasta and Vuddamalay (2006), and Penninx (2005). However, the interconnections between these three aspects have not yet been dealt with. The key objective of this book is to bring together these literatures and explore how the relations between these three aspects can be conceptualised and analysed empirically.

Figure 1.1 shows the three aspects of research-policy dialogues and how these are interconnected. In the sections that follow we will elaborate all three - also in their interrelationships - and further develop the major hypotheses that will guide us throughout this book.

\subsubsection{Dialogue Structures}

The first key question here is how research-policy dialogues are structured. How are dialogues organised, in what venues do they take place, what types of actors are involved, what type of knowledge is communicated, and what issues are discussed?

In the sociology of science literature and in policy sciences, a number of idealtype models of research-policy structures have been defined (see Hoppe 2005; Scholten 2011b). The enlightenment model ('speaking truth to power') is perhaps the one that comes closest to the ideal-typical image of the role that scientific research should have in policymaking. The enlightenment model postulates sharp boundaries between research and policy and assumes that scientific knowledge will 
eventually 'creep' into the policymaking process and thus (indirectly) determine how policymakers interpret and act upon policy problems. In contrast to the sharp boundaries of the enlightenment model, Hoppe (2005) formulates a technocratic model of research-policy relations, where researchers ('experts') are more directly involved in policymaking. In a technocracy, researchers do more than just provide knowledge. In short, they also frame policy problems and develop solutions; they come much closer to taking on the role of policymakers themselves.

Whereas both the enlightenment and the technocratic models assume that research-policy relations should be structured to give research a primary role in policymaking, alternative approaches like the engineering model and the bureaucratic model hold a firm belief in the primacy of politics in policymaking. The latter two models assume that research provides input to policymaking and political decision making while recognising that the outcomes of policymaking are also determined by other considerations, including values, norms and power. In the bureaucratic model, research is supposed to provide data ('facts') that are required by policymakers to develop policies and to reach decisions. This model assumes a sharp Weberian factvalue dichotomy between research and politics. The engineering model, by contrast, allows researchers a more far-reaching role in policymaking, while assuming, however, that politics keeps its primacy and is at liberty to select ('pick-and-choose') those strands of expertise that it sees fit.

Although these models are primarily based on the function that research and knowledge may have for policy and policymaking, they may also be used as heuristic devices for mapping differences between forms of dialogues, or even for comparing research-policy dialogues in different countries. They may also serve to map the dynamics of specific forms of dialogue structures within countries. The assumption then is that each model triggers specific forms of research-policy dialogue structures. Several studies have already indicated that significant differences exist between countries in terms of such structures as well as in their degrees of institutionalisation. Scholten (2011b), for instance, revealed that, whereas the Dutch research-policy nexus was strongly institutionalised in the period between 1980 and 1992, involving a very significant influence of research on policymaking (in the logic of the technocratic model), the French research-policy nexus involved more informal and personal networks between researchers and policymakers, with a much stronger primacy for politics (the bureaucratic model). Boswell and Hunter (2014) showed how in the UK case various independent commissions played an important role in research-policy dialogues. Systematic study of changes over time of researchpolicy structures from one model to another in the same context may shed light on the specific conditions under which these come into existence and disappear.

Favell (2003), Rath (2001), and Scholten (2011a) amongst others, have shown that in various cases migration scholars had a strong policy-orientation that led to a relatively high degree of institutionalisation of research-policy relations. Favell (2003) speaks even of a policy-orientation habitus. Scholten (2011a) shows how particular organisations were established to structure research-policy dialogues. These authors show that a depoliticised context provides a good breeding ground for institutionalisation of research-policy relations. In fact, Rath (2001) refers to 
a 'technocratic symbiosis' to depict a situation where researchers and policymakers jointly frame policies in a technocratic relationship not characterised by politicisation.

Several scholars, however, have argued that the current politicisation of migration has led to changes in specific research-policy dialogue structures (Florence and Martiniello 2005; Scholten and Verbeek 2014). On the basis of earlier studies on politicisation and research-policy dialogues, we hypothesise that the former will lead to a deconstruction of such institutionalised dialogue structures. We assume that these have become less direct, more public and open to more diverse participants, and also more ad-hoc. This leads us to the concrete hypothesis guiding this book, namely that politicisation leads to de-institutionalisation of existing research-policy relations (less direct, more open, more ad-hoc). Conversely we hypothesise that institutional relations will persist in contexts characterised by relatively low levels of politicisation.

\subsubsection{Knowledge Utilisation}

The second aspect of research-policy dialogues focuses specifically on the question of how knowledge is utilised in policymaking. Christina Boswell (2009; see also Chap. 2 in this volume) distinguishes different modes of knowledge utilisation. The most basic type involves the instrumental utilisation of knowledge and expertise, where research outcomes are directly taken as input for policymaking. It is this type of knowledge utilisation that is assumed in the notion of 'evidence based policymaking'. In addition to instrumental use of knowledge, Boswell distinguishes two symbolic types of knowledge utilisation. Rather than being used as input for decision-making, knowledge can also have a substantiating function for policymakers, whereby favourable knowledge and expertise merely provide support for already-decided policies. Besides substantiating policy decisions, research can also have a plainly legitimising function for policy actors and institutions. This legitimising function of research and expertise does not refer to substantive research findings themselves, but to the mere symbolic act of mobilising knowledge and expertise in order to claim authority over a particular policy domain or issue (see also Caponio et al. 2014 and Scholten and Timmermans 2010).

Boswell's landmark work on knowledge utilisation in migration policymaking in the United Kingdom, Germany and the EU (Boswell 2009) alludes to various important contextual factors that may help explain why, where and when a specific type of knowledge utilisation emerges. For instance, her examination of the European Migration Network revealed that this organisation primarily served to substantiate EU migration policies in the context of the fierce politicisation of this issue at the European level. In addition, her British and German case studies point to the relevance of the organisational structure of the policy domain. She claims, for instance, that the fragmented and contested nature of the migration policy domain in Germany helps explain why the role of the BAMF (Federal Office for Migration 
and Refugees) was mostly substantiating rather than instrumental or legitimising (see also Chap. 11 in this volume for a slightly different perspective on the BAMF's role in the German case).

Interestingly, Boswell's case studies suggest that we should study knowledge utilisation and policy-research structures at two different levels. On the one hand, there is the more generic level of national cultures of knowledge utilisation, with different traditions in the UK and Germany for example, that may explain the frequent incidence of certain forms of policy-research dialogues. On the other hand, the particular culture and practices in a specific domain and a specific institution may in reality turn out to be quite different from what one may expect on the basis of national cultures and traditions. For instance, whereas the specific British case revealed a great interest in policymaking based on knowledge and evidence, in reality research mostly served substantiating purposes rather than having a legitimising or instrumental role. Boswell's exploration of these contextual factors further underlines the necessity of more conceptual and empirical work that connects knowledge utilisation to the issue of how research-policy relations are structured in the first place.

What could the possible effects of politicisation be on utilisation of knowledge and on research-policy dialogues? Following Boswell's typology of knowledge uses and our observation that technocratic modes of dialogues are often associated with direct instrumental forms of knowledge utilisation, we formulate as the second hypothesis for our empirical analyses that, when issues like migrant integration become politicised, such technocratic structures and instrumental forms of knowledge utilisation are less likely to emerge and to survive. Instead we would then expect rather symbolic forms of knowledge utilisation, substantiating as well as legitimising ones.

\subsubsection{Knowledge Production}

The third aspect focuses on the relation between knowledge production and research-policy dialogues: how does knowledge production influence such dialogues and, vice versa, how do dialogues affect migrant integration research itself? Research-policy dialogues can create opportunity structures for specific researchers, with specific research programmes and institutes in turn emerging and influencing policy (see Jasanoff 2005; Entzinger and Scholten 2014; Penninx 1988). In the longer run, however, there may also be a significant influence in the opposite direction. Strongly institutionalised relations with policymaking institutions may affect the structural characteristics of migration research as a research field. They may influence the extent of consensus or fragmentation in a research field. For instance, the strongly institutionalised relationship between research and policymaking in the Netherlands and Sweden in the 1980s provided a dominant position for specific dialogue structures and their participants (such as ACOM and EIFO/DEIFO respectively) and thereby created a 'consensus' in research on migrant integration in that period (Penninx 2005; Hammar 2004). In contrast, recent studies show that 
opportunity structures in this domain have become much more diverse, which has contributed to a fragmentation of the research field. We hypothesise that this is an effect, at least to some extent, of the rapid politicisation of migrant integration.

Beyond such effects on the structure of the research field (which have received relatively little attention), various scholars have also pointed to more substantive impacts on 'knowledge production', recognisable in methodological, theoretical and disciplinary developments. For example, Thränhardt and Bommes (2010) claim that research-policy dialogues have hampered the theoretical development of migration research. In particular, they claim that migration research uses the nation state as a 'constitutive frame' for the study of migration. This has hampered the rise of a more critical approach to the nation state and has stressed 'the social importance' of solving integration as a problem of the nation rather than conceptualising and theorising immigration and integration from a more scientific perspective (ibid: 30 ). In the same vein, Favell (2003) claims that the strong policy orientation of research has contributed to the rise of what he calls the 'integration paradigm'. Wimmer and Glick Schiller (2002) refer to comparable biases in migration research, coining the term 'methodological nationalism'. In their view, 'nation state building processes have fundamentally shaped the ways immigration has been perceived and received. These perceptions have in turn influenced, though not completely determined, social science theory and methodology and, more specifically, its discourse on immigration and integration' (Wimmer and Glick Schiller 2002: 301-302).

Related to Bommes and Thränhardt's argument about the field's poor theoretical development and Favell's critique of the exclusive focus on integration within the nation state, it has been claimed that migration researchers have (co-)produced specific national models of integration. Such models have incorporated specific national and historically rooted definitions, interpretations and frames of immigrant integration, as, for example, the French Republican model, the British RaceRelations model, or the Ethnic-Minorities paradigm in the Netherlands in the 1980s (Rath 2001). Many scholars have argued that research-policy dialogues have been structured around such specific models within exclusively national settings. For instance, Bertossi (2011; see also Bertossi et al., Chap. 4 in this volume) shows how French migration scholars have tended to reproduce the French Republican model. Similarly, Thränhardt and Bommes (2010) show how research-policy dialogues in Germany have thus far evolved largely around the institutions of the German welfare state.

Partly as a reaction to the tendencies of migration researchers to confine themselves to national framings, there has been an undeniable upsurge of international comparative research in the field of migration and integration, especially over the past decade. Emerging international research networks such as IMISCOE have triggered this, ${ }^{1}$ but it has also been strongly supported by the European Commission's Directorate General (DG) for Research and Innovation (for instance

\footnotetext{
${ }^{1}$ IMISCOE stands for International Migration, Integration and Social Cohesion in Europe. It started as an EU-funded Network of Excellence (2004-2010) and continued as an independent consortium of now over 30 research institutes in Europe: see www.imiscoe.org
} 
through the European Framework Programmes) and other EU funds (European Integration Fund, European Refugees Fund and European Social Fund: see also Chap. 16 in this volume). Stimulated by DG Research, a number of national research funding agencies within the EU have also started to jointly fund crossnational research, via the NORFACE programme. In the 2009-2013 period this programme focused on migration and integration in Europe. This new direction of research has in turn led to more explicit criticisms of national models of integration and to the rise of transnationalist and post-nationalist perspectives on immigrant integration. Interestingly, as Geddes (2005: 267) argues, the substantial and growing involvement of European institutions in (the funding of) research in this field has contributed to the characterisation of migration and integration as 'problems of Europe' (see also Geddes and Scholten 2014).

Knowledge production can of course involve very different 'types' of knowledge, such as conceptual or theoretical research, applied research, statistical analyses, policy analysis (including policy evaluation and policy-oriented studies), or more personalised and experience-based expressions of 'expertise.' In the field of migration research, all of these knowledge types are present. However, the type of knowledge that is mobilised in research-policy dialogues is very much contextdependent (see also Entzinger and Scholten 2014). For instance, in technocratic sessions one may expect more applied research and policy analyses as well as calls upon specific forms of expertise, whereas the idea of 'enlightenment' often speaks more to conceptual or theoretical forms of knowledge production. This speaks to the broader assumption in this book that knowledge production, knowledge utilisation and research-policy dialogue configurations are inherently connected.

One of these types of knowledge seems to have become particularly important in the field of migration research: administrative data. Most countries have welldeveloped programmes in place for gathering data on migration and integration issues, but the data gathered by institutions are often national in the sense that the target groups are defined by national territory or jurisdiction and nationally specific in their framing or content. This makes cross-national comparisons difficult.

Following the institutionalisation of migration and integration policies throughout Europe, a greater demand has emerged for comparative quantitative data for monitoring and evaluation purposes. Large-scale EU-funded projects, such as COMPSTAT and PROMINSTAT have systematically mapped national data systems on migration and integration and assessed their comparability. European statistical agencies, particularly Eurostat, have been charged with standardising existing national systems to improve their comparability, as well as with designing new ones to replace or complement these. The MIPEX programme to establish comparative indicators on migration policies is another example at the EU level (Huddleston and Niessen 2011). Although such efforts may be defined as technical exercises to attain better comparability, it is also clear that they serve the political goal of stimulating policy convergence through soft means of coordination. In this sense, one might say that such efforts to quantitatively 'measure' migration and integration policies (and their outcomes) with administrative data encounter the same conceptual problems as qualitative research (Favell 2003). Determining what to measure, how to measure 
it and how to interpret data have become central issues of discussion in various countries (see Chap. 3 by Kraler et al. in this book).

Having recognised the mutual influence that research-policy dialogues can have both on policy and on developments within the field of migration research itself (e.g. reproducing specific national models of integration), we can now elaborate some expectations about what will happen in a politicised situation. First, we expect that co-production of knowledge is more likely to come into existence and be sustained in depoliticised settings rather than politicised ones. A depoliticised setting seems to be a condition for sustaining certain structural arrangements, such as subsidising specific research centres or accepting and privileging one specific frame of migrant integration. Turning this argument around, we expect that in a more politicised context a de-institutionalisation of research-policy dialogues is likely to take place. Furthermore, we expect the growing internationalisation of research to challenge 'national models of integration', leading to a fragmentation of research within and across academic disciplines and into more heterogeneous schools of thought. Thus, we expect politicisation, along with certain other trends just described, to contribute to knowledge diversification and, consequently, to more frequent (and more intense) knowledge conflicts.

It is important to acknowledge that the foregoing observations are primarily based on a number of countries that have a longer immigration history and therefore a longer history of policy-research dialogues, at least potentially. It may be interesting to ask the same questions for relatively new immigration countries, such as Southern European countries that were first faced with large-scale immigration in the 1990s, and similarly for the Central and East European countries that introduced the EU policy regime for migration and integration only after their accession to the EU in 2004. Since most of these countries (still) have low immigration and lack historically rooted national models of integration, we will be able to observe how research-policy relations and structures have evolved there from their very beginning. This is why in this volume we include not only 'traditional' immigration countries in the North and West of Europe, but also Italy as relatively new immigration country, and Poland, which has a long experience of emigration, but which hosts only small numbers of immigrants.

\subsection{Contributions to this Book}

The contributions to this book aim to advance empirical and theoretical understanding of how research-policy dialogues have been configured, how they have evolved in diverse (local, national, European) settings, and what their effects have been on migrant integration policy and research. The book brings together the knowledge of researchers who have made empirical studies of research-policy relations, as well as the perspectives of experts who themselves have actively participated in these research-policy dialogues. These researchers and experts not only hail from countries with a longer history of immigration, but also from 'new' immigration countries. 
The chapters in Parts I and II of the book have a common genesis: reflecting the internationalisation of knowledge production on this topic, the chapters originate in exchanges since 2008 among a group of researchers established through the IMISCOE research network, looking at multi-level governance of migration and integration. A first major milestone of this cooperation was the IMISCOE-conference 'Research-Policy Dialogues on Migration and Integration in Europe', held at the University of Twente on May 22 and 23, 2008 (see Penninx and Scholten 2009). Since that conference, the activities on this topic have been continued in two different manners. First, the editors of this book - who were all involved in the Twente conference - invited colleagues involved in empirical research on facets of the policy-research nexus as well as some policymakers to write a book chapter on the theme of the conference. This has resulted in the seven chapters in Part I of this book.

Secondly, the editors of this book decided to prepare a funding proposal for a comparative empirical study on the actual functioning of the policy-research nexus in a number of countries. This proposal, entitled 'Science-Society Dialogues on Migration and Integration in Europe' (DIAMINT) was accepted for funding by the Volkswagen Stiftung under its programme 'Science, the Public, and Society'. This 2-year project of empirical research was carried out between September 2011 and September 2013. Six of the chapters in Part II of this book result from this DIAMINT comparative project: these are the chapters on Austria, Italy, Germany, the Netherlands, the United Kingdom and the European Union. Two more chapters those on Poland and Denmark - were initially meant to be country case studies for Part I, but were later rewritten in accordance with the DIAMINT template used for the other country chapters in Part II.

The two major parts of this book not only have a common origin, but they also share the same theoretical background: the conceptual ideas and exploration of the field - as presented in the foregoing pages - have been the starting point for all authors who have contributed to this volume. The two parts also share a focus on migrant integration, rather than on migration. These are two policy areas which can be distinguished analytically from one another without much difficulty, but which are not always so easy to separate empirically. Developments in one area often have an impact on the other. This becomes of particular interest when the European dimension is considered, since the EU's competencies in the area of migration reach much further than those in the field of integration.

\subsubsection{Part I: Forms and Functions of Research-Policy Dialogues}

The contributions in Part I bring various case studies but primarily have a conceptual orientation. Some of the chapters focus on the production and utilisation of knowledge, whereas others focus on the structure of research-policy dialogues. These chapters further explicate this book's conceptual framework. They are complementary insofar as they all deal with the relationship between research and policy and insofar as they ask crucial questions that can be situated on the knowledge 
production - knowledge utilisation axis outlined above: what national traditions of research-policy relations exist and how do these relate to knowledge production and knowledge utilisation? The chapters differ, however, in other aspects. Some focus on very specific forms of dialogue structures and analyse the mechanisms involved and the dominant functions performed in or through these structures. Christina Boswell (Chap. 2) compares in-house-research facilities in the UK and Germany and looks specifically at knowledge utilisation. Jan Schneider and Peter Scholten (Chap. 5) make a comparative analysis of how politics and policymakers in the Netherlands and Germany make use of ad-hoc committees, how research and expertise are involved in such committees and what functions they have. In Sandra Pratt's contribution (Chap. 7) the central topic of analysis is not the specific form of dialogue, but the genesis of two important EU policy documents. She asks what role knowledge and expertise played in their making and on whose initiative this occurred.

In the other chapters in Part I the emphasis is not on specific dialogue structures, but on general patterns of research-policy relations as these have evolved, as well as on specific mechanisms that play a role in certain phases of their development and at different governance levels. The comparative analysis by Christophe Bertossi, Jan Willem Duyvendak and Peter Scholten (Chap. 4) of the so-called Dutch and French national 'models' of integration shows how scientific and policy models may get conflated and how researchers may contribute to such conflation. Albert Kraler, David Reichel and Han Entzinger's chapter on migration and integration statistics (Chap. 3) looks at another aspect of the interwovenness of research and policy: the national character of administrative definitions, categories and procedures may create 'national facts' and thereby influence the production of knowledge.

Part I thus describes and analyses different aspects of research-policy dialogues with a variety of examples taken from older immigration countries in Europe, often on a comparative basis. Research-policy dialogues, however, are not restricted to the national level, but they also have an increasingly important European dimension. This is particularly evident from the chapters by Kraler et al. and by Pratt, mentioned earlier, while Ann Singleton also deals with the growing importance of policymaking at the EU level. In Chap. 8 she looks critically at the general system of policymaking in Brussels and the involvement of interest groups and researchers in these procedures.

Furthermore, an analysis of the interplay of research and policymaking in integration would not be complete if no attention were paid to the local level. All over Europe major cities in particular are faced with the concrete effects of immigration. It is actually at the local level that the issue of migrant integration manifests itself most clearly, and cities are more and more proactive in developing policies to cope with these challenges. In Chap. 6 Rinus Penninx outlines how cities and local governments have developed their dialogues in search of the knowledge and expertise that they need for policy development. This has recently led to interesting new coalitions between various cities and the European Union, sometimes bypassing the national level. 


\subsubsection{Part II: Science-Society Dialogues in Seven Countries and at the EU-Level Compared}

Part II differs from Part I in that its focus is not primarily on a conceptual contribution on research-policy dialogues on migrant integration, but rather on an application of this book's conceptual and theoretical framework to selected case studies (the EU and seven country cases). Six of the eight chapters in Part II are based on empirical research carried out in the framework of the DIAMINT project 'Science-Society Dialogues on Migration and Integration in Europe'. For this project the scope used in Part I was widened somewhat: the rephrasing of policy-research dialogues into science-society dialogues did not change the research/science pole of the binary essentially, but it did broaden its policy/society pole. In the original policyresearch dialogue frame the questions were primarily asked from a policymakers' perspective: what influence has research had? In the science-society dialogues this question was also reversed: what has been the relevance and use of science for society? The field of potential stakeholders was broadened, and therefore the general impact of research-policy dialogues. Dialogues may no longer be dialogues, but they may become 'polylogues', that involve no longer (bureaucratic) policymakers only, but also politicians, NGOs, interest groups and target groups (the migrants themselves). Indirect ways of influencing may now also become more important, with the role of media entering the picture as well.

The DIAMINT project aimed at a systematic comparison of dialogue structures, knowledge utilisation and knowledge production in five countries and at the EU level. To this purpose six research teams - one for each of the five national cases and one for the EU - worked together closely for two years, on the basis of a commonly agreed research outline and using the same methodology. DIAMINT was coordinated by three of the editors of this book - Han Entzinger, Peter Scholten and Stijn Verbeek - all based at Erasmus University Rotterdam. Rinus Penninx, who also co-edited this book, was an advisor to the DIAMINT project and facilitated linkages between DIAMINT and related IMISCOE activities.

The data collection of DIAMINT had the following elements: first, in all six cases a general literature analysis was made of history and practices of policy-research relations (both academic and applied research) in general and for the domain of migrant integration in particular. The aim of this was to map historical developments and conditions. In the second phase, and in order to enhance comparability of the data, it was decided that each team should select three concrete examples of science-society dialogues for further analysis. These three 'themes' should be as similar as possible, while also covering different dimensions of migrant integration. They should also be relatively recent, that is not older than about 10 years. An additional condition was that the dialogue under consideration should have a 'public dimension', that is, it should have received some broader attention than from researchers and policymakers directly involved in that dialogue. One may think here of politicians, the media, NGOs or other stakeholders. 
The following concrete themes were selected. The politico-legal dimension was covered by looking at naturalisation policies and dialogues around such policies. In terms of the socio-economic dimension, we looked at policies directed towards the education of migrant children (and second-generation children of migrants). Finally, the socio-cultural dimension was analysed by looking at policymaking and dialogue structures associated with the management of religious diversity in society. All country teams then proceeded to the collection of relevant documents and literature, while some twenty to thirty interviews per country were held with active participants in the dialogues studied and with experts.

Chapters 9 through 13 report on the five national cases in a systematic way, in accordance with a template specially designed to facilitate comparison. Nevertheless, these chapters do each have their specific focus. In her report on the Austrian case (Chap. 9) Maren Borkert argues that for many years the impact of scientific research on policymaking in that country was very limited. Only recently, researchpolicy dialogues have intensified. The Italian case highlights a rather typical national form of policy-research relations in which coalitions between NGOs and researchers have been of crucial relevance for policy development. This chapter was written by Tiziana Caponio (Chap. 10). Friedrich Heckmann and Delia Wiest (Chap. 11) report on the fundamental changes that have taken place in Germany since 2000, when large parts of the research community and those responsible for integration policies gradually coalesced into a discourse coalition recognising the urgent need for a new integration paradigm in that country. Stijn Verbeek, Han Entzinger and Peter Scholten cover the case of the Netherlands: it adds to the relatively rich literature on that case particularly by focusing on the role of media (Chap. 12). Alistair Hunter and Christina Boswell then report on the British case (Chap. 13), giving special attention to a characteristic form of dialogue in the UK, namely that of governmentsponsored commissions.

To these five chapters on country cases two more have been added that were not included in the DIAMINT project, but that were developed parallel to the project along the same template used for the DIAMINT chapters. The first of these chapters (Chap. 14) was written by Mikolaj Pavlak on Poland. It deals with the emergence of research-policy dialogues in a country that is only beginning to be an immigration country and where integration is not yet considered a political priority. It is interesting to note how strong the impact of both NGOs and the EU has been on these early developments. Chapter 15 is a contribution by Martin Bak Jørgensen on Denmark, the only Nordic country included in this book. It shows how volatile research-policy dialogues can become in a country confronted with an early and strong politicisation of immigration and integration. In Chap. 16, the closing contribution to Part II, Andrew Geddes and Marthe Achtnich cover the case of the European Union. For them it was not always possible to follow the template applying to the DIAMINT national cases, since policymaking in the field of integration at the European level is of a completely different nature. It involves a complicated system of dialogue between policymakers and researchers that also has to account for the role of individual member states that may not always agree with EU policies in this politically sensitive area. 
Finally, the concluding chapter of the book, written by three of its editors, provides a systematic comparison of findings from the cases studied. We ask what patterns and trends can be found in terms of dialogue structures, knowledge production, and knowledge utilisation, as well as in the relations between these three aspects. We also come back to the conceptualisation and theorisation of researchpolicy dialogues, as presented in the first part of this chapter.

Open Access This chapter is distributed under the terms of the Creative Commons Attribution Noncommercial License, which permits any noncommercial use, distribution, and reproduction in any medium, provided the original author(s) and source are credited.

\section{References}

Bertossi, C. (2011). National models of integration in Europe: A comparative and critical perspective. American Behavioral Scientist, 55(12), 1561-1580.

Bommes, M., \& Thränhardt, D. (Eds.). (2010). National paradigms of migration research. Osnabrück: IMIS.

Boswell, C. (2009). The political uses of expert knowledge: Immigration policy and social research. Cambridge: Cambridge University Press.

Boswell, C., \& Hunter, A. (2014). The political functions of independent commissions: Comparing UK commissions on migrant integration and cohesion. Journal of Comparative Policy Analysis, first published online.

Caponio, T., Hunter, A., \& Verbeek, S. R. (2014). (De)constructing expertise: Comparing knowledge utilisation in the migrant integration "crisis". Journal of Comparative Policy Analysis, first published online.

Entzinger, H., \& Scholten, P. (2014). The interplay of knowledge production and policymaking: A comparative analysis of research and policymaking on migrant integration in Germany and the Netherlands. Journal of Comparative Policy Analysis, first published online.

Favell, A. (2003). Integration nations: The nation-state and research on immigrants in Western Europe. Comparative Social Research, 22, 13-42.

Florence, E., \& Martiniello, M. (2005). The links between academic research and public policies in the field of migration and ethnic relations: Selected national case studies - Thematic introduction. IJMS: International Journal on Multicultural Societies, 7(1), 3-10.

Geddes, A. (2005). Migration research and European integration: The construction and institutionalisation of problems of Europe. In M. Bommes \& E. Morawska (Eds.), International migration research: Constructions, omissions and promises of interdisciplinarity (pp. 265-280). Aldershot: Ashgate.

Geddes, A., \& Scholten, P. (2014). Policy analysis and Europeanization: An analysis of EU migrant integration policymaking. Journal of Comparative Policy Analysis, first published online.

Hammar, T. (2004). Research and politics in Swedish immigration management. In M. Jandl \& I. Stacher (Eds.), Towards a multilateral migration regime. Special anniversary edition dedicated to Jonas Widgren (pp. 11-34). Vienna: ICMPD.

Hoppe, R. (2005). Rethinking the science-policy dialogue structure: From knowledge utilisation and science technology studies to types of boundary arrangements. Poiesis \& Praxis: International Journal of Technology Assessment and Ethics of Science, 3(3), 199-215.

Huddleston, T., \& Niessen, J. (2011). Migrant integration policy index III. Brussels: British Council/Migration Policy Group.

Jasanoff, S. (2005). States of knowledge: The co-production of science and the social order. London: Routledge. 
Okolski, M. (Ed.). (2012). European immigrations: Trends, structures and policy implications. Amsterdam: Amsterdam University Press.

Penninx, R. (1988). Wie betaalt, bepaalt? De ontwikkeling en programmering van onderzoek naar migranten, etnische minderheden en woonwagenbewoners 1955-1985. Amsterdam: SGIreeks/UvA.

Penninx, R. (2005). Bridges between research and policy? The case of post-war immigration and integration policies in the Netherlands. International Journal on Multicultural Societies, 7(1), 33-48.

Penninx, R. (2013). Research on migration and integration in Europe. Achievements and lessons. Valedictory Lecture held on August 29, 2012 in the Aula of the University of Amsterdam. Amsterdam: Vossiuspers UvA. http://dare.uva.nl/aup/nl/record/439850. Accessed 24 Jan 2014.

Penninx, R., \& Scholten, P. (2009). Research-policy dialogues on migration and integration in Europe (IMISCOE Policy Brief 15). http://dare.uva.nl/document/176685. Accessed 24 Jan 2014.

Penninx, R., Berger, M., \& Kraal, K. (Eds.). (2006). The dynamics of international migration and settlement in Europe. A state of the art. Amsterdam: Amsterdam University Press.

Rath, J. (2001). Research on immigrant ethnic minorities in the Netherlands. In P. Ratcliffe (Ed.), The politics of social science research. Race, ethnicity and social change (pp. 137-159). New York: Palgrave Macmillan.

Scholten, P. (2011a). Framing immigrant integration: Dutch research-policy dialogues in comparative perspective. Amsterdam: Amsterdam University Press.

Scholten, P. (2011b). Constructing Dutch immigrant policy. Research-policy relations and immigrant integration in the Netherlands. British Journal of Politics and International Relations, 13(1), 75-92.

Scholten, P., \& Timmermans, A. (2010). Setting the immigrant policy agenda: Expertise and politics in France, the UK and the Netherlands. Journal of Comparative Policy Analysis, 12(5), 527-543.

Scholten, P., \& Verbeek, S. (2014). Politicization and expertise: Changing research-policy dialogues on migrant integration in Europe. Science \& Public Policy, first published online.

Thränhardt, D., \& Bommes, M. (Eds.). (2010). National paradigms of migration research. Göttingen: V\&R Unipress.

Vasta, E., \& Vuddamalay, V. (Eds.). (2006). International migration and the social sciences: Confronting national experiences in Australia, France and Germany. Basingstoke: Palgrave Macmillan.

Wimmer, A., \& Glick Schiller, N. (2002). Methodological nationalism and beyond: National-state building, migration and the social sciences. Global Networks, 2(4), 301-334. 


\section{Part I \\ Forms and Functions of Research-Policy Dialogues}




\title{
Chapter 2 \\ Cultures of Knowledge Use in Policymaking: The Functions of Research in German and UK Immigration Policy
}

\author{
Christina Boswell
}

\subsection{Introduction}

Despite the extensive literature on patterns of knowledge utilisation in policymaking, there is very little scholarship comparing different 'cultures' of knowledge use across polities. By 'culture', I am referring to the historically specific and cumulatively learned patterns of values and beliefs that orient social action (Eckstein 1997: 226). The literature on national policy styles suggests that such values and beliefs can shape patterns of policymaking in different systems of public administration. ${ }^{1}$ But it is likely that such differences in administrative cultures also produce distinct ways of thinking about and drawing on expert knowledge. This chapter aims to explore how such differences might influence patterns of research use in immigration policy in Germany and the UK. ${ }^{2}$

\footnotetext{
${ }^{1}$ There have also been a number of contributions applying cultural theory to understand particular ways of framing public policy problems (Hoppe 2002; Geva-May 2002), information bias in organisations (Thompson and Wildavsky 1986), or constructions of risk (Douglas 1982). These approaches draw on Mary Douglas' famous group/grid typology, explaining variation in terms of quite abstractly defined dispositions which influence actions (Douglas 1982; Douglas and Wildavsky 1982). If we want a more historically specific account of cultural variation, we require a richer empirical account of national policy styles.

${ }^{2}$ Of course, there are a number of other variables not associated with culture that might shape patterns of knowledge use. These include features of the policy area or political debate, or the nature of the organisation responsible for policymaking (as I discuss elsewhere - see Boswell 2008 , 2009). However, in this chapter I would like to focus on the notion that different national or organisational cultures might influence how knowledge is used.

C. Boswell (ه)

Politics and International Relations, School of Social and Political Sciences,

University of Edinburgh, Edinburgh, UK

e-mail: Christina.Boswell@ed.ac.uk
} 
Before we proceed, I would like to suggest a slightly unconventional way of thinking about knowledge utilisation. Most theories of the use of research in policymaking adopt more or less explicitly 'instrumentalist' theories. On these accounts, policymakers draw on research as a resource for informing adjustments to policy. Thus knowledge is valued instrumentally, in the sense that it is mobilised as a means of improving policy. Such theories neglect a number of other important functions that knowledge can play in policymaking. In recent work (Boswell 2009) I have argued for the need to recognise that research frequently plays a symbolic, rather than instrumental, role in policymaking. In many cases, knowledge is not valued so much for its contribution to adjusting policy interventions, but rather for its potential to demonstrate the capacity of policymakers to make informed decisions, or to provide evidence to underpin their preferences. Thus in additional to its instrumental function, research can play a role in legitimising actors involved in policymaking; and/or lending authority to their policy choices. We can therefore distinguish between three possible functions of expert knowledge in political debate and policymaking:

The first of these is an instrumental function. This refers to the use of knowledge to adjust substantive policy, or outputs. Also known as 'problem-solving' knowledge, this is the type of research use most typically referred to in academic and practitioner discussions about knowledge utilisation. The assumption is that policymakers are keen to draw on knowledge to improve the content of policy, in order to realise political and/or organisational goals.

The second possible function of knowledge use is what can be termed a legitimising function. By being seen to draw on expert knowledge, an organisation can enhance its legitimacy and bolster its claim to resources or jurisdiction over particular policy areas. In this sense knowledge can endow organisations with 'epistemic authority' (Herbst 2003: 484).

The third function of knowledge is a substantiating function. Expert knowledge can lend authority to particular policy positions, helping to substantiate organisational preferences in cases of political contestation. As with legitimising knowledge, this type of knowledge use is essentially symbolic: knowledge is drawn on to signal authority or legitimacy, rather than to adjust output. However, whereas legitimising knowledge is about underpinning the authority of policymakers or organisations, substantiating knowledge is mobilised to support specific arguments. As we shall see, this implies a rather different pattern of commissioning, absorbing and marshalling expert knowledge in political debate.

This three-way typology allows us to develop a more nuanced understanding of different patterns of knowledge use. It provides scope for understanding not just the extent to which policymakers appear to be interested in using knowledge, but also the different functions such knowledge might serve in political debate and policymaking. As we shall see, this distinction is crucial in making sense of the notion that there are distinct 'cultures' of knowledge use in different national administrations. As I shall argue, one can indeed identify distinct national cultures in the sense that different administrations appear to attach varying levels of importance to research or expertise in the abstract. However, such general attitudes towards 
research are not necessarily good predictors of how far research is drawn on to shape policy (the instrumental function), or to underpin preferences in political debate (the substantiating function). Indeed, factors other than 'national cultures' - in particular the character of political debate and the nature of the policy sector - appear to have more influence on the actual take-up of expert knowledge.

The chapter draws on the three-way typology of the functions of knowledge to make sense of cultures of knowledge use in two organisations dealing with immigration and asylum policy: the German Federal Office for Migration and Refugees (BAMF - Bundesamt fuer Migration und Fluechtlinge); and the UK Home Office, especially its Borders and Immigration Agencu (previously the Immigration and Nationality Directorate, and now renamed the UK Border Agency). In Sect. 2.2, I provide a brief sketch of the two organisations, setting up a number of expectations about cultures of knowledge use. In Sects. 2.3 and 2.4, I explore whether these expectations are met through analysing patterns of knowledge use over the period 2000-2004.

\subsection{Cultures of Knowledge Use in the BAMF and the Home Office}

Comparative studies of bureaucratic cultures in liberal democracies typically divide these into two types. First is the Anglo-Saxon, entrepreneurial style, in which decision-making is characterised by informal and personalised forms of bargaining and negotiation. The second is the continental rationalist style, in which decisions are based on formal, universalised rules, and organisational roles are more stratified (Peters 1995: 48-9). Within this typology, the UK tends to be depicted as the paradigmatic case of an entrepreneurial bureaucracy, making decisions on a pragmatic, case-by-case basis (Peters 1995: 50). Senior officials are valued for their managerial skills, rather than their technical knowledge. Germany, by contrast, is frequently portrayed as the archetypal rationalist bureaucracy. The state administration tends to derive legitimacy from conformity to formal laws and rational procedures (Jann 2003: 95; Beetham 1996: 52; Koenig 2000: 48). Bureaucrats gain credibility from their Fachkompetenz (professional competence), which usually denotes specialised technical skills (Lodge and Hood 2003: 136) notably law, but also increasingly economics.

These different bureaucratic styles have also been associated by some authors with different attitudes towards science. Willem Halffman, for example, argues that according to the British approach, the credibility of science does not hinge on standardised criteria for science, but rather on 'the quality and reasonableness of the experts who provide the scientific evaluations' (Halffman 2005: 461). Scientific credibility is attested by experts known to and trusted by the government, who are co-opted into informal decision-making circles (Jasanoff 1995). This can be contrasted to countries with more depersonalised ways of ascribing authority, and 
sharper boundaries between policy and science. In Germany, for example, scientific research is more strictly delineated from other forms of expertise, distinguishing itself through its formal standards of proof and evidence (Hellström 2000). As a result, scientific research has tended to be far more sequestered, with disputes among experts rarely becoming the object of public debate. Instead, such debate remains within the realm of acknowledged experts, who are accorded considerable deference for their knowledge. The only viable strategy for non-scientists to gain influence is to re-couch such debates in terms of rival values (Jasanoff 1995: 327), thereby justifying the interventions of non-specialists marshalling arguments based on values and interests, rather than expert knowledge.

Assuming this analysis is correct, we might expect it to produce quite different patterns of knowledge use in UK and German bureaucracies dealing with immigration and asylum. Indeed, one might even talk about different 'national models' of knowledge utilisation. Most notably, we would expect German officials to attach far more weight to research, not just as a means of adjusting output or substantiating decisions, but also in order to legitimise policymakers. In fact, given the more general points about rationalism in German bureaucracy, we might expect research to play an important role in lending authority both to administrative organisations (legitimising function) and to specific decisions (substantiating function). By contrast, we would expect UK officials to display less reverence for research in general, but make use of expertise on a more ad hoc, informal basis. Depending on the policy context, it might be marshalled to adjust output (instrumental function), but it would be less likely to play a major role in justifying decisions (substantiating function) or lending authority to organisations (legitimising function).

In what follows, I shall examine how far these expectations about different cultures of knowledge use are met. I shall do so by looking at the use of research in UK and German administrative agencies dealing with immigration policy. This enables us to examine patterns of knowledge use in different national contexts dealing with the same policy issues. In both cases, the analysis focuses on the period 2000-2004, a period in which both governments were building up in-house research units to provide expertise on migration. In this way we can compare two similar structures for producing and applying research in policymaking, within two ministries dealing with broadly similar policy remits. This allows us to hold constant variations in organisational approaches to knowledge use that might be specific to different policy sectors. Moreover, both Germany and the UK were going through similar phases in the reform of their immigration policies, attempting to introduce more liberal policies on skilled labour migration. Thus we might expect patterns of knowledge use in both cases to be influenced by similar political pressures, notably the need to justify more liberal labour migration policies. In short, many of the factors influencing knowledge utilisation in the two cases are likely to be similar, implying that any variation in knowledge use may well be attributable to cultural factors.

For each of the cases, I shall look at the structure and mandate of the research unit, the content of the research produced, its take-up by policymakers, as well as 
patterns of disseminating research. The latter is of especial interest in ascertaining how far research was valued for its legitimising function, rather than as a means of adjusting output. The research is based on a combination of semi-structured interviews and content analysis of organisational websites, policy documents and research outputs produced by the respective research units.

\subsection{The Federal Office for Migration and Refugees (BAMF)}

The BAMF started life in 1953 as the Federal Office for Foreign Refugees, an implementing agency of the Federal Interior Ministry. Initially responsible for processing asylum applications, it was given new powers by an Immigration Law which came into force at the beginning of 2005. The law made the agency responsible for developing and implementing new integration courses for immigrants coming to Germany. It also established a research capacity on migration, which was to evolve into the BAMF Research Group. In preparation for the changes, from 2003 onwards the agency carried out major restructuring to equip it to take on these new tasks, and by the end of 2005 the number of staff had risen again to 2,231.

The Research Group was based in one of the organisation's five departments, Department Two, which was responsible for external relations, information and communication. Recruitment of research staff began in late 2004, shortly before the group's official launch in January 2005. In line with Article 75 of the Immigration Law, the official goal of the Research Group is the 'production of analytical evidence for migration management'. As the group's website states:

The Immigration Law has increased the significance for policymaking of a number of core questions about migration. In order to underpin rational policy, we need to draw on a wide range of methodological and empirical approaches to address these questions. The particular responsibility of the Federal Office in this respect flows from its national and Europe wide status as a competence centre. To this end, it provides the legal, institutional and economic bases for compiling reports and analyses, reviews the results of its own and external migration and integration research, and thereby contributes to the conditions for efficient migration and integration policies. (BAMF website, 14.03.06)

The group's output was to comprise a mixture of internal research, and externally commissioned projects. Not surprisingly for a German agency, the research mandate is defined in a very legalistic way. As one senior researcher rather formally described it:

Paragraph 74 Number 4 states that the Federal Office... should have the task of developing and expanding the analytical basis for managing migration, and states in brackets that this should be 'supporting research' (Begleitforschung). And this means that it should review measures taken under the Immigration Law, to see how efficient it is in managing migration in the labour market and economic interests of Germany. That's what we focus our research on... These are the questions which we pose, to fulfil the mandate given us by the legislature. To expand and deepen the basis for the management of migration. (BAMF interview, February 2008) 
However, this rather broad-brush legalistic definition of the goals of research left open what sorts of projects the group should carry out. And indeed, when the group commenced its activities in late 2004 and early 2005 there was some uncertainty about its remit and research priorities. One of the earliest recruits notes:

I remember that at that time it was an open process. These people were brought together, then they appointed a head of unit ..., and then we had to sort out what we should actually do. There was the legal mandate to develop analytical evidence about the management of immigration, but not much more. And it was completely open how we should carry out this task. (Interview, Feb 2008)

Others described how the Research Group's activities and role evolved in a rather ad hoc fashion, as it took over projects from other ministries and from the European Migration Network.

Certain actors had a rather clearer picture of the group's role from the outset. The President of the BAMF, Dr. Schmid, was keen to send out a clear signal about BAMF's expertise, defining the Research Group as a 'competence centre' that would enhance the expertise of his organisation. As one official put it, Schmid 'is a politician, he didn't grow up in the administration. He saw clearly the strategic possibilities of research. Therefore he fought hard to have research here' (BAMF interview, Feb 2008). From the point of view of the BAMF leadership, as one official explained, the Centre brought credibility to the organisation. 'From our side, it's about competence. A better reputation, and possibilities for expansion' (Interview, February 2008).

But there was also a more pragmatic consideration, linked to attracting and retaining staff. Almost all of the researchers in the BAMF Research Group appeared to be aware of this, describing their sense of being 'estranged' from the rest of the agency, like a 'foreign body', even a 'separate universe'. Or as one person expressed it, 'My outfit isn't right, I don't wear a tie ... In my opinion we don't fit in here. Research needs autonomy ... It should be free from bureaucracy' (Interview, Feb 2008). This goes hand-in-hand with a sense that the organisation does not understand or appreciate their work.

Some of those from management had the view for a long time that these researchers come here from the university and don't do any work. And some felt that we were just doing what we wanted, for independent research and not for policy. We needed quite some time for them to understand that we work hard, and that we are not producing wild theories that have nothing to do with the office. (Interview, February 2008)

This is linked to the traditional reverence for legal training in the German civil service. One researcher explained how this meant that social scientists had very limited career prospects in the organisation. 'I don't think you can really make a career here in BAMF ... It's difficult, because everything's arranged around lawyers here' (Interview, Feb 2008).

Despite the concern on the part of senior BAMF officials to ensure the Research Group had sufficient academic credibility and autonomy, there was also concern among many of its researchers that their work would not be viewed as serious academic research outside of the organization. A number of younger or mid-career 
researchers were conscious of having to make a decision between returning to the academic system, or being 'co-opted' into a bureaucratic career with the consequent diminution of academic credibility.

The Research Group's first projects were selected in a rather haphazard fashion. Two relatively large projects were imported from the outside, not so much as part of a reflected strategy on the functions of BAMF, but because the new Research Group in BAMF seemed the obvious place to carry them out. One of these was the collation of panel data on new immigrants, which had been run as a pilot study and was now handed over to BAMF by the Interior Ministry. The second was a survey of selected immigrant groups in Germany, which until then had been a joint venture of the Interior Ministry and the Employment Ministry, but was now handed over to BAMF. A third project on migrants in the health sector had been commissioned by the European Migration Network, within which the BAMF served as contact point for Germany.

The BAMF also become responsible for drafting the annual Migration Report, which it considered to be a key part of its activities. As one member of the Research Group put it, 'We've managed to promote ourselves very well in one area, and that's the Migration Report. This is the report where you find very reliable and authoritative data on migration. It's a report that's used by so many people. My wish is that we could achieve a similar thing with other projects' (Interview, February 2008). Not surprisingly, the Research Group has been planning to launch a parallel Integration Report, though this is meeting some resistance from the Commissioner for Migration.

Other topics for research were proposed by the staff, reflecting their particular interests and experience. A number of projects were also commissioned from external researchers, especially in this initial phase. In general, as one researcher puts it, the research agenda 'wasn't really defined ... We had maybe one or two themes that we were required to work on, but otherwise we came up with the themes ourselves' (Interview, February 2008). As another researcher recalls, they defined themes that seemed to be politically topical, and that suited their own expertise. At that stage, the exercise was largely internal to the Research Group: 'I don't remember any strong influence from the BMI' [the Federal Interior Ministry] (BAMF interview, Feb 2008).

The seemingly ad hoc development of the Research Group's agenda suggests little reflection on the possible instrumental or substantiating role of such a research group, at least in this initial phase. Rather, the general impression is that the establishment of the Research Group reflected the BAMF's own interest in having a 'competence centre' to bolster its authority in this area. The Interior Ministry appeared to have no particular interest in making use of the Research Group, but was broadly supportive of its development and recognised the legal necessity of setting it up, given the provision for such a research unit in the Immigration Law.

However, over the course of 2005, officials in the Interior Ministry began to demonstrate increasing interest in drawing on the research group. As BAMF officials noted, the Ministry seemed to 'realise that there was competence here... Then there was almost an avalanche of requests, so that the ongoing projects had 
to be put to one side' (Interview, February 2008). One of the first requests was for an evaluation of the impact of a law on providing accommodation for Aussiedler, ethnic Germans from Central and East Europe who had relocated to Germany. The government's policy of dispersing these immigrants to different regions of the country had been challenged on constitutional grounds, as an infringement of individual rights, and the Interior Ministry was keen to commission research that would inform its response to this challenge. This appears to be a good example of the substantiating use of knowledge, with the government keen to elicit arguments that could feed into its response. However, reactions to the study produced by the Research Group also offer a good example of some of the initial communication problems arising between researchers and other officials. The Research Group had spent one-and-a-half years on the project, compiling data from surveys of Aussiedler and local authorities, which they presented in a 200-page report. ${ }^{3}$ The report was well-received, but it was also clear that a much shorter study would have sufficed. Moreover, the study did not provide any direct answer to the Ministry's underlying question, namely the impact of dispersal on the social integration of migrants. As one researcher points out, 'these were complex relationships', which could not easily be answered through social scientific research.

This gap in expectations between officials and researchers appears to have reflected a more general problem about how each side understood research. One BAMF researcher noted that many of the issues they dealt with required quite indepth study. 'But most don't want to go into too much depth, as they just need it for a specific purpose, a meeting or a political objective' (Interview, February 2008). As another researcher put it, at the beginning:

We needed to find a common language. The top management in the administration are mainly lawyers and suddenly there was this Research Group with social scientists. And the social scientists had a rather different understanding of what a study was... Sometimes a lawyer says he wants a study, and actually a 10-page report will suffice. We had to learn this ... I think we really came to terms with this in the first year. (BAMF interview, Feb 2008)

There have been a number of other studies commissioned by the Interior Ministry, mainly to provide data and analyses on topical areas of policy, such as the Muslim community in Germany, illegal immigrants in Germany, or levels of criminality amongst immigrants. The Interior Ministry appears to take an interest in these projects, and there is some communication during their development. However, the Ministry's interest tends to revolve around the scale and timeframe for research, rather than questions of research design or methodology. As with the Migration Report, one can infer that much of the demand for knowledge is about developing a descriptive overview of different immigrant groups: their location, characteristics and behaviour. The Interior Ministry is keen to elicit knowledge of its target

\footnotetext{
${ }^{3}$ Sonja Haug and Lenore Sauer, Abschlussbericht: Zuwanderung und Integration von (Spät) Aussiedlern - Ermittlung und Bewertung der Auswirkungen des Wohnortzuweisungsgesetzes (Research Report Nr. 3, Nuremberg, November 2007).
} 
populations, and to demonstrate that it has access to this sort of knowledge, and it has realised that the Research Group can be of use in this regard.

In conclusion, the sorts of projects being carried out by the Research Group appear to have shifted since early 2005. In the early stages, members of the Research Group seemed to exercise considerable autonomy in choosing research themes, and many of the projects were quite broad in scope. However, in the course of 2005 and 2006, other parts of the BAMF and the Interior Ministry began to commission studies and briefings. After an initial lack of interest in the Research Group's work, these officials appeared to be beginning to recognise the potential usefulness of the group's expertise. A major part of this has involved routine work preparing briefings and answers to parliamentary questions, arguably tasks for which the Research Group was not intended. Such contributions tend to take the form of legitimising or substantiating knowledge, produced to back up the authority of the Interior Ministry in speeches or briefings. The Interior Ministry has also commissioned some studies providing general data and analyses of key immigrant groups, using the group to provide background information on its target populations. This type of knowledge utilisation is likely to serve a variety of purposes for the Ministry, providing a general resource for enhancing the authority of its claims and, in some cases, guiding adjustments to output. For its part, the BAMF has made some limited use of the group to assist in its evaluations of integration courses, implying an instrumental function of knowledge.

On the whole, though, the Research Group's main benefit to the BAMF appears to have been in terms of its legitimising role. The Interior Ministry and other departments within the BAMF have numerous possible sources for gathering knowledge to inform or substantiate their programmes. Indeed, the integration department within the BAMF prefers to make use of far more specialised and applied expertise in guiding its policies. Instead, the main asset of this in-house research unit almost certainly resides in its legitimising function.

The importance of the legitimising function of research is underlined if we consider BAMF's attitude towards the dissemination of its research. The senior management of the BAMF were quite keen for the Group to have a high profile, and be present in the national media. For them, the main target is the policy community, as well as the wider public:

\footnotetext{
My basic assumption is that they want this (dissemination) because that's tied up with being a competence centre. And we have agreed with the president that we need to take pains to inform the wider public. That our impact increases, that we are invited to conferences. And we'll only achieve recognition if we disseminate our results.

[Author] To whom?

Mainly to the policy community that's dealing with these themes. (Interview, February 2008)
}

Or as another researcher put it, 'If the Federal Agency wants to be taken seriously as a competence centre, people must be able to present their research results and open them to discussion' (Interview, February 2008). This view is shared by the middle-management coordinating the Research Group. 
We've set ourselves the goal of becoming a centre of competence. And we're building that competence in different ways, and also insofar as we do good work, and discuss it... We want to be competent, we want our work to be in demand, we want to present ourselves as a specialist agency for migration and integration and that is an important task, which we've taken on board and which we are achieving. (Interview, Feb 2008)

As one researcher noted, 'Our president stated at the beginning that he wanted us to feature on page three of the FAZ (Frankfurter Allgemeine Zeitung). As far as I'm aware, we haven't managed that yet' (Interview, February 2008).

Thus senior officials within the organisation appear to be in favour of targeting the policy community, to ensure key actors working in the area are aware of the work of the Research Group. This implies an interest in demonstrating the BAMF's competence and expertise in this knowledge, and indicates that knowledge is seen as a source of legitimation.

In sum, despite some limited cases of research being drawn on to adjust output (instrumental function) or underpin policy preferences (substantiating function), the predominant value ascribed to expert knowledge appears to be as a means of shoring up the reputation and credibility of the BAMF (legitimising function). This legitimising function was the key rationale for setting up the unit in the first instance. And, although once in place certain parts of the organisation were able to identify other uses for the unit, the legitimising function has remained the most significant function of the unit over time.

The legitimising role of the Research Group becomes clear if we consider the outcome of the wrangle over how independent the unit should be within BAMF. The question was: should it remain a largely independent unit, thereby retaining research credibility and carrying out a legitimising function for the organisation? Or should it become a more responsive unit, carrying out tasks commissioned by other parts of the organisation, thus being more directly 'useful' as a provider of instrumental or substantiating research? The outcome was to opt for a more independent structure, confirming the importance of the unit's legitimising role within the BAMF - despite the fact that the research group was seen as largely irrelevant to many within the organisation. So one can say that its legitimising role was bought at the expense of performing an effective instrumental or substantiating function.

This conclusion may appear somewhat counter-intuitive, given the general points made earlier in the chapter about the importance attached to expertise in German bureaucratic culture. We shall return to this point after reviewing the UK case.

\subsection{The Home Office}

Immigration has fallen under the jurisdiction of the Home Office since 1793. After World War II, it was given responsibility not just for immigration control and asylum, but also the increasingly important area of 'race relations' (a British term describing what in other countries would be categorised as inter-ethnic relations or 
integration policy). ${ }^{4}$ Both sets of issues were dealt with by the Immigration and Nationality Directorate (IND), by far the largest part of the Home Office, with a staff of around 16,000 employers, accounting for over three quarters of the Home Office's staff..$^{5}$ In 2006 many aspects of race relations were transferred to the new Department for Communities and Local Government, which assumed responsibility for issues of diversity, anti-discrimination, integration and social cohesion, though IND retained responsibility for the integration of refugees. In Spring 2007, the IND was split off into a separate executive agency, the Border and Immigration Agency (BIA), though the agency remained part of the Home Office, and its functions are largely unchanged.

Immigration Research and Statistics Service (IRSS) was established in 2000 within the Home Office's Research, Development and Statistics (RDS) Directorate of the Home Office, with explicitly instrumental objectives. Its research goals were to support the delivery of asylum and immigration policies and programmes, develop knowledge about asylum and immigration, and develop methods for research with asylum seekers and other migrants. ${ }^{6}$ This interest in research appears to have been part of a more general move towards broadening the evidence base of policy. With the establishment of the new IRSS, twelve new research posts were created, covering four thematic areas: asylum, immigration, integration, and research on the new National Asylum Support Service (NASS) (Interview, June 2007). So there was clearly an interest in research across the board, not just in the area of labour migration. Tellingly, the recruitment drive was not limited to immigration and asylum, but was part of a general shift in the Home Office towards embracing evidence-based policy. It involved the recruitment of over 100 specialists across all sections - crime statistics, prisons, policing, and immigration. As one RDS researcher puts it,

The political message was: there should be evidence based policy, and in order to do that you need to bring in people who can do more sophisticated statistical analysis, but also people who can do research, and research management, so in-house research capacity ... And that was the function... To deliver on a series of, at that point ill-defined, research objectives. (Interview, June 2007)

In other words, it represented a drive to improve the evidence base of policy in general, more than an attempt to fill recognised knowledge gaps in particular policy areas.

The mandate of IRSS was initially couched in a rather broad way, as an attempt to define and fill gaps in knowledge, in order to underpin policymaking. It tallied well with the Blair government's modernising agenda and the notion of evidence-based

\footnotetext{
${ }^{4}$ See Chap. 13 on 'Research-Policy Dialogues in the UK' for further details.

${ }^{5}$ It is worth noting that most operational aspects of Home Office work are dealt with by organisations outside of the Home Office - the prison services (which alone employs around 47,000 staff), police, and so on. Immigration and asylum operations are somewhat unusual in being located within the department itself.

${ }^{6}$ See www.homeoffice.gov.uk/rds/immigration.htlm, accessed 6 December 2006.
} 
policymaking. And in line with this rather broad objective, the new researchers were given a degree of leverage in setting their own research priorities. However, many within IND were sceptical or even hostile towards the new cadre of researchers. IND were financing $50 \%$ of IRSS and its activities (the other half came from RDS' budget), contributing to a sense of ownership of the research agenda and output. Yet many were frustrated at the perceived irrelevance of the research being produced. One former official working on policy at the time noted that:

A lot of the time I would get the impression: what are they doing over there? There's a lot of people working there, and what are they producing? It was difficult to really access a structured kind of representation of what they were doing on a week to week basis, what was coming up, that sort of thing. (Interview, September 2006)

Insofar as officials were involved in research, this was certainly not with any great enthusiasm:

The research itself was not particularly prioritised by a lot of people, and meetings where we had to discuss research people would see as a bit of a chore. So what are we going to do? OK, we'll say what's on our mind at the moment, we won't get anything for a year, and then the whole agenda will have changed, it will just be a complete waste of time. (Interview, September 2006)

A former researcher describes the predicament from the perspective of IRSS researchers:

The Head of RDS was basically saying, you need to be identifying and developing evidence to fill gaps in order to inform policy. IND, however, tended to think, "we need evidence on $\mathrm{x}$, $y$ or z' - which were not necessarily broad areas of knowledge that needed to be filled, but areas where they had particular policy objectives driven by the flavour of the day. (Interview, June 2007)

This meant that 'as far as IND was concerned, at that time we were a thorn in their side... I think there was a sense at that point that they'd created something of a monster' (Interview, June 2007).

By around 2002-2003 there was growing dissatisfaction within IND about the role and output of IRSS, and in particular over the perceived lack of fit between IRSS research and the IND's policy imperatives (Interviews, May and June 2007). In the words of one commentator, IRS was seen as 'detached from political reality'; a former Home Office official described the perception as one that the IRS 'had gone off on a frolic of our own' (Interview, June 2007). Some of the criticism was directed at research which did not corroborate IND sources. In other cases, research was seen as being too abstract, and not relevant to the delivery of IND targets. So the complaint was that it was not sufficiently instrumental. There seemed to be little acknowledgement of the value of research as a means of legitimation for the organisation.

The various criticisms of IRSS' role and priorities culminated in a restructuring exercise in 2004, with the IRSS being integrated, or 'embedded', into IND. This followed the model already in place for many other areas of Home Office research, where research was located more closely to the 'customer', who had far more influence in the commissioning, design and dissemination of research projects. 
This contract between researchers and their customers in IND was formalised through a new procedure for authorising studies, a so-called Project Approval Record, setting out the aims, expected outcome, timeframe and purpose of the research. The form would be sent out for peer review (usually within the Home Office), and then scrutinised by a Project Quality Approval Board. Together with the new embedded structure, the aim was to ensure all research was precisely tailored to IND needs:

There should be nothing happening right now in research without there being an identified need for it. Resource is not so magnanimously given that we can afford to do a pile of research and hope some of it is useful. It's very focused. (Head of Research, Interview, May 2007)

The new system was clearly considered by IRSS to lend their research more credibility, and more generally to legitimise their role within IND. As one senior IND official noted about the new system:

Now they're much more going round to their customers and saying, what is it you want to find out about, can we help you? Or customers are going to them and saying, we need this, can you do a research project? So my sense is that it is being driven by our strategic objectives and our need to fill our knowledge gaps, rather than coming from the research community who are saying this is something it would be interesting to find out. (Interview, May 2007)

So IRSS' structure and relation to policy has undergone a significant shift since 2000. It started as a top-down initiative to enhance the 'evidence base' of Home Office policymaking. This structure encountered problems with legitimacy within IND, which did not consider its research to be useful in informing policy, hence the switch to an embedded structure. Once IRSS became embedded in the IND, however, it appears to have become drawn into conducting research that responded far more directly to organisational needs. As one researcher remarked,

what we've seen evolving is much more ... genuine interest, since we've been through a process of them establishing what evidence they need, and how it's going to be produced, then they're immediately involved and part of that research. (Interview, May 2007)

In the initial phase of IRSS there had been some scope for researchers to define their own agendas and initiate projects. To be sure, they needed to agree an annual business plan with IND, which set out proposed research for the up-coming year. Moreover, any major research project commissioned outside of the business plan needed to be approved by means of a 'submission' to the minister. Business plans were discussed at meetings involving senior policy and operational officials from IND, and often followed up by more detailed meetings with the specific IND customer. However, the definition of projects was an iterative process, and researchers had substantial scope to set the agenda and shape the design and methodology of projects. As one IRSS researcher put it,

We tired hard to ensure their ideas were placed in a broader context - situated in a project that was sound. So we'd broaden it, and plant ideas. So there was interaction. Some projects got dismissed out of hand. Or sometimes, IND would say, yes, we should know about that. So we needed to persuade the customer it was important, and why. (Interview, June 2007) 
This more supply-driven process for defining research changed with the introduction of the new structure in 2004, under which, as we saw, the customer had far more influence. The shift is reflected in the studies that emerged from IRSS. In the initial heyday of IRSS research, the service produced a number of seminal studies which were quite influential beyond the Home Office. This type of broader study effectively ceased from around 2003-2004, replaced by far more narrowly defined reports informing quite specific areas of policy. As one former official put it, 'They're now producing in-house evaluation, management information. So the relationship between the customer and provider is much closer' (Interview, June 2007). This pattern of research supports the earlier point about the shift from projects driven by perceived gaps in knowledge, to a more narrowly instrumental function. As the head of IRSS explained the new emphasis:

\footnotetext{
Essentially it's an evidence process, we need evidence for this, information for that, knowledge here, so that we can make a decision or make a process better, or understand things in a way that helps us to shape policy, so it starts with a conversation that with someone in policy or indeed the operational world, or some other part of business, saying we need some evidence. (Interview, May 2007)
}

Beyond this general trend, though, we should note some significant differences between research areas. The IRSS research agenda, as we saw, was initially divided into areas of immigration, asylum, NASS and integration. Of these areas, research on immigration and its economic and social impact was in many ways the most significant, and indeed pre-dated the establishment of IRSS. In 1999, the Performance and Innovation Unit (PIU) at the Cabinet Office initiated a project on 'Migration: A Social and Economic Analysis', which provided strong evidence that immigration was beneficial to the UK economy. The project was carried out by PIU together with economists from the Home Office, and the Institute for Public Policy Research. It was very much the product of PIU thinking, with the Prime Minister and his advisors increasingly influenced by arguments emerging from the National Skills Task Force and the Department for Trade and Industry about labour and skills shortages. The study had a significant impact both on internal policy debates on immigration, and on the emerging Home Office research agenda. It lent weight to the sorts of arguments about the benefits of immigration that were emerging from the Cabinet Office, giving leverage to those within the Home Office who supported managed migration. And it helped shape the research agenda that emerged after 2000, for the first time bringing economic aspects of migration to the fore, and pointing to gaps in existing research (Interview, May 2007). The ensuing study on the fiscal impact of immigration arguably played an even more prominent role in substantiating the government's new policy. Its estimate that immigrants in the UK had made a net fiscal contribution of $£ 2.5$ billion in 1999-2000 was repeatedly cited in speeches, press releases and parliamentary debates (see, for example, Blunkett 2002).

Research in the area of asylum displayed a somewhat different dynamic. Officials were under pressure to meet a number of narrowly defined performance targets, and there was little interest in research that would not help them in this goal 
(Interview, June 2007). Paradoxically, the lack of interest from IND created a wider margin of manoeuvre for researchers in IRSS working on asylum. Probably the most influential report commissioned by IRSS over this initial phase was on the factors influencing asylum seekers' choice of country (Vaughan and Segrott 2002). The findings were controversial within IND, in many ways contradicting operational received wisdom that legislation on asylum had a major impact on asylum-seekers' choice of country. However, it appears to have had some impact on some of those working on policy. One official working on asylum at the time singled out this study as having a definite influence on his thinking. Shortly after attending a meeting on the report, he drew on the findings when advising on policy:

We needed to understand that policy has an effect, and so having that kind of background was quite important. I can't swear to you that ... we referred directly to the research, but it was there as part of the background. (Interview, May 2007)

Another report on asylum played a clear substantiating function, helping the organisation argue for restricting labour market access to asylum seekers. In 2002 the Treasury and the Department for Work and Pensions were keen to permit asylum-seekers to work, but the Home Office argued this would constitute a pull factor for potential economic migrants. They drew on a report commissioned from researchers at the University of Swansea on the role of social networks in disseminating information on countries or asylum. Although the findings did not directly corroborate the notion that access to employment constituted a pull factor for would-be asylum-seekers, the Home Office was able to add weight to its arguments by pointing to the sound evidence base of its policies. As one former official described this sort of tactic,

There would be two paragraphs on the project. The first would say, we've commissioned research on push/pull factors influencing asylum. The next paragraph would say, we're concerned that the right to work acts as a pull factor. The implication was that this was evidence-based. For IND, the fact that we commissioned research helped them to push their preferences through. It showed a willingness to engage with evidence. (Interview, June 2007)

Interestingly, in 2008 RDS was criticised by the Office of Science Innovation for being insufficiently strategic and forward-thinking. In May 2007, as part of the first stage of the review, the OSI observed that there was a lack of 'horizon-scanning in the Home Office, with too much energy taken up with fire-fighting' (Office of Science and Innovation 2007: 3). This was partly attributed to the embedded structure. While there were thought to be clear benefits to having embedded scientists in the sectors of a department... a weakness of this dispersed approach is the tendency to miss out on longer-term, strategic research needs and to not cover issues that cut across sectoral boundaries (ibid.: 2).

So while the shift to more narrowly defined and instrumental research appears to have enhanced the credibility of IRS within IND, external expectations about the need for more strategic policy research appear not to have been met. As the Head of IRSS observed, 
There is a recognition in the Home Office that we need to get back to being more strategic with our research, and have not all of it focused on what we need to know right now, but to be thinking a little bit ahead what are the issues going to be in the future, doing a bit of horizon scanning. (Interview, May 2007)

The implication is an ongoing tension between prioritising research that is seen as useful by members of the organisation (the embedded model), and responding to external pressures to deliver more strategic thinking. The second, more strategic model appears to a large extent to emanate from outside of the organisation. As in the case of discourse on evidence-based policymaking, it reflected a general concern to improve the quality of decisions and output in the organisation. But the take-up of these ideas within the Home Office is limited. Where Home Office officials do internalise such notions, this is likely to reflect a concern to conform to external expectations about appropriate organisational structures and procedures.

Researchers within IRSS are generally keen to publish their work, in order to maintain their standing within the research community. They are frequently under pressure from the commissioned researchers to carry out research to ensure studies are put out as quickly as possible. Indeed, there have been several cases where researchers working with IRSS have been frustrated at delays of up to 2 years in the publication of research.

Not surprisingly, the view amongst IND and especially the operational staff has been somewhat different. There is a general reluctance to publish findings that may potentially contradict the direction of IND policy, or undermine perceptions about its performance. Even where there is no obvious risk of this occurring, the basic preference seems to be not to publish/publicise work. The view is that there is no advantage to be derived from dissemination, and publication implies an extra layer of procedures: preparing a submission to the minister, editing a report, preparing a press release, and so on. As one former official noted of IND officials, 'If the relationship is one of having a customer or consumer, you produce findings, and they can do what they want with them. There is no added value for them of publishing' (Interview, June 2007).

The divide in opinion reflects divergent view on the function of research. Senior policy people who think more strategically are interested in dissemination as a means of substantiating decisions and, to some extent, legitimising the Home Office through demonstrating its evidence base. Researchers within the organisation are above all interested to demonstrate the expertise of IRSS and their own research credentials. By contrast, the predominant view amongst operational staff and those involved in more detailed policymaking is that dissemination is more trouble than it is worth. Insofar as research is valued at all, its usefulness is in adjusting output to help meet clearly specified targets.

How far does the Home Office case conform to expectations about the culture of knowledge use in the UK bureaucracy? As in the German case, the initial rationale for establishing a research unit was partly legitimising: to conform to expectations about evidence-based research, which were particularly modish in UK government at the time. However, as one might expect in the British case, this agenda was viewed with scepticism and suspicion by officials. And it soon prompted the 
adoption of a so-called 'embedded' structure, under which research independence was subordinated to the needs of the 'customer' users within the organisation. So perhaps unsurprisingly, faced with a similar tension to that experienced in the BAMF between independence/credibility of research and its subordination/direct usefulness to other parts of the organisation, the Home Office opted for the latter model. And this may indeed reflect a different culture of valuing research, one in which it simply is not deemed as important for an organisation to demonstrate its research credentials in order to ensure its decision-making authority.

Paradoxically, though, the research unit has played a substantiating role in policymaking, implying that its research output has had more impact than that of the BAMF. IRSS research has played an important role in underpinning Labour's policy reforms of the early 2000s, in a way that German research simply did not. This seems to be despite the evident lack of a culture of valuing research within the Home Office (or UK public administration more broadly). So the implication is that just because an organisation ascribes to the idea that research should inform policy, it does not necessarily follow that it will make use of research in policymaking; and similarly, just because an organisation appears sceptical about research in general does not mean that it will not make use of research findings where these help realise organisational goals. In short, recognition of the legitimising function of research can be decoupled from actual uptake of research in policymaking.

\subsection{Conclusions}

What does the analysis of research use within these two organisations tell us about cultures of research utilisation? The two cases have interesting parallels. They are both instances of a research unit being introduced in a 'top-down' fashion into an organisation, rather than established in response to perceived organisational needs. In this sense the establishment of both units was motivated by a desire to conform to expectations about 'competence' or 'evidence-based policymaking', rather than to meet 'bottom-up' calls for research to inform policy. In both cases this top-down decision met with scepticism across the organisation about the value of the unit, especially among those involved in more operational aspects of policy.

And yet this tension was resolved in opposite ways in the two administrations. In the German case, concerns about the lack of relevance or usefulness of the research in other parts of the organisation were trumped by the perceived value of the unit as a source of legitimation: the unit's independence was seen as vital for shoring up the epistemic authority of the BAMF. In the UK case, a weaker commitment to the mantra of 'evidence-based policymaking' made it easier to override such considerations. The organisation's need for more applied 'management information' trumped concerns about preserving the scientific credibility of the research unit.

So far, then, the findings appear to be in accordance with our expectations about different cultures of research use in German and UK administration. Yet when we 
look at how findings were (or were not) actually used in policymaking, we are confronted with an apparent anomaly. In the German case, while the administration did appear to attach more importance to the value of research, often this was decoupled from the take-up of research in practice. An almost naïve confidence in the value of research was juxtaposed with a readiness to disregard the 'evidence' in decision-making. The disregard for research did not simply involve discrediting findings or playing down their importance, but quite blatantly ignoring them in deliberation. It suggested that respect for research on the part of policymakers was often largely ceremonial. A rhetorical commitment to the importance of research was coupled with a readiness to debate decisions on an entirely different basis.

In the UK administration, by contrast, far less importance was attached to this form of knowledge base. And yet despite this, officials did quite frequently draw on or commission research to substantiate policy. The most pronounced example of research used to substantiate policy was the research on the economic impact of migration, which was drawn on repeatedly to justify the government's liberalisation of labour migration in the early 2000s. Arguably, this says more about the nature of political contestation over labour migration than it does about the Home Office's organisational culture. For a number of reasons (which there is no space to elaborate here), the Labour government succeeded in pitching the debate in quite technocratic terms, shifting the discussion away from more emotive arguments to a discussion of the economic costs and benefits of labour migration. So the demand for substantiating research emanated more from politicians involved in making the case for labour migration, than from within the Home Office. The German debate on the immigration law, by contrast, drew surprisingly little on research findings. Both political discourse and media coverage relied predominantly on arguments linked to values and interests rather than expert knowledge.

These insights underscore how important it is to distinguish between the different functions knowledge can play, if we are to develop a more nuanced understanding of different cultures of knowledge utilisation. A particular organisation may show high deference for knowledge in the abstract (legitimising knowledge), but rather limited interest in deploying it for the purposes of substantiating or adjusting output. Another may attach little importance to the activity of collecting background knowledge, but consider research very important in substantiating specific claims. And organisations may find different types of knowledge more or less reliable when it comes to adjusting output, preferring more scientific studies, or knowledge acquired through practical experience. Thus the different functions of knowledge may be decoupled from one another.

What are the implications of this for thinking about national 'cultures' of knowledge use? First, the analysis supports the idea that there are distinct German and UK cultures in terms of the value attached to research in the abstract. And this appears to have some influence on the legitimising function of knowledge in the two organisations examined. However, this culture of valuing research does not appear to guarantee that research will be taken up in policymaking. Instead, other factors appear to have more weight in determining how far knowledge plays a substantiating or instrumental function. In the case of substantiating knowledge, what seems to be 
more important is the grounds on which political contestation revolves. If debate revolves around technocratic arguments, then we might indeed expect knowledge to be marshalled to substantiate arguments, even in the absence of a strong culture of valuing expert knowledge within the relevant policymaking organisation. So in effect, the nature of political contestation over a given policy area at a given point of time may over-ride more general characteristics of the organisation, such as the value ascribed to expertise.

In the case of instrumental knowledge, meanwhile, the main factor influencing the use of research to inform policy appears to be the extent to which policymakers are under pressure to deliver short - medium-term results. Where an organisation needs to adjust policy to meet measurable targets, for example reducing asylum applications, then a strong culture of knowledge use may well prompt them to draw on research instrumentally. However, most areas of immigration and asylum policy are highly symbolic, with the implication that there is limited political interest in using knowledge to adjust policy: policymakers secure legitimacy through their rhetoric rather than policy delivery. So regardless of the organisation's culture of valuing knowledge, instrumental knowledge use is likely to be limited in policy areas where legitimation is secured through rhetoric rather than action.

The conclusion, then, is that while national cultures may shape the use of research to legitimise decision makers, other factors appear to be more influential in shaping the use of knowledge for substantiating and instrumental purposes: namely, the nature of political debate (how technocratic it is), and the policy sector (whether legitimation is secured through rhetoric or delivery).

Open Access This chapter is distributed under the terms of the Creative Commons Attribution Noncommercial License, which permits any noncommercial use, distribution, and reproduction in any medium, provided the original author(s) and source are credited.

\section{References}

Beetham, D. (1996). Bureaucracy (2nd ed.). Buckingham: Open University Press.

Blunkett, D. (2002, June 26). Home secretary's speech to the social market foundation. London.

Boswell, C. (2008). The political functions of expert knowledge: Knowledge and legitimation in European Union immigration policy. Journal of European Public Policy, 15(4), 471-488.

Boswell, C. (2009). The political uses of expert knowledge: Immigration policy and social research. Cambridge: Cambridge University Press.

Douglas, M. (1982). In the active voice. London: Routledge and Kegan Paul.

Douglas, M., \& Wildavsky, A. (1982). Risk and culture: An essay on the selection of technological and environmental dangers. Berkeley: University of California Press.

Eckstein, H. (1997). Social science as cultural science, rational choice as metaphysics. In R. Ellis \& M. Thompson (Eds.), Culture matters (pp. 221-244). Boulder: Westview Press.

Geva-May, I. (2002). Cultural theory: The neglected variable in the craft of policy analysis. Journal of Comparative Policy Analysis: Research and Practice, 4(3), 243-265.

Halffmann, W. (2005). Science-policy boundaries: National styles? Science and Public Policy, 32(6), 457-467. 
Hellström, T. (2000). Technoscientific expertise and the significance of policy cultures. Technology in Society, 22, 299-512.

Herbst, S. (2003). Political authority in a mediated age. Theory and Society, 32(4), 481-503.

Hoppe, R. (2002). Cultures of public policy problems. Journal of Comparative Policy Analysis: Research and Practice, 4(3), 305-326.

Jann, W. (2003). State, administration and governance in Germany: Competing traditions and dominant narratives. Public Administration, 81(1), 95-118.

Jasanoff, S. (1995). Product, process, or programme: Three cultures and the regulation of biotechnology. In M. Bauer (Ed.), Resistance to new technology: Nuclear power, information technology and biotechnology (pp. 311-331). Cambridge: Cambridge University Press.

Koenig, K. (2000). The administrative state in Germany. In H. Wollmann \& E. Schroeter (Eds.), Comparing public sector reform in Britain and Germany: Key traditions and trends of modernisation (pp. 47-66). Aldershot: Ashgate.

Lodge, M., \& Hood, C. (2003). Competency and bureaucracy: Diffusion, application and appropriate response? West European Politics, 26(3), 131-152.

Office of Science and Innovation. (2007). Review of science in the home office. London: HM Treasury.

Peters, B. G. (1995). The politics of bureaucracy (4th ed.). White Plains: Longman.

Robinson, V., \& Segrott, J. (2002). Understanding the decision-making of asylum seekers (Home office research study 243). London: Home Office Research, Development and Statistics Directorate.

Thompson, M., \& Wildavsky, A. (1986). A cultural theory of information bias in organisations. Journal of Management Studies, 23(3), 273-286. 


\title{
Chapter 3 \\ Migration Statistics in Europe: A Core \\ Component of Governance and Population Research
}

\author{
Albert Kraler, David Reichel*, and Han Entzinger
}

\subsection{Introduction}

'State' and 'statistics' are not only related etymologically. ${ }^{1}$ Rather, statistics represent a fundamental technique of modern government comparable to the role of law in modern societies. Like law, statistics are about procedure and standardisation. Whereas law is about standardising the exercise of power and (legal) relations amongst citizens, between citizens and the state as well as relations within the state, statistics are about knowledge necessary for such exercise of power and authority. Statistics - in James Scott's famous formulation (Scott 1998) - enable states to 'see'. They bring order to the fluid object that is a population, a territory or other objects of power by standardising and structuring social reality into discrete countable units, thereby (so Scott's Foucauldian argument goes) also transforming populations into governable subjects. Indeed, the history of statistics as a specific field of knowledge production is intricately linked to the history of the modern state and modern

\footnotetext{
Agency for Fundamental Rights (FRA) Schmidt 2005).

A. Kraler

ICMPD's Research Unit, Vienna, Austria

D. Reichel

European Union Agency for Fundamental Rights, Vienna, Austria

H. Entzinger $(\bowtie)$

Department of Sociology, Erasmus University Rotterdam, P.O. Box 1738,

3000 DR Rotterdam, Netherlands

e-mail: entzinger@fsw.eur.nl

*The opinions of this author expressed in this chapter do not represent those of the European Union

${ }^{1}$ The word statistics most probably stems from the Italian word statista meaning 'statesman' (cf. 
forms and theories of governance. ${ }^{2}$ Thus, about the same time as Thomas Hobbes published Leviathan, with its famous frontispiece showing the sovereign as made up of people, one of the first more sophisticated endeavours to statistically describe the population was published (see Hacking 2006). Like Hobbes famous picture, population statistics go along with a powerful and suggestive imaginary: statistics sum up a mass of people, thereby also assuming a fundamental 'sameness' of those individuals so summed up, making one population out of many. ${ }^{3}$ In a sense, a population only comes into being as a result of this performative act of (statistically) describing $a$ population. ${ }^{4}$ Yet statistics not only enable the aggregation of individual units into a larger whole (such as individual persons into a population); they also enable one to discern or to differentiate classes of entities within larger wholes. On the general level of total populations, population statistics thus entail the capability to distinguish one population from another. Within individual populations, statistics permit one to distinguish classes of individuals by grouping them according to different characteristics associated with individuals, thus also facilitating the generation of generalisable knowledge about the structure and characteristics of a population. It is this specific knowledge produced by population statistics that provides an entry point for policy intervention. As Espeland and Stevens (2009: 415) put it: 'Seeing something is the first step to controlling it.' 'Seeing something', however, is no simple act. It requires recognition in the literal sense of the term's Latin root, i.e. being able to recognise things through pre-defined categories of difference - which importantly are simultaneously also categories of sameness. Nationality is such a category, as are ethnicity or country of birth; these categories arguably represent the core concepts for ethnic and migration studies.

As Armin Nassehi and Markus Schroer (1999) have argued, nationality was a crucial device for constructing nation states in the wake of the French Revolution. In particular, the invention of nationality as a fundamental legal status responded to the "need to reconcile the universality of human rights with the particularity of its validity within the context of single nation states' (Nassehi and Schroer 1999: 88). ${ }^{5}$ Nationality was to be constructed for societies that sought integration within the boundaries of nation states but at the same time had to define themselves as different to other nation states. Population statistics were crucial in symbolically achieving this goal. With the rise of nationality as a fundamental legal category during the nineteenth century nationality also became increasingly important as a

\footnotetext{
${ }^{2}$ The term 'modern state' is here employed as a heuristic term denoting a number of elements that have increasingly shaped both normative understandings of the state and actual state practices from about the eighteenth century onwards (for an elaboration see Kraler 2009: 110f).

${ }^{3}$ The implicit parallel of Hobbes ' Leviathan and the description of population with statistics is drawn from Reinprecht 2010.

${ }^{4}$ Statistical representations thus can similarly be seen as what John Searle described as 'institutional facts' - facts that are created by performative acts such as legal decisions or statistical procedures (See Searle 1995).

${ }^{5}$ Authors' translation.
} 
marker of difference within individual polities, reflected again in statistics such as censuses and other statistical records for which information on nationality came to be routinely collected by the late nineteenth century in many European countries. ${ }^{6}$

It was in this period that the first efforts to improve data collection on migration ${ }^{7}$ at an international level were initiated, although at that time largely focused on population movements rather than on stocks of foreign citizens or foreign-born. Reviewing the international efforts to improve data collection on international migration since migration statistics were first tabled as a topic for international harmonisation at the 1891 Congress of the International Statistical Institute in Vienna, two things are remarkable: first, the relatively slow progress achieved over the first 100 years of international efforts to promote the collection of harmonised migration statistics, and secondly, the fast pace in which data collection has changed and expanded in the past 20 years or so, in particular in the European Union (see Herm 2006). While technological developments, notably the emergence and increasing sophistication of computerised data collection systems, are also part of this story and certainly have made data collection, analysis and dissemination much easier, the main driver, we would argue, is the increasing salience of migration as a political issue at the international level after 1989 and the increasing political will to collect comparable data on migration both at the national and the international level and to make resources available to improve data collection.

Importantly, statistics is but one field reflecting this increasing salience of international migration at the international level. Indeed the 1990s saw a veritable surge in the attention paid to migration at the international level (both regional and global), prompting one observer in relation to the UN system to state that "suddenly, migration was everywhere" (Newland 2005: 1). The rise in immigration to industrialised countries, and in particular to Europe, following the collapse of Communist regimes in the Eastern Bloc countries, as well as growing numbers of migrants from countries in the global South, have been important drivers for the Europeanisation of policy debates and policymaking on migration in the European context. This has led to various efforts at harmonising asylum policies from the late 1980s onwards, even before migration policy officially became an issue of European Union policymaking. The establishment of the Schengen system by a group of like-minded European states in 1985 and its subsequent communitarisation through the Amsterdam Treaty (1997) was also an important stimulus for the Europeanisation of migration policies and the Europeanisation of knowledge production on migration associated with it. On the global level the internationalisation of debates on migration is reflected, amongst others, by the relaunch in 1989 of the Intergovernmental Committee for

\footnotetext{
${ }^{6}$ However, nationality also competed with other categories of difference (cf. Kraler 2010: 106f). For example, in the Austrian-Hungarian monarchy, language community/ethnicity or local right to residence (Heimatrecht) remained crucial status categories in the Austrian half, reflecting the incomplete homogenisation of territorial rule in the Habsburg empire.

${ }^{7}$ Throughout this chapter, we use migration to refer to international migration for the sake of simplicity, except where otherwise noted.
} 
Migration (ICM) as the International Organization for Migration (IOM). Since then IOM has repositioned itself as an expert organisation, while policy-oriented research has become a core element of its activities, epitomised in the concept of 'migration management' that was popularised by IOM's senior consultant Bimal Ghosh (Georgi 2010: 54-56). Another indication of this development is the massive growth of the office of the United Nations High Commissioner for Refugees (UNHCR) in the 1990s and its increasing engagement in knowledge production on migration more generally. Other elements include the creation of new regional organisations focused on migration such as the International Centre for Migration Policy Development (ICMPD). ${ }^{8}$ Migration also came to play a more prominent role in existing international organisations such as the Council of Europe and the Organisation for Economic Cooperation and Development (OECD). Furthermore, various regional processes focused on migration have been launched, such as the Intergovernmental Consultations on Immigration and Asylum (IGC), founded in 1987, or the Budapest Process, established in 1993. Various global consultation mechanisms on migration have also been established, for example the UN High Level Dialogues on Migration and Development or the Global Forum on Migration and Development. Though framed in terms of migration and development, both are primarily and to a large extent about migration as such (see Kraler 2014). The internationalisation of political debates on migration has massively contributed to the surge in knowledge production on this topic from a global perspective. This has been a major driver for increased efforts to collect comparable and more extensive statistical data on migration not only worldwide, but also at the European level.

In the European Union an additional driver for the institutionalisation of data collection on migration and the development of a specific policy for migration statistics derives from the the EU's knowledge-driven mode of governance, as reflected and acknowledged in the European Commission's White Paper on Governance (Commission of the European Communities 2001b) and in a subsequent Communication on the collection and use of expertise by the Commission (Commission of the European Communities 2002). Not unlike other international organisations, technocratic rationality arguably lies at the heart of EU policymaking. What distinguishes the European Union from most other international organisations is its regulatory power and related quest for legitimacy, articulated also in its complex institutional structures and governance procedures. Given its still limited parliamentary legitimacy (despite the changes following the Lisbon Treaty) and its problematic 'indirect legitimacy', ${ }^{9}$ technocratic and procedural legitimacy arguably

\footnotetext{
${ }^{8}$ ICMPD was founded in 1993 on the initiative of Austria and Switzerland in the context of the massive changes of migration patterns after 1989, the perception of an asylum crisis in the early 1990s, and the crisis of displacement in the Western Balkans. Beyond these immediate concerns, a major impetus for the establishment of the organisation was the increasing political demand for expert advice on migration issues, a factor also relevant for the establishment of academic migration research institutes.

${ }^{9}$ Indirect legitimacy refers to the legitimacy deriving from the sovereignty (and democratic legitimacy) of its component states (Lord and Magnette 2004: 185). Indirect legitimacy is
} 
are the EU's main sources of legitimacy, with both sources stressing a particular kind of rationality and relying on particular types of expertise. Indeed, in a regulatory system like the EU it is to a large extent knowledge rather than budget that is the critical resource in policymaking (Majone 1996, quoted in Radaelli 1999: 759). While (scientific) knowledge that can provide such technocratic legitimacy need not be quantifiable, quantitative knowledge arguably has a much greater persuasive power than narrative knowledge, as numbers convey a sense of authority and objectivity that more qualitative forms of knowledge fail to convey (Espeland and Stevens 2009: 416-422). There is also a peculiar aesthetics around numbers and their capacity to condense complex social phenomena into individual, easily comprehensible indicators. The surge of knowledge production on migration in and by the European Union has to be understood in this context (see also Boswell 2009). It is this story that will be the focus of this chapter.

The remainder of this chapter is structured as follows: in the next part we will provide a brief history of data collection on international migration in Europe. A major focus in this part will be on the evolution of the Statistics Regulation (Regulation (EC) No 862/2007), which is arguably one of the cornerstones of migration statistics policy in the EU. In the part that follows we will discuss the use of migration-related data in Europe for international comparative research with a focus on the categories used in statistics to identify migrant populations and the usefulness of social indicators for migration policymaking. In the final part of this chapter we will see that, though social indicators may be very useful for comparative research, certain limitations exist when it comes to comparing concrete policies and their effectiveness. This is not only because certain differences in definitions and data collection tend to persist, but also because the major political responsibilities for migrant integration, the main theme of this book, still rest with the member states, and not with the EU. Notwithstanding considerable efforts by the EU to achieve more coordination in the field of immigrant integration member states continue to differ significantly in their approaches to this issue.

\subsection{The Politics of Harmonising International Migration Statistics}

Migration and related efforts to harmonise international data collection on migration have been on the agenda of population statistics since it was institutionalised as a field of data collection and research in the nineteenth century, often closely

problematic in different regards. The legitimacy of EU policies is problematised by member state policymakers themselves whether more generally or in regard to specific policies (to which they may have consented or not). Indirect legitimacy can be seen as problematic in the context of the expansion of majority voting and the fact that it is underlying procedural rules, rather than particular policies, which are legitimised by member states' consent. 
linked to wider political projects. In 1843, for instance, participants of the General Conference of the German Customs Union grappled with the problem of how to deal with temporary residence in the territory of the Union and discussed at great length who should be considered as belonging to the ordinary resident population, in the aim of harmonising definitions within the (German) member states of the Union (Schmidt 2005: 133). At a truly international level, migration statistics were first discussed at the 1891 congress of the International Statistical Institute in Vienna. The first attempts to standardise definitions in migration statistics followed 30 years later at the International Conference on Emigration and Immigration in Rome in 1924. This conference was followed by several conferences each adopting resolutions on migration statistics. Institutionally, the International Labour Organisation (ILO), created in 1919, became the main actor in regard to promoting efforts to improve international data collection on migration, albeit seeing migration mainly as an issue of manpower and labour rather than one of population.

An ILO-sponsored conference on migration statistics in 1932 adopted the first more systematic set of recommendations for the improvement of migration statistics (United Nations 1949: 1). From the outset, achieving comparable international migration statistics was considered important not only for statistical, or for that matter, scientific, purposes; it was also seen as a precondition for ' $\ldots$ the regulation of migration by international convention' [and a tool to] 'facilitate cooperation of the administrative authorities of different countries' (International Labour Office 1932: 86, quoted in Kraly and Gnanasekaran 1987: 968). The 1932 recommendations were revised in 1953 and 1976, but both times not widely implemented. The latest revision dates from 1997 (Herm 2006; United Nations 1998). It was preceded by several conferences and studies, also drawing on expertise from outside the UN system such as the Council of Europe, the OECD, ${ }^{10}$ IOM and Eurostat, all of which had become key players in policies on statistical data collection by the time of the 1997 revision, with the role played by Eurostat reflecting the increasing weight of the European Union at the international level more generally (Herm 2006).

\subsubsection{Policies on Collection of Migration Statistics in the European Union}

Efforts at collecting data on migration at the European level extend back to the mid1970s and the ill-fated Community Regulation (EEC) No 311/76 on the compilation of statistics on foreign workers. The latter required member states to supply annual statistics both on the number of workers and on their first employment, without, however, providing guidelines on definitions or data sources to be used. This

\footnotetext{
${ }^{10}$ The OECD has been involved in collecting, disseminating and improving the harmonisation of international migration statistics since the establishment of SOPEMI (Système d'Observation Permanente sur les Migrations) in 1973.
} 
resulted in a potpourri of incomplete and incomparable data, of little use for either policymaking or research. By the late 1980s, Eurostat engaged in renewed efforts to collect basic data on migration and commissioned a number of studies about data collection on migration in the member states of the then European Community, subsequently further extended to European Free Trade Association member states. These studies resulted in a set of tables agreed by member states and Eurostat as a basis for future data collection on migration. A programme for the collection of statistics on international migration was subsequently launched in 1992, and, in the mid-1990s linked to a joint data collection programme run in cooperation with the United Nations Economic Commission for Europe (UNECE), and later also joined by the UN Statistical Division (UNSD), the Council of Europe (CoE) and the International Labour Office (ILO). In 1994 a first publication presenting data on migration flows and stocks based on these new data collection programmes was launched. Data and limited methodological information were also included in Eurostat's statistical database New Cronos. Data collection, however, remained voluntary, incomplete and inconsistent, and doubtful in terms of the reliability of the data included in the dataset (Herm 2006: 93-95).

The nascent cooperation of EU member states on migration and asylum initiated by the Maastricht Treaty (although to some extent actually preceding it) gave rise to separate data being collected through two Council working groups, respectively on irregular migration (the Centre for Information, Discussion and Exchange on the Crossing of Frontiers and Immigration, CIREFI) and asylum (the Centre for Information, Discussion and Exchange on Asylum, CIREA), both established in the mid-1990s. Following the communitarisation of policies on migration and asylum through the Amsterdam Treaty, and responding to the conclusions of the Justice and Home Affairs Council of 1998 ("Vienna Action Plan"), which called for an improvement of the exchange of statistics and information on asylum, data collection was conducted on a more systematic basis from 1998. Responsibility for collecting data was then handed over from the Council Secretariat to Eurostat (Commission of the European Communities 2001a: 4-5). Before 2004 the data were only partly accessible to the public due to member states' concerns about the confidentiality and sensitivity of data on irregular migration, and about their problematic quality. Nevertheless the development of migration statistics policy at the EU level was arguably pushed by member states' interest in statistics directly concerned with migration control, rather than their interest in general demographic data on migration. Tellingly, a Commission Action Plan for the collection and analysis of Community statistics drafted in response to the conclusions of the Laeken Council in 2001, which called for increased efforts to collect comparable statistical data, is most concrete and elaborate in regard to data on asylum and irregular migration, but almost silent on legal migration or migration defined in demographic terms. Implicitly this suggests that the Action Plan simply proposes to carry over Eurostat's data collection on general demographic indicators on migration initiated in 1998 into a legally regulated regime under future Community legislation (see Commission of the European Communities 2003). 
Both the demographic data collection initiated by Eurostat and the data collection on irregular migration and asylum originally initiated and implemented by the Council have been relatively little used. This is because of the limitations of the data collected and the restrictions placed on their public dissemination, but also because a particular policy purpose has been lacking. If they have been used at all, it has been as simple indicators of the size and development of particular target populations, but not for more complex analytical purposes, policy development or policy evaluation. Thus, while the commitment to 'evidence-based policymaking' was a strong factor in further developing data collection, the statistical information produced hardly seemed to matter to policymaking initially, as was the case also with the information collected by the European Migration Network launched around the same time (on the EMN see Boswell 2009).

By contrast, reforms to the collection of social statistics, largely absent from European efforts to improve data collection on migration before the mid-2000s, followed a decisively different path. Linked to the introduction of the Open Method of Coordination (OMC) ${ }^{11}$ as a new mode of governance, social statistics became understood as (quantitative) benchmarks of national initiatives and performance indicators (Bruno et al. 2006). To this end a set of indicators - the so-called Laeken indicators for social inclusion - were defined in 2001. Information was to be collected through the European Union Statistics on Income and Living Conditions (EU-SILC) as of 2003, ${ }^{12}$ and complemented by a set of structural indicators drawn from various data-sources, including the EU Labour Force Survey with regard to basic employment indicators. While these datasets in theory - and at least to a limited extent - would have facilitated the monitoring of social and employment indicators in relation to migrants from the early 2000s, 10 years had elapsed before relevant data came to be systematically used at the EU level to monitor the integration of immigrants in the form of institutionalised integration monitoring (see below).

The development of EU policies on migration statistics relied heavily on the mobilisation of 'external' expertise. The mobilisation of expertise helped to create an 'epistemic community' (Haas 1992) ${ }^{13}$ involving policymakers, academics

\footnotetext{
${ }^{11}$ The OMC was proposed at the 2000 Council Summit in Lisbon (see http://www.europarl.europa. eu/summits/lis1_en.htm, accessed 20 September 2012) and re-endorsed in 2008 (see Commission of the European Communities 2008).

${ }^{12} \mathrm{EU}-\mathrm{SILC}$ is an EU-wide harmonised sample survey which collects comprehensive data on social issues, including indicators on poverty and social exclusion (Regulation (EC) No 1177/2003 concerning Community statistics on income and living conditions (EU-SILC)). EU-SILC replaced the earlier European Household Panel.

${ }^{13}$ The contemporary use of the term goes back to P.M. Haas (1992), who developed the concept in the context of environmental and climate policies. The term itself is older, and has been used by earlier writers, although in a more limited meaning. P.M. Haas' use of the term explicitly takes up the notion of "thought collective" developed by German sociologist Ludwig Fleck in the 1930s. According to Haas (1992: 3), "[a]n epistemic community is a network of professionals with recognized expertise and competence in a particular domain and an authoritative claim to policyrelevant knowledge within that domain or issue-area". These professionals share a set of normative
} 
based at universities and research institutions, statistical institutes and international organisations, sharing a common vocabulary, a common belief in the need to produce comparable statistics, and a common understanding of related challenges. Throughout the 1990s and 2000s, Eurostat commissioned several studies contributing to its data collection efforts. In the mid-1990s, joint meetings on migration statistics were initiated by Eurostat and UNECE, largely drawing on their own expertise and those of national statistical institutes, but also regularly inviting external experts from academic institutions or international organisations (see Herm 2006). Commissioned research and regular meetings were important instruments for creating a like-minded community of experts. In addition, circulation of experts in the form of posting of national statistical experts at Eurostat or UNECE or career trajectories of individuals spanning both spates of service in public office and academia, etc. - were important drivers as well.

In addition, several research projects were funded under the EU's 5th and 6th Framework Programmes for Research ${ }^{14}$ thus contributing to the development of a legal framework for the collection of migration statistics at the EU level. The adoption by the member states of the 'Regulation on Community Statistics on Migration and International Protection' (Regulation 862/2007) in July 2007, first presented as a legislative proposal in September 2005, can be considered a major turning point in EU policies on data collection for migration and asylum.

Reflecting the growing importance of migration issues at the EU level, Regulation 862/2007 breaks with the 'gentlemen's agreement' approach to voluntary data collection by EU member states on issues concerning migration and asylum. Furthermore it provides for mandatory and harmonised statistical data collection on core demographic indicators as well as on key indicators concerning the management of migration. The regulation covers the provision of comprehensive data based on harmonised definitions of population by citizenship and country of birth, migration movements, acquisition and loss of citizenship, asylum, residence permits as well as enforcement of immigration legislation. In an effort to create an incentive for providing accurate data, the allocation of various EU funds on migration and asylum was linked to data collected in compliance with Regulation 862/2007 (Kraler et al. 2006: 70).

While the optional collection of socio-demographic data suggested by the European Commission in earlier drafts of Regulation (EC) No 862/2007 was removed during negotiations, statistical data on migrants' socio-demographic characteristics has seen an enormous expansion through other EU mechanisms. It now also involves quasi-mandatory elements, for example in the framework of European surveys such

\footnotetext{
and principled beliefs, causal beliefs, and notions of validity, and are engaged in a common policy enterprise.

${ }^{14}$ These included the projects COMPSTAT (Comparing National Data Sources in the Field of Migration and Integration), THESIM (Towards Harmonised European Statistics on International Migration) and PROMINSTAT (Promoting Comparative Quantitative Research in the Field of Migration and Integration in Europe).
} 
as the Labour Force Survey (EU-LFS) (notably through its 2008 ad hoc module on migrants in the labour market, repeated in 2014). In addition, in 2008, Regulation (EC) No 763/2008 on Population and Housing Censuses was adopted, stipulating obligatory topics for population and housing censuses for the reference year 2011 and including core information related to migration, most notably information on country of birth, country of citizenship and other basic data related to migration.

Since the implementation of the Regulation 862/2007, statistics, particularly those related to migration enforcement and asylum, have been increasingly used as performance indicators, notably to derive recognition rates from asylum statistics or to calculate ratios between return decisions and actual returns. Ten years after the Lisbon strategy was adopted, social indicators on migrants, as noted above, came to be systematically collected in the form of 'indicators of migrant integration', to be used for 'monitoring the results of integration policies in order to increase the comparability of national experiences and reinforce the European learning process' (European Council 2010). The need to evaluate integration policies through indicators has been put forward several times since the Hague programme, adopted by the Council in 2004, while in the Stockholm programme of 2009 the explicit call for the development of indicators of migrant integration was made. This led to the immediate development of indicators by an expert group. Fourteen indicators were developed in the four areas of employment, education, social inclusion and active citizenship, and were endorsed at the Ministerial Conference in Zaragoza in 2010 (European Ministerial Conference on Integration 2010). These indicators were produced in a pilot study by Eurostat (2011) and were subsequently evaluated and tested for their usefulness and robustness.

As a result of these different developments, which in turn were the result of complex discussions involving national data providers, Eurostat, international actors, researchers and policymakers at both the EU and national levels, data availability and accessibility have indeed enormously expanded in the past decades, allowing data users to tap vast and expanding sources of information. Notwithstanding such significant improvements, major deficiencies remain when it comes to availability, comparability and quality of data. The production and analysis of population and migration statistics as well as the institutionalisation of data production and dissemination have always been a concern to representatives of both governance and independent research. Authorities were interested in reliable, comparable data for policymaking but at the same time independent researchers and academia had an interest in using statistics for research, sometimes in order to criticise the authorities. While the adoption of Regulation (EC) No 862/2007 led to an increased availability of harmonised data, major issues are still unsolved in relation to data quality and comparability. It is often unclear what national source data are reported to Eurostat, and how they relate to data published on the national level, an issue of particular concern to administrative data. But also in respect to core demographic data, such as data on migration flows or stocks, data reported to Eurostat still often deviate from agreed data definitions. While availability of data on the European level has indeed much improved, their comparability and quality are still major issues. What is more, the increasing scope and depth of data collection on migration and related areas 
also raises more fundamental issues regarding the meaning (and meaningfulness) of harmonised statistical categories in an expanding European Union, the limits of such harmonisation, and the dangers associated with the use of concepts such as country of birth and citizenship as master frames. These issues will be discussed in the next section.

\subsection{Availability and Comparability of Migration-Related Statistics in Europe}

A major challenge in migration statistics is the insufficient coverage of migrants in available data sources. International migration movements, for example, are often measured through registration data. Due to the fact that people often do not de-register prior to emigrating from a country, emigration is notoriously difficult to capture (cf. Kupiszewska et al. 2010). At the same time, due to the different definitions used in countries, migration data are rarely comparable. Another problem is under-representation of migrants in sample surveys. This is due to several reasons, including a somewhat higher interview refusal rate among migrants. Even more important, however, is the fact that excessively small sample sizes in general population surveys limit the possibilities for quantitative research on migrants. Finally, and probably most importantly, the information included in datasets for identifying migrants varies significantly over different data sources. Register data usually lack comprehensive information as most registers have been built for the purpose of administration and not primarily for statistical analysis. Consequently, only limited information on migrants is available in registers, for example only nationality or only country of birth, but not both. Sufficiently rich datasets can be constructed only when national data collection systems allow for extensive linkage of different registers, as is the case in the Nordic countries. In comparison, surveys have the advantage that they usually contain more information on migration background, but their availability differs across countries.

One potential way to overcome problems with harmonisation and data availability is the extended use of internationally organised sample surveys, in particular the EU-LFS and EU-SILC. However, the need for, and use of different indicators to define migrants or minorities varies greatly between European countries, as will be discussed in the next section.

\subsubsection{Identifying and Defining Migrants - Different Concepts, Needs and Availabilities}

Different historical contexts and experiences of migration are reflected in countries' data collection practices and availability of data (see also Fassmann et al. 2009; Bijl and Verweij 2011). The core information used for identifying migrants in statistical 
datasets is citizenship and country of birth. However, mapping various datasets available for migration research in the EU, migration researchers can differentiate their groups of interest by several characteristics including nationality (citizenship), origin, residence or migration history, legal status, descent and ethnicity (see Table 3.1; cf. Kraler and Reichel 2010: 69-72).

The appropriate choice of indicator for analytical purposes obviously depends on the question to be answered. The concepts shown in Table 3.1 include demographic, sociological and legal categorisations of persons, although clear-cut differentiations are not possible due to the strong association between some of the concepts. For instance, citizenship and legal status measure political membership and the legal situation of persons. Such information is important for citizenship studies, for analysing the impact of legal status on social integration, or for evaluating the composition of immigrants by categories of admission. Origin and residence/migration history provide information on demographic issues, for instance whether a person actually migrated to a country or not. Information on descent and ethnicity are proxies for different sociologically defined concepts of belonging to certain groups. They are strongly related to concepts of race, which are important for investigating issues such as racism and discrimination. Empirically, the choice of an indicator has primarily depended on the availability of data, making citizenship the most commonly used indicator in many European countries. Although citizenship indicates legal membership of a state, it can be used as a proxy for migration history or ethnicity. ${ }^{15}$

When more complex migration research is considered, requiring more precise research questions and better availability of data, the indicators used for defining the population of study need to be more precise as well. Figure 3.1 below gives an overview of the relationship between two core indicators: country of birth and citizenship in Austria in 2007. It shows that $8.6 \%$ of the total population are nonnationals as well as born abroad. An additional $6.3 \%$ of the population have been born abroad (and thus are immigrants) but hold Austrian citizenship. ${ }^{16}$ Thus, in 2007, only about $58 \%$ of all immigrants in Austria were foreign citizens. At the same time, $1.4 \%$ of all persons born in Austria (i.e. non-immigrants) hold foreign citizenship. This percentage is influenced by Austria's lack of ius soli regulations for children born to foreign citizens in Austria.

Figure 3.2 shows the percentage of the foreign population plotted against the foreign-born population in the European Union and Norway. Not surprisingly the two indicators are closely correlated and countries with higher percentages of immigrants also show higher proportions of foreign-born in their population. It

\footnotetext{
${ }^{15}$ Whether citizenship is an appropriate proxy variable depends on the specific context. In countries with a recent history of migration non-citizens may well represent an overwhelming majority of migrants; in countries with a longer migration history, a colonial legacy and/or very liberal policies on citizenship acquisition, foreign nationals may, by contrast, only represent a fraction of the total population of immigrants defined by country of birth.

${ }^{16}$ The majority of this group are naturalised citizens, since there is only a small number of persons born abroad as Austrians who move to Austria at a later stage.
} 


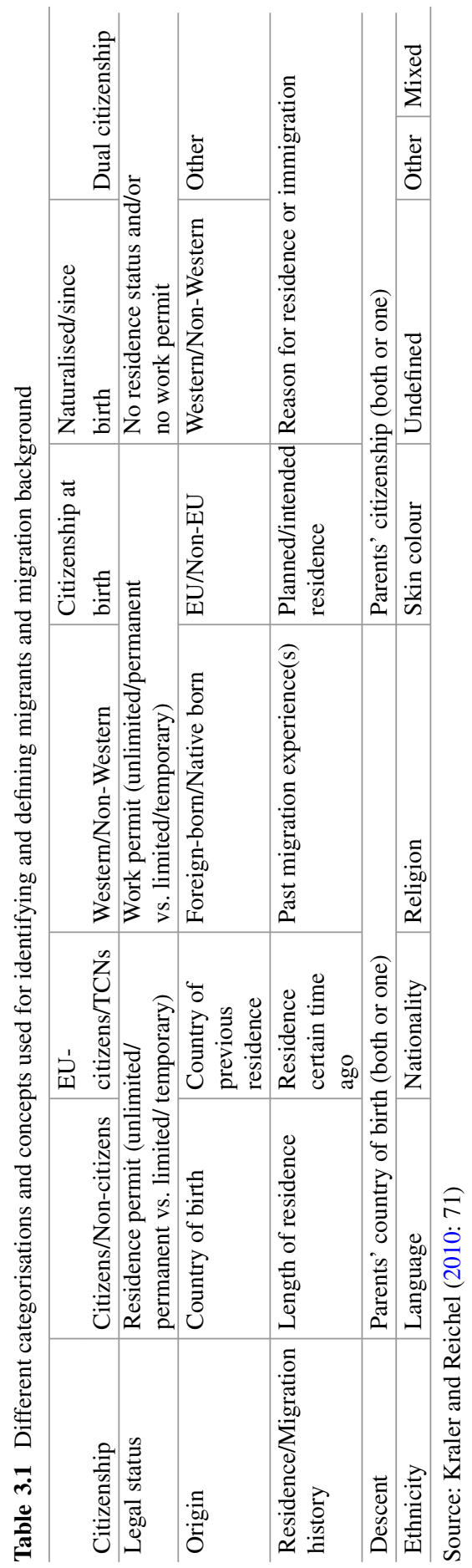


Fig. 3.1 The two main indicators compared: foreign-born and foreign nationals in Austria (2007) (Source: own presentation based on data from Statistics Austria)

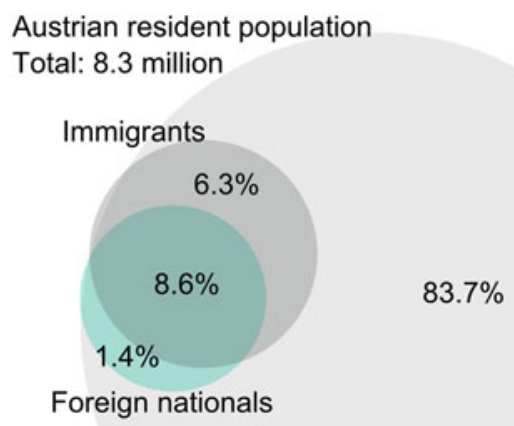

Austrian resident population

Total: 8.3 million

is however important to highlight the apparently small but significant differences between the two indicators. Not all foreigners are foreign-born and not all foreignborn persons are foreigners (e.g. immigrants who were not foreign citizens at the time of immigration or who acquired citizenship after immigration). This difference can mainly be explained by different practices of naturalisation and citizenship policies. Figure 3.2 shows that there is a clear tendency towards higher percentages of foreign-born compared to foreign citizens (the data points tend towards the lower right panel). This difference is influenced by naturalisation rates in the countries, which are affected by naturalisation policies (cf. Reichel 2011, 2012).

Ultimately, however, the particular questions at stake should guide the use of indicators, whether citizenship, country of birth or 'foreign background'. The latter variable was first collected systematically across a large number of EU member states in the 2008 ad-hoc module of the EU-LFS on migrants in the labour market, and usually refers to residents with both parents born abroad, thus including not only the first, but also the 'second migrant generation'. The - at least theoretical availability of different indicators to identify migrant populations also is a useful reminder that 'migrant' is an essentially fluid, contingent and historically variable concept. No matter how it is defined, it does not identify a certain population with immutable traits. Instead it reflects statistical concepts such as country of birth or citizenship that differentiate populations according to certain attributes, e.g. holding the citizenship of another country or having been born in another country. In themselves these attributes mean little. What is more, grasping the importance of international mobility for individuals may require quite different indicators to those regularly collected, including migration experiences of the native population. In a context where international mobility increasingly forms part of the life course, be it for study purposes, employment, family or other reasons, more complex indicators 


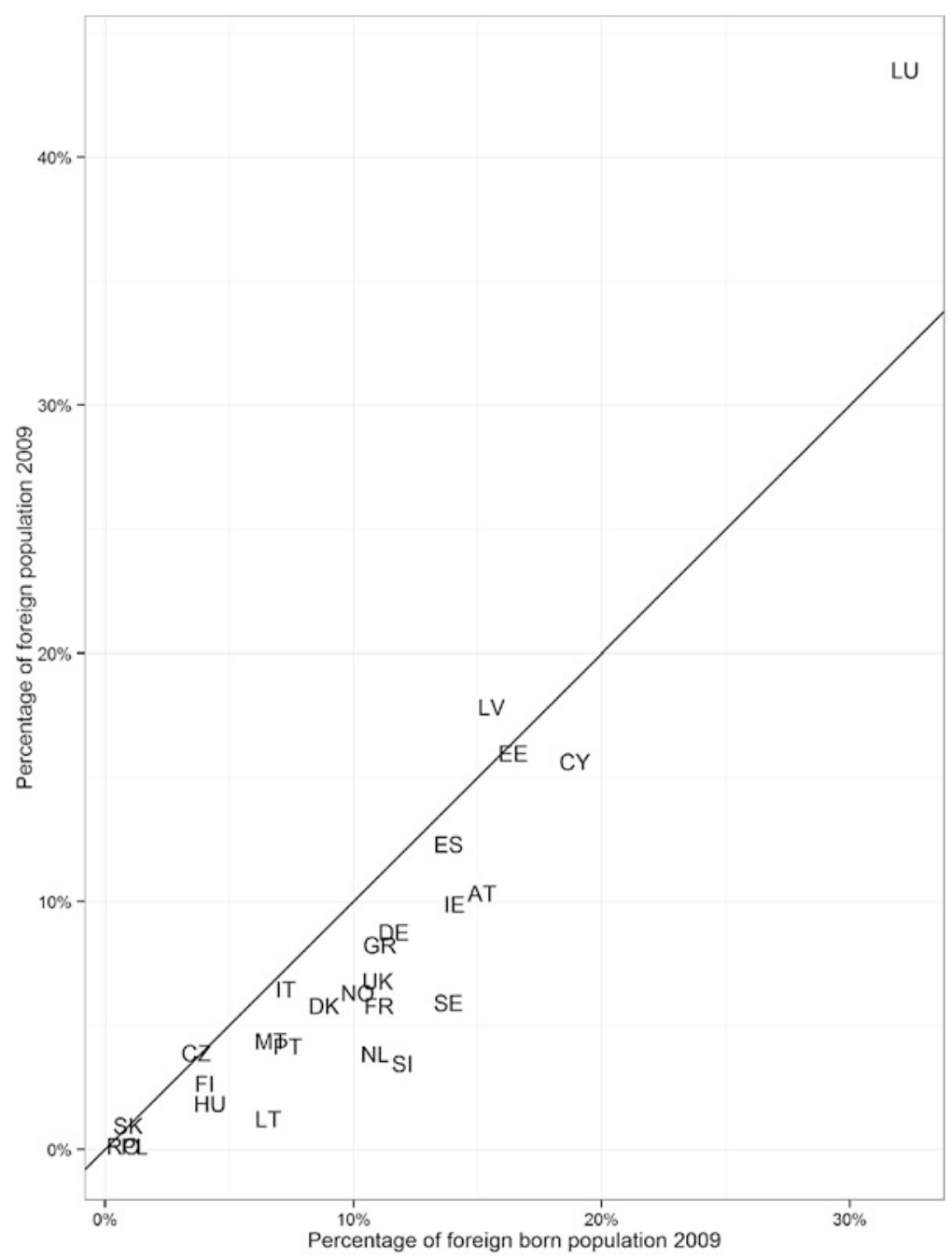

Fig. 3.2 The two main indicators compared: percentages of foreign-born and foreign nationals in the European Union and Norway (2009) (Source: Eurostat database, Migration Statistics. Data for Belgium and Bulgaria are missing)

may well be needed. In the final analysis, however, a flexible use of indicators is required rather than a fixation on particular categories identifying particular segments of the population. While perhaps cumbersome, the allusions of sameness and difference conveyed by statistical indicators and discussed in the introductory section of this chapter need to be regarded as an obstacle to knowledge production on migration, rather than as a facilitator. 


\subsubsection{The Effect of Policy Differences}

With our earlier observation that the share of foreign citizens residing in a country depends not only on past immigration levels, but also on policies regarding naturalisation we touched upon an aspect in immigration research that complicates comparisons even further. While it is true that agreements have been reached in the European Union on the definition of some of the major concepts that relate to the process of migration - albeit after long deliberation - it has proved to be much more difficult to arrive at some common standards on how to measure immigrant integration (see also Chap. 7). This can be explained to a large extent by the fact that European countries differ significantly in their views on how concepts such as integration and social cohesion should be understood and on what role public policy should play in facilitating such processes. This is not the place to elaborate on differences in objectives that countries may define for their integration policies (see, for example, Scholten 2011), but it requires little effort to understand that a policy of multiculturalism requires data that differ from those needed when policies are oriented more to assimilation. In the former case, for example, governments may wish to know how many children attend classes in mother tongue teaching, whilst in the latter case they will be more interested in knowing how many are fluent in the national language.

In the foreseeable future it is not very likely that consensus will be reached at a European level on a definition of immigrant integration and on the indicators used to measure it and to assess the effectiveness of relevant policy instruments beyond the limited - and ambiguous - Zaragoza indicators (see Eurostat 2011). Certain oft-used indicators are not always as clear-cut as they may seem. Segregated housing, for example, is usually seen as the outcome of unfair selection processes and discrimination, and therefore as reflecting a lack of integration. But what if members of a migrant community deliberately choose to live close to co-ethnics or co-nationals, a choice that automatically leads to concentration and, as a logical consequence, to segregation of other communities? And what if a high frequency of contacts with the home country is seen as a sign of lacking integration, as is often the case, while in reality research has shown that migrants with frequent transnational contacts also maintain frequent contacts in their country of residence, usually taken as a sign of integration (Snel et al. 2006)? Thus, one has to be very careful in interpreting immigrant behaviour and in drawing conclusions from it concerning their integration. That commonly used indicators can be interpreted in such different ways makes it extremely challenging to achieve consensus on how the process of immigrant integration should be understood and measured in a comparative perspective.

A final question that arises in comparative research on immigrant integration has to do with reference groups and benchmarks. The following example may clarify this point. Labour force participation among immigrants is generally seen as a reliable indicator for their integration. Now take an immigrant community, say the Turks, which in country A has a labour force participation rate of $70 \%$, while the 
overall participation rate in that country is $80 \%$. Then take country $\mathrm{B}$, where the Turkish participation rate is $60 \%$, while total labour force participation also stands at $60 \%$. In which of these two countries can Turks be seen as better integrated? If we take the total participation rate as a benchmark, the answer would be country $\mathrm{B}$, since the Turkish community and the entire population participate at exactly the same level. However, seen from the perspective of the Turkish community, integration in country A would be more successful, as their participation level is ten percentage points higher there than it is in country A, in spite of the fact that it is below the overall average for that country. The more general question here is: what should be the reference group in comparative research on immigrant integration and in assessing the effects of integration policies? Should it be the same community in different countries, or should it be different communities in the same country? The example just given makes clear that even when comparable data are available conclusions may differ vastly, depending on the questions asked and the methodological choices made.

\subsection{Conclusions}

The collection of migration statistics has always been an important component of official statistics and population research, which is also reflected in the close involvement of academics and public administrators in the process of data collection and analysis. In particular, the efforts of the European Union have led to considerable expansion of available data in the area of migration, notably through the adoption of Regulation (EC) No 862/2007 which made it compulsory for EU member states to provide Eurostat with comprehensive data on migration issues.

The increased availability of international data in the area of migration has led to an enormous expansion of opportunities for research, and the full potential of Eurostat's newly collected data is still to be exhausted. However, on the conceptual level, several questions remain. In particular, the institutionalisation of certain demographic indicators, notably country of birth, begs the question as to how useful these concepts are and whether they need to be complemented by additional indicators which help to identify 'migrants' in a more nuanced and differentiated way. The production and use of social statistics differentiated by 'migration background', be it on the basis of demographic, sociological or ethnic criteria, not only makes these groups visible, but also manifests their very existence and creates a reinforced perception of group differences. As pointed out by Nancy Fraser (2000) we have to be careful when recognising differences within our societies due to the potential effect of reinforcing group identities. Data producers and users, both from policy as well as academia, need to be flexible when dealing with statistics. Yet, this same flexibility, even though it may sometimes be required to cope with the limitations of available data, may also challenge the relevance of the outcomes, particularly in comparative research. This is the case in research on migration, but it is even more so in research on immigrant integration and the effectiveness 
of integration policies. Here significant differences in objectives and instruments persist between European countries, thus creating even more ambiguity in the use of statistics and their interpretation.

Open Access This chapter is distributed under the terms of the Creative Commons Attribution Noncommercial License, which permits any noncommercial use, distribution, and reproduction in any medium, provided the original author(s) and source are credited.

\section{References}

Bijl, R., \& Verweij, A. (Eds.). (2011). Measuring and monitoring immigrant integration in Europe. The Hague: The Netherlands Institute for Social Research SCP.

Boswell, C. (2009). The political uses of expert knowledge. Immigration policy and social research. Cambridge: Cambridge University Press.

Bruno, I., Jacquot, S., \& Mandin, L. (2006). Europeanization through its instrumentation: benchmarking, mainstreaming and the open method of co-ordination ... toolbox or Pandora's box? Journal of European Public Policy, 13(4), 519-536.

Commission of the European Communities. (2001a). The exchange of statistical information in the field of asylum and migration (Commission staff working paper, $\operatorname{Sec}(2001) 602$ ).

Commission of the European Communities. (2001b). European governance. A white paper $(\operatorname{COM}(2001) 428$ final).

Commission of the European Communities. (2002). Communication from the Commission on the collection and use of expertise by the Commission: Principles and guidelines. "Improving the Knowledge Base for Better Policies" (COM(2002) 713 final).

Commission of the European Communities. (2003). Communication from the Commission to the Council and the European Parliament to present an action plan for the collection and analysis of Community Statistics in the field of migration (COM(2003) 179 final).

Commission of the European Communities. (2008). Communication from the Commission to the Council, the European Parliament, the European Social and Economic Committee and the Committee of the Regions. 'A renewed commitment to social Europe: Reinforcing the Open Method of Coordination for Social Protection and Social Inclusion' (COM(2008) 418 final).

Espeland, W. N., \& Stevens, M. L. (2009). Sociology of quantification. European Journal of Sociology, 49(3), 401-436.

European Council. (2010). The Stockholm Programme - An open and secure Europe serving and protecting citizens. Official Journal of the European Union, 2010/C 115/01.

European Ministerial Conference on Integration. (2010, April 15 and 16). Draft declaration. Zaragoza. http://ec.europa.eu/ewsi/UDRW/images/items/docl_13055_519941744.pdf. Accessed 21 Jan 2015.

Eurostat. (2011). Indicators of immigrant integration - A pilot study. 2011 edition (Eurostat Methodologies and Working Papers). Luxembourg: Publications Office of the European Union.

Fassmann, H., Reeger, U., \& Sievers, W. (Ed.). (2009). Statistics and reality: Concepts and measurements of migration in Europe. Amsterdam: IMISCOE-Amsterdam University Press.

Fraser, N. (2000, May/June). Rethinking recognition. New Left Review, 3, 107-120.

Georgi, F. (2010). For the benefit of some: The International Organization of Migration and its Global Migration Management. In M. Geiger \& A. Pécoud (Eds.), The politics of international migration management (pp. 45-73). Houndmills: Palgrave Macmillan.

Haas, P. M. (1992). Introduction: Epistemic communities and international policy coordination. International Organization, 46(1), 1-35. 
Hacking, I. (2006). The emergence of probability: A philosophical study of early ideas about probability induction and statistical inference (2nd ed.). Cambridge: Cambridge University Press.

Herm, A. (2006). Recommendations on international migration statistics and development of data collection at an international level. In M. Poulain, N. Perrin, \& A. Singleton (Eds.), THESIM. Towards Harmonised European Statistics on International Migration (pp. 77-106). Louvainla-Neuve: Presses Universitaires de Louvain.

International Labour Office. (1932). Statistics of migration. Definitions - Methods - Classifications (Studies and report series nr. 18). Geneva: International Labour Office.

Kraler, A. (2009). Migration und die Universalisierung der Nationalstaatsform am Beispiel Ruanda. In A. Sonderegger \& A. Kraler (Eds.), Perspectives on ethnicity and 'Race'. Special issue. Stichproben. Wiener Zeitschrift für Kritische Afrikastudien/Vienna Journal of African Studies, 16, 107-142.

Kraler, A. (2010). Globale Migrationen. Migrationsdynamiken seit 1800. In R. Sieder \& E. Langthaler (Eds.), Weltgeschichte 1800 - Gegenwart (pp. 97-132). Wien: Böhlau.

Kraler, A. (2014). Migration und Entwicklung. Interessen, Akteure und Arenen eines erfolgreichen Diskurses. In I. Ataç, M. Fanizadeh, A. Kraler, \& W. Manzenreiter (Eds.), Migration und Entwicklung. Neue Perspektiven (pp. 23-48). Vienna: Promedia.

Kraler, A., \& Reichel, D. (2010). Statistics on migration, integration and discrimination in Europe (PROMINSTAT final report). Vienna: ICMPD.

Kraler, A., Jandl, M., \& Hofmann, M. (2006). The evolution of EU migration policy and implications for data collection. In M. Poulain, N. Perrin, \& A. Singleton (Eds.), THESIM. Towards Harmonised European Statistics on International Migration (pp. 35-75). Louvain-laNeuve: UCL - Presses Universitaires de Louvain.

Kraly, E. P., \& Gnanasekaran, K. S. (1987). Efforts to improve international migration statistics. A historical perspective. International Migration, 21(4), 967-995.

Kupiszewska, D., Kupiszewski, M., Marti, M., \& Ródenas, C. (2010). Possibilities and limitations of comparative quantitative research on international migration flows (Prominstat thematic working paper 4). http://www.prominstat.eu/drupal/?q=node/73. Accessed 2 Jan 2014.

Lord, C., \& Magnette, P. (2004). E Pluribus Unum? Creative disagreement about legitimacy in the EU. Journal of Common Market Studies, 42(1), 183-202.

Majone, G. D. (Ed.). (1996). Regulating Europe. London: Routledge.

Nassehi, A., \& Schroer, M. (1999). Integration durch Staatsbürgerschaft? Einige gesellschaftstheoretische Zweifel. In U. Davy (Ed.), Politische Integration der ausländischen Wohnbevölkerung (pp. 82-104). Baden-Baden: Nomos.

Newland, K. (2005), The governance of international migration: Mechanisms, processes and institutions. A paper prepared for the Policy Analysis and Research Programme of the Global Commission on International Migration. http://www.iom.int/jahia/webdav/site/myjahiasite/ shared/shared/mainsite/policy_and_research/gcim/tp/TS8b.pdf. Accessed 3 Nov 2013.

Radaelli, C. M. (1999). The public policy of the European Union. Whither politics of expertise? Journal of European Public Policy, 6(5), 757-774.

Reichel, D. (2011). Do legal regulations hinder naturalisation? Citizenship policies and naturalisation rates in Europe (EUI working papers. RSCAS 2011/51). http://eudo-citizenship.eu/docs/ RSCAS_2011_51.pdf. Accessed 2 Jan 2014.

Reichel, D. (2012). Regulating political incorporation of immigrants - Naturalisation rates in Europe (ICMPD working paper no. 4). http://research.icmpd.org/fileadmin/Research-Website/ Publications/working_papers/Reichel_Naturalisation_Rates_Europe_2012.pdf. Accessed 15 June 2014.

Reinprecht, C. (2010). Bevölkerungsstruktur, Migration, Lebensformen. In A. Gächter, F. Kolland, P. Dannecker, \& C. Suter (Eds.), Soziologie der globalen Gesellschaft. Eine Einführung (pp. 77-104). Vienna: Mandelbaum.

Schmidt, D. (2005). Statistik und Staatlichkeit. Wiesbaden: VS Verlag für Sozialwissenschaften.

Scholten, P. (2011). Framing immigrant integration. Dutch research-policy dialogues in comparative perspective. Amsterdam: Amsterdam University Press. 
Scott, J. (1998). Seeing like a state. How certain schemes to improve the human condition have failed. Newport: Yale University Press.

Searle, J. (1995). The construction of social reality. London: Penguin.

Snel, E., Engbersen, G., \& Leerkes, A. (2006). Transnational involvement and social integration. Global Networks, 6, 285-308.

United Nations. (1949). Problems of migration statistics (Population studies 5). Lake Success: United Nations.

United Nations. (1998). Recommendations on statistics of international migration. Revision 1. New York: United Nations. 


\title{
Chapter 4 \\ The Coproduction of National Models of Integration: A View from France and the Netherlands
}

\author{
Christophe Bertossi, Jan Willem Duyvendak, and Peter Scholten
}

\subsection{Introduction}

The notion of national models of integration is a very popular one in comparative migration studies. These models, inspired by a historical-institutionalist perspective, are perceived as nationally and historically rooted ways of framing immigrant integration (Brubaker 1992). According to such models, how integration is defined and acted upon differs primarily according to specific national histories, differences in national identity and different views of the role of the state. A key trait of such national models is that they assume policies to be formulated and coordinated in a strongly state-centred way, reflecting national institutional legacies, national politics and public perceptions of national identity (Brubaker 1992; Koopmans and Statham 2000). In this respect, the literature distinguishes for instance the French republican model, the British race-relations model and the Dutch multicultural model.

This 'models-thinking' has had great resonance in migration studies. A key reference is Brubaker's work that juxtaposes the German and French models of citizenship upon which the foundations for integration policies in these countries were built; a differentialist approach in Germany and an assimilationist approach in France (1992). As a true historical institutionalist, Brubaker shows how the historical conditions in both countries led to the construction of these national models: a strongly developed cultural and apolitical sense of national belonging in Germany

\footnotetext{
C. Bertossi

Centre for Migration and Citizenship, French Institute for International Relations, Paris, France

J.W. Duyvendak

University of Amsterdam, Amsterdam, Netherlands

P. Scholten $(\bowtie)$

Department of Public Administration, Erasmus University Rotterdam, P.O. Box 1738, 3000 DR

Rotterdam, Netherlands

e-mail: p.w.a.scholten@fsw.eur.nl
} 
versus the state-centric tradition of nation building in France. Likewise, the work of Christian Joppke takes national models as a starting-point for comparative studies of immigrant integration (1999), as does Patrick Ireland, whose comparative study of France and Switzerland finds that national institutional conditions provide the best explanation for the type of policies that are developed (Ireland 1994). Similarly, Ruud Koopmans' Dutch-German comparison takes the differences in national models as the main explanation for the differences in effectiveness of the Dutch and German approaches (Koopmans 2007).

This chapter offers a critical discussion of the idea of national models of integration, as a characteristic of an important part of knowledge production in migration research. Our analysis focuses on the Dutch and French cases. These two countries represent two of the most pertinent cases where discourses on two very different national models have been particularly strong. In particular, we will position the alleged national models of integration in the broader academic and policy discourses of the two countries, and subsequently discuss the role that research-policy relations have played in (co-) producing these models. Rather than the models deriving their strength from either academic or policy discourse, it seems that especially the interaction between research and policy played a key role in 'coproducing' national models of integration. Thus, this chapter will reveal the opportunities as well as the great difficulties for research-policy dialogues to critically discuss national models of integration.

\subsection{National Models and Comparative Migration Research}

A national model of integration and citizenship is usually defined as a public philosophy (Schain 2009), a policy paradigm (Favell 1998; Guiraudon 1997), an institutional and discursive opportunity structure (Koopmans et al. 2005) or a national cultural idiom (Brubaker 1992). All these concepts attempt to show how social reality is structured by pre-existing ideas about a nation's self-understanding, and how such ideas frame social interactions, institutional arrangements, policy outcomes and social movements (Bertossi and Duyvendak 2012).

\subsubsection{National Models of Integration: A Critical Assessment}

What notions of politics are implied in 'national modelling'? First of all, it implies that policies are primarily oriented to the nation. Bommes and Thränhardt (2010) argue that these paradigms are national "not just because of their context dependency and insufficient clarifications on the conditions of generalisability. They are national because the modes of presenting and questions are politically constituted by the nation states for which migration becomes a problem or a challenge' (ibid: 10). Similarly, Favell (2003) shows that national models of integration are often the 
product of the 'exclusively internal national political dynamics' or 'self-sufficiency' of debates on immigrant integration in politics as well as in migration research. Thus, the development of these national paradigms must be considered a consequence of the centricity of the nation state in policy and academic discourses, rather than as accurate representations of the uniquely national character of immigrant integration policies. In fact, as Bommes and Thränhardt (2010) argue, national paradigms have distorted international comparative research (see also Bommes and Morawska 2005), often leading to what Favell (2003) describes as 'self-justificatory discourse' (see for instance the role that French-American antagonism played in the justification of the French republican 'model': Fassin 1999). Researchers have shared in this 'methodological nationalism' instead of questioning the 'national' in 'national models'.

Secondly, this perspective of models of integration emphasises that agency and collective interests are marginal dimensions in institutional arrangements and in the structure of public debates (Brubaker 1992: 13-16). Instead, normative and idealistic 'structures', 'idioms' or 'paradigms' are seen as being the primary driving force behind policies and practices related to identity, citizenship, immigration, religious diversity, and so on. Social actors, from politicians to veiled Muslim women, are portrayed as simply inheriting these ideas, using and adapting to them. In turn, a public speech on immigrants or a woman's decision to wear the hijab are also brought down to a single cause, namely the power of French republicanism or British and Dutch multiculturalism to drive individual behaviours, social movements, institutional arrangements, and policies (Koopmans et al. 2005).

Finally, models also tend to oversimplify policies and overemphasise the alleged coherency and consistency of these policies (see Bertossi and Duyvendak 2012). Policy practices tend to be far more resilient and diverse than most policy models would suggest. For instance, in Dutch as well as in French literature there have been many references to differences between how policies are formulated at the national level and how they are put into practice often at the local level. Some even speak of the decoupling of national and local policies in this respect (Favell 1998; De Zwart 2005; Poppelaars and Scholten 2008). In fact, even when policymakers claim to operate according to a specific policy model, their reasons for doing so may be based more on pragmatism and flexibility than on support for the policy model itself in its ideal-typical form. For instance, the reason why some politicians in the 1980s framed immigrant integration in terms of the multicultural model may have much more to do with their fear of anti-immigrant parties playing the race card than with their so-called multicultural policy beliefs (Scholten 2011).

On the one hand, national models seem to offer considerable advantages for comparative research on the incorporation of immigrants and their offspring into Western European countries. For one, it helps to identify striking differences among countries that have implemented different policies and adopted contradictory public conceptions of citizenship. Within this perspective, republican and assimilationist France appears to be a powerful illustration of what multiculturalism is not while in countries such as Britain and the Netherlands multiculturalism remains something undoubtedly un-French. This simplifies the otherwise highly complex and contested 
matter of immigrant integration. Models help to construct international comparative studies to assess processes of convergence or divergence between various European countries. Furthermore, by comparing ideal-typical models with specific periods, modelling can generate a better understanding of the dynamics of migrant integration policies in a country's history.

On the other hand, the danger of modelling is that the models are not only taken as tools for international comparison or for understanding historical periods. When a model begins to shape our understanding and beliefs about policies, the model becomes more than just a model: the model is then taken as an accurate historical reconstruction of policy rather than as a model of it. Models then take the place of historical analysis. In social science literature, this has often led to instances where a model is 'blamed' for the success or failure of a specific policy approach. For instance, various authors have blamed the Dutch multicultural model for the alleged failure of immigrant integration in the Netherlands (Koopmans 2007; Sniderman and Hagendoorn 2007).

\subsubsection{Migration Research and the Coproduction of Models}

Models can be very powerful as a form of 'discourse' (Hajer 1995), not just in politics and policymaking but in public debate, civil society and academia as well. Hajer speaks in this context of the formation of 'discourse coalitions,' which involve actors that are held together by a shared discourse and not necessarily by coordinated interaction. This can include various types of actors, including politicians and policymakers, as well as academics, experts, interest groups, journalists, and so on.

National models tend to be coproduced by this range of actors within such discourse coalitions (see also Scholten 2009; Duyvendak and Scholten 2011). In fact, it is the coproduction of a national model by different types of actors that can lend it significant discursive strength. For instance, the mere involvement of leading academics or reputable research institutes can provide significant authority to a discourse coalition. Furthermore, once a discourse coalition emerges and is supported by a sufficiently large or strong group of actors, a discourse can prove difficult to change. Challenging a discourse means also challenging the beliefs and interests of the groups involved in the discourse coalition. Furthermore, discourses tend to become taken-for-granted: even members of a discourse coalition may be unaware of their tacit beliefs and the presence of alternative beliefs.

This is why, according to Rein and Schön (1994), situations that are characterised by a multiplicity of coexisting discourses (or 'frames') tend to evolve in 'intractable policy controversies'. Such intractable controversies do not just involve mere disagreements about how to resolve a given problem, but fundamental differences in the naming and framing of a problem. Such controversies cannot be resolved by merely studying 'the facts', as discourse coalitions will have very different ways of selecting and interpreting these facts. Hence, intractable controversies would only be resolvable by reflecting on the deeper conceptual and normative premises that 
underlie a specific discourse (which Rein and Schön describe as 'frame reflection'). This means that actors firstly have to become aware of their own models or 'frames', secondly have to be able to put themselves in the shoes of actors with other frames, and thirdly have to be willing to adapt their discourse when required.

Recognising that researchers can and often do play a key role in such discourse coalitions also means recognising that the notion of models used by scholars is heteronomous: academic discussions about models are pervaded by normative, political and moral interests, which stem from ideological debates in the public arena in which scholars also take part (Bowen 2007; Scholten 2009; Bertossi and Duyvendak 2012). The problem here is that scholarly notions of integration models reflect and are influenced by public debates, which in turn are structured by the frames of the dominant elite, which includes influential scholars (see Scholten 2011). As a result, scholarly writings that are presented as analysing social and political phenomena can be normative as well.

This normative dimension is strikingly obvious in the literature that has addressed the issue of a possible 'crisis' of national models of integration in Europe since the beginning of the 2000s (Vertovec and Wessendorf 2009). Research on the integration of immigrants in Europe has turned into a discussion about the success or failure of traditional integration policies on the one hand, and on the other on the legitimacy of claims made by ethnic minorities, particularly when these claims are made by Muslims (Koopmans and Statham 2000). These debates have by the same token reinforced questions about Muslims' loyalty and incorporation ('are they with us or against us?') and the relevance of a category (Muslims) that is used in and is the subject of political debates.

\section{3 'The Dutch Multicultural Model'}

\subsubsection{The Invention of the Dutch Multicultural Model}

For a long time the Dutch case has been taken as one of the strongholds of a multicultural model of migrant integration. The Dutch multicultural model provided one of the first examples of a European country to adopt a multiculturalist approach to migrant integration. However, the so-called Dutch multicultural model has become subject of fierce controversy, in politics as well as in academia. In politics, some claim that the Dutch have said goodbye to the multicultural model foregood, as the Netherlands was also one of the first European countries to experience the 'assimilationist turn' in integration policies. Others contend that the model continues to inform policy practice until today. In academia, the proclaimed 'fall' 'of multiculturalism in policies and politics has also led to criticism regarding the role of social scientists in the Netherlands that had taken a key position in the development of this model. At the same time, others contend that the Dutch case has never really been characterised by a clear national multicultural model, and that in a comparative perspective, the Dutch case has many characteristics in common with other European countries. 
The key trait of the Dutch multicultural model would involve the tendency to institutionalise cultural pluralism in the belief that cultural emancipation of immigrant minorities is the key to their integration into the Dutch multicultural society. This view is often rooted in the peculiar Dutch history of pillarisation, referring to the period from the 1920s to 1960s when most of Dutch society was structured according to specific religious (protestant, Catholic) or socio-cultural (socialist, liberal) pillars. It is in this period that Dutch society became used to emancipating national minorities, to tolerance regarding the sometimes deep differences between these minorities or 'pillars', and to the common Dutch practice of consensus building and negotiating between the pillars' elites (Lijphart 1976).

Historically positioning the 'Dutch Multicultural Model', it seems to refer primarily to policies that were developed in the 1980s and which are held to still be pertinent through so-called 'policy path-dependency.' In the 1980s, an 'Ethnic Minorities Policy' was developed that was targeted at specific cultural or ethnic minorities in Dutch society, such as migrant workers and post-colonial migrants from Surinam, the Moluccas Islands and the Dutch Antilles. Migrants were framed as 'minorities' in Dutch society instead of temporary guests, and the government decided to focus on those minorities whose position was characterised by an accumulation of cultural and socio-economic difficulties and for whom the Dutch government felt a special historical responsibility (Rath 2001). This framing of ethnic minorities reflected the framing of national minorities during the history of pillarisation. Although the Netherlands had been depillarising already since the 1960s, this suggests what Vink (2007) describes as a 'pillarisation reflex.'

This Ethnic Minorities Policy approximated what in the literature is described as a multiculturalist approach to migrant integration (Scholten 2011). It was firmly rooted not just in policy discourse, but also in academic discourse. In fact, this Ethnic Minorities Policy was produced and sustained by a relatively small but close and well-organised network of scholars and policymakers, described by Rath (2001) as a 'technocratic symbiosis'. On the one hand, this technocratic symbiosis was enabled by a culture of depoliticisation, or a 'gentlemen's agreement' not to turn migrant integration into a partisan issue, fearing radical parties that could play the race card. Also, there was a strong belief among policymakers in this period that integration as a social problem could be resolved if approached rationally, reflecting the broader belief in societal steering during that period. On the other hand, researchers played a leading role in policy formulation, via a governmentsponsored Advisory Committee on Minorities Research (ACOM) as well as a highly influential report from the Scientific Council for Government that provided the direct basis for the formulation of the Minorities Policy (Scholten 2011).

Together, researchers and policymakers in this period created a strongly centralised policy structure involving the co-optation of experts and ethnic elites (Guiraudon 1997). An important function of this technocratic symbiosis was to keep the debate on immigrant integration largely behind closed doors; it was structurally depoliticised. This created a specific sort of discourse as this technocratic symbiosis was held together by a so-called 'minorities logic': that is, a focus on what was specific to minorities in terms of culture and ethnicity rather than on their more 
general characteristics or what minorities had in common with other citizens. This illustrates how this discourse coalition not only sustained the discourse of that period, but also was itself held together by this discourse. There was a mutually reinforcing logic between the Minority Policy discourse and the discourse coalition by which it was sustained. At the same time, this symbiosis effectively excluded other discourses, such as the more critical-Marxist discourse that had emerged in the social sciences in the 1970s, anti-racism discourses (see Essed and Nimako 2006) as well as the nationalist (assimilationist) discourse, the latter having very little resonance in the field of politics in the 1980s.

The discourse of a Dutch multicultural model was thus clearly an outcome of coproduction of scholars and policymakers, within a specific historic setting. However, the idea of a Dutch multicultural model of integration also remains prominent in contemporary academic work. A study by Sniderman and Hagendoorn (2007), When Ways of Life Collide: Multiculturalism and its Discontents in the Netherlands, frames the Dutch approach in terms of the multiculturalist model. The authors claim that the labelling of ethnic identities has inadvertently deepened sociocultural cleavages in society instead of helping to bridge these differences. They take the Netherlands as their single exemplary case to establish their claims. They too root the Dutch approach back to the history of pillarisation: 'The Netherlands has always been a country of minorities thanks to the power of religion to divide as well as unite' (ibid.: 13). In addition, the 'collective trauma of World War II where the Dutch failed to resist the massive deportation of Jews would have contributed to that immigrant minorities have been seen in the perspective of the Holocaust $(\ldots)$ or that critical views of immigrants are labelled racist and xenophobic.' In the authors' view, due to these historical circumstances a multiculturalist model has taken root in the Netherlands.

Also among other Dutch scholars, thinking in terms of the Dutch multicultural model has acquired great resonance. Koopmans (2007) roots the Dutch approach to immigrant integration clearly in the history of pillarisation, which stressed ethnocultural cleavages. He claims that the application of this model to new immigrant groups has had strong adverse effects, as multiculturalism 'offers new ethnic and religious groups a formal and symbolic form of equality, which in practice reinforces ethnic cleavages and reproduces segregation on a distinctly unequal basis' (ibid: 5). Koopmans points in particular to 'path dependency' in terms of policy practices. Although formal policy discourse and public discourse seem to have changed, in their actual way of dealing with ethno-cultural diversity the Dutch have remained accommodative.

The abovementioned studies by Sniderman and Hagendoorn (2007) and Koopmans (2007) do not so much contribute to sustaining the Dutch multicultural model, but rather take it as a point of reference for explaining contemporary policy failure. Thus, if they use the term multicultural model, they do this in a normative, pejorative way. The label is used to disqualify certain policies that allegedly have been a failure. They 'blame the model.' Politicians as well as public intellectuals and some scholars retrospectively label the past as a time full of naive multicultural dreams, leading to a 'multicultural drama'. From 2003 onwards, well-known sociologists 
like Koopmans, Sniderman and Hagendoorn supported this perspective through their research, labelling Dutch policies as a multicultural model. This proved very influential in terms of the post-hoc labelling of Dutch policies, including those devised after the 1980s heyday of the Ethnic Minorities approach, in terms of a multicultural model.

Path-dependency is a key argument made in the context of this retrospective labelling of Dutch policies as multiculturalist, claiming that the 'multiculturalist' Ethnic Minorities Policy of the 1980s left institutional and discursive legacies that have continued to inform policy practices to the present day. For instance, Immigrant Language and Culture Instruction continued, although in different forms and with different wordings for its rationale, until after the turn of the Millennium. Whereas its goal was initially formulated as contributing to identity formation of migrants within Dutch society, its rationale was reframed in the 1990s in terms of 'languagetransition' by first mastering the mother-tongue language as support for the subsequent apprehension of Dutch as a second language. Another practice that was continued until well after the 1980s was the institutionalised practice of consultation with migrant organisations. At first, the establishment of migrant organisations and a National Consultative and Advisory Structure for Minorities had the objective of democratically involving migrants in policymaking processes. In the 1990s, the institutional involvement of migrant organisations was largely continued, although its advisory function was gradually marginalised. More recently, an important rationale for maintaining this form of institutionalised 'multiculturalism' is that migrant organisations provide channels for debate when incidents, such as the murder of the film-maker Van Gogh, trigger broad public and political controversy. Also in other fields, there are signs of path-dependency, such as in the existence of broadcast media for migrant groups and in the establishment of Islamic schools with state help.

\subsubsection{A Critical Assessment: Has There Ever Been a Dutch Multicultural Model?}

Social researchers thus played a key role in the construction of a 'multicultural model of integration', though in very different ways in different periods. Whereas at first they were key actors in the coproduction of this model within a technocratic symbiosis, later they contributed to the construction of a multicultural model more through their normative claims that the model was to blame for the 'multicultural tragedy'. Let us now take a more critical assessment of whether there is or ever has been a Dutch multicultural model, as well as the role that social scientists have played in critical reflection on discourses of migrant integration such as this multicultural model.

First of all, the claim that the development of Dutch policies is characterised by path-dependency ignores the sharp discontinuities in Dutch migrant integration policies over the past decades. The historical-institutionalist perspective on which 
the path-dependency argument is based connects Dutch migrant integration policies to the Dutch tradition of pluralism through 'pillarism', that is the institutionalisation of 'sovereignty within the own sphere' for each minority group. This connection between Dutch Ethnic Minorities Policies and the history of pillarisation must, however, be put in perspective. Dutch society was de-pillarising in many sectors already by the 1950s and 1960s, so well before the formulation of the Ethnic Minorities Policy. Pillarisation especially seems to have been powerful as a 'discourse'. The framing of migrants as minorities resonated with the framing of national minorities that the Dutch were already used to.

Others have added that it was not so much the Ethnic Minorities Policy per se that was inspired by pillarisation (Maussen 2009; Duyvendak and Scholten 2011). Rather, there was an influence from more generic institutions in Dutch society that were still to some extent pillarised, such as the Dutch tradition of state-sponsored special (religious) education, a pillarised broadcasting system and health system. Integration policy itself has never been oriented to the construction of minority groups as pillars. Furthermore, minority groups have never achieved the level of organisation (and separation) that national minorities achieved in the early twentieth century. In fact, we would emphasise that there never really was a 'national multicultural model', as slogans such as 'integration with preservation of cultural identity' were rejected already at this early stage. Only later would this slogan be applied, ex-post, to this period in public and academic discourse. Neither pillarisation nor multiculturalism was really embraced as a normative ideal. Instead, statements of multiculturalism referred in a more descriptive sense to the increase of diversity in society. As far as references to pillarisation or multiculturalism were used at all, these seem to have been much more pragmatic than normative. Our conclusion therefore is that 'multiculturalism' was actively co-produced by politicians and social scientists in order to disqualify policies of the past.

Besides the contested continuity between pillarisation and the alleged Dutch multicultural model, it is also obvious that this 'model' has not been very consistent since the 1980s. Already in the early 1990s, formal government policy changed in several important regards, when the Minorities Policy was reframed into the socalled Integration Policy that stressed socio-economic participation of immigrants as citizens over cultural emancipation of minorities. Promoting 'good' or 'active' citizenship became the primary policy goal, stimulating individual migrants to live up to their civic rights as well as their duties and to become economically independent participants in society. Whereas the Integration Policy had stressed 'active citizenship', the Integration Policy 'New Style' that was formulated in the early 2000s instead stressed 'common citizenship', which meant that 'the unity of society must be found in what members have in common $(\ldots)$ that is that people speak Dutch and that one abides to basic Dutch norms' (Treaties of Second House of Parliament, 2003-2004, 29203, nr. 1: 8.). Persisting socio-cultural differences were now considered a hindrance to immigrant integration. It was in this period, that the framing of the 'multicultural model' took place as a 'counter-discourse' against which new policy developments were to be juxtaposed. 
Even if we accept that the Netherlands has known a multicultural model in the 1980s, it still has to be proven that this model was also powerful in terms of concrete policy practices. There is much evidence that some policies that were initiated in the 1980s were continued until well after the Minorities Policy had been formally abandoned. However, the meaning and the use of these policies and the opportunities offered to migrants have radically shifted over time, also because the national and local levels of integration policy seem to have followed very different institutional logics. Whereas national policy discourse was inspired by politicisation, focusing events and a concern with grand themes like national identity and culture, local policy discourse seems to have been much more concerned with pragmatically dealing with problems, in a more instrumental policy logic.

An important instance of divergence in this respect concerns the recognition of ethno-cultural groups and minority organisations. In the early 1990s, national government formally adopted a more colour-blind citizenship approach, approaching migrants as citizens rather than as ethnic or cultural groups. This citizenship approach meant that various group-specific, tailor-made projects would have to be abolished. Yet, in practice, there has been a continued proliferation of such group-specific projects (De Zwart 2005). Often, there is a pragmatic need for policy practitioners to focus on specific groups and cooperate with migrant organisations, to be able to 'reach' the policy target groups and to acquire relevant knowledge and information about these groups (Poppelaars and Scholten 2008). Although these local practices often imply the de-facto recognition of cultural groups, it would be a mistake to consider them as actual multicultural policies. They are not inspired by an ideology of multiculturalism nor by a legacy of pillarisation, but rather by the more pragmatic need to recognise groups and develop tailor-made projects to conduct effective policies. As the mayor of the City of Amsterdam aptly phrases it, such practices are designed to 'keep things together.'

Thirdly, the role of social researchers has also evolved well beyond the 'technocratic symbiosis' that would have led to the coproduction of the Dutch multicultural model in the early 1980s. In fact, social research played a key role as well in 'punctuating' the structural equilibrium of the multicultural model. A new discourse coalition emerged at the end of the 1980s that advocated a more socioeconomic approach to immigrant integration to prevent migrants from becoming too dependent on welfare state provisions. This discourse coalition involved leading politicians (such as Prime Minister Ruud Lubbers, opposition leader Frits Bolkestein) as well as experts (such as Wim Albeda, chair of the Scientific Council for Government Policy and former minister of Social Affairs, and Han Entzinger). A new report from the Scientific Council for Government Policy (1989), clearly reflecting the ideas of this discourse coalition, played a key role in putting migrant integration back on the agenda in the late 1980s and gradually led to the introduction of the Integration Policy in the 1990s.

This episode brought an end to the strongly institutionalised research-policy nexus that had evolved in the 1970s and 1980s. ACOM was dissolved in 1992, and the use of social research in policymaking instead became more selective and more instrumental. Penninx (2005) describes what he calls policymakers' 'pick-and- 
choose strategies' to select only those strands of expertise that helped sustain the new policy discourse. The utilisation of research became more symbolic and dataoriented. Government wanted data to underline its new policy discourse rather than the more conceptual role played by research bodies such as ACOM and WRR. In this context, the government-associated Social and Cultural Planning Bureau (SCP) obtained a particularly prominent role in this field. Its regular 'Minorities Reports' were now often taken as anchor points for policy developments, especially as the SCP addressed a lot of attention to socio-economic areas and increasingly also areas of socio-cultural integration.

\section{4 'The French Assimilationist Model'}

\subsubsection{The Invention of the French Assimilationist Model}

Whereas the Dutch 'model' would be associated in the history of pillarisation, the French 'model' would be associated with images of the Revolution, the Third Republic's Hussards Noirs (the late nineteenth century nickname of teachers at the then newly established state-sponsored secularist schools), a universalistic understanding of citizenship, and an assimilationist perspective on immigrant integration. This cliché is a very pervasive one, in the French and international literature. However, the very notion of a 'republican model of citizenship' was considered as old-fashioned and outdated until the issue of immigrant integration was intensely politicised in the mid-1980s. Since then, the debate on republicanism has acted as a fig-leaf hiding the widely varied and contradictory framings of integration and citizenship issues resulting from public debates at the cross-roads of academic and political struggles to define the French perspective on citizenship.

Over the last three decades, there have been at least four different narratives used to describe the public problem of immigrant integration. Each of them was produced as both a public and a scholarly reasoning, valuing colour-blind and universal citizenship as a policy perspective and analytical framework for the integration of immigrants into contemporary France. More often than not, this dual aspect of the French model resulted from a dialogue between policymakers and scholars, in the form of ad hoc commissions (e.g. on French citizenship in 1987, and laïcité the very specific French conception of secularism, in public schools in 2004) or permanent institutions like the Haut Conseil à l'Intégration (High Council for Integration).

The first framing of the French model held sway in the mid-1980s following the abandonment of the myth that immigrants would return to their countries of origin: immigrants had become part of French society. At the same time, the Front National - an extreme right-wing party - began to impact public debate, achieving its first electoral successes in local (1983), European (1984) and national (1986) elections. The public issue of the integration of immigrant minorities was defined in terms of loyalty and allegiance, and soon thereafter in terms of religion (with the first veil affair in 1989). For the first time, scholars committed themselves to debates 
about how to deal with these issues. The construction of immigrant integration and Islam as a sensitive public issue paralleled its construction as a scholarly research field. In 1987, the Prime Minister launched a new commission in order to reassess the rules of access to French nationality. The so-called Long Commission (named after its president) involved scholars such as $\mathrm{H}$. Carrère d'Encausse, $\mathrm{P}$. Chaunu, E. Leroy Ladurie, D. Schnapper, A. Touraine. The outcome emphasised the importance of the French model of immigrant integration as a process of sociocultural assimilation and civic virtue, and the central role of nationality in access to citizenship. After several attempts, the new 1993 Law set new conditions for access to citizenship, requiring a 'manifestation de volonté' (an explicit voluntary request) and thereby eliminating the century-old tradition of automatic access to citizenship for those born in France (Weil 2002).

This nationality-based frame was replaced at the end of the 1990s by a new one focusing on anti-discrimination. The notion of civic virtue and socio-cultural integration became secondary to the definition of actual equality among French citizens, including those with a migrant origin (Conseil d'État 1997). The issue was of nationals needing to be provided with equal opportunities by French society and institutions - a notion that would easily fit with the programme described as 'multiculturalism' by many scholars.

Soon afterwards, the public framing of republican principles evolved towardss a third framing that precisely denounced the anti-discriminatory element as a "purely moral approach' unsuitable for confronting 'a stream of converging indices reflected in various forms of identity-related movements and tensions' (Haut Conseil à l'Intégration 2006: 17; authors' translation). In the early 2000s, the secular republic appeared as the new yardstick in the integration debate, making laïcité (the French public notion for secularism) the new core element of the definition of the French model. However, far from being defined in the terms of the 1905 Law (the founding law on laïcité), secularism became a moral framework that defined identity and was linked to new debates on gender equality, sexuality, and the 'deviance' of immigrant family structures (e.g.. accusations of polygamy and machismo or concerns about overcrowded households in immigrant neighbourhoods). The public response to this evolution is summed up in the Law of 15 March 2004, which disallowed 'ostensible religious signs' (read: Islamic headscarves) in public schools. This law was based on recommendations made by the 2003 Stasi Commission on laïcité, the composition of which resembled the Long commission on nationality of 1987. Leading scholars, including Jean Baubérot, Jacqueline Costa-Lascoux, Régis Debray, Gilles Kepel, Alain Touraine and Patrick Weil, figured among the 20 members of the commission. Its outcome made neutrality in the public sphere the main normative argument that drove this new definition of 'republican universalism'.

Eventually, a fourth framing of the French model appeared centre-stage after 2007, with a new focus on 'burqas' and a state-sponsored debate about national identity in 2009 and 2010. Debates about integration, and in particular the integration of Muslim groups, were no longer enclosed within the limits of abstract universalism. Different logics were at play in these discourses, including a new law banning fullface veiling (seen in certain instances as a failure of assimilation), the Law of 11 
October 2010, and the invention of the new juridical concept of 'immaterial public order' (Conseil d'État 2010). The new definition of the republic in this period turned to be grounded on a strong interplay between public order, national identity and citizenship. Not only was Islam highly culturalised in this accepted public definition of the French model, but republican identity was also transformed into a programme of strict cultural order.

\subsubsection{A Critical Assessment}

Let us turn back to the idea of a thick, stable, consistent and comprehensive French republican model. This cliché has been very pervasive in scholarship on the French case since the 1990s: most of the comparative social science literature on citizenship takes inspiration from it. What is missed in these analyses is a clear explanation of why and how the constant efforts to impose one standard definition of the idea of 'French republican citizenship' since the mid-1980s have produced highly culturalised conceptions that do not match the usual depictions of the French philosophy of integration and citizenship in colour-blind terms (see Bertossi 2012).

Whether the French model is defined as a discursive and institutional opportunity structure, a policy paradigm, a public philosophy or a cultural idiom, the literature views France as an un-multicultural country. It construes the French model as an institutional and ideological overarching order - a conception of 'institutional order' at odds with the existing literature on institutions. This national model is seen as all-encompassing, capable of organising the separation between public and private realms (through a strict colour-blind approach), the state and the church (laïcité), and foreigners and nationals (through an 'open' nationality regime).

As already mentioned, advocates of the path-dependent nature of models usually highlight the strong resilience of dominant political principles in each national context. Of course, they argue, deviations from- or challenges to- the core principles of a national model are always possible. According to Favell, for example, counterdiscourses or 'strange fruits' can develop from time to time, but 'normal politics' are mostly consistent with the model's principles (Favell 1998). Koopmans et al. (2005) also insist on possible changes in the configuration of citizenship, but they argue that national principles and core values are resistant to fundamental changes.

If this was accurate, however, the observation of official discourses on immigrant integration in France should show a constant effort by public actors to condemn unorthodox racial framings of citizenship, and to return to 'normal politics' and to the standard definition of the colour-blind and universalistic model. However, the analysis of 30 years of public narratives on immigrant integration shows something different, namely, that the production of a 'republican' definition of immigrant integration has paralleled an increased emphasis on ethnicity and race in French official discourses. This ethnic and racial framing cannot be understood merely as either a temporary 'strange fruit' or a marginal deviation from the norm: this is, as we shall see, how the French state has consistently been labelling its citizens over the past 30 years. 
This misconception of the French republican model has had consequences for the research agenda. Recent debates about republicanism among French scholars have highlighted the political power of the contradictions between the republican ideal of colour-blind equality, supposedly the foundation of French integration policies, and the actual discrimination suffered by immigrants and the stigmatisation they face in public and political debates as members of racial and ethnic groups (de Rudder et al. 2000; Fassin and Fassin 2006). One key topic of these debates has concerned the use of 'ethnic categories' to assess the level of racial and ethnic discrimination (Sabbagh and Peer 2008). The dilemma hinges on considering these categories either as a breach of the traditional colour-blind republican approach to citizenship (the French state does not formally recognise ethnic or racial groups), or, conversely, as an impediment to in-depth knowledge of the extent and nature of discrimination against French minority group members (discrimination that contradicts the principle of republican equality) (Martiniello and Simon 2005; Simon 2003).

This discussion of ethnic categories has not been limited to the question of the state's use of ethnic categories in the national census. It has focused on the legitimacy of their use by social scientists researching integration in France (Simon and Amiraux 2006). The issue of the use of ethnic categories in surveys and other social science research is a burning one in France, one which has nothing to do with the legitimate questions involved in scientific discourse and everything to do with the ideological nature of public debates.

This debate over the use of ethnic categories reveals two mutually exclusive conceptions of the French model. For those against using ethnic categories, the immense value of French republicanism is that it emancipates individuals through its specific universalistic programme, despite actual discrimination. By refusing any reference to ethnicity in research on integration and citizenship, many authors call for preserving this fundamental value (Schnapper 1994, 1999). They criticise fellow scholars for using ethnic and racial categories in their research, sometimes accusing them of 'creating' ethnic groups in France (Pierrot 1998: 235). Those in favour of adopting ethnic categories argue that the colour-blindness of the French model impedes the efforts to improve the status of ethnic and racial minority group members and reduce the discrimination they suffer, and that this model must be corrected in order to restore its initial value, upholding the motto of 'liberty, equality, fraternity' (Laborde 2010; Guérard de Latour 2010).

Regardless of the way in which French scholars approach the question of ethnic categories, they do share a similar conception of the value of republicanism: that is, republicanism is the model France has inherited from her political tradition, and compared to other models it represents the best ideological and policy framework to incorporate migrants and minority groups into French society. The existence of a singular French model remains undisputed. Scholars who criticise the contradictions and costs of republicanism nonetheless continue to accept or assume the existence of an imagined normative republic, characterised by abstract universalism, individual equality, and state neutrality in matters of religion. The French model, in other words, is at once a product of wishful thinking, a normative position and an analytical framework. 
Such debates do not only concern French academics or students. They have an impact of their own on the international literature, for various reasons: French scholars' work is read outside of France; French scholars are often the first interviewees that foreign (junior as well as senior) researchers meet in the first days of research in France; and French scholars are also involved in writing public or policy-oriented documents or articles in newspapers that often end up on the desks of international academics who analyse the French situation. This contributes to reinforcing the belief in the existence of the French model when it comes to migrants and minority groups.

\subsection{Conclusions: Coproduction, Integration Models and Their Performative Effect}

The examples of the Netherlands and France reveal the limits of the idea of unequivocally 'national' integration models. These examples also reposition the 'crisis of models' discourse beyond a before-and-after perception of a glorious past era that has given way to current decline. This repositioning allows us to be rid of the idea of normative blocks being put to the test in the early twenty-first century by multicultural and Muslim claims-making or reactionary nationalism.

Having said this, the question remains about the extent to which national models provide either a partial or a complete explanation of reality as it is empirically observed by field researchers. What can national integration models teach us about the practices of those who speak about the French Republic and Dutch multiculturalism? It is not enough to show, as we have done, the problems with concepts such as national models of integration. The fact that these models are not institutionally consistent, normatively coherent, evenly distributed and defined by agreed-on meanings does not mean that they are simply figments of the imagination of researchers who are engaged in ideological debates on the integration of immigrants.

It is not enough to conclude that national models do not exist because the reality that scholars observe is in fact saturated with 'modelised' thoughts and 'modelising' practices. The subjects of our research (social actors) believe in the existence of a French model built on principles inherited from the French Revolution or in the existence of a Dutch multiculturalism linked to the pillarisation legacy. It is therefore wrong to say that national models of integration should not be taken seriously because there are many people who take these models very seriously. Model concepts are used, imagined, negotiated, affirmed, contested, and challenged by different types of individual and collective actors in very different settings in working-class pubs, hospital hallways, in queues at social security offices, in police stations, school staff rooms, the reader commentary sections of newspaper websites, and EU summits of Interior Ministers, to name just a few (Bertossi 2011). A cognitive perspective helps avoid the positivist approach that often reduces questions about national models to questions about how actors are configured in 
idealistic structures and shaped by national cultural idioms or public philosophies. Models are not an a priori resource for action or an ex ante normative frame through which actors give shape to their strategies. Instead, these strategies give shape to varying, polysemic, and contradictory models. In other words, Dutch multiculturalism, French republicanism or other national stylised conceptions of citizenship cannot be held up as objective entities. For this reason and others we have already mentioned, they cannot be turned into the explanatory framework for the differences that exist among national contexts.

Our aim in this chapter has not been to propose a new theory of the notion of national integration models. Instead, we have argued that models of integration are an inappropriate tool for the comparative study of integration inasmuch as the objective of such research is to assess the success or failure of a national approach to integrating migrants and minority groups. We have shown that the notion of national models is tainted by normative (if not moral) connotations that hinder the ability of social scientists to address empirical reality.

If models tend to be taken as a substitute for reality and distort research strategies, we should not discard them entirely. A considerable amount of energy has been spent trying to extract a complex social reality from national integration models, with the risk of caricaturing the world that we study by using extremely attractive, but limited, narratives. It seems that it is time for us to move backwards, so to speak, inducing models from reality and conceiving of them as fluctuating dependent variables that must be explained. If we really want to understand the injustices of our societies, we believe that we need to study the actors who develop a multiplicity of conceptions of equality, inclusion, and identity, and examine from a sociological perspective how national models of integration play a role in these developments.

Open Access This chapter is distributed under the terms of the Creative Commons Attribution Noncommercial License, which permits any noncommercial use, distribution, and reproduction in any medium, provided the original author(s) and source are credited.

\section{References}

Bertossi, C. (2011). National models of integration in Europe: A comparative and critical analysis. American Behavioral Scientist, 55(12), 1561-1580.

Bertossi, C. (2012). The performativity of colour blindness: Race politics and immigrant integration in France, 1980-2012. Patterns of Prejudice, 46(5), 427-444.

Bertossi, C., \& Duyvendak, J. W. (2012). National models of integration: The costs for comparative research. Comparative European Politics, 10(5), 237-247.

Bommes, M., \& Morawska, E. (2005). International migration research. Constructions, omissions and the promises of interdisciplinarity. Aldershot: Ashgate.

Bommes, M., \& Thränhardt, D. (Eds.). (2010). National paradigms of migration research. Osnabruck: V \& R Unipress.

Bowen, J. (2007). A view from France on the internal complexity of national models. Journal of Ethnic and Migration Studies, 33(6), 1003-1016.

Brubaker, R. (1992). Citizenship and nationhood in France and Germany. Cambridge: Harvard University Press. 
Conseil d'État. (1997). Sur le principe d'égalité. Paris: La documentation française.

Conseil d'État. (2010). Study of possible legal grounds for banning the full Veil. Report adopted by the Plenary General Assembly of the Conseil d'État Thursday 25 March 2010. Paris: Conseil d'État/Reports and Studies Section.

De Rudder, V., Poiret, C., \& Vourc'h, F. (2000). L'inégalité raciste: l'universalité républicaine à l'épreuve. Paris: PUF.

De Zwart, F. (2005). The dilemma of recognition: Administrative categories and cultural diversity. Theory and Society, 34(2), 137-196.

Duyvendak, J. W., \& Scholten, P. W. A. (2011). Beyond national models of integration. The coproduction of integration policy frames in the Netherlands. Journal of International Migration and Integration, 12, 331-348.

Essed, P., \& Nimako, K. (2006). Designs and (Co)Incidents. Cultures of scholarship and public policy on immigrants/minorities in the Netherlands. International Journal of Comparative Sociology, 47(3/4), 281-312.

Fassin, E. (1999). 'Good to Think': The American reference in French discourses on immigration and ethnicity. In C. Joppke \& S. Lukes (Eds.), Multicultural questions. Oxford: Oxford University Press.

Fassin, D., \& Fassin, E. (Eds.). (2006). De la question sociale à la question raciale: représenter la société française. Paris: La découverte.

Favell, A. (1998). Philosophies of integration. Immigration and the idea of citizenship in France and Britain. Houndmills: Palgrave.

Favell, A. (2003). Integration nations: The nation-state and research on immigrants in Western Europe. Comparative Social Research, 22, 13-42.

Guérard de Latour, S. (2010). Vers la République des différences. Toulouse: Presses universitaires du Mirail.

Guiraudon, V. (1997). Policy change behind gilded doors: Explaining the evolution of Aliens' rights in France, Germany and the Netherlands, 1974-94. New Haven: Harvard University Press.

Hajer, M. (1995). The politics of environmental discourse: Ecological modernisation and the policy process. Oxford: Oxford University Press.

Haut Conseil à l'Intégration. (2006). Le bilan de la politique d'intégration: 2002-2005. Rapport au Premier ministre. Paris: La documentation française.

Ireland, P. R. (1994). The policy challenge of ethnic diversity: Immigrant politics in France and Switzerland (pp. 62-70). Cambridge, MA: Harvard University Press.

Joppke, C. (1999). Immigration and the nation-state: The United States, Germany, and Great Britain. Oxford/New York: Oxford University Press.

Koopmans, R. (2007). Good intentions sometimes make bad policy: A comparison of Dutch and German integration policies. In Friedrich Ebert Stiftung (Ed.), Migration, multiculturalism, and civil society (pp. 163-168). Berlin: Friedrich Ebert Stiftung.

Koopmans, R., \& Statham, S. (2000). Migration and ethnic relations as a field of political contention: An opportunity structure approach. In R. Koopmans \& S. Statham (Eds.), Challenging immigration and ethnic relations politics. Oxford: Oxford University Press.

Koopmans, R., Statham, P., Giugni, M., \& Passy, F. (2005). Contested citizenship: Political contention over migration and ethnic relations in Western Europe. Minneapolis: University of Minnesota Press.

Lijphart, A. (1976). The politics of accommodation: Pluralism and democracy in The Netherlands. Berkeley: University of California Press.

Laborde, C. (2010). Français, encore un effort si vous voulez être républicains! Paris: Seuil.

Martiniello, M., \& Simon, P. (2005). Les enjeux de la catégorisation. Rapports de domination et luttes autour de la représentation dans les sociétés post-migratoires. Revue Européenne des Migrations Internationales, 21(2), 7-17.

Maussen, M. (2009). Constructing Mosques. The governance of Islam in France and the Netherlands. PhD Thesis, University of Amsterdam. 
Penninx, R. (2005). Bridges between research and policy? The case of post-war immigration and integration policies in the Netherlands. International Journal on Multicultural Studies, 7(1), 33-48.

Pierrot, A. (1998). Le multiculturalism. In G. Ferréol (Ed.), Intégration, lien social et citoyenneté (pp. 234-251). Villeneuve d'Asq: Presses universitaires du septentrion.

Poppelaars, C., \& Scholten, P. W. A. (2008). Two worlds apart. The divergence of national and local integration policies in the Netherlands'. Administration and Society, 40, 4.

Rath, J. (2001). Research on immigrant ethnic minorities in the Netherlands. In P. Ratcliffe (Ed.), The politics of social science research. Race, ethnicity and social change (pp. 137-159). New York: Palgrave.

Rein, M., \& Schön, D. (1994). Frame reflection: Toward the resolution of intractable policy controversies. New York: Basic Books.

Sabbagh, D., \& Peer, S. (2008). The controversy over "statistiques ethniques". French Politics, Culture and Society, 26(1), 1-6.

Schain, M. A. (2009). The state strikes back: Immigration policy in the European Union. European Journal of International Law, 20(1), 93-109.

Schnapper, D. (1994). La communauté des citoyens: sur l'idée moderne de nation. Paris: Gallimard.

Schnapper, D. (1999). La relation à l'autre. Paris: Gallimard.

Scholten, P. W. A. (2009). The co-production of immigrant integration policy and research in the Netherlands: The case of the scientific council for government policy. Science and Public Policy, 36(7), 561-573.

Scholten, P. W. A. (2011). Framing immigrant integration: Dutch research-policy dialogues in comparative perspective. Amsterdam: Amsterdam University Press.

Simon, P. (2003). Challenging the French model of integration: Discrimination and the labor market case in France. Studi Emigrazione, 152, 717-745.

Simon, P., \& Amiraux, V. (2006). There are no minorities here: Cultures of scholarship and public debate on immigrants and integration in France. International Journal of Comparative Sociology, 47(3-4), 191-215.

Sniderman, P., \& Hagendoorn, L. (2007). When ways of life collide. Multiculturalism and its discontents in the Netherlands. Princeton: Princeton University Press.

Vertovec, S., \& Wessendorf, S. (Eds.). (2009). The multiculturalism backlash: European discourses, policies, and practices. London: Routledge.

Vink, M. (2007). Dutch multiculturalism: Beyond the pillarisation myth. Political Studies Review, $5,337-350$.

Weil, P. (2002). Qu'est-ce qu'un Français? Histoire de la nationalité française depuis la Révolution. Paris: Grasset. 


\title{
Chapter 5 \\ Consultative Commissions and the Rethinking of Integration Policies in the Netherlands and Germany: The Blok Commission and the Süssmuth Commission Compared
}

\author{
Jan Schneider and Peter Scholten
}

\subsection{Introduction}

Both Germany and the Netherlands have over the past decade established consultative commissions in an effort to rethink their policies on immigration and integration. In response to growing pressure over the framing of Germany as 'Kein Einwanderungsland' (i.e. 'Germany is not an immigration country'), the German government established an Independent Commission on Migration in 2000, led by the former President of the Bundestag Rita Süssmuth. The findings from this commission sparked fierce public and political controversy, revealing how deeply the then prevailing German belief of not being an immigration country was embedded in German society and politics. In the Netherlands, in response to a broadly supported parliamentary motion that stated that the Dutch approach to integration had thus far been 'insufficiently successful', a parliamentary investigative commission on integration was established in late 2002. Yet, even before this commission, named after its chairman Stef Blok, could present its findings, the commission itself became fiercely contested in public and political debate.

These commissions, calling on various established researchers and experts in both countries, faced the challenge of rethinking national models of integration that are deeply entrenched innational public and political discourses as well as

\footnotetext{
J. Schneider (四)

Department of Social Sciences, Sachverständigenrat deutscher Stiftungen für Integration und Migration (SVR) GmbH, Neue Promenade 6, 10178 Berlin, Germany

e-mail: schneider@svr-migration.de

P. Scholten

Department of Public Administration, Erasmus University Rotterdam, P.O. Box 1738, 3000 DR

Rotterdam, Netherlands

e-mail: p.w.a.scholten@fsw.eur.nl
} 
in specific policy institutions. Both commissions presented findings that became fiercely contested in public and political debate: the German commission concluded that Germany should prepare for permanent immigration and that it should develop a coordinated policy aimed at integration; and the Dutch commission concluded that a new approach to integration was needed because of the supposedly adverse effects of the Dutch multiculturalist model of integration. In addition to controversies over their findings, both commissions also faced fierce controversy about why they had been established in the first place, how they organised their proceedings and the type of expertise that they managed to mobilise. In fact, both commissions were blamed for being elitist, technocratic and out of touch with public sentiments about migration and integration.

We will study these two cases as examples of research-policy dialogues and more particularly as potential opportunities for 'frame reflection' in intractable policy controversies. We have taken this perspective from Schön and Rein (1994). In their view, intractable policy controversies are characterised by a multiplicity of 'frames', in this case fundamentally different ways of defining and interpreting immigrant integration. In fact, both commissions were established because of growing pressure on the prevailing frames of integration in these countries, or more specifically, serious challenges to the German differentialist model of integration (Brubaker 1992) and the Dutch so-called multicultural model of integration (Sniderman and Hagendoorn 2007). The resolution of such intractable policy controversies requires 'critical frame reflection', in other words an open and critical debate not just as regards factual information but also as regards the different ways of naming and framing integration (Schön and Rein 1994).

The aim of this paper is to analyse and compare the extent to which the Süssmuth Commission in Germany and the Blok Commission in the Netherlands have been effective, in the short- or long-term, in triggering critical frame reflection. Have these commissions been successful in terms of rethinking and setting into motion policy frame shifts in Germany and the Netherlands, and how can the effects of these commissions on the rethinking of these models be explained? To this aim, we will analyse not only the impact of these commissions on policy discourse in Germany and the Netherlands, but also how, why and in what context these commissions were established and how they proceeded in terms of their operations, networks, mobilisation of research and formulation of their findings.

Our analysis is based on empirical research both on the proceedings of the Blok and Süssmuth commissions and on the follow-up to both commissions (see Schneider 2010; Scholten 2011). This includes interviews with key actors - both experts and policymakers - that were somehow involved in the commissions, as well as content analysis of available records and minutes, relevant policy documents and parliamentary records, and media coverage that provides insights into the how the commissions were followed up in both countries. 


\subsection{Consultative Commissions and Policy Framing}

\subsubsection{Consultative Commissions}

Throughout Europe there have been many instances of governments or parliaments establishing consultative commissions on issues that are high on the political agenda. In the context of this chapter we define consultative commissions broadly as commissions that have been established as a political initiative from either parliament or government on a temporary basis with an explicit assignment to reflect on a specific policy topic and advise government and/or parliament in terms of policy formulation. As such, these consultative commissions constitute a very specific form of boundary organisation that connect the realms of policy and research in specific ways, as well as often drawing in non-academic sources of expertise such as practitioner knowledge and civil society representatives as well.

Besides the Süssmuth commission on immigration and integration in Germany and the Blok commission on migrant integration in the Netherlands, similar initiatives have been taken in France and the UK amongst others. France has had many consultative commissions set up by government on issues related to migrant integration, such as the 2003 Stasi commission that focused on the specific French concern over laicité. The UK has even developed a tradition of establishing ad-hoc expert commissions under the leadership of authoritative figures when politics is faced with contested issues: take for instance the influential Cantle report in 2001 on community cohesion, the 2003 Crick report on citizenship, or the Commission on Integration and Cohesion in 2007 (see also Chap. 13 on the UK in this chapter, and Boswell and Hunter 2014).

The establishment, composition and proceedings of such consultative commissions can differ strongly between countries (as well as within countries between different cases). In the Netherlands, consultative commissions can be established both by government and by parliament. The Second House of Parliament can establish investigative commissions to research a topic as well as inquiry commissions that even have the right to summon people to testify under oath (Andeweg and Irwin 2005: 144). This power is one of parliament's tools to counterbalance its information asymmetry in relation to government, and therefore is a tool for controlling government.

Besides the political profile of consultative commissions, it is important to recognise that they often have a strong media profile as well. On the one hand it could be argued that establishing a consultative commission can be a means for temporarily taming a policy issue by removing it from the political agenda for some time. On the other hand, both the proceedings of a commission and (especially) the presentation of its findings are usually high-profile events that stir significant public and political attention. 


\subsubsection{Frame Reflection and Intractable Policy Controversies}

Consultative commissions are often set up in response to issues that defy resolution through established governance channels. As such, we can expect that consultative commissions are established with the aim of doing more than just providing instrumental policy suggestions. Rather, we expect consultative commissions to reflect more fundamentally about how problems are defined and what policy paradigm should be adopted.

Thus, we hypothesise that consultative commissions are especially fit for inducing frame reflection on so-called intractable policy controversies. The social scientists Rein and Schön have posed the question of how critical dialogues on such unstructured policy problems or 'intractable policy controversies' can be organised in such a manner that agreement can be reached on the level of problem framing and subsequently first steps can be made towards problem resolution. Intractable controversies involve situations that are characterised by a multiplicity of frames or 'multiple social realities' (1994: 4). This means that within the context of a problem situation there are actors that carry different frames: they name the problem in different terms, they have different ways of categorising and labelling groups, they explain the phenomenon in different ways, and also carry different normative ideas about it (Scholten 2011). Consequently, intractable controversies bring about 'frame-conflicts', or 'struggles over the naming and framing of a policy situation, (... ) symbolic contests over the social meaning of an issue domain, where meaning implies not only what is at issue but what is to be done' (Schön and Rein 1994: 29). Such frame-conflicts differ fundamentally from disagreements about more structured problems, or situations in which the framing of the problem is relatively uncontested (Hisschemöller and Hoppe 1995).

Migrant integration can clearly be identified as an intractable policy controversy in most European countries. In spite of policy efforts, fierce public and political debate persists on what approach would be effective in promoting immigrant integration. This has led to fierce controversies in various European countries, such as the controversies over multiculturalism in the Netherlands, but also to sharp differences between various national approaches, such as the French colour-blind Republicanist approach and the British colour-oriented race-relations approach (Bleich 2003; Favell 1998).

In problem situations that are characterised by a multiplicity of frames, like migrant integration, the involved actors tend to disagree about the nature of their disagreement. As long as actors remain unconscious of their usually implicit or tacit frames or unwilling to critically reflect on their own frames, these situations will lead to dialogues of the deaf rather than rational controversy resolution (Van Eeten 1999). Actors will often be disinclined to become aware of their frames, as these are 'taken-for-granted' or naturalised in everyday discourse and are often also strongly embedded in the actors' normative perspectives.

Nevertheless, Schön and Rein (1994) argue that critical reflection on problem frames is possible. Building forward on a tradition in sociological thinking on 
'reflectivity' as developed by scholars as Bourdieu and Giddens, Rein and Schön conceptualise 'frame reflection' as the capacity of actors to reflect upon their usually tacit frames in actual social practices (Schön and Rein 1994: 37). Such frame reflection would involve critical reflection on a frame's internal consistency and coherency, on its relation to developments in a problem situation and its relation to larger developments in society (ibid). This means that actors would be able to reflect critically to what extent their frame offers a convincing story about a problem situation, whether it fits the evidence (as selected based on the frame itself) and whether it fits with ones broader normative perspective.

The central concern in this paper will be to examine, based on empirical analysis, the extent to which frame reflection has been achieved or induced by the consultative commissions on immigrant integration policies in Germany and the Netherlands, and to examine the extent to which this has contributed to the 'situated resolution' of the controversies in this field. Both commissions faced situations characterised by frame conflict and fierce political controversies. Both commissions also faced the difficult task of rethinking the prevailing framing of integration in both countries and contributed to a rethinking of policy for the future. This makes these commissions ideal cases for studying the opportunities and threats in reflecting on the policy framing of immigrant integration.

\subsection{The Independent Commission on Migration to Germany: The Süssmuth Commission}

The first case to be examined involves the Süssmuth commission, or formally the Independent Commission on Migration to Germany (ICM).

\subsubsection{Background to the Süssmuth Commission: 'kein Einwanderungsland'}

Germany was one of the last Western European countries to formulate immigration and immigrant integration policies. This was due to the normative belief that Germany was not and should not be a country of immigration, i.e. 'Kein Einwanderungsland' (see also Heckmann, this volume). It was not until the end of the Millennium that the coalition government of Social Democrats (SPD) and the Green Party introduced draft legislation for a fundamental reform of citizenship law, introducing ius soli elements and the possibility for children born to foreigners in Germany to hold two citizenships. Two migration-related topics came up in public discourse at the turn of the millennium. The first was the demographic ageing of the German population and the associated risks for social security systems. As early as 1994, a group of scholars had suggested that immigration might balance the 
demographic problem at least to some extent (Bade 1994: 30). In the same vein, a parliamentary commission had investigated the issue since 1992 and stated that in the long run Germany might be in need of several million immigrants. A policy would therefore have to be formulated (Schneider 2010: 169). Secondly, employers' associations and stakeholders in information and communication technology pushed the issue of labour shortages onto the agenda, lobbying for a more liberal approach to admitting qualified personnel from third countries. ${ }^{1}$

When this window of opportunity opened, Chancellor Schröder announced in February 2000 the introduction of a 'Greencard', allowing for labour migration of up to 20,000 high-skilled specialists in areas such as the IT sector. The new Greencard recruitment scheme envisaged temporary work and residence permits only, and received overwhelming support. However, it proved to be successful as symbolic politics only: as a matter of fact, administrative regulations created by the Ministries of Interior and Labour, pragmatically implemented 'backstage' by bureaucrats, turned out to be more effective and sustainable in facilitating labour mobility (Kolb 2005).

As the Greencard had provided vital momentum to the politicised migration discourse, Schröder and Interior Minister Otto Schily took a pro-active stance by appointing an 'Independent Commission on Migration to Germany' (ICM), evading the risk of yet another defeat by 'passing the buck' to 21 external experts and stakeholders. ${ }^{2}$ The Commission received the task to work out concrete recommendations for future immigration policy and, among other things, to present a concept of integration (ICM 2001: 20). The composition, agenda and budget of the ICM were predominantly government-controlled, with the Ministry of the Interior being the driving force. Schily landed a brilliant coup by getting CDU member and popular former President of the German Bundestag Rita Süssmuth to chair the commission. Highly esteemed elder statesman Hans-Jochen Vogel, former Federal Minister of Justice and parliamentary party leader of the SPD, became deputy chairperson. Beyond this, a well-balanced cast of public figures from political parties, foundations, trade unions, industry associations, religious communities, municipal associations and academia promised to provide what the government asked for: a consensus concept able to reframe public discourse, bind opponents and substantiate reform.

The initiative was acclaimed by the Green coalition partner, within the scientific community and in most op-ed pages. Moreover, opposition parties found themselves placed in a tight spot as Schily had managed to include renowned members from both the CDU and the FDP. However, the CDU did not really adopt a constructive position, as it instantly established its own alternative commission on migration.

\footnotetext{
${ }^{1}$ Interview with Director General, Confederation of German Employer Organisations, 26 July 2004.

${ }^{2}$ The ICM was second in a series of high-ranking consultative bodies installed to support policymaking in various areas by the Schröder administration - a hallmark pattern identified by Dyson (2005) as 'binding hands through government by commission'.
} 
This was not solely due to the fact that, at the time, reformist and liberal politicians had internally gained the upper hand when it came to conceptualising migration policies. It was also because of the potential risks to a centre-right party's legitimacy, which are associated with anti-immigrant mobilisation in a period of relative societal receptiveness towards immigration - jeopardising conservative values, internal policy coherence and credibility among constituencies due to gaps between restrictionist rhetoric and political realities (Boswell and Hough 2008: 333 et seq.). As the ICM started its deliberations over all aspects of migration policy after the summer break, so did special task commissions and working groups set up by almost all political parties, forming a genuine rivalry of advisory bodies, and at the same time operating as internal policy formulation tools (Schneider 2010: 221-229, 234237).

\subsubsection{Engineering Consensus}

The Süssmuth Commission, endowed with substantial political capital and wide media interest, attempted to fulfil its mission to engineer a broad consensus by following a clear strategy. First, it rejected the attempts of the Interior Ministry which hosted and partly staffed the commission's secretariat - to influence the Commission's agenda or the contents of its upcoming report, thus actively guarding its independence. In fact, it was agreed at an early stage that all discussions would remain closed and confidential, and that only occasionally the chair would release information to the media (Schneider 2010). Second, as many external stakeholders and experts as possible were to be consulted, in order to gather relevant knowledge and safeguard the commission's legitimacy and approval of its results. ${ }^{3}$ A total of 143 representatives from ministries and bureaucracies, scholarly and advisory institutions, as well as practitioners and experts from schools, the civil service, social partners, NGOs and the EU gave testimony in front of the commission; 18 expert opinion reports were solicited from a number of institutes and academics; and seminars were held with the Commissioners for Foreigners' Issues of the Federal States (Länder), with representatives of the political parties, and with judges from the Federal Constitutional and Administrative Court (ICM 2001: 290-306).

The commission itself gathered for 13 plenary sessions and a total of 27 meetings in three separate working groups. The first group looked into legal aspects of migrant and asylum policies, the second debated future immigration policy from demographic and labour market perspectives, and the third dealt with the variegated issues pertaining to integration and social inclusion. In their internal proceedings, commission members performed an almost exemplary consensus building process (Susskind 2006: 284 ff) by deliberating extensively and deciding unanimously.

\footnotetext{
${ }^{3}$ Interviews with Commission Chairperson, 2 March 2004; Manager of the Secretariat, 2 May 2005.
} 
Despite initial controversies and differing viewpoints, explicit minority reports were avoided. Externally, the commission was successful in its mediating function, integrating and binding stakeholders (Zinterer 2004: 299). On the eve of the commission concluding its work, even a broad cross-party political consensus along the lines of the draft report seemed possible (Schneider: 2010: 269). The other competing forums and commissions had more or less terminated their work in the summer of 2001, and the Süssmuth Commission promised to provide an overall synthesis in July 2001.

\subsubsection{A New Integration Policy and an Immigration Strategy}

'Germany needs immigrants' was not only the first stark sentence of the commission's report, but also the most explicit message conveying to the public what was deemed a consensus among key political and societal actors. Under the heading 'Structuring Immigration, Fostering Integration', the commission presented in more than 300 pages a thorough account of past policies and empirical evidence and statistical data on the impact of immigration in Germany. The suggestions in the areas of immigration, asylum and integration formed an overall plan that was embedded in an evolving European migration system. The key feature of this Gesamtkonzept, ${ }^{4}$ which the commission hoped to transpose into a 'Federal Immigration and Integration Act' (ICM 2001: 266-270), was the strategy for immigration geared to meet future demographic and labour market needs, thereby 'securing long-term prosperity' (ibid).

Under the main heading 'Living in harmony with one another', the commission propagated a new integration policy, conceding that the former policy of 'pragmatic improvisation' had led to significant successes. Yet, the absence of a systematic and comprehensive approach was deemed responsible for difficulties in integrating immigrants into the host country (ICM 2001: 195).

Rhetorically, the commission came up with nothing less than a new frame for integration that implied a balanced precept for action, dovetailing formerly incongruous positions: 'For a long time, Germany held the one-sided view that, as the host country, it could expect ethnic and cultural assimilation from its immigrants. We speak of something different when we discuss integration today. [...] In modern usage, the term integration describes a process that depends on reciprocal contributions that both the host and the immigrant society make. [...] The principle of 'promoting and demanding' demonstrates the reciprocity of this relationship. While the host country is required to provide sufficient opportunities

\footnotetext{
${ }^{4}$ For the commission's proposals in the areas of improving international protection, accelerating asylum procedures, safeguarding return, as well as humanitarian and historically founded migration see ICM 2001, pp. 119-194; for a discussion see Klusmeyer and Papademetriou 2009, pp. 248-250; Schneider 2010, pp. 319-333.
} 
for integration, the immigrant must endeavour to learn the German language and become integrated' (ICM 2001: 196, 254). Thus, the report took position between two perceived extreme scenarios - the chimera of increasing cultural fragmentation through the emergence of separatist ethnic groups in 'parallel societies' as a result of a laissez-faire form of multiculturalism, and the strongly assimilationist Leitkultur model of integration, demanding from immigrants a unilateral adaptation to the values and culture of the German host society.

The Süssmuth Commission held that migrant and host society expectations were equally important: those who have newly arrived need to feel accepted and welcome, and mere toleration will have negative effects. On the other hand, recognition of the constitution and immigrants' willingness to learn the language and integrate were considered indispensable prerequisites. In general, however, the new frame set out for integration was both more inclusive and universalist. The latter could be depicted, for instance, through the fact that the report 'made clear that promoting integration was the driving consideration in its approach towards citizenship policy, and stressed that a policy aimed at this goal must be treated as part of any immigration strategy.' (Klusmeyer and Papademetriou 2009: 248). Thus, in order for immigrants to acquire political rights, the commission favoured a more generous approach to awarding German citizenship and accepting dual nationality (ICM 2001: 244). In a similar vein, granting municipal voting rights to third-country nationals was proposed.

In total, there were about 50 individual recommendations for a new integration policy. With many of these, the commission borrowed from Swedish and Dutch integration policies..$^{5}$ Of greatest salience, both for newcomers as well as for longerterm residents without sufficient language competencies, the commission suggested uniform integration courses of at least $600 \mathrm{~h}$. Besides the primary goal of fostering language acquisition, these courses were to provide an introduction to the legalpolitical system as well as employment and training.

\subsubsection{Swansong for Policy Reform?}

The authors of the ICM report, as well as an influential background report, had called for better policymaking through the use of statistics, evidence and evaluation, particularly with regard to demographic trends and future labour shortages. The commission report with its Gesamtkonzept was a straightforward expression of this endeavour, which immediately took root in media, public discourse and among policymakers. When Interior Minister Schily presented a first draft of a new Immigration Act in August 2001, taking on board several (though far from all) of the commission's proposals, this was at odds with almost all of the actors

\footnotetext{
${ }^{5}$ The report contained two chapters describing the Dutch and Swedish approaches in detail (ICM 2001: 247-251).
} 
involved (Green 2004: 123). Schily found himself caught between two camps. He had to please both the Greens as coalition partner in the Bundestag and the State Governments represented in the Bundesrat for later approval. In the latter, however, the parties forming the Federal Government coalition did not have a clear majority. Furthermore, the timing of the Süssmuth report and Schily's draft bill proved unfortunate, with the events of September 11 complicating and setting back governmental as well as parliamentary negotiations over the Immigration Act. Antiterror legislation in the form of 'Security Packages', which anticipated some of the highly controversial aspects to be regulated in the new Immigration Act, absorbed lawmakers' time and capacities. Thus, as time wore on, the chances for consensual legislation dwindled as parties began to prepare their campaigns for the Federal parliamentary elections in the autumn of 2002.

In January, the conservative parties selected CSU leader Edmund Stoiber as chancellor candidate. He advocated a much stricter line in relation to migration and integration, falling short of the positions manifested via the CDU commission (Green 2004: 123-124; Hell 2005: 155). The Christian Democratic opposition soon rejected the bid to discuss migration policies on a more technocratic, rationally informed basis (Boswell 2009: 169). Rather, they picked up on diffuse anxieties within the majority population, which involved a degree of scepticism towards any new channels for immigration. ${ }^{6}$ When it came to negotiating with the government, the Christian Democrats, who gradually came under the aegis of the Bavarian CSU and its designated chancellor candidate Stoiber, distanced themselves from former positions and shifted to straightforward opposition, 'flagrantly slapping their own concepts in the face'?

After intensive negotiations and in view of the parties' preparations for the election campaign, the Bundestag had to quickly pass a much-revised bill, with the Bundesrat approving the act in a furious and controversial vote in March 2002, which was later declared unconstitutional by the Federal Constitutional Court (ibid.: 126). Thus, the 2001/2002 Immigration Act, which had omitted the commissions' proposals in a number of areas already, failed as it never came to force and had to be reintroduced to the parliamentary process after Federal elections (with SPD and Greens forming a second coalition government) in early 2003.

In the negotiations over the second Immigration Act, which stretched over yet another two years, the report of the Süssmuth Commission ended up playing barely any role at all. Instead, policymaking followed a familiar path with the main actors retreating to their 'old' frames on immigration and integration. ${ }^{8}$ This was well epitomised by one of the respondents' observation that drafting a compromise act on immigration was challenging as trying to 'rewrite the Criminal Code into the

\footnotetext{
${ }^{6}$ Bundestag, Plenary Protocols 15/31, 13 March 2003, p. 2321C/D, and 15/44, 9 May, 2003, p. 3666C.

${ }^{7}$ Interview with Süssmuth Commission Member, 26 November 2003.

${ }^{8}$ For a thorough analysis of the whole process see Schneider 2010, pp. 277-308.
} 
Civil Code'. 9 In the view of Klusmeyer and Papademetriou (2009), the second Immigration Act, which eventually passed in the summer of 2004, failed both to break with the exclusionary model of immigrant integration and to reconceptualise the German migration policy framework: the new law neither created a system to facilitate the immigration of those wishing to work in Germany whose skills were needed, nor established a system that would sufficiently integrate new immigrants or those already living in migrant communities (ibid.: 255).

\subsubsection{Immediate Frame-Setting, Medium-Term Reframing}

The internal frame reflection performed by the Süssmuth Commission was to rub off on the general discourse and create momentum for a new balanced frame and a general political consensus on migration policy reform. This turned out to be a perspicuous misconception. The commission's reframing of integration was largely overshadowed by unresolved underlying frame conflicts over immigration and asylum, causing severe political controversy. The rational socio-economic focus of the Süssmuth commission was at odds with the much more socio-cultural focus of the CDU/CSU that articulated public concerns about the societal impact of migration and the preservation of German 'Leitkultur' (Boswell 2009; Green 2004). Also problematic was the commission's inclusive, recognition- and rights-based frame on immigrant integration, which had never been embraced by the Christian Democratic parties or much of their support base.

Rather than triggering a process of critical reflection about these different frames, the commission had chosen a specific frame, thereby dissociating itself from the multiplicity of frames present in both political and scientific debates. When the commission's frame came to blows with the realities of the policymaking process in a competitive system of party politics, particularly around the general election of 2002, the rational-positivist reasoning of the commission lost its appeal as a guide for policy re-design. At the same time, the political system displayed patterns of path dependency by demonstrating that final approval of a contested policy issue like immigration and integration can only be reached through mediated compromises within an informal 'grand coalition'.

Nevertheless, the commission's deliberations and the much broader public and political debate over migration policy marked a significant shift in the history of German Ausländerpolitik, as Simon Green concluded already at the end of the year 2002 (when the Federal Constitutional Court had just prevented the first Immigration Act from coming into force): 'Politically, the emphasis is no longer simply on the blanket restriction of immigration, but on the management of immigration and integration to Germany's best interest. For a country whose

\footnotetext{
${ }^{9}$ Interview with desk officer for interior affairs of the CDU/CSU group in the mediation commission, 19 July 2004.
} 
government was, as late as mid-1998, arguing that Germany was not a country of immigration, this has represented a remarkable turnaround.' (Green 2004: 128/129).

As regards immigrant integration, the Immigration Act of 2004/2005 implemented the language and orientation courses that had been outlined by the ICM. Thus, the promulgation of a new frame on immigrant integration by the Süssmuth Commission can be traced not only to a number of practical measures, but also to the general approach towards the issue. As Klaus Bade has pointed out: 'When it comes to the conceptual fostering of immigrant inclusion, government did not awake from the dead but through the preparatory considerations by the Independent Commission on Migration.' (Bade 2007: 37). Yet such frame shifts towards a new overall and comprehensive integration policy that the Süssmuth Commission had favoured occurred only gradually. Thus, the regulations that had materialised in the Residence Act were merely one building block in a set of further integration concepts, which were only drafted in the years following legislation. Since March 2005, an interministerial working group has met to 'coordinat[e] federal policy projects in the area of integration [... ] and to further develop these into a comprehensive concept.' Preparations for a Federal Integration Programme resumed in 2003 and the 2005 coalition agreement of the CDU/CDU and SPD (forming the first Grand Coalition at the federal level in decades) declared integration as a 'cross-cutting task involving many areas of policy'. ${ }^{10} \mathrm{New}$ forums aiming to facilitate consultation, frame reflection and discussion included the so-called integration summits, organised by the Federal Chancellery, and the German Islam Conference under the direction of the Federal Ministry of the Interior (Musch 2011).

The Süssmuth Commission was not fully successful in its attempts at frame reflection. It did, however, trigger different individual processes of questioning, debating and adapting frames within a new discourse culture on migration issues. One example is the CDU, which was entrenched behind the distorted frame of 'kein Einwanderungsland' until the end of the 1990s. Apparently, a process of internal frame reflection had been initiated within the CDU at an early stage, paralleling the work of the Süssmuth Commission. A 'major revision of their positions' was undertaken by stating, as a result of internal deliberations in a separate commission, that there was a need for controlled immigration to Germany (Heckmann 2003: 53). And members of the CDU commission on immigration themselves gave discursive meaning to the establishment of the Süssmuth Commission and the other consultative bodies at the time: 'This was probably the most important result of all this commission work: Removing the taboos from the issue - eventually one was allowed to say that indeed there were substantial deficits in integration, that there are 'imported' problems with regard to domestic security. Eventually one was allowed to say, $[\ldots]$ that immigration to Germany of people from other cultural

\footnotetext{
${ }^{10}$ 'Working together for Germany - With courage and compassion', Coalition Agreement between the CDU, CSU and SPD, pp. 112 http://www.bundesregierung.de/Content/EN/Artikel/2006/01/ _Anlagen/coalition-agreement951220, property=publicationFile.pdf
} 
backgrounds differs from immigration we had after the Second World War. What is most interesting was that this debate was quite sober and down-to-earth. ${ }^{11}$

However, new frame conflicts evolved and fierce negotiations are on the agenda time and again in German immigrant integration policy. In the years preceding the Süssmuth Commission, such conflicts appeared intractable. In the aftermath of the 'commissions galore' phase, policies have undergone reframing and are frequently debated based on a common rationale (or issue consensus). To quite some degree, the prevalent divergences between political camps over integration boil down to continuously contradicting frames with regard to citizenship, loyalty and inclusion: 'According to conservative positions, naturalisation was (and is) a final and formal step at the end of the process of integration: integrate first, then apply for naturalisation. For liberals and the left, naturalisation should not be withheld until immigrants prove worthy of it; naturalisation might considerably facilitate integration: naturalise, then integrate.' (Davy 2005: 141).

Furthermore, one should never neglect the institutional and discursive opportunity structures. In the German case, frame conflicts over immigration and integration could not be resolved as political actors proved unable to perform thorough frame-reflection on the spot. Being in a situation of practically constant electoral campaigning due to varying election days across Federal and State (Länder) levels (Wewer 1999), political parties have a hard time following two of the key imperatives as pinpointed by Rein and Schön: the willingness and capability to adapt one's frame if necessary, and the ability to put trust into a communicative situation and towards one's argumentative counterpart (be it a parliamentary debate or 'behind-closed-doors' negotiations during high-level talks).

\subsection{The Parliamentary Investigative Commission on Integration: The Blok Commission}

\subsubsection{The Installation of the Parliamentary Investigative Commission on Integration Policy}

The Netherlands is a key international reference in terms of its allegedly multicultural model of integration (see also Chap. 4 on national models of integration and Chap. 12 on the Netherlands). This approach to immigrant integration reflects a rather uncontested acceptance of the transformation of Dutch society into a multicultural society (see Duyvendak and Scholten 2011). However, around the turn of the millennium, the idea of a national multicultural model became central to debates on the alleged failure of Dutch immigrant policies. In 2000 a public debate emerged on the so-called 'multicultural tragedy' (see also Verbeek et al.,

\footnotetext{
${ }^{11}$ Interview with Deputy Chairperson, CDU Commission on Integration, 22 October 2004.
} 
this volume). A key claim in these debates was that the failure of the integration process was at least partly attributable to the lack of attention to culture and history in integration policies. In 2002 the failure of the integration process became the most important political topic during the parliamentary election campaigns. In these elections, preceded by the murder of the populist politician Pim Fortuyn, a direct link was constructed between the failure of integration policies and the dominance of the Dutch multicultural model of integration. According to Koopmans, the multicultural model produces adverse effects since it reifies rather than bridges ethno-cultural cleavages in society: it gives 'new ethnic and religious groups a formal and symbolic form of equality, which in practice reinforces ethnic cleavages and reproduces segregation on a distinctly unequal basis.' (Koopmans 2006:5).

This controversy over the Dutch multicultural model provided the backdrop for the installation of a 'Temporary Parliamentary Investigative Commission on Integration Policy'. This commission was named after its chairman Stef Blok from the Liberal Party (VVD). The parliamentary motion that parliament adopted to establish this commission already included a conclusion that the integration policy had become a fiasco. It stated: 'Concluding that the integration policy has thus far been insufficiently successful, (...) it would be desirable to evaluate what the cause of this have been' (Parliamentary Documents, TK 2002-2003, 28600, nr. 24). However, the working group that was established after this motion had been accepted, reformulated the research question in a more open manner, making the evaluation of policy success or failure a part of the research problem. The aim was to enable parliament to assess the integration policy of the previous decades, including the intended policy goals and actual policy results, as well as the consistency and coherence of policy in various domains. The domains selected as relevant included housing and recreation, income and labour, and education. The terms of reference of the research commission were eventually formulated as 'To enable the Second House of Parliament to evaluate the integration policy of Dutch government over the past 30 years, to evaluate the intended effects and factual results of this policy and to evaluate the coherence of policy in various policy terrains' (Parliamentary Documents, TK 2002-2003, 28689, nr. 1).

On the commission were representatives from political parties with different views on immigrant integration. Besides the three main political parties, the Liberal Party (VVD), Christian-Democrats (CDA) and Social-Democrats (PvdA), the commission also included representatives from the progressive Green Left party, from the Socialist Party that had taken the initiative for the commission, and the Pim Fortuyn Party that had been established after the rise of Pim Fortuyn in the political arena some years before.

The commission proceedings involved an extensive literature study, a series of closed and open interviews with various persons that had been involved in the national and local integration policy over the past decades, and a series of 'hearings' in four cities that were open to the public. Importantly, an extensive literature review had to provide a provisional answer to all the commission's research questions, provide factual information on policy developments, and address issues such as goal-attainment and effectiveness. This study, which had to be completed in no more 
than two and a half months, was commissioned from the Verwey-Jonker Institute. This institute was selected in an open competition, and chosen for its expertise in this area. An extra argument was that the institute was not involved in the design of the policy under scrutiny (Blok 2004: 17). ${ }^{12}$ For the Verwey-Jonker Institute, an important condition for accepting the request was that the research assignment was open, without any prior conclusion about policy failure or success (see Scholten 2011).

\subsubsection{The 'Relative Success' of Integration in the Netherlands}

The Verwey-Jonker Institute was asked to do an evaluative study of the goals and results of the integration policy over the past decades in specific domains and to determine the extent to which policy had been consistent and coherent. ${ }^{13}$ Moreover, it was asked to determine to what extent the integration policy 'could be qualified as successful.' In particular, this latter question was related to the framing of immigrant integration. The frame of the Verwey-Jonker Institute was manifest in its assumption that 'success in one domain can be of higher importance than that in others' (Verwey-Jonker Institute 2004: 196). The 'success in the domain of education appears [to be] the key for the further success of the integration process', meaning the results in this domain are of extra importance. Based on this assumption, the Institute eventually came to the conclusion that the integration policy had been 'relatively successful' (ibid). Furthermore, it concluded that 'some of the intended goals have been realised (...) especially in the domain of education', as well as in the domain of housing, whereas the goals in the domain of income and labour 'have been less clearly achieved' (ibid.).

This stress on education and labour as key domains of integration reveals that the Verwey-Jonker Institute used a specific frame of immigrant integration, one that did not focus so much on socio-cultural issues but rather on socio-economic aspects of integration. It thus based its conclusion about the relative success of the integration policy on this particular frame. The institute also put its conclusions in a broader perspective, providing an incentive for critical reflection about this problem frame. It argued that, especially in the socio-cultural dimension of immigrant integration, policy was not entirely successful because of the inconsistency of policies. It concluded that 'especially in the socio-cultural domain there is a certain gap between formulated objectives and results that have been attained thus far' (Verwey-Jonker Institute 2004: 197). It warns against an 'anachronistic evaluation' of policy results that have accumulated over the past based on policy objectives

\footnotetext{
${ }^{12}$ Several other experts and institutes did not participate in the open competition because they felt that they had been too strongly involved in policy developments themselves or because they felt that the time period allowed for the research was too limited for any significant research.

${ }^{13}$ Parliamentary Documents, TK 2003-2004, 28689, nr. 11: 5.
} 
that have been set only recently; '[R]esults are lagging mainly in areas where only recently new and sharper goals have been formulated' (ibid).

The Blok Commission itself concluded that 'the integration of many immigrants has been a total or partial success, and (...) this is quite an achievement for the immigrant citizens concerned as well as for the host society' (Blok 2004: 105). How the commission substantiated this conclusion revealed a similar framing as the Verwey-Jonker Institute report. It attributed the success of the integration process especially to the progress that was made in the domains of education, labour, housing and women's emancipation (ibid: 522). These domains concern mainly individual participation of migrants, regardless of gender, rather than group emancipation (as in multiculturalism) or socio-cultural integration (as in assimilationism).

An important difference with the Verwey-Jonker Institute was that the Blok Commission did not conclude that the integration policy had been successful, but rather that the integration process as such had been successful. The commission observed that 'causal relations with the general integration policy are difficult to prove (...)' (ibid: 522). The success of the integration process would have been especially affected by general developments in society and by the efforts of those migrants involved. In this respect too, the Blok Commission seems to have followed a socio-economic frame in which government had only a supportive role in the integration process.

\subsubsection{Credibility on the Line}

The Blok Commission and the Verwey-Jonker Institute did what could be expected from policy evaluation studies, which is evaluating policy effects based on formal policy goals. It adopted the problem frame of the integration policy of the 1990s, and based on this frame both actors came to the conclusion that integration had been rather successful. They pinpointed education and labour as the key sectors of integration. The Blok Commission even concluded that it was the integration process itself, rather than necessarily integration policy per se, which had been relatively successful, based on progress achieved in the sectors that were considered vital from a socio-economic frame of immigrant integration.

However, even before the commission had published its findings, it became the object of fierce public and political controversy. Internal disagreements in the commission received public attention when one of the commission members decided to leave the commission, through pressure from his own party (i.e. the Socialist Party, which led the initiative for the parliamentary motion in 2002). This triggered controversy over the commission's research approach, in particular about the Verwey-Jonker report and over its tentative conclusion that policy had been relatively successful (which had already been leaked to the press). One of the central claims of the dissenter from the Socialist Party was that the commission should not have commissioned the literature review from the Verwey-Jonker Institute, as 
experts involved in this institute would have been too closely involved with policy developments themselves in the past. ${ }^{14}$ The authority of this institute was further questioned due to the alleged political connections of one of the main authors of the study for the Blok Commission (who also happened to be a director of the Institute). In addition, the conclusion that the integration policy had been relatively successful triggered negative responses from public intellectuals as well as politicians who discarded such a conclusion as 'naive'. ${ }^{15}$

In the evolving debate on the commission's findings, the credibility of the researchers involved was clearly on the line. Issues of credibility were clearly connected to alleged bias in terms of framing immigrant integration, namely a bias in favour of the multicultural model of integration that was now so fiercely rejected in public debate. In parliamentary hearings, debate emerged about whether the Blok Commission had 'measured' what it was supposed to measure. Questions arose about the usefulness of an evaluation study when there is no consensus on the definition of integration. Member of Parliament, Hirsi Ali, claimed that because "there has never been a consensus on a definition of the word integration, parliament has given the research commission an assignment that was too vague. ${ }^{16}$ Other parties argued, based on their frame of integration, that the commission report provided a thorough analysis of all the problems, 'but was too reserved when it comes to drawing the proper conclusions from all this. ${ }^{17}$ Based on their frames about integration, various parties pointed to alleged 'blind-spots' in the commission report, such as the role of religion in general and Islam in particular, criminality and the lack of attention for cultural issues in general. In addition, a representative from the Socialist Party asked how the commission could have come to its relatively positive conclusions about policy when it had been given the assignment to investigate why policy had failed. ${ }^{18}$

\subsubsection{Missed Opportunities for Critical Frame Reflection?}

What has been the impact of this parliamentary investigative commission on integration policy in terms of critical frame reflection? The motivation of parliament to establish this investigative commission - which was to provide a new impulse to the integration policy - may in itself be been as an indication of willingness to reflect on the level of policy framing. However, this opportunity for frame reflection failed already in the early stage of formulating the research problem.

\footnotetext{
${ }^{14}$ Interview with the parliamentarian concerned, NRC Handelsblad, 20 September 2003, p. 29.

15 'Harde kritiek uit Kamer op 'naïef' rapport', NRC Handelsblad, 19 January 2004, p.6.

${ }^{16}$ Parliamentary Hearings, April 2004, 63-4102.

${ }^{17}$ Parliamentary Hearings, 6 April 2004, 63-4094.

${ }^{18}$ Parliamentary Hearings, 6 April 2004, 63-4127.
} 
In the parliamentary motion, empathy and critical reflection towards alternative frames were subdued by a reference that concluded beforehand that policy had been 'insufficiently successful.' This substantive conclusion indicates that there was already a particular problem framing for establishing the commission; the implicit frame that asked the commission to examine why policy had failed and become such a fiasco and how 'building blocks' for a new policy could be developed.

A tension developed between the parliamentary commission and the new centreright government established sometime after this parliamentary motion had been accepted. In its attempt to improve its relative information position vis-à-vis government, parliament went beyond this, taking a more substantial initiative in terms of policy development. On the one hand, this provided an indication of the broad parliamentary commitment to policy change in this domain. On the other hand, it created a tension with the new centre-right government, which included parties that had campaigned and presented substantial new plans on immigrant integration policy during the elections.

Furthermore, the parliamentary working group that reformulated this motion into the formal research questions for the Blok Commission did in fact broaden the research questions in terms of allowing for an evaluation of policy success or failure. It also adopted an implicit problem frame in its selection of mainly socio-economic domains that should be involved in the parliamentary investigation. As observed earlier, this selection of domains revealed a socio-economic frame, leaving out the socio-cultural issues that had become prominent in public and political debate at that time, the latter being more in-tune with an assimilationist frame. This selective formulation of the research questions showed that the commission was not aiming to reflect on alternative frames, but instead to evaluate policy and contribute to policy development based on a specific (socio-economic) frame.

Another element of the research design that constrained the opportunities for frame reflection concerned the study of scientific sources commissioned from the Verwey-Jonker Institute. As observed above, the Blok Commission delegated all questions to the Verwey-Jonker Institute, including the normative question concerning policy success or failure. Based on its frame (also socio-economic), the VerweyJonker Institute examined scientific sources and concluded that policy had been relatively successful. The exclusive role of the Verwey-Jonker Institute meant however that only one frame was included in the analysis of sources and the evaluation of policy success or failure. Had the Blok Commission asked for advice from several institutes, or from one institute with the explicit instruction to use various alternative problem frames, it would have been able to reflect (better) upon these alternative frames within the commission. In that case, the role of scientific research would have been to facilitate frame reflection within the politically constituted Blok Commission. The broad political composition of the commission could have enabled frame reflection by a type of scientific involvement that articulated diverse possible frames.

The immense political pressure on the Blok Commission obviously formed a further impediment for frame reflection. This political pressure involved sharply diverging views on immigrant integration as well as political incentives for party representatives to seek publicity for themselves. Asking for expert advice initially 
seemed to offer a way of coping with this political pressure, but eventually appeared to be at odds with the growing questioning of scientific authority and expert involvement in problem framing. Furthermore, this political pressure contributed to the immense time pressure on the commission in general and, more specifically, on the Verwey-Jonker study. These time constraints clearly limited the possibilities for including more frames in the sources study.

In spite of the multiplicity of frames and the expansion of the scale of the debate, the political conditions during this period simply did not allow for critical frame reflection. Frame conflicts (such as the controversy over policy success or failure surrounding the Blok Commission) often decayed into dialogues of the deaf in which actors with different frames selected different data or interpreted data differently, rather than leading to a critical debate at the level of problem framing. These frame conflicts often also shifted attention from the frames involved to the credibility of the actors involved. Finally, this case revealed a powerful disinclination on the part of actors to critically reflect on their own frames. By implication, the case shows that the policy frame shift that was to be codified in the years following the Blok commission was not a product of critical frame reflection.

\subsection{Conclusions: Rethinking Integration Policy Frames?}

This chapter has revealed some of the powerful constraints in rethinking deeply entrenched policy domains with the help of expert advice. Our analysis has revealed that both the Süssmuth and Blok commissions did not (immediately) resolve the policy controversies that led to their establishment in the first place. In fact, rather than resolving these controversies, both commissions evidently became part of the ongoing controversies themselves. Especially in the Dutch case, the experts who had advised the Blok commission were placed under scrutiny through a broad national debate over their credibility and alleged normative (multiculturalist) bias. Where the Dutch multiculturalist model was once blamed for the Dutch multicultural tragedy, now migration scholars were blamed for creating this multiculturalist model. Though such controversies never became as heated in the German case, here too it was not just the findings but also the proceedings and the authority of the Süssmuth commission that was put on the line (for instance, with Süssmuth's own CDU party even establishing another commission to mobilise counter-expertise).

That the authority of both consultative commissions was contested clearly marks a key difficulty in treating intractable policy controversies such as immigrant integration: they cannot simply be resolved merely by studying 'the facts', as the selection and interpretation of these facts is bound to the different frames that give rise to the intractable controversies in the first place. Even as in the case of the Süssmuth Commission, where the 'down-to-earth' approach within the commission seems to have provided an arena for critical frame reflection, the results of such insulated efforts of frame-reflection are not necessarily accepted in a broader policy and political setting. Despite a seemingly widespread 'climate of consensus', frame 
reflection performed internally and by involved actors could not be transposed to the competitive venues of party politics and legislation - which might be due not least to 'external perturbations' causing a reinforcement of politicisation (see also Entzinger and Scholten 2014). For instance, the Dutch case reveals how the Blok Commission ended up choosing a particular frame of immigrant integration itself, stressing the socio-economic character of integration rather than the socio-cultural character that had acquired prominence in political debates since 2000. It seems that in situations characterised by a multiplicity of frames, the selection of one specific frame is an inherently political choice, and that given the political nature of frame controversies, expert advice should not be considered a tool for resolving such frame controversies. In other words, commissions which are entrusted with tackling intractable policy controversies by government or parliament cannot be expected to succeed in terms of constituting a new and undisputed frame in the short term. They are likely to 'fail' in the sense that only very few of their practical recommendations (predominantly those which are all but consensual anyway) are put into practice in the subsequent policymaking process.

However, our analysis has revealed two specific ways in which the commissions contributed to a reframing of national policies on immigrant integration in their respective countries. First of all, both the Blok commission and the Süssmuth commission did function in such a way that they added emphasis, lent expert support to, and bolstered government in undertaking certain small-scale reforms on a more practical level. Hence, there was a more immediate, but relatively modest effect, at a more concrete level of changing and adopting new policy measures (that often relied on relatively broad political support in any case). Take for instance the recommendations on stepping up Dutch civic integration programmes or introducing a systematic (and formerly unknown) approach by enshrining in law a claim for language and civic orientation courses for new immigrants. In fact, analysis has shown that almost all the instrumental recommendations of the Blok commission were eventually adopted in government policy (Scholten and Van Nispen 2008); only its more conceptual conclusions (concerning the relative success of the integration process) were rejected. Similarly, the Süssmuth Commission's factual suggestions on integration policy were controversial to only a minor degree, and thus were largely transposed into policy. Yet even with regard to the highly disputed suggestions in the areas of asylum and labour migration, the Commission yielded several 'long-term consequences', as a thorough implementation analysis several years later shows (Schneider 2010: 311-329, 371-373).

Secondly, beyond this more instrumental effect, both commissions did have a more indirect and discursive impact on frame reflection in both countries. Especially in the Süssmuth case, the commission successfully fostered public debate and loosened the political deadlock on the German differentialist model: it lifted taboos on discussing this model and raised alternatives that provided arguments for a variety of policy stakeholders in a subsequently more gradual process of frame reflection. Even in the Netherlands, the Blok commission did have a discursive effect in triggering reflection on how the Dutch were to frame immigrant integration if the multiculturalist model was to be abandoned; it helped clarify a frame that did not 
define education and labour as key areas of integration (as did the Blok commission), but spurred government to be much more explicit in its more culturalist framing of immigrant integration.

The strength of the similarities between the Dutch and German cases examined in this paper supports our claim that rethinking integration policies with the help of expert advice will in general be very difficult. Governments should not initiate investigative commissions to resolve political controversies, nor should experts (especially scientific experts) have themselves tempted to define policy frames themselves. Nonetheless, the contribution of investigative commissions can be fruitful in other ways; they can provide initiatives for policy changes on a more instrumental level but they can also function as discursive triggers for critical frame reflection (rather than as sources of new frames themselves). However, our analysis has also pinpointed some differences between the Dutch and German cases. In particular, the long-term discursive effects on frame-shifts seem more significant in Germany as compared to the Netherlands. The findings from the Süssmuth Commission are nowadays broadly considered a key impetus for current German policies, whereas the findings from the Blok Commission have largely been forgotten. This may be related to differences between the two countries in terms of the degree of politicisation of migrant integration and the rise of anti-immigrant discourses.

Open Access This chapter is distributed under the terms of the Creative Commons Attribution Noncommercial License, which permits any noncommercial use, distribution, and reproduction in any medium, provided the original author(s) and source are credited.

\section{References}

Andeweg, R. B., \& Irwin, G. A. (2005). Governance and politics of the Netherlands. Houndmills: Palgrave Macmillan.

Bade, K. J. (Ed.). (1994). Das Manifest der 60. Deutschland und die Einwanderung. München: C.H. Beck.

Bade, K. J. (2007). Versäumte Integrationschancen und nachholende Integrationspolitik. Aus Politik und Zeitgeschichte, 22-23, 32-38.

Bleich, E. (2003). Race politics in Britain and France: Ideas and policy-making since the 1960s. Cambridge: Cambridge University Press.

Blok, S. (2004). Bruggen bouwen: Eindrapport van de tijdelijke parlementaire onderzoekscommissie integratiebeleid. The Hague: SDU.

Boswell, C. (2009). The political uses of expert knowledge. Immigration policy and social research. Cambridge: Cambridge University Press.

Boswell, C., \& Hough, D. (2008). Politicising migration: Opportunity or liability for the centreright in Germany? Journal of European Public Policy, 15(3), 331-348.

Boswell, C., \& Hunter, A. (2014). The political functions of independent commissions: Comparing UK commissions on migrant integration and cohesion. Published online first in the Journal of Comparative Policy Analysis.

Brubaker, R. (1992). Citizenship and nationhood in France and Germany. Cambridge: Harvard University Press.

Davy, U. (2005). Integration of immigrants in Germany: A slowly evolving concept. European Journal of Migration and Law, 7, 123-144. 
Duyvendak, W. G. J., \& Scholten, P. W. A. (2011). Beyond national models of integration. The coproduction of integration policy frames in the Netherlands. Journal of International Migration and Integration, 12(3), 331-348.

Dyson, K. (2005). Binding hands as a strategy for economic reform: Government by commission. German Politics, 14(2), 224-247.

Entzinger, H., \& Scholten, P. (2014), The interplay of knowledge production and policymaking: A comparative analysis of research and policy-making on migrant integration in Germany and the Netherlands. Published online first in the Journal of Comparative Policy Analysis.

Favell, A. (1998). Philosophies of integration. Immigration and the idea of citizenship in France and Britain. Houndmills: Palgrave.

Green, S. (2004). The politics of exclusion. Institutions and immigration policy in contemporary Germany. Manchester: Manchester University Press.

Heckmann, F. (2003). From ethnic nation to universalistic immigrant integration: Germany. In F. Heckmann \& D. Schnapper (Eds.), The integration of immigrants in European societies. National differences and trends of convergence (pp. 45-78). Stuttgart: Lucius \& Lucius.

Hell, M. (2005). Einwanderungsland Deutschland? Die Zuwanderungsdiskussion 1998-2002. Wiesbaden: VS Verlag.

Hisschemöller, M., \& Hoppe, R. (1995). Coping with intractable controversies: The case for problem structuring in policy design and analysis'. Knowledge for Policy, 4(8), 40-70.

ICM. (2001). Structuring immigration, Fostering integration. Report by the Independent Commission on Migration to Germany, Berlin.

Klusmeyer, D. B., \& Papademetriou, D. G. (2009). Immigration policy in the Federal Republic of Germany: Negotiating membership and remaking the nation. New York: Berghahn Books.

Kolb, H. (2005). Germany's "Green Card” in comparative perspective. In H. Henke (Ed.), Crossing over. Comparing recent migration in the United States and Europe (pp. 303-317). Lanham, MD: Lexington Books.

Koopmans, R. (2006). Good intentions sometimes make bad policy: A comparison of Dutch and German integration policies. In R. Cuperus, K. Duffek, \& J. Kandel (Eds.), The challenge of diversity. Innsbruck: Studienverlag.

Musch, E. (2011). Integration durch Kosultation? Konsensbildung in der Migrations- und Integrationspolitik in Deutschland und den Niederlanden. Münster: Waxmann Verlag.

Schneider, J. (2010). Modernes Regieren und Konsens. Kommissionen und Beratungsregime in der deutschen Migrationspolitik. Wiesbaden: VS Verlag.

Scholten, P. W. A. (2011). Framing immigrant integration: Dutch research-policy dialogues in comparative perspective. Amsterdam: Amsterdam University Press.

Scholten, P. W. A., \& Van Nispen, F. (2008), Building bridges across frames? A meta-evaluation of Dutch immigrant integration policy. Journal of Public Policy, 28, Nr.2.

Schön, D. A., \& Rein, M. (1994). Frame reflection. Toward the resolution of intractable policy controversies. New York: Basic Books.

Sniderman, P. M., \& Hagendoorn, A. (2007). When ways of life collide: Multiculturalism and its discontents in the Netherlands. Oxford: Oxford University Press.

Susskind, L. (2006). Arguing, bargaining, and getting agreement. In M. Moran, M. Rein, \& R. E. Goodin (Eds.), The Oxford handbook of public policy (pp. 269-295). Oxford: Oxford University Press.

Van Eeten, M. J. G. (1999). Dialogues of the deaf: On science in policy controversies. Science and Public Policy, 26(3), 185-192.

Verwey-Jonker Institute. (2004). Bronnenonderzoek: Tijdelijke commissie onderzoek integratiebeleid. The Hague: SDU.

Wewer, G. (1999). Regieren in Bund und Ländern (1948-1998). In T. Ellwein \& E. Holtmann (Eds.), 50 Jahre Bundesrepublik Deutschland: Rahmenbedingungen - Entwicklungen - Perspektiven (pp. 496-519). Wiesbaden: Westdeutscher Verlag.

Zinterer, T. (2004). Politikwandel durch Politikberatung? Die kanadische Royal Commission on Aboriginal Peoples und die Unabhängige Kommission ,Zuwanderung “im Vergleich. Wiesbaden: VS Verlag. 


\title{
Chapter 6 \\ European Cities in Search of Knowledge for Their Integration Policies
}

\author{
Rinus Penninx
}

\subsection{Introduction}

In the study of integration policies, the national level of individual countries has been the dominant unit of analysis. In such studies, integration policies towards newcomers are studied under the assumption that such a national frame sets conditions for processes of integration everywhere in the country and at all levels. There is an abundance of such national studies, often funded by policy agencies. There is also an established tradition of comparative studies of countries and their integration models, ${ }^{1}$ including a critical stream of studies on such 'national models' (see also Chap. 4). ${ }^{2}$

Studies of integration processes and policies at the lower levels of cities and municipalities are more recent than national ones. A quick inventory of the international literature reveals that such studies appeared already well before the turn of the century. Early studies focused predominantly on the political dimension of integration and policies related to civic and political participation, as in the case of Patrick Ireland's study of four cities in France and Switzerland (Ireland 1994); Rex and Samad (1996) on Birmingham and Bradford; Blommaert and Martiniello (1996) on Antwerp and Liège; Garbaye (2000) on Birmingham and Lille; Bousetta

\footnotetext{
${ }^{1}$ For an overview of European studies, see Penninx et al. 2006. For a recent overview of policymaking (in ten European countries) see Zincone et al. 2011.

${ }^{2}$ See for example Favell 1998; Bommes and Morawska 2005; Thränhardt and Bommes 2010; Entzinger and Scholten 2014.

R. Penninx $(\square)$

Institute for Migration and Ethnic Studies, University of Amsterdam, Nieuwe Achtergracht 166, 1018 WV Amsterdam, Netherlands

e-mail: m.j.a.penninx@uva.nl
} 
(2001) on Antwerp, Liège, Lille and Utrecht and Fennema and Tillie (2004) on Amsterdam, Liège and Zürich. Other studies focused on specific aspects of local policies such as housing and segregation patterns in nine cities (Musterd et al. 1998), policing in Paris, Marseille and Lyon as compared to New York and Chicago (Body-Gendrot 2000), local policies relating to Islam and Muslim institutions in European cities (Rath et al. 2001; Maussen 2009) or the management of diversity in the implementation of local policies in Manchester and Marseille (Moore 2001, 2004). More recently we also saw examples of attempts to compare the making of local integration policies (Caponio and Borkert 2010; Gesemann and Roth 2009).

An early large-scale comparative analysis of integration policies at the local level of cities has been done in the MPMC-project (Multicultural Policies and Modes of Citizenship in European Cities). The MPMC-project ran from 1996 till 2004. It focused in its empirical research particularly on the political participation of immigrants, but that specific focus was framed in a more general comparison of cities, their immigrants and local governmental policies. Systematic descriptions were made of 16 major European cities and Tel Aviv. ${ }^{3}$ In two book publications (Rogers and Tillie 2001; Penninx et al. 2004) general comparisons of policies and cities were supplemented by in-depth comparisons on selected topics. Alexander (2004) used this material not only to construct a first typology of local policies, but also to devise a new in-depth comparison of policies in Amsterdam, Paris, Rome and Tel Aviv (Alexander 2003, 2007).

There is thus an increasing scientific literature on local integration policies, but does this literature inform us about the existence of research-policy structures and dialogues at the local level? Are local policymakers searching for knowledge and/or are researchers providing knowledge relevant for policies? The literature mentioned above is not commissioned and funded by cities or local policymakers, so not part of a research-policy dialogue. But there is also a less well known (and difficult to find) subset of local research on migrant policies. It is this local policy-research nexus that I would like to explore in this contribution.

In the exploration below, I will try to systematise evidence from personal observations as a researcher and policymaker in the Netherlands, ${ }^{4}$ from research institutes within the IMISCOE-consortium, from my participation as a researcher in research projects on local integration policies, such as the MPMC-project and the CLIP-project (Cities for Local Integration: see below), and from advising cities on their policies. In the course of this exploration, I will make some observations

\footnotetext{
${ }^{3}$ The city templates are available on the UNESCO website: www.unesco.org/most

${ }^{4}$ The author worked in Dutch ministries responsible for (stimulating local) integration policies from 1978 till 1988. He was director of the Institute for Migration and Ethnic Studies at the University of Amsterdam from 1992 to 2006. He was co-chair of the International Metropolis-project from 1999 till 2009. He was coordinator of IMISCOE - a European network of research institutes in the field of migration and integration - from its inception in 2004 until 2014. In all these capacities he has been involved in policy-research dialogues, including those at the local level in Dutch cities (Amsterdam and Haarlem) and through the CLIP-project in Copenhagen (Denmark) and Turku (Finland). See: Penninx 1988, 2005a, b, 2009; Penninx et al. 2004; Wolff et al. 1999.
} 
on how cities define their needs and possibilities to acquire knowledge that they perceive as relevant. The special position of local authorities in the multi-level governance of migration and integration (i.e. their relations with national and European Union policies) receives special attention, since this influences their possibilities to collect certain knowledge. I will also outline a number of initiatives led by cities for horizontal exchange of relevant knowledge on good or best practices that have sprung up during the last decade. Finally, I will make some tentative concluding remarks on the policy-research-nexus on the local level.

\subsection{Dutch Cities in the Quest to Acquire Knowledge About Migrant Integration}

In 1986, the Advisory Committee Research on Minorities in the Netherlands (ACOM) published a 'Review of Municipal Minorities Research': a survey of some 100 research projects initiated by 54 municipalities in the Netherlands, not including the four major cities Amsterdam, Rotterdam, The Hague and Utrecht (Uniken Venema 1986). More than $80 \%$ of these municipalities had been engaged in research or were doing so at that time. The four largest cities had built up significant research programmes by then (Uniken Venema 1986: i). The report notes that the decisions to have research done were mostly taken by either researchers or policymakers working for the city who wanted policy-relevant data or information. The research was often implemented by municipal research or statistical departments. Most of it was small in scale.

The significant engagement of Dutch cities and municipalities in research and data collection about migrants in their cities should be understood against the background of a new national policy: the national government had decided in 1980 to have an Ethnic Minorities Policy for the integration of immigrant groups in the Netherlands (Ministerie van Binnenlandse Zaken 1980). One of the starting points of that new policy was that cities and local authorities should develop an active local integration policy for immigrants and minorities. To stimulate local authorities to do so a special temporary regulation was made to finance extra costs for setting up local policies (the 'Extra Bestuurskosten Regeling'), starting in 1980. One of these extra costs mentioned explicitly was research for policy. Local authorities thus received funding from the national government that they could use to have research done. Obviously this funding facility was readily used. This was confirmed in an analysis of research projects on minorities in the Netherlands in the period 1981-1985: the percentage of research projects financed by cities/municipalities had increased from $6 \%$ in 1981 to $25 \%$ in 1984 (Penninx 1988: 13).

Admittedly, such a stimulating environment for research initiatives at the local level was exceptional in Europe in the 1980s: the Netherlands was one of the few countries that developed a national integration policy quite early (i.e. before the turn of the century). The other country that had an integration policy (still earlier, 
since 1975 ) was Sweden. ${ }^{5}$ Probably there was also an early local Policy-Research Nexus in Sweden, although one of the few reviews of policy-research connections in Sweden that covers the period between 1965 and 1984 (Hammar 2004) does not mention cities as initiators or users of research. For the later period, after 1984, there is more evidence that Swedish cities - particularly Stockholm, Göteborg and Malmö ${ }^{6}$ - have initiated and co-financed research from universities in their cities on a significant scale and developed contacts with the universities in their cities on issues of local integration policies.

What function did research on the local level in the Netherlands have for policymakers and what function did that research have in the policy cycle? In view of the specific context, local research projects in the Netherlands were not initiated as tools for recognition and problem definition in the first phase of such a cycle. Instead, recognition and problem definition were attributable to the (national) context and policy. Local research projects had much more of a function for the second phase - that of supporting the concrete instrumentation of policies. Such research was supposed to answer questions about what issues policymakers should prioritise and what instruments could be used. Later, when local policy was in place, the attention shifted to the third phase of the cycle: evaluation. Monitoring outcomes of policy and evaluation of policies became central issues in research. As to monitoring, cities chose predominantly two forms: the first were self-evaluative monitoring systems to be filled in by practitioners themselves. (Sometimes such systems were designed with external help from researchers.) The second is that the statistical services of the city were asked to produce data regularly and in a systematic way.

Cities, particularly larger cities that built up a longstanding tradition of integration policies such as Amsterdam and Rotterdam in the Netherlands, did commission part of their research to external researchers: to universities but also to commercial research institutes. In the case of Amsterdam, for example, the Institute for Migration and Ethnic Studies (IMES) at the University of Amsterdam was commissioned regularly since its inception in 1992 by the city to do evaluation studies, often on a specific part of their policies or a specific strategy. IMES evaluated e.g. the specific strategy of one of the districts of Amsterdam to engage organisations of immigrants in policymaking and implementation in the district (Wolff et al. 1999), and more recently did a study about radicalisation of Muslims in Amsterdam (Slootman and Tillie 2006). In Rotterdam, the Citizenship, Migration and the City (CIMIC) programme of the Faculty of Social Sciences has more recently developed

\footnotetext{
${ }^{5}$ One could argue that also the UK had early integration policies since the mid-1960s, but these policies focused primarily on 'race relations' and did not go under the label of 'integration'.

${ }^{6}$ The city of Malmö is closely connected to the emergence of the MIM-department (Malmö Institute for Studies of Migration, Diversity and Welfare) at Malmö University. The city has financed among other things the Guest Professorship in International Migration and Ethnic Relations in Memory of Willy Brandt since 1998.
} 
regular contacts between the Erasmus University and the city, which includes commissioning research by the city of Rotterdam. ${ }^{7}$

In the fourth phase of the policy cycle, local politicians and policymakers also regularly felt the need to reformulate policies. That need could be based primarily on monitoring and evaluation, but was often also inspired primarily by a need for a political redefinition of the field. Researchers were often asked to participate in commissions to advise politicians and policymakers on this. For example, I participated in an expert commission (Commissie van Deskundigen 1998) that advised the city of Amsterdam on the revision of their minorities policy in 1998.

As regards the question of how cities use knowledge, and what kind of knowledge, the material suggests that they use research and knowledge primarily for the instrumentation of their policies. In the course of time cities have formulated their specific needs more and more in terms of 'exchange of policy practice', often called good or best practices. Initiatives for such international exchange and learning between cities had already started in the Netherlands by the 1990s. For example, in 1998 the city of Amsterdam and its local district mayors invited policymakers and practitioners from Antwerp, Berlin, Birmingham, Brussels, Copenhagen, Frankfurt am Main, Liège, London, Manchester, Madrid, Milan, Rotterdam, Stockholm, Utrecht and Vienna for the Ethnic Minorities and Local Government Conference (Bestuurlijk Overleg Stadsdelen 1998). The conference itself also illustrates a form of research-policy dialogue on the local level: the city organisers hired researchers to prepare the conference and several of the invited cities brought their own scientific advisors to the conference (Amsterdam, Liège, London, Manchester, Rotterdam and Stockholm).

The city of Amsterdam conference in 1998 was not exceptional in the Netherlands: the city of Haarlem, for example, organised a conference in 2004 with its twin cities Osnabrück (Germany) and Angers (France) comparing the integration policies of the three cities. A comparative report was commissioned from the Institute for Migration and Ethnic Studies of the University of Amsterdam (Penninx 2005b). When doing the comparative study, it turned out that the city of Osnabrück had commissioned studies from the Institute for Migration and Intercultural Studies (IMIS) at the University of Osnabrück in 1998 and 2000 (by Michael Bommes and others) to revise its policies. ${ }^{8}$

\footnotetext{
${ }^{7}$ The city's interest in research is also expressed in the fact that the city co-financed in the past a special chair on Islam and recently supported the transition of the coordination of IMISCOE to the Erasmus University of Rotterdam.

${ }^{8}$ The first 1998 report led to new integration policies in the city of Osnabrück in 1999, very much inspired by Dutch local integration policies. In a second report of 2000, IMIS reported on the feasibility of concrete policies in five areas.
} 


\subsection{European Cities and Their National Connections}

Local integration policies have always been in the shadow of national integration policies or in the shadow of the absence of the latter, first of all because immigration policies (decisions about who is allowed to enter and stay) are made at the national level. If immigration policy is followed by a national integration policy, as happened in an early phase in Sweden (since 1975) and the Netherlands (since 1980), then local integration policies are stimulated and facilitated by such national policies. That is why Dutch and Swedish cities do have a longer history of local integration policies than other European cities. By implication, they also have developed forms of local research-policy dialogues, as described above for Dutch cities.

But immigration in Europe in the second half of the twentieth century was not necessarily followed by integration policy at the national level: most West European countries experienced significant immigration but did not enact national integration policies until the turn of the century. Nevertheless, immigrants did settle in cities and municipalities and some of these cities (but by no means all!) did develop integration policies, also in the absence of national policies. Quite a few of the cities that Amsterdam had invited to its conference in 1998 (the ones not coming from the Netherlands, Sweden and the UK) were cities that had pioneered local integration policies without the support of their national authorities.

Similarly, cooperation between universities and cities on research and integration policies, such as we mentioned for the Dutch case, was not exceptional in the late 1990s in Europe. When I was preparing the IMISCOE Network of Excellence in 2003, most of the 19 research institutes that were part of the IMISCOE-project in the beginning had undertaken a significant number of research projects commissioned by cities and local authorities. This was clearly the case for IMES (University of Amsterdam), CEDEM (University of Liège, Belgium), CEIFO (University of Stockholm, Sweden), COMPAS (University of Oxford, United Kingdom), efms (University of Bamberg, Germany), IMIS (University of Osnabrück, Germany), the Austrian Academy of Sciences (in Vienna, Austria) and FIERI (in Torino, Italy). ${ }^{9}$

Swiss cities are interesting cases to illustrate how cities have developed local integration policies in a national context with a long history of temporary employment of foreign workers in which the concept of integration was non-existent (D'Amato and Gerber 2005; Wicker 2003). In the second half of the 1990s, anthropologists (ethnologists) at universities in the cities of Zurich, Bern and Basel conducted research on the integration of immigrants and - in collaboration with city authorities - developed so called 'Integrationsleitbilder' (integration policy frames: Begert 2005; Kessler 2005; Tremp 2005). Contrary to what I described for cities in the Netherlands, this input of researchers did function as the first phase of a policy cycle, that of recognition and problem definition. At the same time

\footnotetext{
${ }^{9}$ It is not accidental that five of these institutes formed the consortium that would provide CLIPcities with the case-study research and the comparative reports of their policies between 2006 and 2012.
} 
the cities cooperated - amongst other things by organising a joint conference in which these Leitbilder were presented and discussed - in presenting their initiatives to national authorities, suggesting that the national government should have an integration policy and should support cities in their integration policies. However this latter initiative was not successful: it took several more years before the concept of integration was introduced at the national level in Switzerland.

Whatever the history of local integration policies, a common characteristic during the last decade seems to be that tensions between cities and national governments on a number of issues developed or increased (see e.g. Scholten 2013 for the Dutch case). Such tensions may relate to different views on how to implement (restrictive) immigration policies: how to handle irregular migrants in practice, particularly the ones that cannot be returned to their country of origin? How to implement restrictions on access to facilities and services in the domains of employment, housing, education and health in order to combat illegal residence ${ }^{10}$ Disagreement between national and local authorities may also relate to the new reception policies, the civic integration courses, the increased cultural requirements for continued residence and for naturalisation: where national policies may be quite ideological on such matters, local policy practitioners tend to look more for feasible practical solutions that are acceptable in immigrant communities. Tensions also arise when the financing of integration facilities is at stake, particularly when national policies prescribe new action, but do not deliver the financial and other resources needed to implement it.

Such tensions make it clear that the interests at stake in integration policies and their implementation may differ substantially, or be perceived as different, at the local and national level. At the city level, the confrontation with the day-today consequences of immigration is far more direct, and especially immigrants more immediately feel the implications of policies. European cities are increasingly aware that they need long-term, consistent integration policies in order to preserve their viability as communities and their liveability for all residents. During the last decade, cities have increasingly turned to new partners outside the national arena in their search for knowledge and resources for their policies, as we shall see below.

\subsection{EU Integration Policy and Horizontal Cooperation Between Cities}

Recently European cities have developed significant new relations outside their national context, particularly in the form of networks of cities that exchange knowledge and practical experiences in local integration policies. Although such initiatives primarily aim at cross-national horizontal forms of cooperation between

\footnotetext{
${ }^{10}$ The Linkage Law in the Netherlands, for example, obliges all public service providers to check for legal residence of clients. Illegal clients should not be served.
} 
cities, all of these networks have strong connections with and support from the European Commission. New coalitions have emerged in the multi-level governance of migration and integration in Europe.

This new constellation goes back the Amsterdam Treaty of 1997 and the Tampere Summit of ministers responsible for migration and integration policies in 1999. These had stipulated that asylum and migration should become a common EU policy domain, that existing migration policies and practices should be harmonised, and that third-country nationals who are long-term residents should be granted rights that approximate those of EU-citizens as closely as possible (which was the interpretation of the integration concept at that time).

In the first period of the Tampere Programme (1999-2004), EU policymaking concentrated strongly on the harmonisation of migration and asylum policies; integration was nearly absent (Van Selm and Tsolakis 2004). In fact, until 2003 EU policies started from the implicit assumption that if the legal position of immigrants was made as equal as possible to national citizens (as the Tampere programme stipulated), and if adequate instruments were put in place to combat discrimination, then integration processes could be left to societal forces. Thus, legal integration of TCNs was to be ensured by means of the directives on family reunification and free movement after 5 years on the one hand, and by anti-discrimination directives on the other.

It was only in 2003 that the European Commission came up with a more comprehensive view on integration policies in its Communication on Immigration, Integration and Employment. ${ }^{11}$ This Communication defined integration as 'a two-way process based on reciprocity of rights and obligations of Third-Country Nationals and host societies that foresee the immigrant's full participation' (European Commission 2003). This holistic policy approach targets all dimensions of integration (economic, social and political rights, cultural and religious diversity, citizenship and participation). In November 2004, the Council of Ministers responsible for integration agreed on the Common Basic Principles (CBP) for integration as a first step towards a common framework for a European approach to immigrant integration. $^{12}$

In contrast to EU migration policies, which are governed by communitarian principles (first pillar), EU integration policymaking is on an intergovernmental basis (third pillar). This means that policies have to be decided through consensus of member states and there is no binding legislation and directives. This has two effects on the making of policies. On the one hand, national governments do protect their sovereign right to decide in many domains that are important in the broad

\footnotetext{
${ }^{11}$ EC COM (2003) 336 final.

${ }^{12}$ This shift to a very broad conception of integration, however, did not go together with a broadening of the target group: integration policies are supposed to be for Third-Country Nationals only. Immigrants who are citizens from EU member states are supposed to be integrated by definition. The latter assumption has been criticised recently by local authorities in regions that received many new immigrants from accession states after the enlargements of 2004 and 2007 (Collett 2013).
} 
concept of integration, like social security, education, housing and health. In this sense, EU integration policies are clearly 'soft' policies and limited to what national governments allow them to be. On the other hand, through intergovernmental policymaking national governments may also try to transpose their national policies to the EU-level. Since 2004 some West European countries, for example, have increasingly 'uploaded'13 their cultural integration requirements for new Thirdcountry immigrants to EU-integration policies. What had started in the Netherlands as voluntary toolkit programmes for early reception at the local level in the 1990s became mandatory national civic integration courses in the 2000s, and these gained currency in other EU member states after 2004, including testing and sanctions.

Although this specific mechanism of policymaking and implementation is 'soft' - the method is called the 'open method of coordination' - the European Commission has managed to get agreement on some influential practical tools for concrete action. From 2004 to 2006 the INTI- programme (Integration of ThirdCountry Nationals) financed action and research, followed by two more substantial funds running from 2007 to 2013: firstly the European Integration Fund (EIF), and secondly the European Refugee Fund (ERF), designed especially to compensate states for their efforts regarding the reception and integration of refugees. For the European Commission as a policymaker, these funds are important, since they create direct relations between the EU and local and regional authorities (and their policies) on the one hand, and non-governmental civil society partners at all levels on the other.

It is against this new constellation of the multi-level governance of integration that a new coalition between the European Commission and new networks of European cities came into existence shortly after 2004. That new constellation is also the reason why most of the network initiatives of cities for integration policies though not all of them ${ }^{14}$ - are networks of European cities exclusively. I will describe the four most important networks (and the involvement of research in these initiatives) below.

The first is the CLIP-Network (Cities for Local Integration Policies ${ }^{15}$ ), established as a European Network of cities in 2006 by the Congress of Local and Regional Authorities of the Council of Europe, the City of Stuttgart and Eurofound. ${ }^{16}$ It comprises some 30 European cities. The basic idea of the CLIP-project

\footnotetext{
${ }^{13}$ Hannelore Goeman uses this term in her analysis of the constitution of integration policies at the EU level: Goeman 2012. See also Guild et al. 2009.

${ }^{14}$ The Cities of Migration project (http://citiesofmigration.ca) is an initiative taken by the Canadian Maytree Foundation. It is a project rather than a network. Cities of Migration does not have members. Cities are invited to (mostly virtually) share their experiences and learn from each other. The Cities of Migration project's main instrument is its website. The Cities of Migration project is now supported by a dozen private foundations from Europe, North America and elsewhere.

${ }^{15} \mathrm{http} / / / \mathrm{www}$.eurofound.europa.eu/areas/populationandsociety/clip.htm

${ }^{16}$ The European Foundation for the Improvement of Living and Working Conditions (Eurofound) is a tripartite European Union Agency, whose role is to provide knowledge in the area of social and work-related policies.
} 
is to learn by exchanging knowledge and experience between cities. This is done in a systematic process involving research institutes that collect material on integration policies in the participating cities. Five research institutes of the IMISCOE Network of Excellence ${ }^{17}$ have been engaged to do case studies in each of the cities and to compare these cases. The project is organised as a suite of consecutive modules in which specific aspects of local integration policy are studied empirically and compared systematically. The first module was on housing for immigrants (Bosswick et al. 2007), the second on diversity policies in employment and service provision (Spencer 2008), the third on inter-group relations (LükenKlassen and Heckmann 2010), and the fourth on immigrant entrepreneurship (Rath et al. 2011). Each module generated some 25-30 case studies, one comparative synthesis report ${ }^{18}$ and specific policy briefs. Each module was followed by a conference in which the results were discussed among the cities involved and with a wider interested audience. CLIP was funded from 2006 to 2012 by the European Foundation. The CLIP materials focus strongly on policy practices in particular subdomains of integration policies, enabling analysis of the complete chain from policy formulation to implementation and results, showing the often strong dependence of such policies on the functioning of general institutions at the local and national levels. It also gives important insights into the administrative and bureaucratic mechanisms involved in policymaking and implementation.

The second network is Integrating Cities ${ }^{19}$ a project (also since 2006) carried out by Eurocities, a large network of some 140 major European cities. Integrating Cities can be seen as a policy dialogue between Eurocities and the European Commission. The most important platform for dialogue between cities and the European Commission are the Integrating Cities Conferences (2008-2013 in Rotterdam, Milano, Berlin, London, Amsterdam and Tampere). The network has developed the Eurocities Charter on Integrating Cities as a programme for city governance.

In terms of searching for relevant knowledge, Eurocities has implemented a number of EU-funded projects on local integration as well as initiatives from the Eurocities' Working Group on Migration and Integration. The oldest of these projects was the INTI-Cities project that ran for 18 months during 2007-2009. The project was about 'Benchmarking Integration Governance in European Cities': peer reviews were used to assess integration policies in European cities. By measuring policies against a benchmark of high standards, it aimed at delivering expert-

\footnotetext{
${ }^{17}$ The five institutes involved in CLIP are the European Forum for Migration Studies (EFMS) at the University of Bamberg, the Centre on Migration Policy and Society (COMPAS) at the University of Oxford, the Institute for Migration and Ethnic Studies (IMES) of the University of Amsterdam, the Austrian Academy of Sciences and the Centre for Ethnic and Migration Studies (CEDEM) of the University of Liège.

${ }^{18}$ These case studies are available in the e-library of the European Urban Knowledge Network (EUKN: www.eukn.org) and on the website of the European Foundation (www.eurofound.europa. $\mathrm{eu}$ ). The comparative synthesis reports are published by the Council of Europe and at www. eurofound.europa.eu

${ }^{19}$ www.integratingcities.eu/
} 
validated, comparative knowledge on local practices in twelve cities from nine EU member states. Four dimensions of integration policy were assessed:

1. General governance arrangements in the field of migrant integration;

2. Policies in support of individual migrant empowerment;

3. Structures and effectiveness in administrative cooperation;

4. Policies creating and supporting partnerships with civil society and migrant associations.

The final report (Niessen and Kirchberger 2009) summarises benchmarks and recommendations.

The INTI-project was followed by the DIVE-project that had a different and narrower focus on the promotion of diversity and equality in local policies, examining how cities and municipalities can effectively implement diversity policies in management and employment policies led by principles of equality. The project was co-financed by the European Integration Fund. The project resorted again to the methodology of benchmarking and peer reviewing:

1. A set of four benchmarks with regard to the four key responsibilities of cities in promoting mutual accommodation were designed: municipalities as policymakers, employers, service providers and buyers of goods and services;

2. Empirical research was carried out on local integration policies through peerreviews in four major European cities (Berlin, Rome, Amsterdam and Leeds), involving senior city officials with relevant responsibilities;

3. The benchmark report that resulted from this exercise was shared with actors across Europe. It nurtured the Integrating Cities conferences of Berlin 2009 and London 2010 and contributed to the Cities' charter on the role of local government in the integration of migrants. ${ }^{20}$

The results of the project were published in the report 'Cities Accommodating Diversity' (Moloney and Kirchberger 2010).

The MIXITIES-project (Making integration work in Europe's cities 2010-2012) built on the work developed by the INTI- and DIVE-projects. It aimed to develop peer reviews, structured exchange workshops, and toolkits to support cities in delivering the commitments of the Charter. The project focused on three key areas, namely anti-discrimination policy, diversity competences in public services and introductory courses for newcomers. Peer reviews were held on each of these themes respectively in the cities of Gent, Barcelona and Stockholm in 2011. The project's findings and recommendations were presented at the Integrating Cities conference held in Amsterdam in March 2012.

\footnotetext{
${ }^{20}$ The Integrating Cities Charter, launched in 2010, commits signatories to fully acknowledge the presence of migrants in their roles as policymakers, service providers, employers and buyers of goods and services. By September 2013, 30 European cities have signed the charter, which is complemented by a process of monitoring and peer learning.
} 
The third network is Intercultural Cities, ${ }^{21}$ a joint action of the Council of Europe and the European Commission started in 2008. It emerged from the White Paper on Intercultural Dialogue that the Council of Europe had submitted for the European Year of Intercultural Dialogue in that same year. The concept of the Intercultural City was developed earlier by the British think-tank Comedia. In 2004, Comedia conducted a 2 year research programme in the UK, United States, Australia, New Zealand and Norway entitled 'The Intercultural City: Making the Most of Diversity'. It looked at cultural diversity as a source of innovation, creativity and entrepreneurship and how increased intercultural dialogue, exchange and activity can be the catalyst for such a process (Wood 2009).

The Intercultural Cities strategy is a management strategy that publicly advocates respect for diversity and a pluralistic city identity. The Intercultural Cities Programme was developed and first applied in eleven European pilot cities and has evolved since then. The Programme develops tools such as the Intercultural Cities Index for cities to evaluate and develop their policies. It organises international conferences for cities to exchange experience.

The fourth network is a more specific horizontal cooperation initiative, the European Coalition of Cities Against Racism (ECCAR ${ }^{22}$ ) established in 2004 upon the initiative of UNESCO. The aim of this coalition of cities is to share experiences in order to improve policies to fight racism, discrimination and xenophobia. Since 2008, its annual general conference is the main tool for exchange between cities. In the meantime, 104 municipalities from 22 European countries have joined the network and adopted the 'Ten-Point-Plan of Action'.

These four European networks described above are all networks that have built up some form of organisation and continuity of cooperation. But apart from these, there have been numerous forms of cooperation of cities that have existed only during the period that they have been funded (mostly by EU-funds). Examples are ELCI - European Local Cooperation for Integration $(2010)^{23}$ - an 18-month project funded by the European Integration Fund that aims to promote knowledge and understanding of the valuable role that migrant organisations could play in integration process. Another example is DELI - Diversity in the Economy and Local Integration - financed by the Council of Europe and the EIF. It focuses on migrant-owned small and medium size enterprises in the local economy. If we were to scrutinise the long list of projects funded by the ERF, the EIF and also the ESF (European Social Fund) for material relating to local integration of migrants, we would certainly find many more. The ESF in particular has funded a number of projects on local labour market integration and on entrepreneurship in which (im-)migrants have a significant place.

\footnotetext{
${ }^{21} \mathrm{http}: / / \mathrm{www} . c o e . i n t / \mathrm{t} / \mathrm{dg} 4 /$ cultureheritage/culture/Cities/

${ }^{22} \mathrm{http}: / /$ www.citiesagainstracism.org/ICCAR.6.0.html

${ }^{23} \mathrm{http}: / /$ menedek.hu/
} 


\subsection{Conclusions}

This brief exploration of local research-policy dialogues in European cities and municipalities leads me to the following conclusions and hypotheses for further, more systematic research. The first is that - at first sight - local research-policy dialogues as such are nearly invisible in the international literature, but their existence turns out to be much older and more concrete if we turn to the local and national grey literature and to sources close to the partners involved: i.e. cities and their policymakers (and policy documents) on the one hand, and researchers and their institutes on the other. Obviously, much of what is produced in the context of local research-policy dialogues has to be made with more modest means than what is financed at the national level; it is also published in less well-known outlets, mostly in the local language. As a consequence, it does not reach a wider (international) audience.

Secondly, the above exploration suggests that - at least historically - cities and municipalities are more likely to start integration policies and use research (or any other form of systematic knowledge) to underpin their local policies when they are stimulated and supported to do so by higher level governance. The relatively strong and early development of local research-policy-relations in the Netherlands is clearly related to active national integration policies since the beginning of the 1980s. A comparably favourable situation may also have stimulated cities in Sweden in the 1980s and 1990s to develop local policy-research-dialogues. In terms of the functions of research, the data on Dutch cities suggests that - given the national framing of policies - cities used research primarily for instrumentation of policies in the beginning and monitoring and evaluation thereafter.

While an active integration policy at the national level might thus increase the probability of a local research-policy nexus emerging, the absence of such a national policy does not prevent cities from developing local integration policies. A significant number of European cities did so, often using research and initiating research-policy dialogues. Contrary to Dutch and Swedish cities in the 1980s and 1990s, the case of Swiss cities in the late 1990s suggests that, particularly in the beginning, such (externally commissioned) research did fulfil the function that research normally has in the first phase of a policy cycle, namely in recognising and defining problems and setting the frame for local policies.

The above exploration has thus established the existence of local research-policy dialogues in European cities on a larger scale than was known before and in diverse regions of Europe. The material, however, is still too scant to make substantial statements neither on the frequency of such local dialogues, nor on their continuity over time. As to the latter, I would venture the hypothesis that more continuous forms of local dialogues have developed in those cities in which the interest in integration policies developed simultaneously both in local universities or research institutes and among local politicians and civil servants. Those cities seem, however, to be exceptional. Most local research-policy-dialogues, one may hypothesise, are incidental and short term. 
The relevance of what happens at the other levels of the increasingly multilevel governance of integration in Europe becomes clear after the European Union initiated its own integration policy in 2003. Although the European Commission has a very specific definition of integration and of target groups (which is certainly not always shared by cities), increasingly direct policy cooperation has come into existence between the European Commission and local authorities, bypassing the national governance level. In that new constellation of multi-level governance, an interesting form of research-policy dialogues has mushroomed: networks of European cities that evaluate and share their own practical knowledge, assisted in that process by researchers, and financed by the European Commission. A systematic study of what has been produced in three of these networks, Cities for Local Integration Policies, Integrating Cities and Intercultural Cities, would teach us a lot about local policy-research relations as these have evolved in the last decade, both in terms of the individual cities involved and in terms of their cross-national cooperation.

Open Access This chapter is distributed under the terms of the Creative Commons Attribution Noncommercial License, which permits any noncommercial use, distribution, and reproduction in any medium, provided the original author(s) and source are credited.

\section{References}

Alexander, M. (2003). Host-stranger relations in Rome, Tel Aviv, Paris and Amsterdam: A comparison of local policies toward migrants. $\mathrm{PhD}$ thesis, Universiteit van Amsterdam, Amsterdam.

Alexander, M. (2004). Comparing local policies towards migrants: An analytical framework, a typology and preliminary survey results. In R. Penninx, K. Kraal, M. Martiniello, \& S. Vertovec (Eds.), Citizenship in European cities. Immigrants, local politics and integration policies (pp. 57-84). Aldershot: Ashgate.

Alexander, M. (2007). Cities and labour immigration. Comparing policy responses in Amsterdam, Paris, Rome and Tel Aviv. Aldershot: Ashgate.

Begert, U. (2005). Städteleitbild und migrationspolitische Erfahrungen der stadt Bern. In G. D'Amato \& B. Gerber (Eds.), Herausforderung Integration. Städtische Migrationspolitik in der Schweiz und in Europa (pp. 93-99). Zürich: Seismo Verlag.

Bestuurlijk Overleg Stadsdelen Amsterdam. (1998). Ethnic minorities and local government. Report of the conference'. 22 and 23 January 1998, Bestuurlijk Overleg Stadsdelen, Amsterdam.

Blommaert, J., \& Martiniello, M. (1996). Ethnic mobilisation, multiculturalism and the political process in two Belgian cities: Antwerp and Liège. Innovation, 9(1), 51-73.

Body-Gendrot, S. (2000). The social control of cities? Oxford: Blackwell.

Bommes, M., \& Morawska, E. (2005). International migration research. Constructions, omissions and the promises of interdisciplinarity. Aldershot: Ashgate.

Bosswick, W., Lüken-Klaßen, D., \& Heckmann, F. (2007). Housing and integration of migrants in Europe. Strasbourg: Council of Europe.

Bousetta, H. (2001). Immigration, post-immigration policies and the political mobilisation of ethnic minorities: A comparative case study of Moroccans in four European cities. $\mathrm{PhD}$ dissertation, KUB, Brussels. 
Caponio, T., \& Borkert, M. (2010). The local dimension of migration policymaking. Amsterdam: Amsterdam University Press.

Collett, E. (2013). The integration needs of mobile EU citizens: Impediments and opportunities. Brussels: Migration Policy Institute Europe.

Commissie van Deskundigen. (1998). Amsterdam heeft de wereld in huis. Advies van de commissie van deskundigen Herziening Minderhedenbeleid van de gemeente Amsterdam. Amsterdam: Gemeente Amsterdam.

D'Amato, G., \& Gerber, B. (Eds.). (2005). Herausforderung Integration. Städtische Migrationspolitik in der Schweiz und in Europa. Zürich: Seismo Verlag.

Entzinger, H., \& Scholten, P. (2014). The interplay of knowledge production and policymaking: A comparative analysis of research and policymaking on migrant integration in Germany and the Netherlands. Journal of Comparative Policy Analysis, 18, 1-15.

European Commission. (2003). Communication on immigration, integration and employment, 3 June. EC COM (2003) 336 final.

Favell, A. (1998). Philosophies of integration. Immigration and the idea of citizenship in France and Britain. London: Macmillan.

Fennema, M., \& Tillie, J. (2004). Do immigrant policies matter? Ethnic civic communities and immigrant policies in Amsterdam, Liège and Zurich. In R. Penninx, K. Kraal, M. Martiniello, \& S. Vertovec (Eds.), Citizenship in European cities. Immigrants, local politics and integration policies (pp. 85-106). Aldershot: Ashgate.

Garbaye, R. (2000). Ethnic minorities, cities and institutions: A comparison of the modes of management of ethnic diversity of a French and a British city. In R. Koopmans \& P. Statham (Eds.), Challenging immigration and ethnic relations politics: Comparative European perspectives (pp. 283-311). Oxford: Oxford University Press.

Gesemann, F., \& Roth, R. (Eds.). (2009). Lokale Integrationspolitik in der Einwanderungsgesellschaft - Migration und Integration als Herausforderung von Kommunen. Wiesbaden: VS Verlag für Sozialwissenschaften.

Goeman, H. (2012). Integrating integration. The constitution of a EU policy domain on migrant integration. $\mathrm{PhD}$ thesis, Vrije Universiteit Brussel, Brussel.

Guild, E., Groenendijk, K., \& Carrera, S. (Eds.). (2009). Illiberal liberal states: Immigration, citizenship and integration in the EU. Farnham: Ashgate.

Hammar, T. (2004). Research and politics in Swedish immigration management 1965-1984. In M. Jandl \& I. Stacher (Eds.), Towards a multilateral migration regime. Special anniversary edition dedicated to Jonas Widgren (pp. 11-34). Vienna: ICMPD.

Ireland, P. (1994). The policy challenge of diversity: Immigrant politics in France and Switzerland. Cambridge: Harvard University Press.

Kessler, T. (2005). Das Integrationsleitbild des Kantons Basel-Stadt. In G. D’Amato \& B. Gerber (Eds.), Herausforderung Integration. Städtische Migrationspolitik in der Schweiz und in Europa (pp. 104-111). Zürich: Seismo Verlag.

Lüken-Klassen, D., \& Heckmann, F. (2010). Intercultural policies in European cities. Strasbourg: Council of Europe.

Maussen, M. (2009). Constructing mosques. The governance of Islam in France and the Netherlands. $\mathrm{PhD}$ thesis, University of Amsterdam, AISSR.

Ministerie van Binnenlandse Zaken. (1980). Regeringsreactie op het rapport "Etnische minderheden" van de Wetenschappelijke Raad voor het Regeringsbeleid. Den Haag: Min. van BiZa.

Moloney, Th., \& Kirchberger, A. (2010). Cities accommodating diversity: Findings and recommendations from the peer review project "Diversity and Equality in European Cities". At http:// www.migpolgroup.com/public/docs/171.CitiesAccommodatingDiversity_DIVE_22.02.10.pdf

Moore, D. (2001). Ethnicité et Politique de la Ville en France et en Grande-Bretagne. Paris: L'Harmattan.

Moore, D. (2004). In R. Penninx, K. Kraal, M. Martiniello, \& S. Vertovec (Eds.), Citizenship in European cities. Immigrants, local politics and integration policies (pp. 127-138). Aldershot: Ashgate. 
Musterd, S., Ostendorf, W., \& Breebaart, M. (1998). Multi-ethnic metropolis: Patterns and policies. Amsterdam: Kluwer Academic Publishers.

Niessen, J., \& Kirchberger, A. (2009). Strategic thinking on equality and mobility. INTI-cities: Key findings and recommendations for European-level policy makers. At: http://www.archive. migpolgroup.com/public/docs/150.INTI-Cities_MPG_Presentation_BenchmarkingReport_28. 01.09.pdf

Penninx, R. (1988). Wie betaalt, bepaalt? De ontwikkeling en programmering van onderzoek naar migranten, etnische minderheden en woonwagenbewoners 1955-1985. Amsterdam: SGI-reeks.

Penninx, R. (2005a). Integration of migrants: Economic, social, cultural and political dimensions. In M. Macura, A. L. MacDonald, \& W. Haug (Eds.), The new demographic regime: Population challenges and policy responses (pp. 137-152). New York/Geneva: United Nations.

Penninx, R. (2005b). 'Integratiebeleid in Angers, Haarlem en Osnabrück: visies, strategieën en de praktijk' (pp. 9-16), 'Integrationspolitik in Angers, Haarlem en Osnabrück: Ansichten, Strategien und Praxis' (pp. 43-52), 'Politique d'integration à Angers, Haarlem en Osnabrück: points de vue, stratégies et pratique' (pp. 77-86). In Multiculturalité et Integration à Angers, Haarlem et Osnabrück, Multiculturaliteit en Integratie in Angers, Haarlem et Osnabrück, Multiculturalität und Integration in Angers, Haarlem et Osnabrück, Haarlem: Gemeente Haarlem. Also published on: http://www.eukn.org/netherlands/themes/Urban_Policy/Social_ inclusion_and_integration/Integration_of_social_groups/multiculturality-in-angers-haarlemand-osnabruck_1024.html

Penninx, R. (2009). Vergleichende Studien zu Integrationspolitiken europäischer Städte. In F. Gesemann \& R. Roth (Eds.), Lokale Integrationspolitik in der Einwanderungsgesellschaft Migration und Integration als Herausforderung von Kommunen (pp. 611-634). Wiesbaden: VS Verlag für Sozialwissenschaften.

Penninx, R., Kraal, K., Martiniello, M., \& Vertovec, S. (Eds.). (2004). Citizenship in European cities. Immigrants, local politics and integration policies. Aldershot: Ashgate.

Penninx, R., Berger, M., \& Kraal, K. (Eds.). (2006). The dynamics of international migration and settlement in Europe. A state of the art. Amsterdam: Amsterdam University Press.

Rath, J., Penninx, R., Groenendijk, K., \& Meyer, A. (2001). Western Europe and its Islam. Leiden/Boston/Cologne: Brill.

Rath, J., Swagerman, A., Krieger, H., Ludwinek, A., \& Pickering, L. (2011). Promoting ethnic entrepreneurship in European cities. At: http://www.eurofound.europa.eu/publications/ htmlfiles/ef1138.htm

Rex, J., \& Samad, Y. (1996). Multiculturalism and political integration in Birmingham and Bradford. Innovation, 9(1), 11-31.

Rogers, A., \& Tillie, J. (Eds.). (2001). Multicultural policies and modes of citizenship in European cities. Aldershot: Ashgate.

Scholten, P. (2013). Agenda dynamics and the multi-level governance of migrant integration: The case of Dutch migrant integration policies. Policy Sciences, 46, 217-236.

Slootman, M., \& Tillie, J. (2006). Processes of radicalisation - Why some Amsterdam Muslims become radicals. Amsterdam: Institute for Migration and Ethnic Studies.

Spencer, S. (2008). Equality and diversity in jobs and services: City policies for migrants in Europe. Strasbourg: Council of Europe.

Thränhardt, D., \& Bommes, M. (Eds.). (2010). National paradigms of migration research. Göttingen: V\&R Unipress.

Tremp, J. (2005). Vom Integrationsleitbild zur Integrationspolitik der stadt Zürich. In G. D’Amato \& B. Gerber (Eds.), Herausforderung Integration. Städtische Migrationspolitik in der Schweiz und in Europa (pp. 87-92). Zürich: Seismo Verlag.

Uniken Venema, P. (1986). Overzicht gemeentelijk minderhedenonderzoek. Leiden: ACOM.

Van Selm, J., \& Tsolakis, E. (2004). The enlargement of an 'area of freedom, security and justice': Managing migration in a European Union of 25 members. Policy Brief, May 2004. Washington: Migration Policy Institute.

Wicker, H.-R. (2003). Einleitung: Migration, Migrationspolitik und Migrationsforschung. In H.-R. Wicker, W. Haug, \& R. Fibbi (Eds.), Migration und die Schweiz (pp. 12-62). Zürich: Seismo. 
Wolff, R., Van Heelsum, A., \& Penninx, R. (1999). Erkend, aangesproken, aanspreekbaar? Evaluatie van het migrantenbeleid van voormalig stadsdeel Oost en de participatie van organisaties van migranten, 1996-1998. Amsterdam: Stadsdeel Oost/Watergraafsmeer.

Wood, P. (Ed.). (2009). Intercultural cities: Towards a model for intercultural integration. Strasbourg: Council of Europe Publishing. Also available at http://www.coe.int/t/dg4/ cultureheritage/culture/cities/ICCModelPubl_en.pdf

Zincone, G., Borkert, M., \& Penninx, R. (Eds.). (2011). Migration policymaking in Europe: The dynamics of actors and contexts in past and present (IMISCOE Research series). Amsterdam: Amsterdam University Press. 


\title{
Chapter 7 \\ EU Policymaking and Research: Case Studies of the Communication on a Community Immigration Policy and the Common Basic Principles for Integration
}

\author{
Sandra Pratt
}

\subsection{Introduction}

Inter-governmental discussions on asylum and migration issues within the European Communities, as they then were, began in the 1980s in response to the growing concerns of several member states about migration to the EU and in particular the increasing numbers of asylum seekers reaching Europe. A special Task Force was later set up in the General Secretariat of the European Commission to facilitate these meetings. A particular issue was the number of third-country nationals crossing internal borders within the EU and then taking advantage of the different conditions contained in national legislation in order to apply for asylum - sometimes in more than one country - (so-called 'asylum shopping'). These concerns were heightened by the signing of the Schengen Agreement in 1985, designed to abolish internal border controls, which came into effect in 1995.

In the autumn of 1999, responding to new responsibilities conferred on the European Commission by the Amsterdam Treaty, which came into force in that year, a new Directorate General - for Justice and Home Affairs (DG JHA) was established. Included within it was a unit concerned with the development of immigration and asylum policy the core personnel of which had been previously working together on these issues within the Task Force. The Treaty of Amsterdam contained, for the first time, a skeleton legal framework for the development of a coordinated response to immigration and asylum and the protection of the external borders of the EU. It was therefore possible to provide a more comprehensive structure to carry out these tasks within the new DG.

The European Council held in Tampere in October that year agreed that a broad and comprehensive programme should be implemented. The Presidency

\footnotetext{
S. Pratt $(\varangle)$

Formerly Deputy Head, Immigration and Asylum Unit, Directorate General for Justice and Home Affairs, European Commission, Brussels, Belgium
} 
Conclusions of that meeting set out the so-called Tampere Milestones ${ }^{1}$ which provided not just for the coordination of national policies on admission and residence of third-country nationals but for the development of a Common EU asylum and migration policy including the following main elements:

- partnership with countries of origin

- a common European asylum system

- fair treatment of third-country nationals (with the aim of approximating their legal status to that of member states' nationals).

The Tampere milestones have remained at the heart of EU policy ever since and they were developed via a number of broad 5-year programmes called after the name of the city in which they were adopted (Tampere 1999-2004, The Hague 2004-2009, Stockholm 2009-2013). The objective was to increase cooperation both between member states and between the EU and third countries so as to regulate legal migration while also helping to reduce illegal flows. Over these years increasing priority was given to the prevention of illegal migration including the development of more robust controls at the EU's external borders and incentives to third countries to play a greater role in promoting the legal movement of their nationals and countering illegal movements.

As part of the common policy, the Amsterdam Treaty called for the harmonisation of existing legislation in certain key areas of asylum and, with respect to immigration, on the conditions of entry and stay of third-country nationals. However, the Tampere Council Conclusions opened the way for the development of a detailed programme designed to create a truly European approach to immigration and asylum. This would require creating a consensus amongst the then 15 and later 27 member states and finding sufficient common ground to move forward in an area where national sovereignty was strong, where the existing policies and legislation of member states were very diverse and where political priorities with respect to immigration and asylum varied, reflecting the different migration history and situation of each one.

The main drivers of policy from the European point of view were the fact that the movement of people was seen as an international phenomenon which responded to demand for immigrants for economic and social development within the Union but which needed to be managed more effectively. However, it was clear that, as internal border controls were removed, migration from outside the EU could certainly not be controlled by individual countries acting independently. It was recognised that the demand for labour was stronger in some countries than in others but the Commission believed that, because of changing economic and demographic factors, labour migration was likely, in a few years, to become a matter of concern to the EU as a whole. Although, at the time, movement of people between member states was low, it was thought that, with the development of the Single Market and closer financial and monetary union and as more countries joined Schengen, such

\footnotetext{
${ }^{1}$ Presidency Conclusions, Tampere European Council 15-16 October 1999 (SN200/99).
} 
movements were not only likely to increase but also to be increasingly necessary to ensure the economic development and competitiveness of the Union. In this respect third-country nationals might be particularly mobile. The key policy response was seen to be effective management strategies, which must be coordinated between the member states.

Consequently in the autumn of 1999 officials in DG JHA began the task of drafting detailed proposals for an EU immigration policy based on the general principles which had been agreed at the Tampere Council. These reflected a political consensus that had been developed over the previous two decades during the period of ad hoc intergovernmental activity but, as a new and substantial area of EU policy, one of the first tasks was to obtain more information about existing policies and practices at both national and international levels.

To do this a range of sources was tapped into: Commission papers from the earlier period, national reports from governments and other agencies and available research from national and international bodies. The research community in Europe played a particularly important role at this stage when the foundations of the common policy were being laid and the different ways in which this took place provide an interesting light on how the research-policy nexus operated during this period. This chapter will examine the complex relationships between migration research and policymaking at this time focusing on two of the key policy documents adopted in those early years, which are still fundamental to EU migration policy today - namely the Communication on a Community Immigration Policy, issued in November 2000, ${ }^{2}$ and the Common Basic Principles on Integration, adopted by the Justice and Home Affairs Council in November 2004. ${ }^{3}$

\subsection{The Communication on a Community Immigration Policy}

In 1999 there were already a number of EU sources on which to draw in the preparation of a common policy on migration. From the 1970s there existed Council resolutions concerning national legislation and the conditions in which migrant workers (both EU and third-country nationals) and their families lived in the member states. In the 1980s the Commission had published guidelines for a community migration policy ${ }^{4}$ specifying a number of areas where Community action could be most effective in managing migration. This had been followed by a Council Resolution in July $1985^{5}$ calling for greater exchange of information

\footnotetext{
${ }^{2} \mathrm{COM}(2000) 757$ final of 22 November 2000.

${ }^{3}$ Council Document 14615/04 of 19 November 2004.

${ }^{4} \mathrm{COM}(89) 48$ final of 1 March 1985 'Guidelines for a Community Policy on Migration'.

${ }^{5}$ Council Resolution of 16 July 1985 concerning guidelines for a Community policy on migration (85/C186/04).
} 
amongst member states about the numbers and conditions in which third-country nationals were received in their respective countries. Then in 1991 a Commission Communication argued that a common response was needed to deal adequately with immigration. ${ }^{6}$ In 1994 a more comprehensive Communication had been published on migration flows and ways in which greater cooperation between the member states could enhance the overall management of migration movements in Europe. ${ }^{7}$ Finally in December 1998 the 'Vienna Action Plan' had been adopted by the European Council setting out priorities, including asylum and immigration, for the area of freedom, security and justice, which was to be established the following year by the Amsterdam Treaty. ${ }^{8}$

However, having in 1999 for the first time a legal basis for taking concrete and enforceable measures and setting priorities, it was important to find out as much as possible about national policies in the field at the beginning of the twentyfirst century, to see what was common to more than one member state, where the major differences lay and the contexts in which these policies operated. At the time the 15 member states could be divided into broad categories depending on their experience of migration. There were those with a long history of immigration (and often of emigration as well) such as France, Belgium, Germany, Luxembourg, The Netherlands and the UK. Others had experience mainly of emigration of their nationals - notably the southern countries Italy, Spain, Portugal, Greece and also Ireland - a situation which was soon to change. Some had little recent experience of either kind of movement - particularly in northern Europe, notably the Scandinavian countries. The New member states who joined the Union in and after 2004 mostly fell into this latter category.

For European Commission officials to obtain detailed information about the migration policy of the member states was not always easy since much was contained in legal texts in the national language and if more general policy documents were available they were also mostly in the national language. Information could always be requested from senior officials in national administrations via questionnaires and relevant statistics could be collected but this was time-consuming for all concerned and was not a very realistic option given that about 6 months were available for the preparation of the Communication including the consultation procedure within the Commission and the time needed for translation.

Some very valuable comparative information was, of course, available from international sources, notably the Organisation for Economic Cooperation and Development (OECD), the United Nations (UN) and the International Organisation for Migration (IOM). Since the establishment in 1985 of the IGC (the InterGovernmental Committee on international migration) there had also been an exchange of information amongst a number of European countries, the USA, Australia, Canada and New Zealand. The European Commission participated in

\footnotetext{
${ }^{6} \mathrm{SEC}(1991) 1855$.

${ }^{7} \mathrm{COM}(94) 23$ of 23 February 1994 on immigration and asylum policies.

${ }^{8}$ Presidency Conclusions of the Vienna European Council 11-12 December 1998.
} 
these discussions. Comparable statistics, however, were extremely difficult to obtain and it was not until the adoption of a Regulation in 2007 that common definitions and standard topics were agreed by member states for the provision of data to Eurostat, the statistical office of the European Union. ${ }^{9}$

A very important information avenue at that time was, therefore, that of academic research. In this first phase the Commission developed an active policy of seeking out research which would provide reliable evidence on which to base detailed policy. Research findings were especially useful when they were objective and included comparative analysis of the impact of national policy both in the EU and in other parts of the world. However, in the early 2000s there was very limited comparative information available and certainly very little which gave an overview of all or even a number of the then fifteen member states. Relevant research was often difficult to access. Bibliographical searches took time - search tools were not as advanced then as they are now - and in particular it was difficult to quickly unearth what was relevant to policymaking from research results, which were often very detailed and limited in scope.

At the same time research carried out under the EU Research Framework Programmes largely covered immigration from a socio-economic point of view since these were the areas of most interest for EU policy at the time, particularly for DG Employment and Social Affairs. It should be remembered that the topics for the Calls for Proposals made within these programmes were decided in general terms by the Commission to reflect the needs of the different DGs, but there was then an open competition for the allocation of resources and specific proposals within the general guidelines were made by those applying. There was, therefore, scope for researchers to develop their own ideas within the overall strands. It was only with the Amsterdam Treaty that it was possible for the Commission to include a wider range of issues and to promote the development of comparative study in broader research programmes on different aspects of immigration and asylum. Such research has since become a very valuable source of information to inform policymaking with procedures in place to evaluate results and to bring policymakers and academics together in seminars and conferences to examine the results. ${ }^{10}$

After 1999 other sources of funding were also available to DG JHA to commission more focused research with shorter deadlines and precise specifications arising from specific and immediate policy needs. These were open to the research community, usually via restricted tender proceedings, and were invaluable methods of obtaining information to inform some of the early legislative and policy proposals. The drafting of most of the initial migration and asylum legislation, for example the

\footnotetext{
${ }^{9}$ Regulation (EC) No 862/2007 of the European Parliament and of the Council of 11 July 2007 on Community statistics on migration and international protection and repealing Council Regulation (EEC) No. 311/76 on the compilation of statistics on foreign workers.

${ }^{10}$ For an overview of 34 large-scale projects related to migration/integration funded by DG Research through its FP6 and FP7 programme, see Ann Singleton, Moving Europe: EU research on migration and policy needs, European Commission, DG for Research, EUR 23859 EN.
} 
EU directives on family reunification and those on asylum, benefited from analyses resulting from a specific research contract, usually including a comparative survey of existing national legislation. Commissioned research was also an important element in the early work on the formulation of integration policy. There were studies for example on the use of benchmarking to evaluate integration policies and practices and feasibility studies such as on the possibility of setting up a European Migration Observatory.

However, because time was short, a more direct approach was taken with respect to the 2000 Communication, through consultations with the research community on a formal and informal basis, as individuals and via the establishment of expert groups. Contacts were made through colleagues in the Commission and via senior civil servants, members of relevant Council committees, who advised on their national experts. A selection of immigration specialists from across Europe, including input from researchers from North America and elsewhere, was brought together on a number of occasions to discuss preliminary ideas and to advise on the different policy options which were under consideration within the Commission at the drafting stage. A particularly important seminar took place at the Luso-American Foundation in Lisbon in the spring of that year where some of the early ideas were analysed and discussed with a number of leading researchers. At the same time European Commission officials participated themselves in academic conferences to pick up information and to make contacts in the academic world across the member states.

The history of this Communication also illustrates a very important element of immigration policymaking and that is the influence of research from outside Europe, which had a major impact on the drafting of the publication. Early in 2000, the UN published demographic forecasts of changes expected in the world's population in the twenty-first century. These highlighted for Europe a dramatic decline in population in the EU, a significant increase in people over 65 and a decrease of those of working age. They were extrapolations based on different scenarios concerning death rates, birth rates and immigration but they showed that whether one took the high, medium or low possibilities, significant changes were to be expected and the report, published in March, suggested that migration could be one of the ways to deal with declining and ageing populations. ${ }^{11}$ The press seized on the results when the report was first published - and they created considerable interest all over the world, but particularly in the EU. The significance of immigration, the need for immigrant workers to take up the jobs created by a shrinking work-force, coming at a time when job shortages were beginning to be felt in a number of countries - notably in the much publicised, although it turned out also exaggerated, IT industry - caught both politicians' and the general public's attention.

\footnotetext{
${ }^{11}$ United Nations, Replacement Migration: is it a Solution to Declining and Ageing Populations? Population Division, Department of Economic and Social Affairs, United Nations Secretariat, 21 March 2000 (ESA/WP.160).
} 
This created an opportunity to abandon the cautious position taken in the early drafts of the 2000 Communication, of migrant flows and how they might impact on EU policy, and to take a much more pro-active position stressing the need for economic migration and consequently for management at the European level. The climate created, in terms of the acceptance of the economic value of immigration by business leaders and by the media and their impact on public opinion, has never been so propitious. In this context the emphasis in the new draft could be placed on identifying best practice and on taking an objective and long-term view of the kind of policy that would best meet the future economic and social needs of the EU. As outlined above, the role of the research community in this endeavour was considerable.

The Communication was adopted without major comment from the member states and it was also given a favourable reception by both the European Parliament and the Economic and Social Committee to which it was referred for an opinion. It was, of course, only a document setting out and giving justification for the proposed common policy and it contained no specific issues on which decisions had to be taken. However it created the framework for the EU approach to immigration, which has served as the basis for the wide-ranging policy we see today. It was a founding document for a new policy field and the Commission and policymakers had drawn extensively on the research community. The influence of the latter was probably greater then than it has been ever since.

There was less influence from other policy areas within the Commission and from national governments since the likely impact of migration and of the policy options that had been put forward were perhaps not fully appreciated at the time. The period of grace was not to last long as discussions about how far migration issues should be mainstreamed into other policy areas at national and European level and to what extent and for how long they should have a special status became more important. The impact of migration policy first on employment and then on external affairs and trade was quickly recognised by the relevant DGs. Issues of national sovereignty became stronger as national officials became more involved in the decision-making process at the EU level.

The proposals subsequently put forward for a coordination procedure for member states' migration policies were not accepted and the drafts for specific directives concerning the approximation of the legal status of immigrants were either withdrawn (as was the case for the directive on the admission of labour migrants) or adopted after long months of discussion and amendment by the Council. The publication of the Süssmuth report in Germany in $2001^{12}$ and the subsequent constitutional challenge of the proposed policy options put forward by the German government had the effect of slowing down on-going discussions in the Council. This was particularly important with respect to the directive on the admission of labour migrants - an extremely sensitive issue for many member states in spite of

\footnotetext{
${ }^{12}$ ICM - Independent Commission on Migration to Germany (2001) Structuring Immigration, Fostering Integration, Report by the Independent Commission on Migration to Germany, Berlin.
} 
the fact that the Commission's proposals concerned only the status of those who might be admitted but had no impact on the number to be selected which was to remain a decision taken by the member state concerned. The absence of a common position on labour migration to the EU is still today a major defect of the common policy. With the accession of the New member states in 2004 and the rapid growth of mobility within the EU, public opinion hardened against migration, the subject shot up the political sensitivity agenda and has remained there ever since, making progress with the development of EU policy on migration ever more difficult.

The slightly laissez-faire days of the early 2000s together with the very close links between policy and research are now in the past. However, the overall blueprint which was accepted then has remained in place as the basis of EU policy even though subsequently it has been influenced in tone and in direction by an increasingly negative public opinion and in recent years by rising unemployment in Europe and the financial and economic difficulties resulting from the banking crisis of 2008.

\subsection{The Common Basic Principles for Integration}

The development of a common approach to integration policy during the period 2002-2007 illustrates other ways in which the research-policy nexus operated in an area where there was no legal basis at that time for the Commission to propose legislation (see also Chap. 16 on the EU). However the need for greater cooperation and exchange of information about the way integration took place in the member states was becoming more evident. As a result in 2002 the Justice and Home Affairs Council decided to establish National Contact Points on integration and in 2003 the European Council invited the Commission to present annual reports on migration and integration in the EU.

The National Contact Points were senior officials from the member states chaired by the Commission who met two or three times a year on an informal basis (and were therefore not part of the formal Comitology structure that assisted the European Commission in policymaking). They played a very important role in the exchange of information and good practice and particularly in the development of ideas for policy on integration. Because of their informal nature, they were able to interact directly with the research community. Results of interesting research were presented by the researchers concerned at meetings of the National Contact Points, the project to establish a series of handbooks of good integration practice brought the members of the committee together with researchers and practitioners from civil society in a series of technical workshops and contributed enormously to the exchange of information, the sharing of ideas and of research results. Many members of this group were also actively involved at national level in the preparation of the ministerial meetings that developed national integration agendas. The flow of information between member states developed substantially involving exchanges not only between senior officials and researchers, but also with civil society and others involved in integration programmes. This took place not only at European 
level but there was a spin-off effect at national level too. As interest spread on the effectiveness of national models of integration the national research community became more involved with decision makers as these programmes were reviewed and compared at national level. The establishment in 2003 of a fund to finance pilot projects and preparatory actions in the field of integration (known as the INTI Fund), which was the precursor of the EU Integration Fund, had an important impact on these exchanges.

Meanwhile, the Commission had published a Communication in 2003 on immigration, integration and employment ${ }^{13}$ setting out proposals for the development of vigorous integration policies for third-country nationals as a response to the mandate given in the Tampere conclusions. The preparation for this document had also included a meeting of researchers, politicians and others called by the Commission and held in Florence in the spring of that year. A number of interesting ideas were born at that meeting including the notion of civic citizenship, which played an important role in subsequent discussions of the nature of citizenship for third-country nationals resident in the EU. This Communication, which was prepared in cooperation with DG Employment and Social Affairs, emphasised both the importance of the role of migrants in meeting the Lisbon employment goals, and that the economic and social benefits of migration could only be realised through successful integration. It also introduced arguments for mainstreaming integration within the framework of a number of existing policies and programmes at EU level.

The Communication was scheduled for discussion at the European Council to be held in Thessaloniki under the Greek Presidency in June 2003. As a preparation for this Council the research community took part in what might have been seen as a surprising new initiative by the Presidency, but one which subsequently played an important role in policymaking at the European level and in the preparation of the Common Basic Principles: the Athens Migration Policy Initiative (AMPI). The instigator was an American with Greek origins, Demetrios Papademetriou, director of a leading migration think-tank in Washington - The Migration Policy Institute (MPI). He had close connections with members of the Greek government at that time and persuaded them to prepare for the discussions at the Council via a seminar of senior officials with input from the research community. He was able to draw on European expertise, readily accessible through the International Metropolis network, to bring researchers from Europe and North America to work with European policymakers. The issues were new at the EU Council table in the early 2000s and there was a need to develop and inform the process of information exchange and consensus building among the senior national civil servants who participated in the decision-making process, together with the officials of the Commission and the Council Secretariat. The researchers concerned saw and seized an opportunity that had far-reaching impacts on the formulation of policy. ${ }^{14}$

\footnotetext{
${ }^{13} \mathrm{COM}(2003) 336$ final of 3 June 2003.

${ }^{14}$ The Athens Migration Policy Initiative (AMPI) started in 2002-2003 and continued providing support to a number of successive presidencies at a time when some significant landmarks were reached in the development of European policy. The method was the same - the organisation of informal workshops or seminars for senior civil servants to discuss the issues and possible options,
} 
However, the Thessaloniki Council did not attempt to develop a common definition of what integration might mean in the EU context since there was no legal basis (until the Lisbon Treaty in 2007) for doing so. In fact the Commission did not then, or now, feel that it would be helpful, given the very different situations in the member states concerning migration and integration, to propose a specific model for integration in Europe. However, it was felt that there was a need for a more detailed interpretation of what integration in the EU might mean. This was in a context where measures harmonising the conditions of residence of legal migrants were coming into force as part of EU Directives on the admission of different categories of immigrant, notably those coming in as family members ${ }^{15}$ and those qualifying after 5 years for long-term residence status. ${ }^{16}$ The coming into force in 2003 of EU employment and racial equality legislation ${ }^{17}$ was also having an impact, particularly noticeable since many member states had not previously had national legislation of this kind. Political attention was being drawn to the issues arising from the growing social diversity in many countries and this in turn influenced thinking about policy developments in the area of integration. There was a perceived need to clarify the principles and practice of integration and to provide a framework to assist member states developing policies at national level.

As a result in July 2004 at the beginning of its Presidency, the Dutch announced in the Council at a meeting of the SCIFA (Strategic Committee on Immigration, Frontiers and Asylum) their intention to develop common basic principles to form the basis of this framework. The Dutch Ministry of Justice immediately prepared a draft on which they consulted with MPI in Washington, with whom they were also working on the preparation of a seminar of senior officials in the member states and leading researchers to be held in Amsterdam in the autumn. In its turn, MPI used its AMPI network to mobilise European integration specialists, in particular researchers in The Netherlands, and involved them in the drafting of a series of statements which contained principles, guidelines and some priority topics which could form the basis of each member state's integration policy. As a result of these exchanges between researchers, MPI and Dutch Ministry officials, the principles were focused on key areas and common problems rather than on national practices. That made them in the end acceptable to all member states, the

based on papers prepared with the active assistance of researchers. This led to the development of a level of consensus which could be built into the preparation of the Council conclusions which announced the new policy including support for the preparation by the German Presidency of the Potsdam conference of integration ministers in 2007 which set the agenda for integration policy for the next few years.

${ }^{15}$ Council Directive 2003/86/EC of 22 September 2003 on the right to family reunification.

${ }^{16}$ Council Directive 2003/109/EC of 25 November 2003 concerning the status of third-country nationals who are long-term residents.

${ }^{17}$ Council Directive 2000/78/EC of 27 November 2000 establishing a general framework for equal treatment in employment and occupation and Council Directive 2000/43/EC of 29 June 2000 implementing the principle of equal treatment between persons irrespective of racial or ethnic origin. 
Netherlands included. The Dutch Ministry of Justice held a series of discussions on the draft document during the autumn with member states and the Commission, leading to the adoption of the Common Basic Principles (CBPs) by the JHA Council in November $2004 .{ }^{18}$ It is interesting to note, however, that the draft presented to the meeting of SCIFA in September 2004, largely put together by AMPI and Dutch researchers, did not change substantially from the version finally adopted by the Council.

While they had no binding legal status on the member states the CBPs have nevertheless made an important contribution to the thinking about national integration policies in a number of countries, notably in Spain and Ireland and some of the new member states. Implementation of the CBPs was promoted through the European Integration Fund and they remain a point of reference at EU level - an interesting example of how European policy can take a very different path from national policy.

\subsection{Conclusions}

What do these examples illustrate about the research-policy nexus in the context of the early development of common European immigration and integration policies?

Firstly, there was a very strong input of researchers to European policymaking. Since there was not at first great interest from other policy areas in the Commission nor from national governments, there was an opportunity in those early years of the new millennium for researchers not only to influence policy indirectly through their research publications, but also directly. This took place through contributions individuals made in seminars held by the Commission and other institutions to discuss ideas for policy options, but also by their impact on policymaking via their contributions to the preparation of documents such as the drafts of the Common Basic Principles. The research-policy nexus that developed at this period also had an impact on the development of this nexus at national level both in terms of procedures (relationships with the research community) their closer involvement in policymaking and with respect to content. This was particularly so since many countries, for example Sweden, Spain, Germany, Ireland, and the Netherlands, were either undertaking fundamental re-thinking of their integration policies or developing such policies for the first time.

The influence of (members of) the research community was in part the consequence of the vision of the Commissioner for Justice and Home Affairs, Antonio Vitorino, and of his officials, to fulfil the Tampere mandate by proposing for the long term a policy which was as objective as possible and based on the best practice and experience available in Europe. In doing so they were greatly helped by the fact that in such a new policy area they could mobilise and finance a variety of sources and

\footnotetext{
${ }^{18}$ Immigrant Integration Policy in the European Union, Annex to the JHA Council Conclusions of 19 November 2004.
} 
procedures as described above. The progressive development of relatively open new research opportunities under the Fifth, Sixth and Seventh Framework Programmes by DG Research, and the increase of more targeted research by DG JHA and DG Employment and Social Affairs, provided a wide range of possibilities for the research community to influence policymaking in these areas albeit less directly than in the early years this chapter has been discussing.

A further significant factor was that public opinion towards immigration, which always had and still has a major impact on politicians and policymakers in this area was, at that time, mainly neutral or even positive, reinforced by the new information available about the demographic changes taking place in Europe and a favourable economic situation. This is illustrated by the rewriting of the early version of the 2000 Communication to take a more positive view of migration as a factor in EU development. That early episode contrasts starkly with the subsequent period in which the making of European legislation on immigration and asylum became much more problematic in the difficult process of trying to reconcile very diverse national viewpoints in an environment that became ever more hostile to immigration. New proposals were invariably much watered down, after long months of negotiations in the Council decision-making process, and later also in the co-decision procedure with the European Parliament.

It is important to note that the nature of the research-policy nexus at European level was complex; a complexity that was not only due to the constantly changing political context but also to the fact that so many different interests (and interest groups) were involved in European policymaking. These included different interests in the Council (representing the member states) and the Commission on the one hand; within the Comitology structure of the EU itself, the advisory role of institutions such as the Committee of the Regions, the European Economic and Social Committee - which was particularly influential with respect to integration and the European Parliament, especially when reinforced through the co-decision procedure but at that time still in an advisory role. Within the EU, DG JHA played a leading role in consulting the research community. There were, however, numerous other external agents with specific interests such as employers' organisations and trade unions, human rights groups and migrants' rights NGOs, all of whom had access to Commission officials who welcomed their views. Many of these interest groups also mobilised research for their own purposes.

In the context of such complexity, the content and form of the information that was exchanged between policymakers and researchers was very varied. It was not only through publications, the traditional way in which research findings are made available to policymakers, that influence was exercised. Since 2002 there has been a gradual rise in the preparation of policy papers and policy briefs, short extracts and other documents drawing the attention of policymakers to research findings and to new ideas. The Commission itself developed procedures to plan and highlight results of research carried out under successive Research Framework Programmes as they increasingly included research in the field of immigration from FP5 onwards. Through these programmes, the Commission made a significant contribution to the development of a European research community by supporting comparative 
research and fostering the establishment of research networks such as the IMISCOE Network of Excellence (2004-2010). The Commission (DG JHA) also set up its own research facility to promote cooperation between member states (the European Migration Network), and, in consultation with the research community, started on the long road to improving the collection of basic and comparable statistics.

Finally, it can be seen from these examples that without compromising choice of subject or scientific rigour, the relationship between the research community and policymakers can work well when a fairly regular interaction develops between them on the basis of a common agenda. This requires on the part of the researchers a thorough understanding of the way in which decisions are being taken, and the time and form in which to present research results that are relevant, and usable. The Athens Migration Policy Initiative shows what can be achieved. The policymaking context at that time was particularly favourable but it is nevertheless quite remarkable how the research community in Europe was mobilised over a period of several years in the early 2000s to provide such a degree of input and influence to European migration and integration policy.

Open Access This chapter is distributed under the terms of the Creative Commons Attribution Noncommercial License, which permits any noncommercial use, distribution, and reproduction in any medium, provided the original author(s) and source are credited. 


\title{
Chapter 8 \\ Speaking Truth to Power? Why Civil Society, Beyond Academia, Remains Marginal in EU Migration Policy
}

\author{
Ann Singleton
}

The dynamics of the EU's academic-policy nexus and the EU's attempts to create a common migration policy are documented in the previous chapter and elsewhere in this book. This volume also demonstrates that the nexus is now the subject of a stream of academic writing, as are the outputs on the migration-security nexus (Walters 2010) and the migration-development nexus, in which migrants are increasingly being seen as Transnational Development Agents (Faist 2008). Migration research is something of an industry in its own right, in which examination of these connections illuminates understanding, yet still most non-academics and those in civil society without access to policy-makers remain excluded from the policy discussions. The EU's Global Approach to Migration and Mobility (GAMM) includes some aims to include migrants in a rights-based approach to policy-making (BanulescuBogdan 2011) however this is in a context in which the main EU policy objectives have already been set. (How this happened is described below in Sects. 8.3 and 8.4). The general absence of migrant voices and civil society from the researchpolicy nexus is the result of several factors which have positioned migrants as the object of study and recipients of policy measures. These factors include: the lack of transparency and accountability in EU migration policy-making; the focus of much migration research on policy concerns (currently integration and security); the use of research methodologies which investigate migration-related topics from theoretical and expert, academic positions; the exclusion of migrant voices from media coverage.

Many migrants are excluded from much of society, let alone the migration debates, by citizenship laws, poverty, gendered social and economic injustice and institutional racism. They are structurally excluded and their lives are hidden from the priorities and gaze of the academic-policy nexus (notwithstanding some

\footnotetext{
A. Singleton $(\varangle)$

School for Policy Studies, University of Bristol, Bristol, UK

e-mail: Ann.Singleton@bristol.ac.uk 
excellent qualitative research, social media and 'on the ground' campaigns). Those whose lives are directly affected by migration policy and practice, namely recent migrants, migrant groups, as well as the wider civil society, remain largely marginalised and their voices unheard in the policy discussions. It begs the question, what is academic research on migration for? In the meantime, the focus on integration and security policy appears to dominate the migration research industry. Those outside the nexus, had they the time or inclination to consider it, might wonder what it's all about.

The previous chapter outlines how academic research influenced and became part of the EU policy discussions, particularly regarding demographic change, employment and integration. This chapter argues that these discussions were framed by policy priorities and examines the reasons why there is little meaningful inclusion in policy debates of the views of recent migrants or wider civil society. ${ }^{1}$ It discusses the lack of transparency and accountability in EU and member states' decisionmaking processes and the generally negative media coverage, which informs public opinion and drives much of the content of public discussion.

In order to better inform policy discussions and public debate, it is also essential to understand why some 'truths' about migration become received wisdom and policy priorities, whilst other realities of the lives and deaths of migrants remain largely unheard or ignored. This also raises questions about how much influence it is possible for non-Brussels-based civil society to have on the production of knowledge in the academic and policy domains? It is argued here that the member states and the EU both constrain and enable research in this field.

\subsection{The Relationship Between Research and Policy? The EU, Academia and Civil Society}

Historically, research has been a driver of change in social policy fields, including public health and poverty (Dean 2012: 89). However, in certain fields, including migration, rather than policies being informed by evidence, research is usually commissioned to justify pre-ordained policy decisions: in other words, policy-based

\footnotetext{
${ }^{1}$ The terms 'migrant', 'academic' and 'policymaker' are not mutually exclusive at the individual level, but they describe groups with differing power and influence over migration policy. Recent migrants are those whose lives are most immediately shaped by the effects (intended or not) of the policies. This is being seen to have catastrophic effects for thousands of people who die every year attempting to enter the EU as a result of the prioritisation of border controls and immigration over just migration policies. Civil society is here taken to be organised or collective groups of individuals with common interests, other than state institutions and organisations, the executive (governments), the economy and economic actors. The 'academics' are taken to be those academics who are involved in dialogue with policymakers on migration.
} 
evidence making. Policymakers in the EU, as in many member states, often claim that policymaking is evidence-based. However the evidence that may inform migration policy is a product of a process of knowledge generation that is shaped by the policy priorities themselves. Many individual academics (including the author) and teams of researchers have advised officials and policymakers with various roles on different aspects of migration policy. A number of policy Directorates General (DGs Home, Justice, Employment and Social Affairs) have commissioned research and funded numerous projects on migration and integration, security and the labour market. The policy outcomes generally take little of this work into consideration and policy results 'are often poorly conceived, narrow and contradictory' (Castles 2004: 222). The research parameters in this process are set by officials and usually relate to specified policy objectives. Evidence that does not support policy aims tends not to be considered by the policymakers. Academics facing these constraints tread a delicate path in working on EU and government-funded research projects. At the same time, in the context of economic austerity, it is becoming more difficult to attract national Research Council funding, so funding from government departments and the European Union has become more attractive.

The Commission's Directorate General for Research has also funded, through a succession of Framework Programmes, a wide range of migration-related or -focused research projects (Singleton 2009). The work of these projects has covered several fields including labour market needs, the demographic challenges of Europe's ageing population, the experiences of undocumented migrants, the feminisation of migration, and integration. European Commission officials have often despaired of the lack of 'policy focus' in recommendations from these projects, whilst the migration policy agenda continues to be dominated by security concerns. The academic literature on policy-relevant research agendas has focused on the relationship between policy priorities and research agendas, whilst migrant organisations in civil society have been marginalised throughout the process. There are some good examples of academic research providing resources for wider civil society, for example the Migration Policy Index (MIPEX http://www.mipex.eu/) website, which makes publicly available good quality information on integration policies. This provides material for those engaging in the integration agenda. However, such good examples appear to address, or attempt to influence, mainly the policy parameters of the official work programmes, in this case the integration agenda, with research findings often reflecting the evidence to support or develop established priorities. In general, wider civil society is excluded from the agendasetting role allowed in some instances for academics. Despite strenuous efforts by a number of academics it seems that academic debates often ignore many of the realities of the lives of migrants. Civil society and NGOs are pulled into research projects and legitimate the process, providing empirical evidence, yet not being part of setting the research and policy agenda. A research agenda framed instead in terms of social justice and the social harm effects of policy might encompass a wider field and capture a fuller picture of the rich detail and realities on many migrants' lives. 


\subsection{The Media}

There is a complicated relationship both between the media and policymakers and between the media and the public. The media, another section of wider civil society, play a key role in shaping national public opinion on migration, through information, and misinformation, which is transmitted electronically and in hard copy. This information, including frequent misinterpretation of migration statistics, shapes public perceptions towards migrants and influences the tone and content of public debate. The media also influence government policy with anti-immigrant rhetoric, which in turn is framed by government policy priorities. Negative coverage creates a climate of hostility and fear experienced by those living in migrant communities and stokes a fear of immigration in the whole population across Europe (Canoy et al. 2006). This endangers the chance of rational discussion of what might constitute fair and effective migration policies. In fact, "In most immigration debates, fear resonates much more viscerally than hope" (Papademetriou and Heuser 2009: 4). The stigmatisation of migrants is usually accompanied by a rise in hate crime, whilst in the current economic crisis, migrantled NGOs find it increasingly difficult to obtain funding. Many studies have been carried out at national level into the media coverage on migration (Spigelman 2013; Migration Observatory 2013; Philo et al. 2013). In the UK, its role in transmitting information (and misinformation) on asylum and migration issues has been shown to be unremittingly negative (Philo et al. 2013). This can be seen in the vocabulary of news coverage across all newspapers in which the term 'illegal' is used in predominance to describe 'immigrants' and 'migrants' in general (Migration Observatory 2013).

Some positive stories about individual migrants are published, but reports generally do not include interviews with migrants. In the UK in early 2014, a survey by Migrant Voice of television and press coverage found that migrants were quoted in only $12 \%$ of stories (Migrant Voice 2014). This study found that when stories included interviews with migrants, this added credibility to the reports, however the coverage of migrant groups and communities was found to be generally negative. The picture at EU level reflects that which exists in the member states. As reports cover the crisis and humanitarian disaster of migrants dying in the Mediterranean, the policy framework is poorly explained, if at all. There is little well-informed EU public debate over the causes of the current crises and possible policy options. Those who are rescued from the sea have no say in the policies and practices being juggled between the EU, Frontex and the member states. In addition, most Brusselsbased journalists who have to cover the whole range of EU policies have little time to spend on investigative journalism. On EU migration issues, the media have a generally abysmal record of simply duplicating press releases from the Commission, instead of investigating stories and issues. On the occasions when they do follow up a migration-related story, they have to make a judgement about whether their national editors will give any priority to, or even print, a story on EU migration policy. 
There are some encouraging signs of a will to improve and rebalance the quality and tone of reporting on migration. Migrant Voice (2014) is encouraging journalists to meet a migrant and to reflect more accurately the complexities and realities of the lives of recent migrants. An initiative by the International Federation of Journalists in the form of The Ethical Journalism Initiative (http://ethicaljournalisminitiative. org/), and the global Ethical Journalism Network http://ethicaljournalismnetwork. org/, both offer some hope for improvements in the quality of reporting on migration. Accessing accurate information and being able to inform public debate responsibly remains problematic however, when even well-connected journalists are prevented from having access to the closed meetings of EU officials.

\subsection{Structural Barriers to the Inclusion of Civil Society and Recent Migrants in EU Justice and Home Affairs Policymaking}

The EU policymaking process may take into account evidence from some academic research, but it has not included wider civil society other than in 'consultation'. This section examines how EU policy on migration and asylum has been produced and why input from civil society and migrants has been minimal.

From 1976-1993, the Trevi era, EU cooperation on justice and home affairs issues was intergovernmental. The Maastricht Treaty in 1993 saw many changes that shaped the way in which migration policies would develop, with the setting up of the Justice and Home Affairs Council and the Tampere Summit in 1999.

Between 1976 and 2006, immigration and asylum policy was effectively decided by the Council of Ministers (by the JHA Council after 1993), with measures proposed by the Commission (often following 'informal' discussions about what was possible and desirable between officials in the two institutions). The European Parliament was 'consulted'. After 1993, national parliaments had little power (and rarely exercised that which they had) and civil society was too often a lonely and ignored voice seeking to protect the rights of migrants and refugees. The dangers of the lack of transparency and openness in this process and the implications for democratic decision-making have been well documented by Curtin and Meijers (1997) and Bunyan (2007).

The European Parliament's powers were limited throughout this early period to being consulted on immigration and asylum. Its views were routinely ignored. It was not until 2006 that the Parliament was given the power of co-decision with the Council - and the Council also introduced the practice of first reading trilogues. This is a negotiating process in which the Council and the Parliament discuss and agree a 'compromise' text - and still none of the documents under discussion are officially published, thus excluding civil society from making its views known.

This policy process has throughout been marked by an historical and ongoing reluctance of member states to surrender sovereignty over border controls, whilst 
they cooperate to establish ever tighter external border controls at the physical outer limits of the EU, beyond EU territory and internally. Consequently, the EU reflects and compounds the largely negative stance of the member states towards migration. In fact, much of EU migration policymaking could be described as 'reactive and piecemeal', as has been observed of Greek policymaking (Triandafyllidou 2009). The focus is on the control of immigration, particularly that defined as 'illegal' immigration, rather than on the development of a comprehensive common migration policy. As control of borders is prioritised, Frontex acts as coordinator of the member states' frontline in a war against 'illegal' migration. The consequences include the thousands of deaths each year of people who try to cross the Mediterranean.

\subsection{Why Is It Believed That Civil Society Plays a Role in the Policymaking Process?}

The notion that civil society takes part in the policymaking process is firmly rooted in the dominant academic theory of multi-level governance (MLG), which permeates the disciplines of international relations, European studies and political studies. For many this assumes that 'participation' and 'consultation', as defined by EU institutions, are meaningful in the policymaking process. This may be true to some extent in certain policy areas. However, the involvement of civil society in the migration policymaking process is limited to 'consultation' by the Commission, and only then after a proposal has been drafted (whereas consultation with the member states takes place before proposals are drafted). The Commission then presents its proposal to the Council of Ministers and the European Parliament (EP). Following this, the proposal will be considered in a Council Working Party, chaired by the Council Presidency, with advice from the General Secretariat (which can have a major influence on the content and direction of discussions). At this crucial stage the Council works out its 'position' and civil society has no input. This can take weeks and the documents are usually not made public. Once the 'position' is agreed it goes to COREPER (the Committee of Permanent Representatives of the member states) then to the JHA Council before opening 'trilogues' with the Parliament.

This might be an opportunity for civil society, including recent migrants, to have a say, however the discussions in the trilogues are only recorded by the Council and are not made public. When the Council and EP reach a 'compromise', the text is agreed and the Council Presidency sends a formal letter to the chair of the parliament's Civil Liberties (LIBE) Committee. The text, usually agreed at first reading, then cannot be amended by a 'dot or comma' by the European Parliament in committee or in the plenary. At this stage in the LIBE Committee, $84 \%$ of measures are decided in the first reading trilogues.

It is arguable that civil society has more chance of influencing the European Parliament than the Council or the Commission. However, for any such input to be meaningful, it would be necessary to know the content of the Council discussions and the discussions in the trilogues. 


\subsection{Transparency and Access to Documents}

EU and national officials and the governments of the member states have thus defined the parameters of migration policy and legislation and the terms of debate in this field. The biggest obstacle faced by civil society in attempting to influence migration and asylum policy has been to discover which measures are being proposed. During the years of inter-governmental cooperation, the only voices heard from outside the institutions were those of international organisations such as the UNHCR. As described above, during the inter-governmental phase of EU JHA policies, which established the framework and core basis of JHA common policies, decision-making and policy development took place in the EU institution's committees, principally in the Council of Ministers. This process was largely ignored by the media and did not come to general public attention, meaning that there was no general public discussion of the proposed measures. Many national parliaments remained ill-informed about proposals or had no opportunity to debate them.

Statewatch - an organisation that identified Justice and Home Affairs as a key defining policy area in the emergence of an EU state - has monitored EU activities and the consequences for civil liberties since 1992 (Statewatch 2012). For more than 20 years it has attempted, with some success, to gain access to the documents produced in this policymaking process and to make them publicly available. It has found that lack of transparency and access to documents has resulted in having to devote substantial resources to inform civil society about the development of Justice and Home Affairs policies, including those on migration and asylum. In the absence of 'an EU public access culture' (Bonner 2006: 149), this has been an uphill struggle. The story of this long and continuing attempt to open up information on EU policymaking has been documented elsewhere (Statewatch 2014). Backed by successful complaints from the European Ombudsman, Statewatch has persevered in applications for documents, finding that the path has been blocked by officialdom within the institutions. The EU has been critical of these attempts, claiming at times they are 'vexatious', that the Commission needs the 'space to think' outside public scrutiny and finally, in an Orwellian move, proposing changes to the definition of a 'document', so as to remove the right of access, effectively until measures have been adopted.

There is, in the absence of open access to policy documents, no trilogue or nexus of any meaning or accountability between academics, the rest of civil society and policymakers. When the voices of civil society groups are heard, it is merely through consultation processes, whilst the Commission is drafting the proposal. There is no requirement for policymakers to take any action in response to civil society, whereas there are increasing concerns about the EU's migration activities in general, in particular the externalisation of migration control beyond its geographical and legal borders (Migreurop 2012). Major issues, in addition to the unaccountability of Frontex, are the militarisation of migration control, EU detention camps in nonEU countries, inadequate scrutiny of the implementation of the Returns Program 
and privatisation of many of the activities carried out on behalf of member states, including the detention of children. Migreurop, a coalition of pro-migrant groups across Europe, reports regularly on the consequences of these activities. In addition to the thousands of people who have died trying to enter the EU, EU citizens have been traumatised by witnessing the consequences of Frontex activities in the Mediterranean. These witnesses remain scattered around the seaports of Europe's southern borders. However there is no indication that the member states intend to change current practice. Despite the efforts of Migreurop and others, the general public remains largely ignorant of the policies, the practices, or of their effects. Nothwithstanding the 'noise' around migration policy, those at the sharpest end of policy and practice in the member states are absent from the nexus debates. Asylum seekers in privatised detention centres are not able to meet policy makers or academics and in the UK have resorted to hunger strikes in 2015. In at least one case, in Ireland, politicians have been banned from entering asylum detention centres (The Journal.ie, 22.06.14).

\subsection{Conclusions}

There have been some moves to include civil society organisations in the migration policy field. The work of PICUM is a shining example as is that of the European Network of Migrant Women. The Network of European Foundations has funded the European Programme for Integration and Migration (EPIM). The Hungarian Presidency ran a conference in June 2011, which addressed good practices in reporting migration. Developments in research methodology and knowledge exchange offer new ways to include the voices and direct experiences of those experiencing the effects of policies. In the UK, the Joseph Rowntree Foundation has funded research on the role of NGOs in influencing policy. This research identified the potential of the 'Change from Experience' NGO partnership (Lukes et al. 2009), which employed a critical pedagogy approach to support the effective representation of migrants. The Poverty and Social Exclusion (PSE 2014) project offers a fine example in Northern Ireland of research collaboration between academics and people whose lives are the object of study. This pioneering 'on-the-ground' research has widened community engagement in the research process and collection of qualitative data. The investigation and presentation of research findings has been led by those living with social deprivation and poverty (Kent 2013). Using digital media, the research outputs include films produced by people, adults and children, speaking directly to policy-makers. This model offers an opportunity to include recent migrants in the research process, with the potential to produce and present findings in a form directly accessible to policy makers.

For civil society organisations participating in a liberal democracy, it is essential to have access to information about policy options and to participate in decisionmaking. The absence of this information in this central policy area both calls into question the nature of the EU and raises concerns about the democratic deficit. 
Transparency was presented as the EU's answer to the democratic deficit. The struggle of NGOs, notably Statewatch, for access to documents suggests however that the EU institutions have a long way to go before reaching the stated aim of transparency, let alone full participation of civil society in democratic decisionmaking on immigration policy.

The absence of full participation by civil society in EU policymaking is a matter of concern to all who wish to see evidence-based policymaking in a true sense, as well as democratic decision-making and scrutiny of policy implementation. It cannot be addressed happen without accountability of the EU institutions to the public, particularly those who are subject to the effects of its policies. Where the policies have an impact on non-EU citizens, on or off the territory of the EU, EU citizens must also accept them as legitimate. Without informed public debate on migration, this cannot happen. The EU's border agency, Frontex, epitomises the most negative of EU action on migration, which is least accountable to the citizens of the EU. The agency is characterised by a lack of transparency in its activities, which also reflect the primacy of security over observance of international obligations on the human rights of migrants and asylum seekers. The creation of a consultative committee has not led to independent oversight of Frontex activities.

In summary, there is inadequate scrutiny of the effects of policies or the experiences of migrants within and outside the EU. The media generally fail to investigate the full picture, including the impact of policies. Many or most experiences of migrants within detention and in transit remain hidden from the public. Academic and medical research on the health effects suffered by children and adults in detention has not resulted in the end of such detention.

There are chinks and contradictions in the overall picture. It is possible occasionally to advance and develop policy discussions beyond immediate policy objectives. Arguably, this has happened in relation to the understanding of gender and migration, undocumented migration and integration. Many officials of the EU institutions are well informed on the realities. However, no matter how high the quality of their discussions with academics, or how much innovative research methodologies can bring the voices of migrants to the debate, this better understanding of the issues is unlikely to have significant or measurable impact on the policy priorities of the member states and in the Council of Ministers.

Open Access This chapter is distributed under the terms of the Creative Commons Attribution Noncommercial License, which permits any noncommercial use, distribution, and reproduction in any medium, provided the original author(s) and source are credited.

\section{References}

Banulescu-Bogdan, N. (2011). The role of civil society in EU Migration Policy: Perspectives on the European Union's engagement in its neighbourhood. Migration Policy Institute. www. migrationpolicy.org/pubs/EUcivilsociety.pdf

Bonner, P. (2006). When EU civil society complains. In S. Smismans (Ed.), Civil society and legitimate European governance (pp. 141-168). Cheltenham: Edward Elgar. 
Bunyan, T. (2007). Secret trilogues and the democratic deficit. Statewatch Viewpoint. http://www. statewatch.org/analyses/no-64-secret-trilogues.pdf. Accessed 15 Nov 2013.

Canoy, C., Beutin, R., Horvath, A., Hubert, A., Lerais, F., Smith, F., \& Sochacki, M. (2006). Migration and public perception Bureau of European Policy Advisers (BEPA). European Commission (09.10).

Castles, S. (2004). Why migration policies fail. Ethnic and Racial Studies, 27(2), 205-227.

Curtin, D., \& Meijers, H. (1997). The principle of open government in Schengen and the European Union: Democratic retrogression? In H. Meijers (Ed.), Democracy, migrants and police in the European Union: The 1996 IGC and beyond (pp. 13-44). Utrecht: Forum.

Dean, M. (2012). Democracy under attack. How the media distort policy and politics. Bristol: Policy Press.

Faist, T. (2008). Migrants as transnational development agents: An inquiry into the newest round of the migration-development nexus. Population, Space and Place, 14, 21-42. doi:10.1002/ psp.471.

Kent, G. (2013). We are sitting with the big people now. Final report on the PSE's pilot community engagement project in Northern Ireland (March 2012-August 2013). http://www.poverty.ac.uk/

Lukes, S., Jones, V., \& San Juan, Y. (2009). The potential of Migrant and Refugee Community Organisations to influence policy. JRF.

Migrant Voice. (2014). Migrants invisible in UK media (16th June). http://migrantvoice.org/

Migration Observatory. (2013). Migration in the news: Portrayals of immigrants, migrants, asylum seekers and refugees in national British newspapers 2010-2012. www.migrationobservatory. ox.ac.uk/sites/files/migobs/Report\%20-\%20migration\%20in\%20the\%20news.pdf. Accessed 5 Dec 2013.

Migreurop. (2012). At the margins of Europe. The externalisation of migration controls. www.migreurop.org/IMG/pdf/Rapport_Migreurop_2011_Version_anglaise_27012012_ pour_derniere_relecture_et_validation_FASTI-SM.pdf. Accessed 13 June 2014.

Papademetriou, D. G., \& Heuser, A. (2009). Public opinion, media coverage, and migration: Developing strategies for immigration and integration reforms. Migration Policy Institute. http://www.migrationpolicy.org/research/public-opinion-media-coverage-and-migrationdeveloping-strategies-immigration-and

Philo, G., Briant, E., \& Donald, P. (2013). Bad news for refugees. London: Pluto Press.

PSE. (2014). PSE poverty and social exclusion website. Part of the poverty and social exclusion in the United Kingdom research project (ESRC reference RES-060-25-0052). www.poverty.ac.uk

Singleton, A. (2009). Moving Europe: EU research on migration and policy needs. European Commission, Luxembourg: Office for Official Publications of the European Communities.

Spigelman, A. (2013). The depiction of Polish migrants in the United Kingdom by the British press after Poland's accession to the European Union. International Journal of Sociology and Social Policy, 33(1/2), 98-113.

Statewatch. (2012). FOI in the EU. Freedom of information in the European Union. http://www. statewatch.org/foi/foi.htm. Accessed 15 Nov 2013.

Statewatch. (2014). Observatories on civil liberties, openness and secrecy in Europe. http://www. statewatch.org/observatories.htm

The Journal.ie (22.06.14). Politicians are not allowed to talk to people seeking asylum in Ireland. http://www.thejournal.ie/direct-provision-politicians-not-allowed-canvas-1463456-May2014/

Triandafyllidou, A. (2009). Greek immigration policy at the turn of the 21st century. Lack of political will or purposeful mismanagement? European Journal of Migration and Law, 11(2), 159-177.

Walters, W. (2010). Migration and security. In J. Peter Burgess (Ed.), The handbook of new security studies (pp. 217-228). London: Routledge. 


\section{Part II \\ Research-Policy Dialogues in the European Union and Seven of Its Member States}




\title{
Chapter 9 \\ Research-Policy Dialogues in Austria
}

\author{
Maren Borkert
}

\subsection{Introduction}

Despite Austria's long standing history as a multi-ethnic and pluri-religious country, Austrian policymakers and the public tend to experience migration and integration as a novel phenomenon. Discourse on the "integration' ${ }^{1}$ of migrants ranks high on the political agenda and is fiercely disputed in society, with a particular focus on perceptions of migrants as 'unintegrated'. Thus, to understand migrant integration in Austria, three contextual aspects appear to be crucial: first, there is a 'lack of integration' widely attributed to migrants and their offspring. About two thirds of Austrian citizens are dissatisfied with the integration of migrants who, in contrast, feel integrated in Austria and support 'Austrian' values and life style (Statistik Austria 2011). Second, attention is directed both in the public imagination and in political measures at migrants from Turkey and the former Yugoslavia, while the major immigrant group by far is constituted by Germans (Statistik Austria 2012). Third, one may observe a tendency in data collection to follow - and therefore reinforce - the dominant perception of migrant integration in Austria.

Indeed, the Austrian Statistical Yearbook on Migration and Integration, which measures integration achievements for several key indicators such as education and

\footnotetext{
${ }^{1}$ Both in science and public the term integration is widely used, yet it assumes very different and sometimes opposed meanings. In this article the term integration is used according to the national integration discourse in Austria. Yet one may observe that the use of the term integration in the Austrian integration debates corresponds to what some scientists may refer to as assimilation. The various meanings of integration and the usage of the concept in migration research are elaborated by Heckmann and Bosswick (2006).
}

M. Borkert ( $\triangle)$

Institute for International Development, University of Vienna, Vienna, Austria

e-mail: maren.borkert@univie.ac.at 
employment, differentiates between migrants from EU/EEA/CH, Turkey, former Yugoslavia and other countries, suggesting a high relevance of Turkish and ExYugoslavian migrants for Austrian integration (policies) ${ }^{2}$ (Statistik Austria \& Staatssekretariat für Integration 2012). This observation is even more relevant when one bears in mind that migrants are not identified by their present nationality but grouped into a political-geographical unit that ceased some 20 years ago.

Against this background, this chapter sets out to explore what role knowledge and science play in shaping dialogues on migrant integration in Austria. Additional light is shed on the question of how knowledge and particularly scientific knowledge impacts on decision-making and the evolution of policies aiming at integrating migrants in Austria, and if whether this leads to the 'objectification of the topic of integration' as formulated by the State Secretary for Integration as one of its mission goals. Empirical evidence is drawn from both quantitative and qualitative research methods including literature and document analysis, network and media analysis, and more than 30 qualitative interviews with experts.

\subsection{Challenges in Migrant Integration: A Historic Overview}

Historically, the development of Austrian migration policy is closely linked to broader societal and political transformations that marked the Habsburg Empire and its successor states. Five turning points can be identified which are related to historical events including the dissolution of the Austro-Hungarian monarchy; the Cold War and the division into Communist-ruled and Western states; the opening of Austrian migration policy in the 1960s due to post-WWII labour market needs, the collapse of the Soviet Union and the fall of the Iron Curtain between 1989 and 1993; and the silent Europeanisation of migration policymaking since 1997.

\subsubsection{Historical Legacies: The Habsburg Empire and the Fall of the Iron Curtain}

As a successor of the Habsburg monarchy, Austria has a long history of migration, including immigration, emigration and transit migration. The Habsburg monarchy did not possess a migration policy in the modern sense, but several mechanisms of controlling the movement of people within its territory. For instance, by documenting individual identity and regulating access to rights and related obligations. In this context the Heimatrecht, the right of residence which tied all individuals to

\footnotetext{
${ }^{2}$ Historical reasons may offer some explanation for the particular interest in the aforementioned migrant groups: the successor states of the former Yugoslavia are for example referred to as 'inner colonies' of the Habsburg Empire by post-colonial historians. See e.g. Komlosy (2005).
} 
their municipality of origin, played a pivotal rule in granting social rights to people (e.g. poor relief), but also in expelling and deporting individuals to their community of origin in case of delinquency or political activism (Burger and Wendelin 2002). The first modern migration policies were established with the foundation of the first Austrian republic in 1918 and the adoption of the so-called Protection of Native Workers Act in 1925. This act was based on the idea that labour markets had a limited intake capacity and thus needed to be regulated. It marked an important shift from local control of public welfare to labour market regulations as a state responsibility (Heiss 1995; Kraler 2011).

During the Cold War period Austria became one of the main receiving and transit countries for about two million refugees from 'communist' regimes. Alongside the reception of refugees, in the 1960s and 1970s Austria actively recruited large numbers of labour migrants to feed its post-war economic boom by forging bilateral agreements with southern and south eastern European (Bauer 2008; Currle 2004; Kraler 2011). The first temporary immigration agreement, subject to annual re-negotiation, granted access to 37,120 foreign workers in 1961 (Kraler 2011; Perchinig 2010). Interestingly, these agreements were negotiated by the so-called social partners, mainly the Chamber of Labour and the Trades Unions, the Chamber of Commerce and the Federation of Austrian Industries. These actors almost exclusively steered migration and integration policy at that time (Perchinig 2010).

Austria's need to regulate the entry and residence of migrants also triggered the first research on migration and integration at that time (Bauböck and Perchinig 2003; Perchinig 2005).

\subsubsection{The Politicisation of Migration and Integration}

In the 1980 s and 1990 s three major changes led to an increasing politicisation of migrant integration in Austria: first, the rise of new political actors with clear statements on migration; second, a massive increase in the numbers of immigrants, refugees and asylum seekers; and third, a growing awareness in both politics and society that the 'guest workers' were about to stay and establish families and communities. In the 1980 s the general perception of immigrants as 'guest workers' was more and more shaped by both a transformation of the existing political landscape and the institutional framework dealing with migration. Two new actors, i.e. the Green Party (Die Grünen) and the Freedom Party (Freiheitliche Partei Österreichs, FPÖ) gained political momentum. This not only changed the previous two-party system comprising the Social Democratic Party (SPÖ) and the People's Party (ÖVP), but also lifted the issue of migration up the political and public agenda (Kraler 2011; Perchinig 2005). Both the Green Party and the Freedom Party made migration a central issue of their politics - the first focusing on integration and equal rights and the latter claiming legal and social priority for Austrian citizens. Consequently, having been an issue that previously was decided by a small number of actors (i.e. the social partners) in informal, non-public settings, migration developed into a publicly contested domain. 
It was not before the 1990s, however, that the issue of migrant integration entered public and political debates. A first 'rational discourse' (Perchinig 2010) on migrant integration ended abruptly with the fall of the Iron Curtain and the subsequent major changes in the European political landscape at the beginning of the 1990s, when Austria was confronted with an unprecedented influx of refugees from Bosnia-Herzegovina. In reaction to this, the fear of mass immigration from Eastern European countries gained momentum and all parliamentary parties, except the Greens, called for strengthening immigration controls. In addition, a new social issue quickly gained political significance in the 1990s: the ageing of society. This issue further fuelled migration and integration debates but regarded migration not as a threat to social peace but as a potential instrument to control demographic developments. As leading demographers argued that controlled migration might contribute to a positive population outcome in Austria, this discussion eventually led to a quota-system of immigration, but without improving the legal status of migrants (Perchinig 2010).

As a result of the dramatic developments in the late 1980s and early 1990s, new actors and institutions emerged in the realm of migration and integration policy. The most important of these was the Ministry of Interior (MoI), which took over the responsibility for migration-related issues from the social partners, and the Ministry of Social Affairs in the late 1980s and early 1990s. By so doing it defined immigration as a matter of internal security (Sohler 1999). Nevertheless, Caspar Einem, then Minister of Interior, presented a bundle of migration law amendments under the name of the Integration Package (Integrationspaket) in 1995, marking the birth of Austrian migrant integration policy as a distinct policy concern (Kraler 2011).

\subsubsection{Integration Policymaking at the Crossroads}

In the following decade, scientification, ${ }^{3}$ politicisation and a silent Europeanisation of migrant integration policies seemed to go hand in hand. On the one hand, the formation of a coalition government between the conservative Austrian People's Party (ÖVP) and the right-wing Freedom Party (FPÖ) in 2000 introduced increas-

\footnotetext{
${ }^{3}$ The increased interference between science and politics and, more generally, the increasing importance of expert knowledge for practices of regulation and governance of societies, is considered a structural feature of the late nineteenth and twentieth century which transcends regions and political systems. Lutz Raphael (1996) referred to this process as the 'scientification of the social'. He pleaded not only for devoting more attention to this previously overlooked historical phenomenon, but also for sensitising social history to the historicity of the social science data material on which it is based. Already in 1983, however, Peter Weingart suggested that the then current legitimation crisis of science can be ascribed to two opposing processes, i.e. the scientification of societal institutions (in the sense of the dissolution of traditional action orientations) and the politicisation of science.
} 
ingly restrictive immigration policies and more and more symbolic measures on integration. For example, it introduced significant changes in the Aliens Act and the Asylum Law in 2002 aimed at reducing in-migration in general. This legislation also included a so-called integration agreement that obliged long-term migrants to sit language tests. Both measures proved largely ineffective as the main sources of immigration soon turned out to be other EU member states - with Germany being by far the most significant country of origin for labour migrants. Just 4 years after this revision a new Aliens Legislation Package entered into force in 2006, which again intensified restrictions for migration and increased the integration requirements on new migrants. The reform strengthened the link between citizenship and integration of migrants while simultaneously refusing naturalisation to most migrants by raising the requirements significantly. At this time political measures on migration and integration in Austria also became increasingly influenced by scientific discourses and spill-over effects linked to other countries' integration paradigms. One example of this is the distinction between high-qualified (good) and low-qualified (bad) migrants. Introduced in Austria by the emergent internationalisation and Europeanisation of science and politics, this scientific distinction had a pivotal influence on politics and public debate in Austria.

To conclude, on overview of the evolution of Austrian Integration Policy is provided in the Table 9.1 .

Table 9.1 The evolution of Austrian integration policy - at a glance

\begin{tabular}{|c|c|}
\hline & Development phases \\
\hline \multirow[t]{2}{*}{$1960-1990$} & The 'Guestworker'-Paradigm \\
\hline & $\begin{array}{l}\text { Social partners (Sozialpartnerschaft) regulate immigration through bilateral } \\
\text { recruitment agreements; due to the dominance of the rotation principle legal, } \\
\text { political and social aspects of integration are not considered }\end{array}$ \\
\hline \multirow[t]{2}{*}{ 1980/1990s } & Integration enters the political arena \\
\hline & $\begin{array}{l}\text { New political actors (Greens, FPÖ); fall of the Iron Curtain increases } \\
\text { immigration from Eastern Europe, particularly Bosnia Herzegovina; } \\
\text { 'Integration before new immigration' becomes guiding principle; Ministry of } \\
\text { Interior assumes central role }\end{array}$ \\
\hline \multirow[t]{2}{*}{$1995-1997$} & Milestones of Austrian integration policy \\
\hline & $\begin{array}{l}\text { The then liberal Minister of Interior, Caspar Einem, proposes amendments to the } \\
\text { Foreigners Law under the heading of 'integration package'. He experiences a } \\
\text { defeat. His successor Karl Schloegl is successful in enforcing a consolidation of } \\
\text { the right to stay (Aufenthaltsverfestigung). }\end{array}$ \\
\hline \multirow[t]{2}{*}{ Since 2000- } & 'A duty to integrate' (“Fordern statt Fördern') \\
\hline & $\begin{array}{l}1998 \text { - Citizenship Law Amendment }=\text { Proof of personal and professional } \\
\text { integration as well as language knowledge; } 2002 \text { - Integration agreement makes } \\
\text { language course compulsory; } 2006 \text { - citizenship test; } 2010 \text { - National Action } \\
\text { Plan for Integration; } 2011 \text {-Reform of language requirements, pre-entry courses } \\
\text { become compulsory }\end{array}$ \\
\hline
\end{tabular}

Source: Author's own elaboration 


\subsection{Dialogues on Migrant Integration: What Role for Science?}

While there are some isolated studies on the interrelation between migration researchers and Austrian politics and society, contemporary Austrian science studies are generally characterised by a focus on natural sciences, technology and innovation (Bogner and Menz 2010; Fassmann et al. 2009; Münz 2011; Perchinig 2005, 2010). According to Ulrike Felt (2000, 2001), interaction between science, politics and society in post-war Austria is generally shaped by the establishment of expert systems and advisory bodies, a multiplication of actors and topics in the public sphere, a mostly marginal position in Austrian decision-making for the public and an institutionalisation of science in politics. She argues that scientific bodies increasingly lack authority because they are no longer considered to be able to solve modern society's complex problems (Beck 1986; Felt 2001). Instead, hybrid spaces between science, politics and the public, and the 'proto-professionalisation' of other actors, have flourished (Felt 2001: 58). The question whether similar developments can be depicted for migration research will be discussed in the following sections.

\subsubsection{Knowledge Production on Migrant Integration: Research Landscape, Funding Structures, Paradigms}

In Austria, migration and integration hardly received scholarly attention until the late 1960s and early 1970s, when Austria attracted large numbers of guest workers (Perchinig 2005). This initial phase was primarily marked by individual researchers focusing on either particular movements of migrants or migrant groups, and on the issue of 'guest workers'. A first paradigm shift towards 'integration' took place in the 1980s, when the first representative census on migrants in Austria was published by the Institute of Advanced Studies (IHS) (Bauböck and Perchinig 2003).

The 1990s witnessed an expansion and disciplinary diversification of migration research, leading to an institutional fragmentation in Austria. In contrast to most European countries, migration research in Austria has continued to exist as a fragmented field with mostly small research groups and individual researchers. Even today, there is no research facility focused solely on migration research. Researchers are instead embedded in institutions focusing on broader issues and often represent a minority in their institution (Fassmann et al. 2009: 13). Aside from academic institutions there are also a number of NGOs involved in conducting or documenting research on migrant integration (policies) such as the anti-racism NGO ZARA (Zivilcourage und Anti-Rassismus-Arbeit) or the Austrian Asylum Coordination (Asylkoordination Österreich 2012; ZARA 2012). The Poverty Conference also maintains a database for (partly unpublished) scientific studies on a variety of subjects. In contrast to scientific knowledge, civil society groups, in particular NGOs, are perceived as political actors and 'knowledge translators'. Even though there are tight connections between science and the NGO sphere (i.e. NGOs having 
scientists as staff members), the knowledge produced by NGOs is largely not considered a neutral source of knowledge but rather politically influenced. The diffusion of science into society has been pushed further by the MoI, which has established its own research facilities by recruiting graduates from various academic fields and by offering further training to its staff, particularly so in the Austrian Integration Fund that is part of the ministry.

The institutional and disciplinary disconnection of migrant integration research in Austria has led to mutual scepticism among scholars about the theoretical or methodological quality of rival research (Bauböck and Perchinig 2003). More importantly, however, the lack of proper institutionalisation of research has made this subject area a lot more dependent on third-party funding than others (Fassmann et al. 2009: 13). While several experts agreed that migration and integration research has gained relevance in the past decade, this has not led to more cooperation among researchers or better funding opportunities (Fassmann et al. 2009; Bauböck and Perchinig 2003; Stacher et al. 1997). Even though the disciplinary and institutional diversity opens up the field to a variety of potential financing institutions, Fassmann shows that the Austrian Science Fund (FWF), the Austrian National Bank (OeNB) and Austrian Ministries such as the MoI and the Ministry of Science and Research clearly constitute the most common sources of funding (Fassmann et al. 2009: 14). Consequently, researchers are constrained by a high degree of dependency on financial resources provided by political actors involved in migration policymaking (Perchinig 2010; Fassmann et al. 2009; Bauböck and Perchinig 2003).

These institutional and funding conditions have obviously had a major effect on the issues that have been researched. Due to institutional fragmentation there is a large diversity of topics and approaches pursued. A historical overview, though, reveals some general paradigm shifts over the past decades. As outlined above, migration research in Austria developed with a strong focus on the paradigm of guest workers (Bauböck and Perchinig 2003). Changes in Austria's political system in the late 1980s and the epochal geo-political transformation in Europe in the 1990s acted as major driving forces of change in migration policy and research (Bauböck and Perchinig 2003; Schock and Schimany 2010). The fall of the Iron Curtain and the subsequent influx of refugees from Bosnia-Herzegovina initiated a paradigm shift towards 'integration' both in the research landscape and in publicpolitical debates. Integration at that time however was framed as assimilation and soon political debates and initiatives arose promoting a rejection of refugees and a strong legal divide between foreigners and nationals. Since the turn of the new millennium Austrian migrant research has focused on integration more generally as a process of adaptation to the 'receiving society'. In this vein, research has been concerned with: a general monitoring of integration and perceived 'deficits'; assessment of integration of particular migrant groups or in specific geographical areas; citizenship, diversity and equality; as well as issues of forced and arranged marriage or 'intercultural tracking' (Fassmann et al. 2009). Despite these shifts in Austrian integration research, the economic paradigm of (preferably high skilled) labour migration has remained pivotal for both public interventions and scientific research. 


\subsubsection{Dialogue Structures: From Informal Circle to Institutionalisation}

While Austria's first decades of migration policies were characterised by a closed circle of labour market actors regulating migration, the topics of migration and integration became publicly contested and politicised in the public domain with major shifts in the political landscape in Austria in the 1980s and 1990s. As a result not only new discourses and issue domains emerged but also new actors and institutions entered the migration and integration policy scene. As interviewed experts argue, the emergence in particular of the $\mathrm{MoI}$ as the central authority on migration and integration had a significant effect on the subsequent development of science-society dialogues. Similarly, the upsurge of human rights groups at that time also opened up new political spaces for participation and paved the way for public dialogue. Even though public debates remained heavily influenced by right-wing populism and scapegoating, the increased interest in the topic also led to its steady scientification.

In the new millennium this new openness experienced both setbacks and successes. In the early 2000s the new ÖVP-FPÖ government stopped regular consultations between NGOs on the one hand and governmental actors such as the Chancellery, the MoI, and the Ministry of Social Affairs on the other (König and Perchinig 2005: 19-23). By contrast, under the grand coalition of Social Democrats and the ÖVP since 2007, roundtable meetings were initiated to integrate NGOs, scientists and other stakeholders in decision-making over a new integration policy. In this context two new bodies were also created to support policymakers in dealing with migrant integration: the Advisory Committee on Integration (Integrationsbeirat) ${ }^{4}$ and the Expert Council on Integration (Expertenrat für Integration $)^{5}$ (Kraler 2011). These two bodies, together with more general panels of science and policy exchange in Austria such as Forum Hirschwang or European Forum Alpbach, the expert committee of the Austrian Poverty Conference ${ }^{6}$ and the Commission for Migration and Integration Research (at the Austrian Academy of Science), constitute the major science-society dialogue structures presently dealing with migrant integration in Austria.

\footnotetext{
${ }^{4}$ The Advisory Committee on Integration involves representatives from several federal ministries (e.g. Ministry of Interior; Ministry of Labour, Social Affairs and Consumer Protection; Ministry of Science and Research), all federal state governments, the Austrian Association of Towns, the Austrian Association of Municipalities, the Austrian Chamber of Labour, the Austrian Chamber of Agriculture, the Austrian Chamber of Commerce, the Federation of Austrian Industries and the largest relief organisations in Austria (Caritas, Diakonie, Hilfswerk, Red Cross and Volkshilfe).

${ }^{5}$ The Expert Council on Integration involves established experts in the field of migration and integration from the sciences like Heinz Fassmann, Ruth Wodak, Gudrun Biffl and Rainer Münz, and less well known journalists like Hans Winkler or businessmen like Thomas Oliva from the Austrian Association of Branded Goods Industry.

${ }^{6}$ The Poverty Conference involved most civil society actors in this field (such as SOS Mitmensch and ZARA, besides the largest relief organisations).
} 


\subsubsection{Knowledge Utilisation: What Knowledge for Society?}

By critically analysing specific patterns or types of knowledge utilisation, this chapter will draw upon the three ideal-types of knowledge utilisation in sciencesociety interaction developed by Christina Boswell (2009) (see also Chap. 2): instrumental knowledge use (to rationally adjust policy instruments), legitimising knowledge use (to bolster an actor's political role or authority), and substantiating knowledge use (to justify decisions and orientations). In addition, a fourth type will be used to distinguish between knowledge utilisation (as an active way of appropriating knowledge for action) and knowledge consumption as a more passive attitude, which implies acquisition of knowledge, but no direct subsequent use. The latter shall be named knowledge shelving or knowledge storing. Knowledge shelving or storing occurs when funding institutions receive scientific input by means of research reports but do not process the knowledge contained therein. ${ }^{7}$

In Austria, the main knowledge users are public administration (such as ministries) and NGOs. What is common to all of them is that they put a focus on a knowledge transfer or dialogue between science and politics. Only the Advisory Committee on Integration explicitly involves non-scientific actors.

Even though some NGOs and coalition organisations conduct research or documentation projects on migrant integration (e.g. ZARA or the Austrian Asylum Coordination), their knowledge is neither key for nor systematically incorporated into institutionalised decision-making processes. This does not mean, of course, that they are exempted from Austrian integration dialogues: all NGOs are allowed to submit statements on draft regulations to the federal ministries, and a few are involved in the Advisory Committee on Integration, established by the MoI. But the large number of involved parties in the Advisory Committee (30 institutions) and the dominance of political and administrative institutions among them (threequarters of the parties involved) move the NGOs into a comparatively marginalised position. Even though they are not officially regarded as 'experts', NGOs may get heard by politics and science through informal networks, joint projects with scientific institutions and/or political institutions as well as shadow reports for international organisations. According to interviewed experts, personal networks had been a vital platform for exchange among NGOs and scientific institutions in the past. The utilisation of scientific knowledge, in turn, appears to be desired and facilitated by the official dialogue structures (Advisory Committee and Expert Council on Integration). The ways by which political institutions 'receive' this knowledge, however, suggests an ambivalent relationship to scientific knowledge. Equally the establishment of in-house research facilities, such as the Austrian Integration Fund, may be interpreted in this way. Furthermore, most researchers complain that research data is misused and misinterpreted by political institutions

\footnotetext{
${ }^{7}$ Possible reasons for knowledge shelving are e.g. an incapacity to translate scientific findings into policy relevant paradigms (missing connection), bad timing in terms of political opportunity, and work overload among public servants.
} 
and research results are seen as instruments to enhance the legitimacy of political programmes. One may thus observe that scientific knowledge on migrant integration in Austria evolved to have a substantiating and, particularly, legitimising function for politics and policy. Even if the MoI assembled different kinds of knowledge (scientific and practical experience) in its major dialogue forums, it is nonetheless the case that key NGOs were excluded and their expert status was denied, indicating mistrust towards outside scientific knowledge. At the same time, the participation was permitted of several 'experts' who were not well known or highly reputed in the field. These latter points all suggest that knowledge has a rather legitimising function for integration policymaking in Austria. Both scientific findings and NGO statements do not seem to be taken into account in a comprehensive manner. All interviewed experts, in fact, agree that 'expertise' is used according to political rules not to scientific considerations. To become heard by public authorities, migrant integration scholars or activists either try to trigger widespread public attention or use personal networks and demonstrate willingness to cooperate with the public bodies dealing with a specific issue area. Besides this substantiating and particularly legitimising function, interviewed experts also mentioned knowledge shelving as a standard procedure in Austrian integration politics when dealing with scientific findings and studies whose results seem not to suit or, on the contrary, stand in opposition to current political interests.

Generally, science serves as a reliable source of legitimacy for policymakers and political camps in migrant integration policies in Austria as it enjoys a high reputation in the public and is regarded as 'neutral' and 'objective'. Especially quantitative analyses and opinion polls from established universities, research institutes or international organisations are cited regularly. As one respondent confirmed, both political actors and NGOs tend to utilise this particular kind of knowledge for two reasons. On the one hand, established and renowned institutions lend legitimacy to knowledge users. On the other hand, studies that provide 'facts' and 'numbers' are (seemingly) easy to interpret and to communicate to a wider public. Aside from the utilisation of 'expert knowledge' by the MoI and other ministries, consulted experts also mentioned knowledge utilisation in applied projects with NGOs where the knowledge created in the project is directly utilised by the participating NGOs and associated organisations. Nevertheless, networks seem to have a great importance in Austrian science-society dialogues, as different forms of knowledge (scientific and practitioner knowledge) seem to flow through personal networks more than through institutionalised dialogue structures.

\subsection{Key Topics in Science-Society Dialogues}

In order to identify and critically analyse this flow of information and knowledge between science, politics and the wider public in Austria, the following chapter will provide an in-depth analysis of key topics in migrant integration, namely the naturalisation of newcomers, the reception of migrant children in education and the accommodation of religious pluralism. 


\subsubsection{Naturalisation of Newcomers: Towards an Institutionalised Monologue?}

As confirmed both by the interviews and the network analysis conducted for this study, the Austrian MoI and related institutions ${ }^{8}$ are central and dominant actors in naturalisation policy - particularly, when it comes to decision-making processes. Interviewees attributed its powerful position to its legal competence, its responsibility for social security, its capacity to establish (and impose) dialogue structures, as well as its influence over domestic media. In contrast, scientists and civil society organisation play a marginal role in naturalisation policy in Austria: according to interviewed experts, domestic scientific research on naturalisation is largely absent. Similarly, NGOs are seen to carry out meaningful activities in the area of naturalisation, but play a very limited role in decision-making processes. NGOs are instead regarded as periphery actors. Their involvement in the drafting of laws is limited to giving comments to an already amended draft law and their statements are usually not taken into consideration.

In terms of formal dialogues structures in the area of naturalisation interviewees referred to the Expert Council on Integration and Advisory Committee on the one side $^{9}$ as well as expert appraisals (Begutachtungsverfahren) and statements submitted by non-governmental actors on draft legislation (Stellungsnahmen) on the other side. However, as our research revealed, dialogues on naturalisation in Austria tend to be held within the MoI rather than with other actors, be they scientists, civil society organisations or the wider public. It is, therefore, not surprising that informal relationships in the area of naturalisation are considered important: according to network analysis, formal contacts and cooperation among actors accounts only for $30 \%$ (compared to $81 \%$ of interactions in religion and $60 \%$ in education), while $50 \%$ of interactions amongst actors in this area are informal contacts. One can thus conclude that the area of naturalisation shows the lowest level of institutionalisation among the topics investigated.

These dialogue structures have a direct impact both on knowledge production and utilisation. While scientists report having very limited formal communication with governmental actors on naturalisation, they are in frequent contact with other scientists through various university research platforms and department structures. The overall need for knowledge and information is however striking. The dominant paradigm in Austrian naturalisation policies holds that citizenship is a valuable good which is only given to those who 'deserve' it. In this vein, only those who are well integrated deserve citizenship and therefore citizenship is not regarded as an integration instrument but as its end-point. This idea of citizenship was

\footnotetext{
${ }^{8}$ This includes also the State Secretary for Integration established in 2011 by the Ministry of Interior and located within its structure.

${ }^{9}$ Even if citizenship is not mentioned in the National Action Plan for Integration (NAPI), interviewed experts stated that the topic was discussed to some extent within the mentioned structures.
} 
widely supported by most of the actors in politics - except for the Green Party. Therefore, recent restrictions of integration and citizenship law went through without major opposition. Furthermore, in the absence of knowledge produced by academics, the MoI assumes a pivotal role in producing key knowledge, for example by commissioning studies on naturalisation, which further support this dominant paradigm.

With regard to the utilisation of scientific knowledge on naturalisation, experts stated that there was no or minimal use. According to them there is little need to legitimise naturalisation policy, because the idea of citizenship as the end-point of integration and a 'rare good to treasure' was and is widely supported. Furthermore, it is a widely held belief that more votes are gained by making citizenship regulations stricter than by fostering images of 'well integrated migrants'.

Interviewed experts widely agreed that what scientists offer, is basically ignored by both legislative and executive actors. According to them, most members of parliament do not even know the basic fact that $36 \%$ of the citizens naturalised each year are actually born in Austria. Instead they would believe that those are all 'complete strangers' that had no relation with Austria but want to become Austrians. The same image is said to prevail among the public or worse used by the xenophobic party. Experts also stated that all 'facts' used in current naturalisation debate in Austria seem to support the Austrian national mode of integration, while alternative knowledge claims are largely missing. The informal nature of contacts between science and politics as stated above might partly explain why scientific knowledge in naturalisation is not influential in policymaking.

\subsubsection{Reception Policies for Migrant Children in Primary and Secondary Education: The Role of Boundary Actors in Facilitating Dialogue}

In the area of education the two ministries perceived as having influence over integration dialogues are the Ministries of Education $(\mathrm{MoE})^{10}$ and Interior $(\mathrm{MoI})$. The latter was seen as influential, but less dominant than in naturalisation and religion. ${ }^{11}$ As in the area of naturalisation, scientists are in frequent contact with other scientists through various research platforms and university structures. They have, however, very limited formal communication with government actors as the network analysis shows. Nevertheless, universities together with the teachers'

\footnotetext{
${ }^{10}$ While the Ministry of Interior was named 59 times in total, the Ministry of Education was next with eleven references. Besides being a relevant actor in education (eight times), it was also named in the area of religious accommodation (three times). Interestingly, the Ministry of Finance was also named as a relevant actor in education (four times), but not in naturalisation or Islam.

${ }^{11}$ While the MoI was cited 46 times by all nine interviewees as a central actor in citizenship, it was mentioned ten times by six interviewees on religion and three times by three interviewees on education.
} 
college (pädagogische Hochschule) were regarded as having an important though indirect impact on integration policies for children with a migration background. As interviewed experts stated, their role lies first and foremost in educating teachers and making use of scientific knowledge in training teachers to be qualified as practitioners of school integration. Moreover, most scientists concerned with reception policies for migrant children in Austrian education maintain informal contacts with the Ministry of Education. According to network analysis, the main rationales for interaction between the two are organising joint projects (29\%), information sharing (23\%) and seeking advice for practical problems (19\%). The central position of the $\mathrm{MoE}$ as an (informal) interlocutor for integration actors can also be linked to the active role of boundary actors such as Rüdiger Teutsch and Elfie Fleck at the ministry and Barbara Herzog-Punzenberger at the Federal Institute for Education, Science and Culture (BIFIE).

As with citizenship, civil society organisations were regarded as having an important but limited role to play in the area of school integration. According to interviewed experts, this is because they need to work through schools to be effective and they need higher authoritative power to actually instigate change. Though NGOs implement many good projects in the area of school integration, they are seen to have very little decision-making power or influence in politics.

Contrary to the field of naturalisation, knowledge production on school integration shows one major conflict point. This conflict regarded the topic of monoversus multi-lingual school education, and centred on the question whether schools should provide equal conditions for all or ensure equal opportunities among migrant children in school. The current Austrian system is predominantly run under the mono-lingual 'submersive' model except for some minority schools. It is perceived as being supported by the education institutions themselves, the State Secretary for Integration, some political parties, and also the teachers' union. The alternative system of promoting multilingual education to ensure equal opportunities is unanimously supported by international and Austrian scientists as well as relevant members in the Mol's Expert Council.

What is the role of science, one might ask, in providing evidence and knowledge on this point of conflict? To answer this question, a closer look at a special fund set up by the MoE providing up to 2 years of extra German language support for children whose first language is not German is instructive. While language support runs for 2 years, it is widely recognised amongst linguists that it takes 4-6 years for genuine language training to be effective. As to the question why this knowledge is ignored one interviewee declared that it was the Ministry of Finance (despite its lack of expertise on the issue) which decided that 2 years would be sufficient.

Interestingly, in the area of school integration in Austria, European and international studies seem to play a major role. Several scientists from German universities were cited as providing scientific knowledge on the issue of integration in schools. The importance of international discourse was also confirmed with regard to the PISA study. Although PISA seemed to have primarily influenced policy changes related to strengthening pre-school education in Austria, it has certainly encouraged more discussion in Austria on issues of equal opportunity at school - a topic that 
was previously predominantly international. The impact of these debates on national policymaking is, however, perceived as rather weak.

As one of the most relevant events in terms of knowledge utilisation, ${ }^{12}$ interviewed experts referred to a meeting by the Expert Council for Integration to discuss the issue of equal opportunity in the Austrian education system. As the interviewees stated, all participants including the Council members acknowledged the importance of multilingualism and stressed the necessity to promote it. Only one week later, however, Austria's State Secretary for Integration publicly suggested creating extra support classes for children whose first language is not German. Even if his idea was criticised by the Green Party as a 'Ghetto-class', it spread rapidly, illustrating how professional expertise might be counteracted by political interventions. Asked why scientific knowledge on multilingualism is not put into practice, interviewed experts explained that the existing monolingual school system in Austria is not willing to accommodate change. Equally politicians, education councils and the teachers' union would be reluctant to implement such change. One interviewee also identified political inertia as the main reason, meaning that Austrian parties (with the exception of the Green Party) are seen as reluctant to even discuss integration politics in the context of schooling, because it is hard to change an established institution. Other interviewees referred to practical problems: in particular the implementation of mother-tongue or multilingual class is deemed difficult, because it cannot be offered to all languages, especially less common ones. Overall, the introduction of a multilingual school system in Austria is deemed unlikely by interviewed experts. Instead, the common paradigm on school integration is, as one interviewee puts it, to invest everything in 'German, German, and again German'.

\subsubsection{Accommodation of New Religious Pluriformity: Highly Institutionalised Dialogues}

Based on recommendations from the Expert Council on Integration, in 2012 the MoI set up the Islam Dialogue Forum bringing together governmental actors, civil society and faith-based organisations as well as scientists. As it meets on a monthly basis, the Islam Forum is seen as a frequent and regular formal structure for exchange. Unlike the Expert Council, the choice for personnel in specific topicareas is deemed transparent and the members of the Forum and its working groups are highly regarded in terms of their scientific expertise. The Forum's aim is to foster 'feedback loop' mechanisms between scientists and politics.

\footnotetext{
${ }^{12}$ In the area of education various types of knowledge, i.e. theoretical, practice-based and statistical knowledge, are used by a variety of actors. In content, this knowledge concerns disciplinerelated knowledge on, for instance, how to teach German as a second language. Discipline-related knowledge is certainly widely used and put into practice in the Austria school system. In contrast, scientific knowledge with regards to the integration of children with a migration background, which will be discussed in this chapter, shows distinct patterns of knowledge use.
} 
Despite its expertise, concerns have been raised, though, with regard to the involvement of the MoI: interviewed experts felt that hosting both the State Secretary for Integration and the Islam Dialogue Forum within the MoI structure is inappropriate. Some suggested that the Ministry of Education and Culture would be a more appropriate host as a coordinator of integration issues as they have competence in education and cultural matters. Experts stated that integration entails much wider social aspects than security, which is of primary interest to the MoI, and that it is dangerous and inappropriate for the MoI to handle integration. Particularly with regard to Islam, experts expressed their fears that the current arrangement stigmatises migrants if all aspects of migration and integration are dealt with by the MoI.

Furthermore, the Forum is regarded as an 'elite-based closed circle' based on personal contacts and not an open dialogue forum. Invitations to participate in the Forum are decided by the MoI or the State Secretary for Integration. Due to the prominence of the Islam Forum most contacts and cooperation among actors in this field are formalised $(81 \%)$. While some respondents emphasise engaging in a mixture of formal and informal contacts (19\%), none of the interviewees mentioned informal contacts as the only mode of engagement. Interestingly, funding relationships between actors in religion play a very limited role: only $19 \%$ of the interaction in religion is based on financial aspects - in comparison to $37 \%$ and $47 \%$ in education and naturalisation, respectively.

Similarly to naturalisation and education, scholars working in the field of religious diversity are in frequent contact with other scholars through various research platforms and university structures. However, they are seen as having very limited formal communication with government actors - except through the Islam Dialogue Forum.

In addition to governmental and scientific actors, faith-based NGOs are identified as relevant actors. Furthermore, this is the only area in which interviewees suggested that NGOs play a central role. Above all, the Islamic Faith Community of Austria (IGGiÖ) is seen as a crucial actor, having established good networks with relevant ministries and dialogue with the government. Nevertheless, there is controversy over the fact that IGGiÖ was appointed as the official dialogue partner for the Islam Forum, because it does not represent all Muslim communities in Austria. The establishment of the Islam Dialogue Forum and the positioning of the IGGiÖ as central dialogue partner for the MoI has, in fact, led to a major shift in the researchpolicy dialogue concerning Islam in Austria. This included both a change of actors and a change of dialogue structures: according to interviewed experts, it was previously the Islam Federation in Austria which was consulted on accommodation issues and met with respective government actors twice a year and more frequently before elections. The Federation has, however, been pushed out from the centre to the periphery of dialogues because of the appointment of the IGGiÖ as the official dialogue partner in the Forum Islam. Furthermore, various forms of informal dialogue were mentioned as being undermined. The most frequently mentioned informal structures were dialogue forums between Islamic associations and other religions, especially Christian and Jewish. These dialogue structures included, for 
instance, the annual Vienna International Christian-Islamic Summer University in which scientists and experts from various disciplinary backgrounds come together. Others have historical roots, such as the communications between Islam and the protestant churches, since they share the same legacy of being a minority religion in Austria.

With regard to knowledge production, the most frequently brought-up point of conflict was the issue of religion, especially Islam, which some see as a problem rather than an opportunity for society. Unlike the US, there is hardly any discourse in Austria on the potential opportunities which migration and religious pluralism can bring to society. Overall, religion is seen and treated as a societal problem to be 'mastered'. When it comes to knowledge production in the area of Islam, the Austrian media play a prominent role in fuelling the dominant view that Islam is a problem rather than an opportunity. The most frequently brought up issue by interviewees was the prejudice in the media towards Muslims and Islam as a religion, also described as 'Islamophobia' (although some preferred not to use this word and instead called it 'racism'). Experts referred to the media being responsible for disseminating prejudice among the general public, or aligning with groups of people hostile to Islam. According to them, the media discourse is dominated by a monolithic and homogeneous image of Islam evoking 'oppressed women' or 'violent tribes' and full of comments of hatred towards Muslims in online newspapers.

Furthermore, many of the interviewed experts see Austrian politics as being no different to the media in how it treats Islam. By contrast, scientific discourses are centred on issues with regard to the legal rights of Orthodox Christians and Muslims, as well as the relation between religion, state and society. These discourses are embedded in the MoI's preferred structure for dialogue, namely the Islam Dialogue Forum.

On knowledge utilisation the majority of interviewed experts stated that scientific knowledge on accommodating Islam in Austria is mostly used according to current needs and convenience. A major concern of experts was that mediagenerated knowledge is not differentiated with - and sometimes even taken more seriously than - scientifically produced knowledge. Generally, the media pick the scientists who suit their needs, and well-researched pieces of journalism are rare.

Such interest-driven utilisation is also attributed to political and scientific actors. Actors from politics (not only restricted to the right-wing parties) would rely on whichever scientist is available and some scientists would try to deliver what politicians want to hear because they need access and connections to them. Interviewees also referred to 'pseudo scientists' being invited to seminars organised by the FPÖ politician Elisabeth Sabaditsch-Wolff, which would result in FPÖ slogans against Muslim migrants. The much-debated study by Mathias Rohe on the 'unwillingness of Muslim migrants to integrate' was cited as an example of scientific knowledge falsely communicated by the MoI.

Evidence suggests that German science-society dialogues are a relevant point of reference also in the field of accommodating Islam. Interviewed experts stated that the establishment of the Islam Forum was inspired by the German Islam Conference 
(Islamkonferenz) with one difference: while the German Islam Conference is viewed as being open to a variety of actors including controversial scholars, Austria has adapted its structure by appointing IGGiÖ as the only official dialogue partner and by making the Forum more controlled and closed by carefully selecting its members.

\subsection{Conclusions}

When it comes to integrating migrants in Austria, knowledge, and particularly scientific knowledge, plays a central role in related discourses and dialogues. Scientific knowledge claims have a high reputation in society and are perceived by most parties as a source of neutrality and objectivity. Practical everyday knowledge from civil society organisations active in the field of migrant integration is, however, not deemed relevant. In fact, there seems to be a division between scientific and non-scientific bodies and the 'knowledge' or 'expertise' they are able to provide. As interviewed experts explained, there is a great difference between 'scientific knowledge' and the knowledge provided by NGOs. Given that NGOs always argue from a certain political position and mostly focus on the practical application of theoretical knowledge, their 'knowledge' or 'expertise' is perceived as less neutral. Instead of being producers of knowledge, NGOs are instead seen as 'translating' scientific knowledge for other societal spheres, utilising it to develop campaigns and legitimising their political positions. Hence, there is a certain division of labour between scientists as primary 'knowledge producers', NGOs as primary 'knowledge translators' and political decision makers as primary 'knowledge users'. In reality, however, the clear-cut division between knowledge providers and users is blurred by several overlaps: non-scientific bodies such as NGOs and state ministries have recently assumed and incorporated scientific personnel within their structure, and often individuals are engaged in several activities. The status of an 'expert', however, is not automatically granted to any scientist. Instead, most interviewees point out that being considered as an 'expert' by political decision makers is very much dependent upon informal and personal networks, political patronage and employment at one of the well-known and respected Austrian research institutions.

Dialogues on migrant integration in Austria can be hence characterised as follows: first, the MoI assumes a central and dominant position in all three topic areas as well as the migrant integration debate in general. Second, science-society dialogues unfold as an exchange between science on the one side and politics on the other, while civil society organisations and the broader public are not seen as an equal dialogue partner. Both the media analysis, interviews and network analysis are illustrative in this regard. Third, there are great differences between the national level and the municipal level (e.g. City of Vienna) as regards how dialogues on migrant integration are structured and what the leading paradigms are, even if the actors and experts involved partly overlap. While the national agenda on migrant integration is 
marked by a narrow understanding of integration, dominated by the MoI, the City of Vienna is seen as a focal point for issues related to education, multilingualism and diversity. Fourth, most interaction is happening between similar kinds of actors, i.e. scientists most frequently interact with university actors, NGOs with NGOs and governmental actors with other governmental and semi-governmental actors. The exceptions to this are few in number, and pertain to the interaction between scientists and 'minor' NGOs. However, all types of actors, i.e. scientists, NGOs and governmental actors, are in contact with the social partners, confirming both the de-facto centrality and continuity of the social partners as an influential group of actors in integration policymaking. Topics discussed with the social partners are mainly concentrated on labour market integration and labour rights, but they are also involved in other political issues such as mosque constructions and religious teachers' education. Unlike the (primarily self-referential) government and nonprofit organisations, the social partners are in contact with a diverse range of actors.

These dialogues structures have a huge impact on the question of how knowledge is produced, consumed and utilised. As the MoI promoted the recent institutionalisation process, dialogue structures are certainly marked by this government department. In the area of naturalisation, as could be shown, the dominance of the MoI is such that it successfully claimed knowledge authority and established itself as a knowledge producer. When confronted with Austria's low score on naturalisation policy in the MIPEX survey, the MoI not only ignored the scientific critique but re-interpreted it successfully as a vindication of its restrictive policy model. Only in the area of school education, in which the Ministry of Education has competence, does some sort of national dialogue exist. One may thus conclude that the MoI seems to promote the institutionalisation of dialogue structures between science and politics as a means to consolidate and reinforce its primacy in Austrian migrant integration policies.

Overall, three different types of knowledge use in the area of migrant integration could be identified in Austrian integration policymaking: legitimising use (to bolster an actor's political role or authority), substantiating use (to justify decisions and orientations) and knowledge shelving, i.e. when the results of government-funded research are consumed and archived and, eventually, used for decision-making at a later stage. Indications of legitimising knowledge use were most often referred to by interviewees in the field of naturalisation, but ranked high in general. However, the MoI itself stated that it does not have an in-house competence in all issues related to integration and therefore has established the Expert Council to increase its 'authenticity'. Interviewed experts instead see the set-up of the Expert Council as a justification strategy used by other ministers to gain competence in an area of responsibility.

While most interviewees referred to a legitimising use of scientific and expert knowledge, differences between the three topic areas could be identified: in naturalisation, where continued national research is absent and the MoI established itself as a knowledge producer, little need is felt by policymakers for scientific knowledge. The area of education, in contrast, is marked by the active role of boundary actors 
(especially from the MoE) facilitating dialogue and requesting applied science with regard to teaching German as second language. While the benefits of intercultural education or plurilingualism in school are widely recognised by scientists, NGOs and policymakers alike, the current Austrian system is predominantly run under the mono-lingual school model. In the field of religious pluriformity - a topic discussed in terms of the accommodation of Islam in Austria - scientific knowledge is mostly used according to current needs and convenience. Interviewed experts interpreted the set-up of the Islam Dialogue Forum, established in 2011 by the MoI, in the same vein. Furthermore, the majority of the interviewed experts were concerned that media-generated knowledge is not differentiated with - and sometimes even taken more seriously than - scientifically produced knowledge. Generally, media actors pick the scientists that suit their needs, and well-researched pieces of journalism are rare. Similarly, political and scientific actors use scientific knowledge for their own political and personal ambitions.

Also, the institutionalisation of migration and integration policies in the MoI turned out to play an important role in perceiving and defining migration and integration as a security problem for both the state and society. For police forces and legal advisors, it is part of their job to produce security knowledge. They have a professional disposition to frame political concerns in securitised terms, and to propose security measures to deal with such concerns. As a consequence, they encounter immigrants, asylum seekers and refugees as a security problem, which is fundamentally different from a policy that concentrates, for example, on human rights issues in asylum matters or emphasises labour law aspects of international mobility (Huysmans 2000: 756). In this sense, one can theorise that scientific knowledge is utilised by the MoI when it relates with and is 'translated' into the dominant security paradigm. As interviews with experts suggested scientists are widely aware of this fact. This could be shown particularly for the topic of accommodating Islam.

With regard to the role of the print media in migrant integration policies in Austria this study analysed media coverage and articles in the analysed topic areas (naturalisation, education and religion) from the late 1990s until 2012, focusing on claims articulated around scientific studies. This analysis showed that the media focus on political lines of argument rather than discussing the validity/plausibility of scientific findings. Representatives of NGOs play a very marginal role in all media debates. Some important differences among the three topic areas have emerged though. Media analysis seems to suggest that the socio-economic dimension (education) and the cultural dimension (religion) of integration are given much more prominence in the media than the legal-political dimension (naturalisation). Overall, naturalisation appears as a 'non-issue' in the media. Media coverage is mostly limited to reports on rising or falling numbers of people naturalising in a given year. Even though the media emerged as the second most important integration actor after the MoI by interviewed experts, it was not possible to establish a causal relation between the degree and kind of media attention and knowledge utilisation by governmental actors. 
In Austria the direct relation between the politicisation of migrant integration and the spread of related research and recurrence on scientific findings in national debates seems particularly strong. In this regard, the ÖVP is perceived as a key player in defining (and also fuelling) integration paradigms. The influence of the ÖVP in the MoI's policymaking on migrant integration was mentioned several times by interviewed experts. The influence of the ÖVP is seen to be rooted in its 'nationwide hegemony' as a majority catch-all party especially in conservative areas. The SPÖ as a coalition partner is seen as having abandoned the integration debate related to citizenship (except for Vienna) for fear of losing voters either to the left or to the right. Interestingly, the influence of right-wing parties such as the FPÖ is considered weak compared to that of the ÖVP (dominating the MoI) by interviewed experts. Experts referred to the Green Party as continuously vocal in its opposition to the dominant integration paradigm but stated that its influence is not big enough due to its rather small support base, especially outside the cities. Overall, however, the $\mathrm{MoI}$ is perceived as the main actor in introducing gradually restrictive measures for acquiring long-term resident permits and citizenship.

As the study revealed, the national context of migrant integration and the pursuit of a national integration mode based on history and tradition is particularly strong in Austria. The role of the EU is deemed 'not influential enough' by interviewed experts, especially in the field of naturalisation. Five regional and international studies (INTEC, MIPEX, NATAC, OECD and EUDO Citizenship) were mentioned by interviewed experts, but all in the context of not playing a major role or influencing Austria's naturalisation policymaking. In the area of education, the situation is rather different. Here, the PISA study was the predominantly cited international study in the field of school integration. The majority of the interviewed experts, in fact, agreed that the PISA study had the greatest impact on school education policy compared to other international comparative studies on children's school performance.

When it comes to accommodating Islam in Austria, the influence of Germany seems to be particularly strong in the MoI, including the formation of the Islam Dialogue Forum. As the interviewed experts suggested, the establishment of the Forum seemed to be influenced by the Islam Conference (Islamkonferenz) in Germany, with one major difference: while the German Islam Conference is viewed as being open to a variety of actors including controversial scholars, Austria has adapted its structure by appointing IGGiÖ as the only official dialogue partner and by making the Forum more controlled and closed by carefully selecting its members. As interview partners declared, Austria tends to wait until discussions take place in Germany before embarking on the topic itself.

Open Access This chapter is distributed under the terms of the Creative Commons Attribution Noncommercial License, which permits any noncommercial use, distribution, and reproduction in any medium, provided the original author(s) and source are credited. 


\section{References}

Asylkoordination Österreich. (2012). Selbstverständnis (mission statement). http://www.asyl.at/ about/mission.htm. Last access 4 Jan 2012.

Austria, S. (Ed.). (2011). Statistisches Jahrbuch für Migration und Integration: Zahlen, Daten, Indikatoren 2011. Wien: Kommission für Migrations- und Integrationsforschung der Österreichischen Akademie der Wissenschaften.

Bauböck, R., \& Perchinig, B. (2003). Migrations- und Integrationsforschung in Österreich Ansätze, Schnittstellen, Kooperationen: Ergebnisse des Workshops der Arbeitsgruppe EMIS vom 4. und 5. Juli 2003, Kommission für Migrations- und Integrationsforschung Working Paper $1 / 2004$.

Bauer, W. (2008). Zuwanderung nach Österreich, Österreichische Gesellschaft für Politikberatung und Politikentwicklung - ÖGPP. http://www.politikberatung.or.at/typo3/fileadmin/02_Studien/ 8_Migration/zuwanderungnachoesterreich.pdf. Last access 7 Feb 2012.

Beck, U. (1986). Risikogesellschaft. Auf dem Weg in eine andere Moderne. Frankfurt am Main: Suhrkamp.

Bogner, A., \& Menz, W. (2010). How politics deals with expert dissent: The case of ethics councils. Science Technology Human Values, 35(6), 888-914.

Boswell, C. (2009). The political uses of expert knowledge. Immigration policy and social research. Cambridge: Cambridge University Press.

Burger, H., \& Wendelin, H. (2002). Staatsbürgerschaft und Vertreibung. Vertreibung, Rückkehr und Staatsbürgerschaft: Die Praxis der Vollziehung der Staatsbürgerschaftsrechts an den österreichischen Juden, report to the Historikerkommission, Vienna. Available at: http:// www.historikerkommission.gv.at/pdf_hk/WENSTAATSBUERGERSCHAFT.pdf. Last access 15 Oct 2013.

Currle, E. (2004). Migration in Europa. Daten und Hintergründe. Stuttgart: Lucius \& Lucius.

Fassmann, H., Sievers, W., Buchl, W., \& Kraus, V. (2009). Migrations- und Integrationsforschung in Österreich: Institutionelle Verankerungen, Fragestellungen und Finanzierungen, KMIWorking Paper Nr. 15, Kommission für Migrations- und Integrationsforschung, Vienna: Verlag der Österreichische Akademie der Wissenschaften.

Felt, U. (2000). 'Die "unsichtbaren” Sozialwissenschaften: Zur Problematik der Positionierung sozialwissenschaftlichen Wissens im Öffentlichen Raum', Österreichische Zeitschrift für Soziologie (Special Issue 5 'Soziologische und historische Analysen der Sozialwissenschaften'), pp. 177-212.

Felt, U. (2001). Zur Begegnung von Wissenschaft und Öffentlichkeit im städtischen Raum: Rückund Ausblick auf die Wissenschaftsstadt Wien. In B. Görg (Ed.), Innovation \& Verantwortung: Werte, Wege und Aufgaben für das 21. Jahrhundert (pp. 55-75). Vienna: Holzhausen.

Heckmann, F., \& Bosswick, W. (2006). Integration of migrants: Contribution of local and regional authorities. Dublin: European Foundation for the Improvement of Living and Working Conditions.

Heiss, G. (1995). Ausländer, Flüchtlinge, Bolschewiken: Aufenthalt und Asyl 1918-1933. In G. Heiss \& O. Rathkolb (Eds.), Asylland wider Willen: Flüchtlinge in Österreich im europäischen Kontext seit 1914 (pp. 86-108). Vienna: Dachs Verlag.

Huysmans, J. (2000). The European Union and the securitisation of migration. Journal of Common Market Studies, 38(5), 751-777.

Komlosy, A. (2005). Innere Peripherien als Ersatz für Kolonien? Zentrenbildung und Peripherisierung in der Habsburgermonarchie. In E. Hárs et al. (Eds.), Zentren und Peripherien in der k.u.k. Monarchie. Tübingen/Basel: Francke.

König, K., \& Perchinig, B. (2005). Austria. In J. Niessen, Y. Schibel, \& C. Thompson (Eds.), Current immigration debates in Europe: A publication of the European migration dialogue. Brussels: Migration Policy Group. 
Kraler, A. (2011). The case of Austria. In G. Zincone, R. Penninx, \& M. Borkert (Eds.), Migration policymaking in Europe. The dynamics of actors and contexts in past and present (pp. 21-59). Amsterdam: Amsterdam University Press.

Münz, R. (2011). Lohnt sich wissenschaftliche Begleitung von Migrationspolitik? In T. Köhler \& C. Mertens (Eds.), Jahrbuch für politische Beratung 2010/2011: Eine klassische Alternative (pp. 223-240). Wien/Köln/Weimar: Böhlau Verlag.

Perchinig, B. (2005). Migration studies in Austria - Research at the Margins, KMI Working Paper 4/2005, Kommission für Migrations- und Integrationsforschung, Vienna: Verlag der Österreichische Akademie der Wissenschaften.

Perchinig, B. (2010). Migration studies in Austria - Research at the margins. In D. Thränhardt \& M. Bommes (Eds.), National paradigms of migration research (pp. 187-204). Göttingen: V\&R Unipress.

Raphael, L. (1996). Die Verwissenschaftlichung des Sozialen als methodische und konzeptionelle Herausforderung für eine Sozialgeschichte des 20. Jahrhunderts. Geschichte und Gesellschaft, 22(2), 165-193.

Schock, H., \& Schimany, P. (2010). Migrations- und Integrationsforschung im Spiegel von Datenbanken. Folgerungen für die österreichische Forschung, Österreichische Akademie der Wissenschaften. http://www.oeaw.ac.at/kmi/Bilder/Jahrestagung/Schimany_Schock_Paper. pdf. Last access 15 Oct 2013.

Sohler, K. (1999). Zur Neuformulierung der Politik der inneren Sicherheit im Kontext der Immigrationskontrolle in Österreich 1989-1999. Diploma thesis, Vienna University.

Stacher, I., Demel, K., \& Dostal, E. (1997). Machbarkeitsstudie für ein österreichisches Forum für Migrationsstudien und Entwurf für die Organisation eines Forums für Migrationsstudien. Vienna: Schlussbericht.

Statistik Austria. (2012). Bevölkerung zu Jahresbeginn seit 2002 nach zusammengefasster Staatsangehörigkeit - Österreich. http://www.statistik.at/web_de/statistiken/bevoelkerung/ bevoelkerungsstruktur/bevoelkerung_nach_staatsangehoerigkeit_geburtsland/index.html. Last access 27 June 2013.

Statistik Austria \& Staatssekretariat für Integration (Hrsg.). (2012). Statistisches Jahrbuch für Migration und Integration: Zahlen, Daten, Indikatoren 2012. Wien: Kommission für Migrations- und Integrationsforschung der Österreichischen Akademie der Wissenschaften.

ZARA - Zivilcourage und Anti-Rassismus-Arbeit. (2012). Projekte. http://www.zara.or.at/index. php/projekte. Last access 4 Jan 2012. 


\title{
Chapter 10 \\ Research-Policy Dialogues in Italy
}

\author{
Tiziana Caponio
}

\subsection{Introduction}

Italy is usually characterised by political scientists as a country with a high degree of penetration of party politics over public administration and civil society, where experts are considered either marginal or controversial figures. Especially when involved in policymaking, experts are regarded as being linked to a political party, and claims of impartiality are met with suspicion. This seems to be particularly the case for the social sciences: in a recent reconstruction of the history of the Italian Council for the Social Sciences, founded in 1973 by a group of prestigious scholars including the political philosopher Norberto Bobbio, the organisation is described as an 'anomaly for the time... as it was independent, not linked to any political party or cultural clan' (Silj 2006, p. 8).

With regard to the immigration field, existing studies on policymaking assign either marginal or variable relevance to expert knowledge. In a recent history of Italian immigration policies (Einaudi 2007), the role of academic experts emerges as marginal compared to the centrality of political actors, in particular the Ministers responsible for immigration issues and the parties' political leaders. However, according to another reconstruction carried out by Zincone (2011), centre-left governments have shown a greater inclination to rely upon independent experts and top-level civil servants than centre-right politicians, who show a greater trust in internal party staff. A party's political ideology, in particular the left-wing proimmigrant and right-wing anti-immigrant positions, seems to have some influence on processes of institutionalisation and deinstitutionalisation in research-policy dialogues.

\footnotetext{
T. Caponio $(\triangle)$

Department of Cultures, Politics and Societies, University of Turin, and Collegio Carlo Alberto, Torino, Italy

e-mail: tiziana.caponio@unito.it
} 
This chapter intends to develop further these insights through a systematic analysis of knowledge production, policy-research dialogue structures, and the uses of knowledge in the migrant integration policy field. The next section is devoted to an illustration of the main developments around the framing of migrant integration in Italy since the first inflows of foreign workers. In the third section I reconstruct the intertwining of knowledge production (Favell 2003; Penninx 2005), dialogue structures (Bommes and Morawska 2005; Geddes 2005), and uses of knowledge (Boswell 2009) in order to identify some characteristic features of science-society dialogues on migrant integration in Italy. The fourth section is devoted to an in-depth analysis of science-society dialogues on three specific issues, i.e., naturalisation, the reception of migrant children in schools, and accommodation of new religious pluralism. In the conclusion I draw some reflections on research-policy dialogues on migrant integration in Italy and advance some considerations of the relevance of this case study for the advancement of our knowledge on science-society dialogues more generally.

Similarly to the other country studies presented in this book, empirical evidence is drawn from literature review, document analysis, analysis of newspapers articles and 27 semi-structured interviews with academic experts (11), experts affiliated with independent research institutes (4) and boundary organisations (3), and policymakers, both politicians (5) and civil servants (5).

\subsection{Immigrant Integration: Key Issues}

Immigration was first acknowledged as a relevant phenomenon in Italy at the end of the 1980s, even though initial flows from former colonies in the Horn of Africa (Eritrea, Ethiopia, and Somalia) had already started in the mid-1960s (Einaudi 2007; Colombo and Sciortino 2004). Table 10.1 provides an overview of the main phases of development of migrant integration issues and related policies.

The first phase is characterised by a complete neglect of the migration issue in the public debate. The first arrivals of migrant workers were dealt with by administrative bureaucracies within the Interior and Labour Ministries, behind closed doors and in a highly discretionary way (Einaudi 2007). Immigration only entered the political

Table 10.1 Periodisation of Italian migrant integration policies

\begin{tabular}{l|l}
\hline Period & Description of period \\
\hline $1965-1986$ & Early phase: migration flows developing spontaneously, no public debate \\
\hline $1986-1996$ & $\begin{array}{l}\text { Functionalist approach: migrants as 'useful workers'; emerging } \\
\text { migration-security link }\end{array}$ \\
\hline $1996-2002$ & Integration enters the policy agenda: the 'reasonable integration' model \\
\hline $2002-2006$ & Regionalised - and fragmented - integration policies \\
\hline $2006-2012$ & Culturalist approach \\
\hline
\end{tabular}

Source: Authors' own elaboration 
agenda in 1986 when the first immigration law was approved. In terms of framing the migrant integration issue, this first law conveyed the idea of immigrants as a temporary presence, strictly functional to labour market needs (Caponio and Zincone 2011). No financial resources were provided to the regions in order to promote the integration programmes that the law requested them to undertake. Integration also remained a neglected issue in the second immigration law approved in 1990: It was de facto delegated to the good will of local administrations, proimmigrant NGOs and Catholic associations.

The early 1990s were also marked by the emergence on the political scene of a new, explicitly anti-immigrant party, the Lega Nord, which proved successful in focusing attention on the 'dark side' of migration, i.e., undocumented entries, immigrant criminal organisations, and so on. A focus on events such as the mass arrival of undocumented Albanians on the Apulian coast contributed to the perception of Italy as being invaded by chaotic and uncontrolled migration flows, and to the consolidation of an immigration-security discourse in Italian politics.

As indicated in Table 10.1, migrant integration only entered the political agenda in 1996, with the first centre-left Prodi government, and on the initiative of the then Minister of Social Affairs Livia Turco. In this period, public attention was monopolised by continuous new arrivals of Albanians due to the so-called 'financial pyramids' crisis, later followed by Kosovars escaping war in the Balkans (Colombo and Sciortino 2004), leading to a high politicisation of issues of borders control and immigration regulation. Vis-à-vis these emergencies integration remained a neglected issue in public debate. However, in 1998 law no. 40, also known as the Turco-Napolitano law after the then Ministers of Social Affairs and Interior, addressed the issue explicitly for the first time by introducing the so-called 'reasonable integration model.' This initiative intended to pursue two goals: nationals' and immigrants' physical and psychological well-being on the one hand, and positive interaction between different groups on the other (Zincone 2011). A number of policy measures aimed at fostering individual equality and at promoting intercultural relations were devised in all the crucial spheres of immigrant incorporation. Furthermore, in order to make the 'reasonable integration' model work, a National Fund for Immigrant Policy was introduced and allocated to the regions on the basis of programmes to be agreed upon with the municipalities.

However, with the approval in 2000 of the federalist reform which assigned to the regions complete autonomy on matters of social policy, migrant integration policies entered a new phase. Since 2003 the regions have received from the central government a share of the National Social Fund (Fondo sociale nazionale) and are held responsible for its allocation. This institutional reform, combined with the considerable cuts to the NSF taking place since 2005, led most regions to considerably reduce immigrant integration programmes if not simply to cancel them altogether (Campomori and Caponio 2013). The burden was shifted to cities, with the emergence of an extremely fragmented scenario, leading to a de facto erosion of the reasonable integration model.

Parallel to this decentralisation of migrant integration policy, at the national level the early 2000s were marked for the first time by a sudden politicisation of the 
integration issue, taking place in the context of a debate on Italian identity and against multiculturalism triggered by the reactions to 9/11 and terrorist events in Europe. In this politicised climate, the centre-left majority elected in May 2006 proposed a new culturalist approach to migrant integration, as highlighted by the drafting of the Charter of the Values of Citizenship and Integration promoted by the then Minister of the Interior Giuliano Amato. The Charter was initially presented as a reaction to a controversial initiative of the Union of Islamic Communities in Italy (UCOII) to publish an advertisement in the main Italian newspapers comparing Israeli repression in the Palestinian territories to the Nazi Holocaust. However, the Minister enlarged its scope by affirming that it had to be endorsed by individuals applying for Italian nationality more generally. ${ }^{1}$ Integration was presented as a process requiring migrants to 'show a good command of the Italian language, know the essential elements of Italian history and culture and share the principles regulating the Italian society.' (Carta dei valori della cittadinanza e dell'integrazione - principle no. 5).

This culturalist shift was at the very core of Law no. 94, known as the 'Security Package' (Pacchetto sicurezza) and approved by the fourth Berlusconi government in July 2009. Integration was defined as a 'process aiming at promoting cohabitation between Italian and foreign citizens on the basis of respect for the Italian Constitution, with a mutual engagement to participate in the economic, social and cultural life of the society' (art. 4-bis). The so-called 'Integration Agreement' was also introduced, requiring signature by first-time applicants for the residence permit. The Integration Agreement requires immigrants to fulfil specific integration conditions within 2 years in order to have their residence permit renewed, with a particular emphasis on the mastery of the Italian language and on the knowledge of the country's history, institutions, and civic culture.

This cultural definition of integration was further emphasised in the document 'Integration and security programme. Identity and encounter' (Piano integrazione nella sicurezza. Identità e incontro), approved by the government in June 2010, where a so-called 'Open identity' model of integration (Modello dell'identità aperta) was proposed. This model favoured the 'pursuit of a real encounter implying an understanding and respect for who we are, reciprocated by a natural curiosity towards others' cultures and traditions' (p. 5). The respect of 'who we are,' that is of 'our cultural identity,' defined as 'an original combination of Jewish-Christian and Roman-Greek cultures' (p. 4), is regarded as an essential pre-condition in order to start a path towards integration based on 'rights and obligations, responsibilities and opportunities' (p. 4).

However, the Integration Agreement was implemented only in March 2012, i.e., more than 2 years after it was introduced, and it has not challenged regional autonomy on matters of migrant integration. In fact, integration policy in Italy

\footnotetext{
${ }^{1}$ See: «La Carta dei valori non è solo per l'Islam» ['The Charter is not just for Islam'], Corriere della Sera, 10 April 2006, V. Piccolillo.
} 
today takes place in a complex multi-level governance setting (Hepburn and ZapataBarrero 2014), characterised by a high level of inconsistency between national, regional, and local definitions of integration.

\subsection{Research-Policy Dialogues: A State of the Art}

To understand science-society dialogues on migration in Italy a premise has to be made. Compared to other countries (for instance the Netherlands: See Scholten 2011), research on migration in Italy has not developed so much in response to policymaking but rather stems from pro-immigrant activism. In fact, the first research studies on the topic were undertaken at the end of the 1980s not by academics or by governmental research institutions but by NGOs traditionally involved in offering support to Italian emigrants and/or linked to trade unions or the labour movement more generally. This overlap between activism and research explains the difficult relations between experts and policymakers, with the latter often reluctant to cede decision-making power on such a 'hot' electoral issue.

However, research-policy dialogues on migration in Italy have developed and changed over time, and some technocratic experiments have also been promoted, especially by centre-left governments in the 1990s. In what follows, we will firstly analyse the development of the research infrastructure on migrant integration, i.e., knowledge production, before turning to focus on dialogue structures and use of knowledge in this policy field.

The early research on migrant integration in Italy was inspired by two main schools of thought: the Catholic one, adopting a 'social problems' approach (i.e., focused on the description of immigrants' living conditions and everyday problems of integration); and the macro-structuralist and critical one, looking at immigration as a product of the structural contradictions of capitalism (Rella and Vadalà 1984). The first perspective proved to be prolific and influential in subsequent decades. The NGO Caritas is a case in point: having been particularly active in the past in providing assistance to overseas emigrants and in compiling reports on Italian communities in the world (Pugliese 2002), in 1991 it started to produce a yearbook on immigration in Italy (Dossier Immigrazione), which is still published today. A similar background in Catholicism and approach to social problems also characterises the Institute for the Study of Multi-ethnicity (Ismu), founded in Milan in 1991, which can be considered the first Italian research centre specialising in immigration.

At the beginning of the 1990s academics also started to get more interested in the phenomenon, firstly demographers, followed by sociologists, political scientists, and legal experts. In this context, a third, more policy-oriented school of thought emerged, composed of scholars with a strong orientation towards political reformism who took theoretical inspiration from the experiences of other European countries. As we shall see below, this group of experts has been particularly 
engaged in pursuing a dialogue with policymakers and, together with the Catholic school of thought, has taken part in the various commissions on migrant integration established at the national level.

In the last decade, the research infrastructure on immigration in Italy has further diversified, with the scientific production becoming more academic and, thanks to a new generation of scholars, internationally oriented (Caponio 2010). This diversification and fragmentation of knowledge production does not seem to be directly related to the politicisation of the migrant integration issue, but is rather a product of the internal dynamics of the research infrastructure on this topic. This is still marked today by a strong separation between academic research, supposedly 'neutral' or at least with a primary scientific orientation, and socially involved research, more oriented towards pro-immigrant activism. Furthermore, academic research is also fragmented internally along disciplinary lines and methodological approaches. Most independent research centres explicitly seeking to influence policymaking - such as Ismu and FIERI, Forum internazionale ed europeo di ricerche sull'immigrazione - characterise themselves as interdisciplinary. ${ }^{2}$

In terms of dialogue structures (Bommes and Morawska 2005; Geddes 2005), different periods can be identified: firstly enlightenment-like forms of dialogue operated in the early 1990s (1990-1992), followed by technocratic (1993-2001) and engineering phases more recently (2002-2009). As for the early 1990s, a first window of opportunity for research-policy dialogues on migration came with the explosion of the first crisis over immigration (but not integration, see above), leading to a mobilisation in favour of immigrants' rights on the part of trade unions and Catholic NGOs. In June 1990 and March 1991 two conferences were promoted by the then Minister of Justice, the Socialist Claudio Martelli, gathering together experts in different migrant integration policy subfields (children's education, labour market, health care, housing, etc.), from both academia and pro-immigrant organisations (Presidenza del Consiglio dei Ministri and OCDE 1991; CENSIS and CNEL 1991). In the second conference European scholars were also invited and the concept of a national integration model entered the debate, putting on the agenda the necessity of devising consistent Italian integration policies.

The two conferences can be regarded as attempts to establish an enlightenment boundary configuration between policymaking and expert knowledge, with policymakers inviting prestigious experts (either for their academic position or for their experience in the field) to deliver the technical knowledge and the analytical tools needed to develop rational and evidence-based policies. To this end, a preparatory study was also commissioned by the government from Poleis (Centro di politica comparata - Centre for Comparative Politics), a research institute in comparative

\footnotetext{
${ }^{2}$ FIERI was founded in 2002 in Turin and until recently it was the only Italian member of the IMISCOE (Immigration, Integration and Social Cohesion in Europe) network of excellence, funded by the EU in the context of the VIth Framework Programme and now self-financed by its members. It can be considered an indicator of the increasing international profile of migration research in Italy.
} 
policy analysis at Bocconi University (Milan). However, no reform of the 1990 law was undertaken during Minister Martelli's mandate, in part because of a crisis in the then centre-left government. The conferences of the early 1990s seem to have played essentially a legitimising function for the then Minister of Justice who had promoted the 1990 law. This law was especially criticised by NGOs for its predominant focus on border controls and entry restrictions. In the politicised climate of the time, with the Lega Nord becoming more and more aggressive, the launching of the two conferences can be regarded as an attempt to counter radicalisation by sending the message that the government had invited prestigious and well-known experts to find solutions. If and to what extent there was really an intent to implement the mobilised knowledge is hard to say, given the short life of that particular centre-left government.

As far as integration was concerned, however, both the conferences and the Poleis study succeeded in putting the issue on the policy agenda, suggesting the necessity for a balanced approach between recognition of cultural differences and equal access to citizenship rights (Conferenza nazionale dell'immigrazione et al. 1991, p. 12). This conception of migrant integration was reiterated throughout the decade in the various technocratic commissions established since 1993 to reform the immigration law. Experts in this period were assigned the task of translating their knowledge into viable policy (namely a new law) and were directly involved in policymaking.

The first commission, established in 1993 by the then Minister of Social Affairs Fernanda Contri, was composed of academic experts from different disciplines, although legal experts prevailed. ${ }^{3}$ The result was a bill composed of 174 articles, the so-called Contri bill, which attempted to strike a balance between issues of border control and favourable integration policies. The commission concluded its work a few days before the 1994 political elections, which were won by the centreright coalition headed by Silvio Berlusconi and included the Lega Nord. The new majority took a clear anti-immigrant stance, and did not show any interest in the bill prepared by the commission (Einaudi 2007, p. 183). Again, no use was made of the mobilised knowledge.

Nevertheless the Contri bill was taken as a starting point by the first centreleft Prodi government elected in April 1996. A second commission was appointed, chaired by the then Minister of Social Affairs Livia Turco, and formed by more or less the same academic experts and top-level civil servants as in 1993 (Zincone 2011, p. 266). Experts were again directly involved in the elaboration of a new comprehensive law, even though, in contrast to 1993, a greater collaboration with ministerial bureaucracies was sought (interview with a civil servant from the Prime Minister's office). The original text of the Contri bill was simplified, adapting it to the everyday needs of public administrators, yet this simplification did not happen without conflicts among some of the experts (interviews with (i) a civil servant from the Prime Minister's office; (ii) an expert in immigration law). In any case, there is

\footnotetext{
${ }^{3}$ Of a total of thirteen members, five were legal experts. As for the others, there were four sociologists, two of them representing respectively CENSIS and ISMU, a political scientist, a demographer, an economist, and a philosopher.
} 
no doubt that the 1996 Turco Commission had an instrumental function insofar as the revised bill was discussed in the Parliament and constituted the backbone of the 1998 Immigration Law.

The technocratic model of research-policy dialogues was institutionalised to some extent by art. 46 of the new law, which established the Commission for the Integration of Immigrants. This commission had the task of monitoring policy implementation, suggesting possible adjustments and providing answers to requests on the part of the government. Chaired by Giovanna Zincone, who had already taken part in the two previous commissions and in the Poleis comparative study, the Commission was composed of eight top-level officials, nine experts (eight from academia and one from an NGO), and two business representatives, one of whom was an entrepreneur of Somali origin. Hence, in contrast to the previous two commissions, experts in the field and pro-immigrant activists were represented, pointing towards a more open science-society dialogue structure.

The Commission for the Integration of Immigrants was inspired by a strong belief in the ability of knowledge to orient policymaking towards reasonable and appropriate solutions shared by the Minister of Social Affairs, Livia Turco, and by the head of her staff, Guido Bolaffi. In particular, the Minister relied upon commission advice in her attempt to reform the 1992 Naturalisation law and a bill was prepared and discussed in the government (interviews with (i) a minister in the first Prodi Government; (ii) a senior civil servant in the Prime Minister's office). However, this attempt was ultimately fruitless.

On the other hand, in order to inform the government about the implementation of the new law, the commission compiled two reports on migrant integration. And, contrary to what we would expect in the case of instrumental use of knowledge (i.e. minimal interest on the part of researchers and policymakers in publicising research reports, see Boswell 2009: 86), the President of the Commission and the Director of the Department for Social Affairs sought broad dissemination and high visibility for the Commission's work. In fact, the two reports were published by a leading academic house, Il Mulino. Furthermore, the commission organised three international conferences, respectively on naturalisation policies in Europe, immigrants' political participation, and Roma minorities' rights, and actively participated in the organisation of a conference on migration held in the context of the 2000 Vatican Jubilee events.

Through the organisation of conferences and the publication of reports, it appears the commission was attempting to legitimise itself as an impartial and technocratic institution in the contested field of migration policy. And actually, according to one of the key actors at the time, the Commission was perceived as 'an institution characterised by autonomy, plurality and scientific rigour' (interview with a minister in the first Prodi Government). However, this strategy of legitimising knowledge use did not prove completely successful, since the next Berlusconi government in 2001 abolished the commission. As a matter of fact, the new centre-right political majority did not conceive it as an independent body, but rather as a political instrument set up by the previous centre-left government in order to signal its positive stance towards immigrants integration. 
The end of the commission marked the end of the attempt to establish a technocratic model of relations between experts and policymakers on the migration issue. At the beginning of the 2000s, as already mentioned above, migrant integration became an increasingly politicised issue, leading to a profound re-orientation not only of policy (see the culturalist approach above) but also of research-policy dialogues. Politicians on both sides started to show a clear preference for seeking ad hoc consultancy and setting up commissions on specific issues. As we shall see in greater detail below, this is the case of the two initiatives on naturalisation and new religious diversity promoted by the Minister of Interior Giuliano Amato in 2006, as well as the few and informal initiatives to seek advice on the implementation of the Integration Agreement introduced by the Minister of Labour and Social Policy in the fourth Berlusconi government. These cases can be regarded as typical examples of an engineering-like boundary configuration between research and policy (Scholten 2011), since experts were called upon to accomplish specific tasks established by the political leadership, in a principal-agent type of relationship.

In terms of knowledge utilisation, engineering relations in this period seem to have had a primarily substantiating function, since the role of experts was essentially that of providing scientific support for certain policy decisions against possible alternative courses of action (Boswell 2009). Yet, some instrumental use of this 'mandated knowledge' can be also noted, in the sense that ad hoc expertise indeed contributed to the refinement and specification of the policies to be undertaken. Nevertheless, the setting of policy priorities rested firmly in the hands of politicians.

\subsection{Key Topics in Research-Policy Dialogues}

In the sections below I analyse how science-society dialogues on key topics in migrant integration policy have unfolded in the 2000s. As with the other chapters in part 2 of this book, I will cover naturalisation of newcomers, reception of immigrant children in primary and secondary school, and the accommodation of new religious diversity. I will consider first the production of knowledge on each topic, to turn then to dialogue structures and uses of knowledge.

\subsubsection{Naturalisation of Newcomers}

The issues of naturalisation and citizenship more generally were primarily discussed by legal experts in migration after the 1992 reform to nationality law. This reform toughened the naturalisation requirements for non-EU immigrants, from 5 years of legal residence under the previous law to 10 years (see: Zincone 2011). Experts in comparative and constitutional law were particularly prominent in criticizing this law, both through academic publications and editorials in the newspapers. 
In the mid-1990s, political scientists and sociologists also became more and more interested in matters of naturalisation. Citizenship was conceptualised by these scholars primarily as a set of civil, political, and social rights accorded to immigrants. Comparative studies on immigrants' citizenship rights in the main EU immigration countries were carried out in order to draw meaningful insights for analysis of the Italian case. From a comparative perspective, the 1992 nationality law has been interpreted by Zincone (2006) as evidence of the family-based approach to the issue in Italy, given its openness towards the descendents of Italian emigrants (just 3 years of legal residence required in order to apply for naturalisation) and the foreign spouses of Italian citizens (until 2009 only six months of legal residence were required), set against its stringency towards other non-EU immigrants. Zincone's study, carried out in the context of FIERI's research activities (see above) and published by one of the main Italian publishing houses (Laterza), did not receive much attention from the media, yet some of the interviewees considered it a relevant piece of research in the policymakers debate on the issue (interviews with (i) a centre-right political leader; (ii) a centre-left political leader).

As already mentioned above, the Commission for the Integration of Immigrants was particularly active on matters of naturalisation. The bill prepared by the Commission envisaged naturalisation after 5 years of legal residence and the introduction of 'moderate jus soli' for children: the parents of minors who were born in Italy or had arrived very young could apply for Italian nationality provided that their children had completed primary and secondary school obligations in Italy. ${ }^{4}$ These two innovations remained at the very core of subsequent reform proposals aimed at liberalising access to nationality in Italy (Zincone 2011).

In the 2000s, the main attempt to reform the nationality law was pursued during the second Prodi Government by the Minister of the Interior Giuliano Amato, in 2006. The 2006 bill was an updated version of the one prepared by the Commission for the Integration of Immigrants in 1999, on the basis of a new comparative study prepared by an expert who had already participated in that commission (Zincone 2011, p. 25). On the one hand the new bill reduced the residence time requirement from ten to five years, yet on the other hand it added new conditions by introducing a language test and oath of allegiance, thus copying the initiatives pioneered in other European countries. This bill was discussed in the Constitutional Affairs Parliamentary Commission, where various experts, primarily legal experts, were invited to provide their opinion and advice. The hearings promoted by the Constitutional Affairs Commission can be considered an 'enlightenment-type' dialogue structure since experts, both academics and practitioners, were not directly involved in the policymaking process but were consulted on a bill which was already prepared by policymakers (i.e. the Minister, his undersecretary, and the Democratic Party rapporteur in the Chamber of Deputies [lower chamber of the Italian Parliament]).

\footnotetext{
${ }^{4}$ According to the present law, in order to be eligible for citizenship, foreign children have to be born in Italy and to have regularly lived in the country without interruption until the age of 18 .
} 
Usually, expert hearings in parliamentary commissions have a functional purpose, in the sense that debate with experts is sought in order to improve a certain bill and to facilitate its approval in Parliament. Yet this was not the case with the nationality law: the final adoption was delayed due to problems in finding the financial resources needed for implementation (interview with a minister in the second Prodi government), then in 2009 the second Prodi government lost its majority. The new centre-right majority in parliament, including the new Interior Minister Roberto Maroni (Lega Nord), were not interested in pursuing nationality reform. However, according to one of our interviewees (an expert on immigration law), the advice delivered by the Constitutional Affairs Commission was sometimes critical towards the bill, and legal experts especially found it less than satisfactory from a constitutional point of view. If and to what extent the final text that Minister Amato intended to present to the Chambers took these criticisms into account is not clear.

There is unanimity among the interviewees about the hostile role played by the media during this period. In fact, the media did not give much attention to debates in the Constitutional Affairs Commission, which - similarly to other Commissions of this kind - worked in the shadows. The main target of the news was the Amato bill, which was depicted by newspapers and journalists close to centre-right parties and the Lega Nord as indiscriminately open towards jus soli. In general, the interviewees share the opinion that the issues of naturalisation and citizenship have attracted more media attention because of the clamour created by politicians than the arguments and proposals put forward by experts.

\subsubsection{Reception Policies for Immigrant Children in Primary and Secondary Education}

The first research on immigrant children and school reception policies dates to the 1990s, when NGOs working in the field began to notice increasing numbers of foreign children enrolling every year in Italian schools. Catholic organisations have been particularly prominent, which accounts for the prevailing 'social problems' approach. As regards independent research centres, Ismu (see above) and Fondazione Agnelli were the first to carry out studies on the topic, primarily at local levels, i.e. in the Lombardy and Piedmont regions respectively.

Academic research on second-generation and migrant children is more recent, and dates to the late 1990s. New centres were founded, some, such as the CDLei in Bologna, directly linked to the University, while others, such as the Centro Come in Milan, were sponsored by the local administration (in particular the Province of Milan). According to one of the interviewees (an academic expert on the second generation), two approaches to the study of migrant children's integration can be identified: on the one hand, a normative approach, characterising primarily educationalists and sociologists of education, who have specialised in the 
definition of the intercultural model of education and intercultural policy; on the other hand, an empirical approach, followed by demographers and sociologists of migration, which is concerned first and foremost with data collection and analysis. The relevance of these different perspectives is also confirmed by literature reviews on migrant children's integration in Italy (see for instance: Ponzo and Ricucci 2007).

In the 2000s some important studies on migrant children's integration were carried out, among them one coordinated by Gianpiero dalla Zuanna, demographer at the University of Padua, comparing the educational achievements of migrant children and their Italian schoolmates in nine Italian regions (Veneto, Lombardy, Tuscany, Marche, Lazio, Campania, Apulia, Calabria, and Sicily). This study demonstrated the critical relevance of regional school systems and reception policies, and publication of its results (Dalla Zuanna et al. 2009) raised a lively debate in the expert community, albeit with far less interest at the level of the media and the public more generally. In this respect, the interviewed experts remarked how the media have been more attentive to reporting politicians' statements than scientific studies on immigrant pupils' integration. A case in point is represented by the controversy that was raised in 2008 by Lega Nord MP Roberto Cota, who argued for the necessity of arranging separate classes for immigrant children.

Notwithstanding this neglect on the part of the media, in the 2000s two important dialogue structures were set up on the issue: firstly, a mixed group composed of teachers, public officials, and academic experts started by Minister Moratti in 2004 during the third Berlusconi government; secondly, a National Observatory for intercultural education and foreign pupils' integration, established in 2006 during the second Prodi government. In terms of dialogue structures, these boundary organisations can be characterised as technocratic institutions, since academic experts, together with public officials and other experts in the field, were directly involved in the definition of the lines of action to be pursued by the Ministry to strengthen immigrant children's access to school.

The mixed group was an initiative of the then Director General for Student Services in the Ministry of Education, Mariolina Moioli, appointed by Minister Moratti. Before becoming a political activist in the Berlusconi Forza Italia movement, Moioli was a secondary school teacher with a longstanding interest in reform of the school system. ${ }^{5}$ According to some interviewees (academic experts on the second generation and education issues, and members of the mixed group), she played a crucial role in ensuring the adoption in 2006 of the 'Guidelines for the reception and integration of foreign pupils,' a document drafted by the mixed group which established a series of benchmarks to which schools were expected to conform. Academic experts appointed in the mixed group were key in drafting the guidelines, starting with the experiences and suggestions of experts in the field

\footnotetext{
${ }^{5}$ http://www.comune.milano.it/portale/wps/portal/CDM?WCM_GLOBAL_CONTEXT=/wps/ $\mathrm{wcm} /$ connect/contentlibrary/In+Comune/In+Comune/I+Gruppi+Consiliari/Milano+al+centro+ Letizia+Moratti+Sindaco/Moioli+Maria+Mariolina/
} 
such as schoolteachers and headmasters. The document was judged by NGOs and trade unions as unexpectedly open-minded and progressive for a political majority where the Lega Nord played a pivotal role.

As mentioned, in 2006 the second Prodi government institutionalised the experience of the mixed group with the establishment of the National Observatory. This was articulated at two levels: the Scientific Committee, composed of almost the same academic experts already involved in the previous mixed group and of experts from the field (school teachers and community link-workers), placed side by side with a technical committee formed by senior officials in the Ministry; and the general assembly, where NGOs and other pro-immigrant organisations as well as school headmasters and teachers were represented. In this case, the main promoter of the initiative was also a politician, the undersecretary of the Ministry of Education Maria Letizia De Torre, of the Democratic Party, who had a professional background as a schoolteacher.

Despite the change in the political majority, there is a clear continuity between the two experiences, as indicated by the fact that key experts appointed in 2004 were confirmed in 2006. Furthermore, in both dialogue structures a crucial role was played by a senior public official of the Ministry, Vinicio Ongini, former teacher, described by most interviewees as an atypical civil servant, insofar as he was particularly interested in keeping contacts with experts and facilitating the translation of their ideas into viable policy documents. As is clear, in the education sector personal commitment and interest in the issue seem to represent crucial assets in order to initiate and continue research-policy dialogues, regardless of the ideological make-up of the ruling majority.

Contrary to the previous mixed group, the Observatory did not succeed in elaborating any new normative provision. A general declaration of principles was adopted, entitled 'The Italian way towards intercultural education and foreign pupils' integration.' ${ }^{6}$ According to the interviewees, the short (2 year) lifespan of the Prodi government impeded more effective action, and the National Observatory was discontinued in 2009, when the fourth Berlusconi government came to power. Nevertheless, the reflections developed by this institution were not completely abandoned. According to two interviewees, they continued to represent a point of reference for the Ministry's administrative staff as indicated by circular no. 2/2010 on the so-called 'bridge classes.' Issued under pressure from the Lega Nord, which intended to establish special ethnic classes for migrant children, the ministerial circular introduced a maximum threshold of $30 \%$ non-Italian-speaking children per class 'to be adjusted to specific local conditions.' This reflected the positions of the experts participating in the National Observatory, who were particularly concerned with creating favourable conditions for immigrant children to learn the

\footnotetext{
${ }^{6} \mathrm{http}: / /$ hubmiur.pubblica.istruzione.it/alfresco/d/d/workspace/SpacesStore/cecf0709-e9dc-4387a922-eb5e63c5bab5/documento_di_indirizzo.pdf
} 
Italian language. To this end, they considered a high number of non-Italian-speaking pupils to be detrimental (interviews with (i) a senior civil servant in the Ministry of Education; (ii) academic experts and members of the Observatory).

\subsubsection{Accommodation of New Religious Diversity}

Knowledge production on religious pluralism in Italy is characterised by a plethora of academic groups, individual scholars, and research centres, among which three strands emerge as particularly relevant (interviews with two academic experts). The first strand is represented by a group of sociologists of religion from the University of Padua who have specialised in the study of multiculturalism and Islam. The second is formed by specialists in religious and canon law in Rome, Milan (Catholic University), and other universities in Italy, who have been active on matters of religious liberty and have always taken part in the various committees established at a local and national level. The third strand is that of the centres of oriental studies established in various Italian universities (Rome, Venice, Naples, etc.), which, while primarily concerned with linguistic and cultural aspects, have also devoted considerable attention to religious matters.

Contrary to the other two topics discussed above, research on immigrant religions and Islam has always attracted a certain level of attention from the media, as emphasised by the fact that, according to two interviewed experts, their books have usually received reviews in the main newspapers, although this has not always resulted in accurate and unbiased accounts (interviews to two academic experts on matters of religious pluralism and Islam). The media's interest in this aspect of migrant integration is particularly well illustrated by what can be called the 'Sartori case': in 2002 Giovanni Sartori, a well-known political scientist at Columbia University (albeit with negligible experience in cultural, religious and migration studies), published a pamphlet against multiculturalism which raised heated debate in the academic community and in the public at large. Various factors contributed to the escalation of this case: first of all, the personal charisma of the scholar, always alluring to the Italian media because of his critical voice on political parties and the political class more generally; secondly his indisputable prestige in the academic sphere as an expert on democracy; third, his provocative argument. According to Sartori, multiculturalism is inherently dangerous for Western civilisation since its cultural relativism leads to the acceptance of value systems in contradiction with democratic principles, such as those characterising Islam. Yet Sartori's book cannot be considered a proper scientific study, since it was not based on any kind of systematic research or data analysis.

Sartori's position contributed to the politicisation of the religious issue at the beginning of the 2000s. As anticipated above, in order to oppose radicalisation especially on the part of the Lega Nord, in 2006 the then Minister of Interior Amato established the Scientific Committee for the drafting of the Charter of the Values of Citizenship and Integration. Experts were selected because of their authority 
on religious issues and Islam in particular, as indicated by their biographies: the president, Carlo Cardia, and Roberta Aluffi Beck-Peccoz are both legal experts on religious law; Adnane Mokrani is a professor of Islamic Theology and Islamic Law; Khaled Fouad Allam was professor of Sociology of Islam and a deputy in the Italian Parliament (at the time belonging to the centre-left party La Margherita); Francesco Zannini is an expert on the history of contemporary Islam. Moreover, two representatives of the Home Office Ministry were also involved, acting as a liaison with the Minister. None of these experts had been involved in the previous commissions, even though the committee's president was close to the Interior Minister and had collaborated with the Socialist government in 1984 on a revision of the agreement with the Catholic Church (Concordato con la Chiesa Cattolica) (interview with academic expert and member of the Scientific Committee).

In order to draft the Charter, the committee undertook extensive consultations with the main immigrant and religious communities present in Italy, as well as with voluntary organisations supportive of immigrants' integration. Furthermore, the Committee identified a number of relevant matters about which specific studies were undertaken, including civic integration programmes in Europe. The media followed the initial steps of the committee's work and dedicated some attention also to the final text of the Charter, officially presented by Minister Amato in April 2007. However, the focus of media news continued to be UCOII's controversial attitudes towards the Scientific Committee (see Sect. 10.3), rather than the day-to-day work of this group.

The Scientific Committee can be regarded as a typical example of an engineering structure in research-policy relations: experts were called upon to accomplish a specific task, i.e., drafting the Charter, a task which was established by the political leadership in a principal-agent type of relation. Indeed, the role of the experts was essentially that of giving scientific substance to an already established normative goal. Such a goal was clearly shared by the president of the Committee (interviews with (i) a minister in the second Prodi government; (ii) an academic expert and member of the Scientific Committee).

As for knowledge utilisation, by establishing a committee of experts on such sensitive issues as Muslim religion and integration, the Minister of the Interior was affirming his credibility in the domain of migrant integration as well as enhancing his culturalist approach, in contrast with the more solidaristic and universalist stance of the then Minister of Social Policy, the ex-Communist Gianni Ferrero. Some of the characterising features of the Scientific Committee are indicative of a substantiating use of knowledge (Boswell 2009, p. 86): from an organisational point of view, the committee was composed of external experts plus two senior civil servants, thus ensuring direct exchange with the decision makers; the research agenda was centred around the linkages between culture (specifically in terms of religion), Italian identity, and integration, which were critical issues in the public debate at the time; the outcome, i.e. the Charter, was selectively publicised among those audiences considered the most directly concerned, i.e. religious and immigrant communities, schools, and public administration offices dealing with immigration.

Another dialogue structure on the topic is the Constitutional Affairs Parliamentary Committee, which convened in November 2009 to examine two bills on Islamic 
women's dress codes, the so-called 'Burqa Commission.' The three interviewed academic experts who took part in the commission were dissatisfied with its outcomes: '[T]hings were very well planned before and probably already decided.... [W] e were invited to articulate our position, but there was no real interest in taking this into account' (interview with an academic expert on immigration law and member of the 'Burqua Commission'). The Commission seemed to play essentially a legitimising function for the two proponents of the bills under discussion, i.e., the Popolo delle Libertà MP Suad Sbai, a woman of Moroccan origin known for her provocative positions on Islam, and the Lega Nord MP Roberto Cota, always highly vocal on matters of migration (see above for his initiative on the so-called 'ethnic classes'). Neither law was approved in the end, but they raised quite a lot of debate in the media.

\subsection{Conclusions}

Similarly to other European countries, research-policy dialogues on migrant integration in Italy have taken different forms throughout Italy's 40-year history of immigration. As in the UK and the Netherlands at earlier times (Scholten 2011, pp. 271-272), in Italy during the late 1990s an attempt to establish a consistent model of integration policies, implying both individual equality and some (soft) cultural recognition, was accompanied by the establishment of technocratic venues for research-policy dialogues, e.g. the Commission for the Integration of Immigrants. While short-lived, the commission provided a crucial contribution to the development of scientific research and, to some extent, also to policymaking. This is particularly the case for the naturalisation issue, where the reform of the nationality law elaborated by the commission has represented something of a benchmark for the bills that followed, even though to date no reform has been approved.

Analysis of dialogue contributions in the 2000s, on the three subsectors of naturalisation, school reception policies, and accommodation of new religious diversity, reveals how knowledge utilisation indeed represents a major issue. Dialogue contributions autonomously provided by experts seem to have had minimal influence on policymaking, even though, according to the interviewees, some research studies have indeed contributed to enhancing experts' status and consideration in the eyes of policymakers, offering experts an opportunity to participate in various boundary organisations. As for the experts' contributions to researchpolicy dialogues, a distinction can be made between expert hearings promoted by parliamentary commissions and expert committees appointed at the governmental level. Whereas in the former case the influence in policymaking appears negligible, notwithstanding the strictly instrumental purpose of these commissions (to improve bills and speed up their approval), for the latter we find contrasting evidence.

In particular, engineering structures such as the Scientific Committee for the drafting of the Charter of the Values of Citizenship and Integration, and technocratic forms of dialogue as exemplified by the boundary organisations set up at the 
Ministry of Education, seem to have exerted quite an influence on policymaking especially in the long run. This is the case for the National Observatory for intercultural education and foreign pupils' integration: even though its work did not translate into any new piece of legislation or policy action, it influenced how the Ministry's senior civil servants responded to political requests (see the 'bridge classes' issue above).

Hence, dialogue contributions directly promoted by the government appear to have more chances of being used instrumentally, i.e., in order to modify existing policies or legislation. Nevertheless, this does not rule out symbolic uses, as evidenced by the case of the Scientific Committee for the drafting of the Charter of the Values of Citizenship and Integration, which played primarily a substantiating function in the - hidden - conflict between Ministers in the framing of migrant integration.

In order to understand knowledge utilisation (or lack thereof), an intervening factor has to be taken into account, i.e., the personal commitment and interest of policymakers in a specific issue. This seems to be particularly the case for education, where the key decision makers - politicians from both right-wing or left-wing parties and public officials - show considerable experience in school matters and a particular sensitivity towards the issue of migrant children's integration. In the other two policy sectors, this condition is met only in the case of Minister Amato, who as a professor of Constitutional Law already had an interest in matters of citizenship and religious liberty. However, in both these sub-sectors the role of public officials, i.e., the bureaucracy of the Ministry of the Interior, appears to be negligible, which may be the reason for the scarce implementation of the mobilised knowledge.

On the other hand, media attention does not seem to have been relevant for knowledge utilisation. The relationship between the media and migration in Italy has been the object of several studies (Sciortino and Colombo 2004; Gariglio et al. 2010; Binotto et al. 2012) which converge in highlighting the high degree of selectivity towards the 'dark side' of migration, i.e. arrivals of undocumented migrants, criminality, and the like. In this context, new religious diversity (above all Islam), has received some attention as underscored by the 'Sartori case' and confirmed by the majority of the interviewees. On the contrary, as far as the other two issues are concerned, media attention has been reported as intermittent and limited to political controversies. The media have indeed contributed to the politicisation of some issues and this may have led to the decision to start a dialogue with experts, as in the case of the Scientific Committee for the drafting of the Charter of the Values of Citizenship and Integration. However, the media do not seem to have played any relevant role in the utilisation (or non-utilisation) of experts' knowledge.

To sum up, demand for expert knowledge in Italy does not seem to be necessarily the prerogative of certain political actors, even if it is undeniable that centre-left majorities have been more keen to pursue science-society dialogues. On the other hand, knowledge has been used primarily for symbolic purposes (Boswell 2009), either of a legitimising or substantiating kind, or not used at all. According to our 
analysis, for instrumental utilisation to occur, responsible and interested policymakers (and, even more importantly, responsible and interested public officials) must be in place, a condition that seems to have clearly been met only in the case of school reception policies for migrant children.

Open Access This chapter is distributed under the terms of the Creative Commons Attribution Noncommercial License, which permits any noncommercial use, distribution, and reproduction in any medium, provided the original author(s) and source are credited.

\section{References}

Binotto, M., Bruno, M., \& Lai, V. (2012). Gigantografie in nero. Ricerca su sicurezza, immigrazione e asilo sui media italiani. Rome: Lulu Press.

Bommes, M., \& Morawska, E. (2005). International migration research: Constructions, omissions and the promises of interdisciplinarity. Aldershot: Ashgate.

Boswell, C. (2009). The political uses of expert knowledge. Immigration policy and social research. Cambridge: Cambridge University Press.

Campomori, F., \& Caponio, T. (2013). Competing frames of immigrant integration in the EU: Geographies of social inclusion in Italian regions. Policy Studies, 34(2), 162-179.

Caponio, T. (2010). Italy - Migration research coming of age. In D. Thränhardt \& M. Bommes (Eds.), National paradigms of migration research (pp. 207-231). Göttingen: V\&R Unipress.

Caponio, T., \& Zincone, G. (2011). Study on the national policy frame for the integration of newcomers - Italy (Research paper for the PROSINT project). http://research.icmpd.org/1429. html

CENSIS, \& CNEL (Eds.). (1991). Immigrati e società italiana. Rome: Editalia.

Colombo, A., \& Sciortino, G. (2004). Italian immigration: The origins, nature and evolution of Italy's migratory systems. Journal of Modern Italian Studies, 9(1), 49-70.

Conferenza nazionale dell'immigrazione, Università Bocconi, \& CNEL (Eds.). (1991). Immigrazione e diritti di cittadinanza. Rome: Editalia.

Dalla Zuanna, G., Farina, P., \& Strozza, S. (2009). Nuovi italiani. I figli degli immigrati cambieranno il nostro paese. Bologna: Il Mulino.

Einaudi, L. (2007). Le politiche dell'immigrazione in Italia dall'Unità a oggi. Roma-Bari: Laterza.

Favell, A. (2003). Integration nations: The nation-state and research on immigrants in western Europe. Comparative Social Research, 22, 13-42.

Gariglio, L., Pogliano, A., \& Zanini, R. (2010). Facce da straniero. 30 anni di fotografia e giornalismo sull'immigrazione in Italia. Milan: Mondadori.

Geddes, A. (2005). Migration research and European integration: The construction and institutionalisation of problems of Europe. In M. Bommes \& E. Morawska (Eds.), International migration research: Constructions, omissions and promises of interdisciplinarity (pp. 265280). Aldershot: Ashgate.

Hepburn, E., \& Zapata-Barrero, R. (2014). The politics of immigration in multilevel states: Governance and political parties. Edinburgh: Edinburgh University Press.

Penninx, R. (2005). Bridges between research and policy? The case of post-war immigration and integration policies in the Netherlands. International Journal on Multicultural Societies, 7(1), 33-48.

Ponzo, I., \& Ricucci, R. (2007). Italy. In T. Caponio, I. Ponzo, \& R. Ricucci (Eds.), Literature review on identity and social inclusion of young migrants and people of migrant background. www.fieri.it

Presidenza del Consiglio dei Ministri, \& OCDE. (1991). Atti della Conferenza internazionale sulle migrazioni, 13-16 marzo 1991. Rome: Editalia. 
Pugliese, E. (2002). L'Italia tra migrazioni internazionali e migrazioni interne. Bologna: Il Mulino. Rella, P., \& Vadalà, T. (1984). Sociological literature on migration in Italy. Current Sociology, 32, 143-174.

Scholten, P. (2011). Framing immigrant integration. Dutch research-policy dialogues in comparative perspective. Amsterdam: Amsterdam University Press.

Sciortino, G., \& Colombo, A. (2004). The flows and the flood: Immigrants in the Italian newspaper discourse'. Journal of Modern Italian Studies, 9(1), 94-113.

Silj, A. (Ed.). (2006). Scienze sociali e società italiana. L'esperienza del Consiglio Italiano per le Scienze Sociali. Venice: Marsilio.

Zincone, G. (Ed.). (2006). Familismo legale. Come (non) diventare italiani. Roma-Bari: Laterza.

Zincone, G. (2011). The case of Italy. In G. Zincone, R. Penninx, \& M. Borkert (Eds.), Migration policymaking in Europe. The dynamics of actors and contexts in past and present (Imiscoe series, pp. 247-290). Amsterdam: Amsterdam University Press. 


\title{
Chapter 11 \\ Research-Policy Dialogues in Germany
}

\author{
Friedrich Heckmann and Delia Wiest
}

\subsection{Introduction}

"Germany is an immigration country." This statement has become almost commonplace in present day Germany's political and cultural public. Thirty years ago the same statement was regarded almost as 'heresy' by the large majority of this public. How could this change come about? This chapter is about the role that the social sciences played in changing the societal definition of the immigration situation. It focuses not only on the development of research on migration and integration, but particularly on the institutional nexus between migration and integration research and a broader cultural and political public.

Changing the societal definition of the immigration situation has had consequences for integration and integration policies. In the following we look briefly at this development and then try to reconstruct some of the highlights of the "internal" migration research development, which could be transported into the societal and political spheres. This has prepared the ground for discussing the research-policy dialogue structures, which is the main theme of this book. At the end of the first decade of the twenty-first century more than 16 million people with a migration background lived in Germany. Several research findings show that migrant integration made significant progress (Beauftragte der Bundesregierung für Migration, Flüchtlinge und Integration 2011; Sachverständigenrat Deutscher Stiftungen 2010). Nevertheless, in several areas, such as education and vocational training as well as integration into the labour market, there is still a need for action to promote equal opportunities for migrants.

Labour market participation of the immigrant population is considered to be a key indicator for successful integration. Several research results indicate structural

F. Heckmann $(\bowtie) \cdot D$. Wiest

EFMS Bamberg, Bamberg, Germany

e-mail: friedrich.heckmann@uni-bamberg.de

(C) The Author(s) 2015

P. Scholten et al. (eds.), Integrating Immigrants in Europe,

IMISCOE Research Series, DOI 10.1007/978-3-319-16256-0_11 
disadvantages for migrants on the German labour market. The unemployment rate among foreigners is nearly twice as high as among the total population (Beauftragte 2011: 75). ${ }^{1}$ Low-skilled and young persons with a migration background are especially affected by unemployment (Sachverständigenrat Deutscher Stiftungen 2010: 173).

As to school education, there has been an increase in educational achievement for both young people with and without a migration background. Yet, native Germans tend to acquire significantly higher school-leaving qualifications than migrant youth, of whom half obtain only lower school-leaving certificates (e.g. Hauptschulabschluss) or have no school-leaving qualifications (Sachverständigenrat Deutscher Stiftungen 2010: 138). Nevertheless, a considerable increase in upper level school-leaving certificates can be observed amongst young people with a migration background (Beauftragte 2011: 34).

Access to adequate and affordable housing is considered as another important indicator for integration. In the past decades, living conditions of urban immigrant populations have improved, but there are still differences between migrant and majority populations in terms of size of living space, rental costs and residential property (Sachverständigenrat Deutscher Stiftungen 2010: 193). Residential segregation is often interpreted as a factor counteracting integration; while there are districts in several large cities with large concentrations of migrants, ethnic segregation in Germany is less of an issue than in other European countries (Musterd 2005: 335).

\subsubsection{Migrant Integration Policies and Institutional Developments}

By the beginning of the twenty-first century, integration policy had become a central concern in Germany. Table 11.1 below gives an overview of different periods of integration policy development.

The recruitment of foreign guest workers started in 1955 and rapidly increased through the 1960s. There were no special integration policies, but foreign workers were generally employed under the same labour conditions as German workers, including membership in the welfare state institutions.

The end of guest worker recruitment in 1973 was meant to lead to a diminution of foreign workers and of the foreign population. Even though the number of foreign workers decreased, the foreign population in Germany increased due to family reunification. This should have led to a re-definition of the immigration situation by the government, but paradoxically the formula 'Germany is not a country of immigration' became the official governmental definition and political guideline until 1998.

\footnotetext{
${ }^{1}$ Official statistics of the Federal Employment Agency only distinguish between total population and foreigners.
} 
Table 11.1 Developments in German integration policy since 1955

\begin{tabular}{|c|c|}
\hline Definition of the immigration situation & Integration policy development \\
\hline \multirow{2}{*}{$\begin{array}{l}\text { Temporary guest worker recruitment } \\
(1955-1973)\end{array}$} & No specific integration policy \\
\hline & Inclusion into welfare state institutions \\
\hline \multirow{3}{*}{$\begin{array}{l}\text { Denial of the immigration situation } \\
(1973-1989 / 1990)\end{array}$} & Controversies on integration policies \\
\hline & $\begin{array}{l}\text { Appointment of a Federal 'Commissioner for } \\
\text { foreigners' }\end{array}$ \\
\hline & Support for labour migrants' voluntary return \\
\hline \multirow[t]{2}{*}{$\begin{array}{l}\text { New immigration and initiation of a } \\
\text { policy paradigm shift (1990-1998) }\end{array}$} & $\begin{array}{l}\text { Continuing denial of immigration situation and lack } \\
\text { of comprehensive political concepts at national level }\end{array}$ \\
\hline & $\begin{array}{l}1998 \text { change of government and official recognition } \\
\text { of the immigration situation }\end{array}$ \\
\hline \multirow[t]{6}{*}{ New Integration Policy (since 2000) } & Milestones of the new integration policy: \\
\hline & New Citizenship Law 2000 \\
\hline & New Immigration Act 2005 \\
\hline & German Islam Conference 2006 \\
\hline & National Integration Plan 2007 \\
\hline & National Action Plan 2011 \\
\hline
\end{tabular}

Source: compiled by efms

The new coalition government of Social Democrats and Greens in 1998 declared Germany as a country of immigration. The new citizenship law in 2000, which introduced elements of ius soli, can be interpreted as an official acknowledgement and re-definition of the immigration and integration situation (Heckmann 2003: 53).

This emerging dynamic and a growing consensus on migration and integration were strongly promoted by the official establishment of an Independent Commission on Migration in the autumn of 2000. The commission was initiated by the Interior Minister Otto Schily and headed by the CDU Member of Parliament and former President of the German Bundestag Rita Süssmuth. On the one hand, the commission's aim was to examine how to manage and how to determine Germany's immigration needs. On the other hand the commission was requested to elaborate a concept of integration.

Interestingly, the establishment of the commission had an impact on all political parties in Germany: 'They too, in a competitive process, installed their own commissions for migration $[\ldots]$ and published their own position papers. [...] The surprising result of the other parties' papers was that their positions were all quite close to those of the official commission' (Heckmann 2003: 54). This political paradigm shift was facilitated by labour shortages in some segments of the labour market and an increasing awareness of the consequences of recent demographic changes.

The recommendations of the Independent Commission on Migration laid the foundations for a new integration policy in Germany. The New Immigration Act of 2005 can be considered a significant step, because 'for the first time in Germany's 
legislative history, regulations for immigration, labour market access, resident regulations and the integration of migrants [were] combined in one legislative act' (Borkert and Bosswick 2007: 10).

In response to the growing number of Muslims in Germany, the Interior Minister Wolfgang Schäuble established the German Islam Conference (DIK) in 2006, a dialogue between the German state, individual Muslims as well as Muslim associations to facilitate the integration of the German Muslim population. The establishment of the DIK can be interpreted as the official recognition of Islam as the third largest religion in Germany.

The National Integration Plan, in 2007 constitutes another milestone in Germany's new integration policy. It is not really a plan in the sense of state planning, but rather a coordinated commitment by political and civil society actors at all levels of government and civil society to initiate certain integration policies in their field of responsibility. In December 2011 the National Integration Plan was converted into a National Action Plan including concrete, obligatory and verifiable targets (Beauftragte der Bundesregierung 2013)

As part of the National Integration Plan the German Government committed itself to developing a monitoring system of indicators to make integration in Germany more measurable. In 2009, the first Report on Indicators of Integration established the basis for a monitoring system at the national level. The report aimed to provide an objective and evidence-based view of the living conditions of migrants in Germany.

\subsection{Knowledge Production}

In the second decade of the twenty-first century, research on migration and migrant integration in Germany could be described as a very 'differentiated and increasingly specialised field of research which includes various disciplines of the social sciences such a sociology, geography, history, linguistics, education, political science, economics, law, psychology and social anthropology' (Bommes 2010: 127).

A major step to understand the development of knowledge production in migration and migrant integration is to reconstruct various features of this research community: who have been the main actors and research institutions involved, and what are the main 'schools of thought'? Four main periods of knowledge production can be distinguished:

1. Late 1940s and 1950s: migration research on refugees, expellees and ethnic Germans

2. 1970s and early 1980s: Ausländerforschung ('research on foreigners')

3. Institutionalisation of migrant integration research at the end of the $1980 \mathrm{~s}$ and in the $1990 \mathrm{~s}$

4. Current migrant integration research: a highly differentiated and specialised field of research. 


\subsubsection{Migration Research on Refugees, Expellees and Ethnic Germans}

Between 1945 and the beginning of the 1950s, about 12 million German refugees and expellees came to the Western part of Germany. This large number of refugees was expected to evoke conflict. Extensive research on refugees and expellees was an answer to this problem, elaborating various issues that would later become relevant for the 'Ausländerforschung' of the 1970s and 1980s (Angenendt 1992: 186). The research was closely oriented to policy and political applicability due to a 'fear that political radicalisation might spread among these migrant groups under the severe social conditions of the immediate post-war period, i.e. a lack of housing, employment, food and clothes' (Bommes 2010: 128).

At the end of the 1950s, when different studies showed that refugees and expellees were quite well integrated and better off than expected, funding and research on this topic came to an end (ibid.: 132).

\subsubsection{From Ausländerforschung to Migration Research}

Early research on labour migration in the 1960s was focused on labour market issues and was done mostly by economists (Wilpert 1984: 307). It started under the term Gastarbeiterforschung, but was re-named Ausländerforschung soon afterwards (Bommes 2010: 134).

According to Treibel (1988), the number of publications on the 'Ausländerproblem' rose noticeably between 1970 and 1973. The mid-1970s and the early 1980s can be interpreted as the main research phases of the German Ausländerforschung, not only in terms of the quantity of studies and publications, but also with regard to the development of research and funding structures (Treibel 1988: 34).

A common characteristic of the various studies during the Ausländerforschung phase was their 'social problem' orientation. Migration research in the 1970s was mainly designed as applied science reacting to social problems of labour migrants, such as housing issues, health, political participation, education in schools and occupational training of the second generation (Treibel 1988: 38; Angenendt 1992: 189f; Bommes 2010).

Research on foreign children and youth - an area called 'Ausländerpädagogik' considerably expanded in this period as well. This approach can be characterised by a focus on educational and social problems connected with the underachievement of migrant children. Today this often rather descriptive and often quite normative approach continues in the education of social workers. The research programme 'Guest-worker Research - Migration and its Social Consequences' established and funded by the Volkswagen Foundation in 1974, marked a step forward in the development of scientific research on the topic. Addressing return migration, social integration (with an emphasis on the second generation, families and women), and 
basic research, the programme supported about 60 research projects (Korte and Schmidt 1983, also Bommes 2010: 137).

At the end of the 1970s, the results of an interdisciplinary research network named 'Problems of Foreigner Employment' attracted the interest of both research and society. This research network published numerous publications dealing with economic, socio-economic and theoretical aspects (see e.g. Esser 1978; Gaugler 1978; Hill 1984; Korte 1980). Funded by the Federal Ministry of Labour and Social Order, a first 'Representative Study on the Situation of Foreign Employees and their Family Members in the Federal Republic of Germany' was carried out by the Research Institute of the Friedrich-Ebert-Foundation, under the direction of Ursula Mehrländer (see Mehrländer and Hoffmann 1981). This survey has been repeated several times.

At the beginning of the 1980s an intra-disciplinary discourse on Ausländerforschung set in and the terminology and research concepts of Ausländerforschung were critically reviewed (Treibel 1988: 45). Treibel argued in her study on German Ausländerforschung that much of the research during the 1970s and early 1980s was characterised by a strong political and normative involvement and a corresponding lack of scientific detachment. A defined discipline of migration and integration research did not yet exist in Germany. ${ }^{2}$ Only the structural functionalist approach by Hans-Joachim Hoffmann-Nowotny $(1970,1973)$ could be considered as a systematic and theoretical approach (Heckmann 1987: 48). It did not, however, leave much of an impression on other researchers.

The early 1980s marked the slow beginning of a reconceptualisation of German Ausländerforschung as general migration research (Bommes 2010: 134). Of particular importance in this context are the works of Esser (1980), Heckmann (1981), and Bade (1983); they marked a qualitative step forward with regard to the development of migration research. This research established a sociology of migration and integration that increasingly opened itself to international traditions and concepts. ${ }^{3}$ Within this development three major approaches evolved which will be discussed in the next sections.

\subsubsection{Methodological Individualism and Rational Choice Theory}

Hartmut Esser's work of 1980 follows a clearly defined theoretical model of rational choice or value expectancy theory, which has become a major school of thought in integration research. Migrants are seen as rational actors who base their decisions on a motivation to maximise their wellbeing through migration and integration. The

\footnotetext{
${ }^{2}$ Interview with academic in the social sciences.

${ }^{3}$ Interviews with a social scientist and political scientist; see also Wilpert (1984).
} 
work by Esser and his school of thought is open to other theoretical perspectives as well and currently works a lot with hypotheses from social capital theory.

The 'Esser school' (among them Paul B. Hill, Frank Kalter, Nadia Granato, Claudia Diehl, Cornelia Kristen and Sonja Haug) has produced a great number of quantitative studies of high methodological quality and relevance. Esser's approach has been the most influential in the field of migration and integration research (Bommes 2010: 145).

\subsubsection{Socio-historical Approach}

This school of thought is closely connected with the name of Klaus Bade. Being a social historian by training, Bade has contributed much to establishing an interdisciplinary field of migration and integration research. Bade argued that 'any research on migration and settlement processes needs to be embedded in the demographic, economic, social and cultural history of both the regions of origin and of destination' (Bommes 2010: 148).

In Bade's extensive work, broad knowledge of historical and internationally comparative research is combined with a critical stance towards contemporary political discourses. By founding the Institute for Migration Research and Intercultural Studies (IMIS) and later on the new research body 'Expert Council of German Foundations on Integration and Migration' in Berlin in 2008, Bade has contributed much to the institutionalisation of migration research in Germany. Increasingly Bade's research has become more sociological, applying both quantitative and qualitative methods. Bade is and has been in close contact with the media and political actors and up to the present has a strong influence on public opinion in Germany. ${ }^{4}$

\subsubsection{Ethnic Minority Approach}

This approach is represented by Stephen Castles (1984) and Friedrich Heckmann (1981). The central category of ethnic minority is meant to indicate a status of belonging to a society that in many ways rejects the notion of inclusion. While Castles and Heckmann both agree on this, their approaches differ in the conceptualisation of minorities. Heckmann differentiated immigrant minorities from traditional national minorities. In the tradition of the Chicago School he viewed the minority status as a temporary status of transition to full integration or 'assimilation'. Castles, working in Germany in the 1980s, follows the British tradition of regarding groups of migrants with a common background as rather stable ethnic minorities in a multicultural society.

\footnotetext{
${ }^{4}$ Interviews with an academic in the social sciences and a historian.
} 
The ethnic minority approach has contributed to opening up of the scientific discourse in Germany to international debates and their concepts as well as their theories. In political terms, the approach has greatly influenced the process of recognising Germany as a country of immigration. The sociological recognition of migrants as ethnic minorities is also mirrored in the naming of the German Sociological Association (DGS) working group on 'Migration and Ethnic Minorities', founded in 1985 (Treibel 1988: 72). The subsequent recognition of the working group as an independent section within the DGS was a major step towards establishing a defined field of migration and integration research. However, minority approaches in German migration and integration research did not gain the same prominence as they did in the Netherlands for a time or in Great Britain (Bommes 2010: 142).

\subsubsection{Institutionalisation of Migrant Integration Research}

With the introduction of these three research paradigms Ausländerforschung came to an end. At the same time a process of empirical differentiation and institutional anchoring of migration research began. Klaus J. Bade, Hartmut Esser, Friedrich Heckmann, Hans-Joachim Hoffmann-Nowotny and Ursula Mehrländer, the main protagonists of migration research during the 1970s and 1980s, were primarily involved in these processes of institutionalisation (Bommes 2010: 135).

The first step of the institutionalisation process of migration and integration research was the establishment of the already mentioned working group on 'Migration and ethnic Minorities' within the German Sociological Association in 1985. In the period from the late 1980s until the mid 1990s, several research centres linked to universities were founded. The first institutes to be founded were the Institute for Migration Research and Intercultural Studies (IMIS) at the University of Osnabrück, founded in 1991, and the European forum for migration studies (efms) at the University of Bamberg, established in 1993.

Other institutes that increasingly focused on migration and integration research were the Centre for Studies on Turkey (ZfTI) at the University of Essen, and the Institute for Interdisciplinary Research on Conflict and Violence at the University of Bielefeld in 1996. Research centres, such as the Centre of European Social Research (MZES) at the University of Mannheim and the Social Science Research Centre Berlin (WZB) increasingly engaged in migration research as well. In the meantime, migration research has been established in more and more institutions and a continuing disciplinary differentiation is going on which makes it increasingly difficult to keep track of the development of the field.

The institutionalisation process of integration research in the 1990s was accompanied by substantial funding activities for research projects. The main funding institutions were the German Research Council (DFG), the Volkswagen Foundation and the Federal Ministry of Education and Research (Bommes 2010: 149). 


\subsection{Dialogue Structures}

In this section we look at processes and structures of science-society dialogues that contributed to changing and shaping integration policy in Germany. The following typology of dialogue structures is partly in accordance with Boswell's categories (Boswell 2009), and partly reconstructed in an inductive manner by looking at the empirical structure of relations between the social sciences and society. We found variations of the enlightenment and bureaucratic models (Scholten 2011); in addition we identified types of dialogue that we called 'academies', consultancy and mutual learning models. ${ }^{5}$

\subsubsection{Academies}

Since the end of World War II and with the construction of a new Germany several institutions have been created for a kind of societal re-education programme. One major effort has been the founding of numerous 'Akademien' as centres of information, education and dialogue in society. Academies have been founded by political parties, unions, churches, employers' organisations and NGOs for educating their members, but also a wider public. They are part of an adult education system in which people learn in a pleasant environment and usually stay together for several days. The academies teach history, take up intellectual currents in society, political debates and controversies and basic ethical and normative issues.

For more than 30 years, the migration-integration issue has been and is a major topic of dialogue and debate in the academies. Much of the effort to convince society of the reality of Germany being an immigration country has happened in the Akademien and through their work. Social scientists have continuously been invited for presentations and discussions in the academies and have found an interested audience of opinion leaders for their topics. Participants of the workshops meet politicians and other important social actors in face-to-face situations and can establish relations with them to influence their work. With controversial topics, like migration and integration, journalists have quite often taken part in the conferences and have reported in their respective media. Thus, on the one hand, politicians have been influenced by the Akademie workshops, on the other hand journalists (of quality media) have transferred messages from these workshops to an interested public.

\footnotetext{
${ }^{5}$ The research for these sections is based on literature and media analysis. As to the media analysis the efms has had a media reporting system (efms Migration Report; www.efms.uni-bamberg.de) from 1994 to 2008, which gives summaries of political and intellectual developments in migration and integration.
} 


\subsubsection{Enlightenment Models}

We found three major forms of enlightenment models; manifestos, model projects and self-appointed consultancy. Manifestos are public statements by groups of scientists or scientific organisations addressing an 'enlightened public' of educated readers, politicians, journalists, other scientists, but also organisations like political parties, employers' organisations, unions, churches and different kinds of NGOs. A manifesto is an appeal to get attention for an urgent social problem. The content of a manifesto is a concise distillation of research findings, including conclusions and recommendations concerning political action to be taken. The potential impact of a manifesto depends greatly - but not exclusively - on the attention it receives in the media and the way the media convey the manifesto's messages. A manifesto that gained wide public attention was the 'Manifest der 60. Deutschland und die Einwanderung' (Bade 1994), a manifesto signed by 60 renowned researchers from various disciplines, such as history, sociology, political science, economics, law, demography, education, anthropology. The manifesto proposed an improvement of important preconditions for integration, namely a reform of the existing citizenship law. Moreover, the researchers promoted a new concept of immigration taking into account the demographic evolution of Germany. The widely circulated manifesto fed into discourses in the political system, society, science and the media.

Model projects are projects usually funded by foundations or other civil society organisations that focus on an under-researched and under-funded social problem. Model projects - like manifestos - address a broader public and political class with an appeal or recommendation for action. The appeal is based on scientific research findings or an evaluation that 'proves' the efficacy of a certain measure or policy.

Self appointed consultancy aims at reaching and enlightening a broader public, but also addresses politicians through offers of advice. It can be regarded as a hybrid between enlightenment models and consultancy models.

In the project interviews, experts also emphasised private foundations as important actors in science-society dialogues, such as the Bertelsmann-Foundation, the Mercator-Foundation, the Freudenberg-Foundation, the Volkswagen Foundation and the Schader-Foundation. ${ }^{6}$ These foundations funded and carried out various model projects in the migrant integration field, especially projects concerning educational support for migrant children and youth, in order to promote political and public awareness. The 'frühstart' project by the Hertie Foundation is an example. Starting from hypotheses about the relevance of early child education, a programme for early childhood development for migrant children was developed and evaluated. The programme is supposed to influence the political system to invest more in early childhood education, particularly for migrant children. The project 'Förderunterricht' by the Mercator Foundation is another example in the

\footnotetext{
${ }^{6}$ Interviews with an academic in the social sciences and a theologian engaged in intercultural policies.
} 
realm of migrant education. Thus, foundations helped to enlighten the public and to promote science-society dialogues. Manifestos and model projects have been a means of slowly enlightening the political system in terms of Germany's status as an immigration country, and helped to establish the reform policy of the new government of 1998.

The Council of Experts of German foundations for migration and integration (SVR), established in 2008, is an example of self appointed consultancy as a dialogue structure. The Council is financed by eight large German foundations, who mainly work in the field of migration and integration. It publishes annual reports on the development of integration and migration and on assessments of German integration and migration policy. Each report discusses major challenges in the respective policy area and gives recommendations for political action. The evidence presented is partly based on original research by the SVR, but is often based on other sources as well. The strength of the reports is that they are very well written in a precise yet simple language. Results of the reports are presented in public and afterwards are communicated to politicians:

For a long time [we thought] the best way to attract politicians' attention to our research results was to get in contact with them directly [...], but that was the wrong course. To critically follow political and public debates means using the media and the public in order to raise political interest in findings and expertise from migration research (interview with Bade).

\subsubsection{Bureaucratic Dialogue Structures}

In Germany there is a differentiation between free scientific research - in universities and publicly funded institutes like the Max Planck Gesellschaft - and so called Ressortforschung. The latter is scientific research, but the research questions and the uses (and misuses) of research results are controlled by the administration that has commissioned the research. In Scholten's terminology, such relations are coordinated according to the 'engineering model' (Scholten 2009). This does not necessarily mean the research results remain secret and are used only for internal purposes. The administration that has commissioned the research may have an interest in influencing a wider public and NGOs via the publication of the research reports.

Regarding Ressortforschung about migration and integration in Germany, the work of the well funded research department of the Federal Office for Migration and Refugees (BAMF) is a very good example of efforts to inform politicians, other parts of state- and local- administrations, and a broader public of NGOs. An impressive array of such publications is available on the internet. There is other research, of course, that has been produced for internal governmental and administrative purposes, and that has not and will not be published. 


\subsubsection{Consultancy}

The forms of consultancy identified in this category differ from self-appointed consultancy by providing advice that was requested by government or civil society organisations.

Individual consultancy is a form in which individual scientific experts advise a public or private institution or organisation. There are numerous such activities in all spheres of migration and integration. As a single illustration one might mention the influence that the jurist Kay Hailbronner has played advising the German Ministry of the Interior during different governments in matters of immigration policy and naturalisation.

Collective consultancy models: These are dialogue structures in which a body of scientific experts either alone or with experts from other fields provides advice to a public or private organisation or administration (government, agency, city, political parties, unions, NGOs, foundations, corporations). The aim is to improve the policy and prestige of the respective organisation. At the same time the experts may be and sometimes are expected to communicate about the activities of the organisation consulted and help shape its image in the experts' milieu.

An example of such a collective consultancy body in Germany is the BAMF scientific expert body that advises the research department of the agency. BAMF as a whole additionally has installed an advisory board called 'Expertengremium' which meets twice a year for one and a half days. This committee partly consists of scientific experts, but mostly of representatives of other governmental departments and NGOs active in migration and integration policies. It discusses a wide range of topics related to BAMF's activities and enables the scientific experts to bring in their expertise.

Project consultancy is a form of consultancy in which a scientific institute is cooperating with a public or private body developing a policy or set of measures to improve a particular situation or initiate something new. Formative evaluation, in which the evaluator has an intervening role in the project, is a case in point. The institute is using its scientific expertise and methods to develop a certain policy or measure.

\subsubsection{Mutual Learning Models}

This is a form in which public or private bodies cooperate among themselves and with scientific institutes for the purpose of mutual learning and knowledge sharing about successful policies. The public bodies, cities for instance, share their experience regarding the application of certain policies, while the institutes contribute scientific evidence on the issues.

The CLIP project is an example of a mutual learning process. It consists of a network of European cities and European research institutes and has recently com- 
pleted work on four major areas of migrant integration issues: housing, diversity, inter-group relations, and ethnic entrepreneurship (www.eurofound.europa.eu).

\subsection{Knowledge Utilisation}

Turning now to knowledge utilisation, knowledge may be used by policymakers in three different ways, as Boswell (see Chap. 2) suggests: in an instrumental way, to legitimise the authority of an organisation, or to substantiate a policy initiative which has already been decided in advance. Equally, of course, knowledge may be ignored and not utilised at all. The latter was the case during the period of Ausländerforschung in the 1970s and for most migration research in the 1980s.

The efforts of the academies and the other forms of enlightenment dialogue structures that we elaborated above consisted in offering existing knowledge to an open-minded public and to some of the political institutions. But the political institutions generally did not feel the need to take notice of migration research, since they still believed that Ausländer were a transitory problem and that Germany was not an immigration country.

In the 1990s, however, there were signs of a change of attitude on the part of government. One indicator was the interest of the Federal Government and the Bundestag in 1999 to officially publish the 'Migrationsbericht' (migration report) that the European forum for migration studies (efms) had prepared. The Migrationsbericht is an annual overview of all types of migration into and from Germany. ${ }^{7}$ Another indicator of growing attention and utilisation of migration research happened in connection with the Independent Commission for Migration of 2000, which was asked to develop a concept for a new migration and integration policy in Germany. Migration researchers were strongly represented in the different working groups that the commission had installed and which prepared the recommendations for policymakers. Although it is difficult to establish a direct link between expertise and immediate policy changes (Schneider 2010: 309), it is safe to say that the Commission's work had a strong impact on the subsequent migration legislation. But, of course, the final decision on the legislation was dominated by political considerations and power relations:

It is evident that independent commissions established by the government, such as [...] the Independent Commission on Migration [ . . ], primarily provide input and preliminary work through their advisory activities. However, the final and constitutional decision-making procedures remain unaffected (Süssmuth, in Schneider 2010).

To talk of utilisation of knowledge makes sense only after successful dialogue structures between migration research and the public and policymakers have been established and continue to create a need for such knowledge. The change of gov-

\footnotetext{
${ }^{7}$ From 1999 to 2004 the efms prepared and published the Migrationsbericht; since then the Federal Office for Migration and Refugees has taken over the report.
} 
ernment in 1998 marks a turning point in that sense: the new Red-Green government and all other governments since then increasingly have utilised migration research. Knowledge utilisation happens in three forms that we have termed consultancy, bureaucratic and mutual learning dialogue structures. These forms imply that advice is requested by the polity, that there is a demand structure, and not just supply as in the early phase of migration research. All forms of consultancy that we have identified - individual, collective and project consultancy - represent a demand for scientific knowledge.

The bureaucratic model of science-polity relations has been established by policymakers, because the political system feels that there is a continuous need for scientific knowledge of migration and integration processes. When the German Ministry of Interior Affairs established the research unit in the Federal Office for Migration and Refugees in 2005 this was the beginning of a large number of research projects, all commissioned by the government. At present this research unit is the largest amongst all the research units in Germany. It is characteristic of the bureaucratic model that the ministry controls research questions and publication of results.

The mutual learning dialogue structure is another form of knowledge utilisation by practitioners. The structure is such that the practitioners want input from the scientists and the scientists profit from access to empirical data they would otherwise get only with great difficulty or not at all. The CLIP project mentioned above, the 10year project 'Migration Dialogue' by the German Marshal Fund or the 'Transatlantic Discourse on Integration' by the efms (www.efms.de) are all examples of such mutual learning processes. On the whole one could say for Germany:

In recent years politics increasingly began to take note of the wide range of expert knowledge already in existence. Even if they do not use and implement all expertise that is proposed by commissions, advisory boards and researchers, they at least acknowledge it (interview with university researcher in history).

Yet, the question remains as to how expertise from research finds its ways into policy decision-making today. Especially in the field of integration monitoring, there are some indications of 'evidence-based' policymaking through the increasing deployment of expert knowledge from empirical social research to deliver information and data on the state of integration processes. ${ }^{8}$

Other experts argue that policymakers often draw selectively on external expertise and forms of consultancy by choosing the expertise that strengthens and subsequently fosters their own positions and concepts. If it doesn't, policymakers take note of the expertise but don't use it.' 'Politics only uses expertise from research in order to achieve determined objectives. Often those researchers are chosen who strengthen certain political positions' (interview with academic in the social sciences). 'I get the impression that the political sphere makes use of expert knowledge only very selectively in order to adapt or legitimise certain

\footnotetext{
${ }^{8}$ Interview with a theologian engaged in intercultural policies.

${ }^{9}$ Interviews with an academic in the social sciences, a political scientist, and a theologian engaged in intercultural policies.
} 
policy measures. I feel that political actors only use knowledge from research to subsequently ensure or strengthen already existing concepts, which have often been developed under pressure from international and EU debates. I don't see a systematic linkage between policy and science' (interview with academic in political science).

Hence, researchers have to live with the fact that their knowledge is either used to improve migrant integration policies or misused for legitimising political positions. ${ }^{10}$

In the next sections we shall look at science-society dialogues in more detail in three particular areas: naturalisation of newcomers, education of migrant children and accommodation of new religious diversity.

\subsection{Naturalisation of Newcomers}

\subsubsection{Issues}

A new discourse on citizenship developed out of a legitimation problem for the democratic system in view of mass immigration. Due to immigration and settlement since the 1960s millions of residents in Germany were without political representation; as foreigners they could not take part in elections. Since the constitutional court had forbidden the participation of foreigners in elections, naturalisation remained the only way to ensure migrants' political participation.

Citizenship is the question of belonging to the political and legal community of a state and nation. Thus, the concept of nation is basic for any concept of citizenship. Distinguishing in a somewhat ideal-typical way between a 'nation by design' (Zolberg 2006) or republican model, and descent-based concepts of nation, the traditional German concept of nation has been that of a community of common descent ('blood'). In other words, the issue was: can someone be a German, who has not been born in Germany, or who has been born in Germany, but whose parents are foreigners? The question of ius soli in relation to ius sanguinis thus became a central issue in German citizenship and integration policies. The new citizenship law of 2000, after heated controversies, eventually sanctioned ius soli for the children of foreign parents born in Germany.

German citizenship law traditionally is based on the notion of belonging to and being loyal to one nation. Double (or even multiple) citizenship should be avoided. The renunciation of one's citizenship is seen as a precondition for naturalisation. Since migrants often are legally and emotionally attached to the citizenship of their country of origin, migrant associations and many experts opted for a toleration of double citizenship. Controversies over the issue of double citizenship reached a peak when the federal election in Hesse in 1999 was unexpectedly won by a CDU candidate who had made the issue the central part of his campaign. Due to

\footnotetext{
${ }^{10}$ Interview with a theologian engaged in intercultural policies.
} 
this victory in Hessen the Red-Green government in Berlin lost its majority in the Bundesrat, meaning many policies of the federal government could be vetoed.

Another major and controversial issue in citizenship policies has been the role of naturalisation in the integration process. Should it be the end point of the process of integration, or a means to integration? The practical implications of the issue relate to the required duration of legal residence in the country before filing an application, as well as knowledge of language and civics as conditions for naturalisation. Traditional immigration countries have short periods of 3-5 years, since they take naturalisation as a means for integration. In Germany, before the reforms of 2000, foreigners had to wait 15 years before being able to file a citizenship application.

\subsubsection{Knowledge Production}

It is not so easy to talk of 'knowledge production' in the field of citizenship and naturalisation. A lot of the literature consists of an exchange of arguments in certain controversies that can hardly be decided by research and 'knowledge', but are determined by interests, values and convictions. It is safe to say, however, that there has been knowledge production about behavioural aspects of naturalisation, about the historical and internationally comparative dimension of citizenship and naturalisation, and about the connections between concepts of nation and citizenship.

As to the behavioural aspects there is, for example, new empirical research by Diehl (2007) and Diehl and Blohm (2008) on contextual and individual determinants of naturalisation; while Wunderlich (2005) has studied the subjective side of the naturalisation process. Furthermore, there has been knowledge production in Germany on naturalisation via transfer and reproduction of the laws and experiences of classical immigration countries like the United States, Canada and Australia, and of France. This knowledge includes the function of naturalisation rules in the process of integration (an instrument of integration, not the endpoint of the process), the necessary duration of residence in the country before application, rules on double citizenship, and ceremonial elements of the naturalisation process. As an example for acquiring this knowledge one may cite Hailbronner (1992), Hagedorn (2001) and Thränhardt (2008).

Being more and more mindful of having (unwillingly) become a country of immigration, social scientists, historians and jurists argued that the traditional German concept of nation as a community of descent (Abstammungsgemeinschaft) could no longer be held and that nation and nation-building would have to integrate foreign migrants and their children. Internationally comparative research with a historical dimension greatly helped to slowly bring about a new understanding of the nation. Comparing concepts of nation in Germany and France played a key role in this process (Brubaker 1992; Hagedorn 2001; Schnapper 1995). Scientific works which reflect these influences are found in Oberndörfer (1994), Wollenschläger (1994) and Mommsen (1990), the latter defining the new understanding of the nation in Germany as follows: 'A new understanding of the nation has evolved in the Federal Republic, which is no longer under the influence of the Kaiserreich. 
This national consciousness is based on economic achievement and the successful building of a liberal political system and is no longer in contrast to the political cultures of Western Europe and the US' (Mommsen 1990, 272).

\subsubsection{Dialogue Structures and Utilisation}

The dialogue structure of the Academies was identified and described in an earlier section. More specifically concerning legal aspects of integration and naturalisation, the Katholische Akademie Hohenheim stands out for organising dialogue and learning between academics, judges, state attorneys, administrators, politicians, journalists and representatives of civil society and the churches. Between 1989 and 2002 twelve workshops on legal aspects of migration, integration and naturalisation were held at this institute. Several volumes published by the Nomos Verlag mirror the discussions that took place. For example, Barwig et al. (1994) is a volume uniquely focused on citizenship and naturalisation in Germany.

Other science-society dialogue structures, in which naturalisation and related issues were a constant topic, resemble the academy model and - like the Hohenheim structure - consist of a series of conferences and workshops over a longer time, sometimes lasting for several days. The Migration Dialogue by the German Marshall Fund of the United States was a series of conferences for a core group of academics, administrators, politicians, representatives of foundations and journalists that took place in different countries, including classical immigration countries like the US and Canada, and the new European immigration countries like Austria, Germany or France. The Migration Dialogue meetings were partly academic workshops, and partly they consisted of field trips. As to enlightenment models the topic of naturalisation was part of the Manifest der 60 that we characterised already in section 3 of this paper. Research and dialogue of the bureaucratic type are found in work by the BAMF research group and their exchange with the Interior Ministry (Worbs 2008; Weinmann et al. 2012)

We now turn to another area of science-society dialogues, namely the education of migrant children.

\subsection{Education of Migrant Children}

Education is one of the key mechanisms for successful integration of migrant children into German society. International comparative assessment studies, such as TIMSS, ${ }^{11}$ PISA $^{12}$ or PIRLS ${ }^{13}$ are considered as measuring the efficiency and

\footnotetext{
${ }^{11}$ Third International Mathematics and Science Study.

${ }^{12}$ Programme for International Student Assessment.

${ }^{13}$ Progress in International Reading Literacy Study.
} 
integrative potential of education systems. In Germany, the results of PISA in particular have been widely discussed since its first publication by the OECD in 2001. For the first time, PISA clearly demonstrated that children's educational success in Germany is largely dependent on their social and ethnic background. We take PISA as a case study to investigate relations between science and integration policy in Germany.

No other study on education before received as much public and political attention as PISA. The results of the first PISA survey in 2001 influenced the educational policy and reform discourses long after the period in question. Even 10 years after the initial 'PISA shock' the study and its follow-up replications still determine public debates on education, in which various actors and institutions from policy, science and society take part (politicians, researchers, foundations, trade unions, teachers, churches, welfare and migrant organisations).

\subsubsection{The Programme for International Student Assessment (PISA)}

The TIMSS-study in the mid 1990s had already highlighted certain strengths and weaknesses of the German educational system. This prompted the German government to opt for participation in other international comparative studies on education. In 1997, the Conference of Ministers of Culture (KMK) voted for Germany's participation in the Programme for International Student Assessment (PISA) ${ }^{14}$ The study aims to provide evidence-based knowledge for policymakers to improve national education systems (PISA Konsortium 2000). Areas tested within the framework of PISA cover three major topics: reading literacy, competences in mathematics and science as well as cross-curricular skills among 15-year old students. In Germany, the ministers of education in the 16 Länder decided for an extension of the PISA-study, which allows comparisons between federal states. The methodological design of the study allows for an in-depth examination of the relationship between social background and student performance. The results of PISA revealed that in Germany educational performance is closely linked to a student's socio-economic and ethnic background. Compared to other PISAcountries, the German educational system performs worse in compensating for disadvantages resulting from family background.

\footnotetext{
${ }^{14}$ Konstanzer Beschluss zur Durchführung länderübergreifender Vergleichsuntersuchungen zum Lern- und Leistungsstand von Schülerinnen und Schülern (280. Sitzung der Kultusministerkonferenz, 23./24.10.1997).
} 


\subsubsection{Knowledge Production: State of Research and General Data on Education}

Migrant children and young people with a migration background and their integration processes in the educational system have been topics of research for more than 30 years. Until the new millennium, however, relatively few representative data existed on the situation and educational success of migrant children in Germany. It was PISA in particular that raised public and political awareness about the poor performance of and disadvantages facing children with a migration background in the German school system (Baumert et al. 2006, 397). But PISA also stimulated research activities within the education research community, among them sociologists, pedagogues and linguists, and a wide variety of books and articles analysing the role of migrant children and the school system in general have been published since then (e.g. Kristen 2002, 2006; Diefenbach 2010; Stanat 2006; Stanat and Christensen 2006; Esser 2006; Baumert et al. 2006; Gomolla and Radtke 2002; Auernheimer 2010; Matzner 2012). The scientific and public discussion that emerged revolved around dependence of school performance on social status, institutional discrimination, school structures, language acquisition, early childhood education, and the comparison of educational achievements between certain ethnic groups.

As a result of PISA, several governmental institutions commissioned research of their own. On behalf of the Standing Conference of the Ministers of Education and Cultural Affairs of the Länder in the Federal Republic of Germany (KMK) the most prominent example is the 'Bildungsbericht' (education report). The report is published every 2-years by a consortium of research institutions. The first report in 2006 had a particular focus on the situation of children with a migration background. Another publication that recently has been introduced is the annual 'Bildungsmonitor' (Education Monitor), ${ }^{15}$ published by the Initiative for a New Social Market Economy (INSM). This organisation is closely linked to employers, and therefore also rather focused on the economic benefits of an improved education system, including better educational achievements of young adults from migrant families.

\subsubsection{Dialogue Structures and Pressure for Change}

PISA research did not directly influence education and integration policies. Instead, its enormous impact was forthcoming because the media took up the topic, reinforced it and gave it continuous publicity. The dialogue structure is therefore one which encompasses the OECD publishing the report, the German media picking up the topic and putting pressure on the political system, where it led to a change in mentality (Baumert 2011: 40).

\footnotetext{
${ }^{15}$ See http://www.insm-bildungsmonitor.de/ for more details.
} 
In the first year after the 'PISA shock' several hundred articles were published in the leading German print media. ' . . between December 2001 and December 2002 we found 54 articles in Der Spiegel, 81 in FOCUS and 125 in Die Zeit, all directly referring to PISA. In the same period the Süddeutsche Zeitung had 462 articles about PISA. We could not count the numerous talkshows, panel discussions and parliamentary debates' (Tilmann 2008: 3). PISA continued to be a main topic in the media in the following years. No one had foreseen such levels of attention for such a study.

Increasingly, education and integration policies came under severe criticism and were blamed for the poor results of students in Germany. The media had been the catalyst for spreading the discussion, but other civil society institutions like foundations and unions demanded reforms as well.

\subsubsection{Reforms and Knowledge Utilisation}

It is difficult if not impossible to directly trace the influence of PISA on reforms to the education system, but it is safe to say that PISA significantly contributed to such reforms, all of which are of high relevance for migrant students, though not only directed towards them. Because of the federal structure of education policies in Germany the Standing Conference of Ministers of Culture of the German Länder $(\mathrm{KMK})$ played a leading role in bringing about the following reforms:

1. Early childhood education: all Länder have established legal frameworks for early language training at pre-school age. Almost all Länder have carried out standardised language proficiency tests for both children with and without a migration background, and implemented measures for language training at nursery level. Criticism arises, however, that there is a lack of coordinated language programmes among the Länder. Instead, a vast number of measures and temporary projects are realised. The sovereignty of the Länder still appears to challenge the implementation of consistent programmes in the field of early childhood education (Baumert 2011: 41).

2. Full day schooling: Germany has a tradition of morning instruction in schools and homework activities in the afternoon. This is still the dominant pattern, but processes of change are under way in which more and more schools extend instruction and activities into the afternoon. This stronger role for the school environment is particularly meant to improve opportunities for migrant children, who can get more support in school.

3. Stronger parent involvement: This again is a general measure, but again it is of particular relevance for migrant parents, since they tend not to participate in school life, unless pro-active measures involving mediators from ethnic communities are undertaken.

4. Quality management and reporting systems: PISA has produced and continues to produce many new data, but has stimulated other research and measures 
producing even more data on the performance of the education system. A national education reporting system has been installed; its first edition in 2006 focused on migrant children. Several Länder have introduced performance standards for students and performance testing is no longer an unusual activity.

Additionally, PISA resulted in a de-politicisation of party political discourses and provided the basis for political consensus on fundamental questions, such as the expansion of full-day schooling, introduction of educational standards and centralised achievement tests, as well as early childhood education and language training.

The analyses of science-society dialogues on education and integration in the course of PISA also demonstrated that 'research results provided in a political context are also dealt with in a political way. In other words: political action in the area of education cannot only be based [ ... ] on thorough considerations of research results in order to derive the "right" measures' (Tillmann 2008: 12).

The last section on science-society dialogues in Germany concerns the accommodation of new religious diversity that has resulted from immigration.

\subsection{Accommodation of New Religious Diversity}

Increasing cultural and religious diversity is one of the main social consequences of immigration and a challenge for integration. Most of the issues arising from this challenge of new religious diversity are discussed in relation to Islam, by far the biggest migrant religion. We shall concentrate in this section on Islam as well.

\subsubsection{Issues}

Islam is not organised like the Christian churches. There are many Islamic organisations, but they do not generally fulfil the criteria for being legally recognised as a public body in the same way as the Christian churches. Thus, they cannot enjoy the privileges that are connected to the status of a public body, including the right to give religious instruction in the public school system. Religious Islamic instruction is one of the main issues connected to the status and role of Islam in the school system. Despite the structural problems of legal status many efforts are under way in the different federal states to overcome the obstacles and to ensure Islamic religious instruction.

The problems of legal status are reinforced by widespread Islamophobia in large segments of the population. They have historical roots going back to the conflicts with the Ottoman Empire, but are fuelled by present media. Urban conflicts about the building of representative mosques in city centres are an expression of such tendencies. 
Other issues are related to religious practises in everyday life. Dress codes, like wearing a scarf at work, dietary requirements and burial rules are issues that play a role in integration policies and practices. ${ }^{16}$

Patterns of radicalisation among Islamic migrants and problems of Islamisation are other major issues concerning the integration of the Muslim population. Acts of Islamist terrorism or plots to commit such terrorism, particularly by so-called homegrown terrorists, be it in Germany or other Western countries, fuel antiIslamic prejudice among the native population, despite the distancing of Islamic organisations from such acts.

\subsubsection{Production of Knowledge}

'Orientalistik' (Oriental Studies) is the traditional historical, archaeological, philological and theological discipline for the study of Middle Eastern countries, cultures and religions. Orientalistik continues to exist, but a modern version has evolved from within the traditional discipline, as well as from 'outside', i.e. from other social sciences like sociology and political science: 'Gegenwartsbezogene Orientforschung' (Contemporary Oriental Studies). There are departments, institutes and chairs for Gegenwartsbezogene Orientforschung for instance in Bamberg, Berlin, Erlangen-Nürnberg, Hamburg, Marburg and Mainz. As to the most important religion of immigrants, Islam, Orientalistik and Gegenwartsbezogene Orientforschung have greatly contributed to general knowledge production on Islam and on Muslim countries in Germany.

Within Gegenwartsbezogene Orientforschung, but also in other social sciences, a lot of research has been done on aspects of Islam in every day life: on the building of representative mosques, on Muslim social milieus (Wippermann und Flaig 2009), on the scarf, on dietary requirements, and on burials and cemeteries (Lüken-Klaßen and Heckmann 2010, 111-138).

Commissioned by the Interior Ministry, the research department of the Federal Office for Migration and Refugees (BAMF) has produced empirical research on a wide range of facets of Muslim life in Germany (Haug et al. 2009) and on Islamic communities in Germany (Hahn et al. 2012). The ministry commissioned two other studies on Muslims (Brettfeld und Wetzels 2007) and on young Muslims (Frindtke et al. 2011). The particular interest in these studies was to learn about the potential for the radicalisation of young Muslims and how to prevent that.

\footnotetext{
${ }^{16}$ For an overview on solutions for meeting religious needs of Muslim communities in cities see Lüken-Klaßen and Heckmann (2010).
} 


\subsubsection{Dialogue Structures}

Islam has been a topic of nearly all the Akademien in Germany, through which academics could transfer knowledge to a broader public of interested organisations and individuals. A bureaucratic dialogue structure has been installed by the Interior Ministry with the research department of the Federal Office for Migration and Refugees. Within this relation two major empirical studies on Islam were done; one on Muslim life in Germany (Haug et al. 2009) and one on Islamic organisations in Germany (Hahn et al. 2012).

Die Deutsche Islam Konferenz is not a direct dialogue structure between academia and policymakers, but social scientists could play a role within this communication frame. In the preparatory phase of the conference in 2006 academics were involved in consultations with the Interior Minister Schäuble on the relation of the German state with Muslims. In the same year the Deutsche Islamkonferenz was installed as an institutionalised continuous dialogue between the German state (Federal, federal states, cities) and Muslim organisations and individuals. The Islamkonferenz thus is not a dialogue between academics and the polity, but academics have and will play a role in this dialogue as experts for topics dealt with in this influential setting: value consensus in society, equality of sexes, religious instruction of Islam in schools, the teaching of Islamic theology in German universities, media stereotypes of Islam and the prevention of radicalisation and security.

\subsection{Conclusions}

Regarding knowledge production on immigrant integration in Germany, it is safe to say that since the 1980s there has been an enormous increase in research on these processes. Furthermore, the institutional settings for such research have greatly expanded and diversified. Not only has academic research greatly expanded, but bureaucratic research funded by the political system as well.

We have identified five basic forms of science-society dialogue in Germany:

Academy model

Enlightenment models

Bureaucratic models

Consultancy models and

Mutual-learning models.

What are the relations of these dialogue forms to the political system? In three cases there is a direct relationship:

1. In the bureaucratic structure, demand for research comes directly from the political and administrative system and the results and uses are under the control of the latter 
2. In the consultancy structure, when policymakers directly engage academic expert knowledge there is a direct relationship as well

3. The mutual learning model could be identified only at the level of city politics.

In all three cases there is political primacy over the use (or misuse) of the research and knowledge in question.

In the academy and enlightenment models there are two possible routes for impacting the political system: one in which politicians and administrators are influenced by the messages from these dialogue forums; the other in which the influence of academies and enlightenment is taken up by the media and the political system consequently faces pressure from the media, but has some primacy over what kind of expert knowledge will be transformed into political change. In Germany we observe a development from an initial context in which migration and integration research was ignored by the political system, to the present day situation in which demographic pressures reinforce the influence of migration and integration research.

Open Access This chapter is distributed under the terms of the Creative Commons Attribution Noncommercial License, which permits any noncommercial use, distribution, and reproduction in any medium, provided the original author(s) and source are credited.

\section{References}

Angenendt, S. (1992). Ausländerforschung in Frankreich und der Bundesrepublik Deutschland. Gesellschaftliche Rahmenbedingungen und inhaltliche Entwicklung eines aktuellen Forschungsbereiches. Frankfurt am Main/New York: Campus Verlag.

Auernheimer, G. (Ed.). (2010). Schieflagen im Bildungssystem. Die Benachteiligung der Migrantenkinder. 4th edition (pp. 7-20). Wiesbaden: VS Verlag für Sozialwissenschaften.

Bade, K. J. (1983). Vom Auswanderungsland zum Einwanderungsland? Deutschland 1880-1980. Mit einem Geleitwort des Präsidenten der Bundesanstalt für Arbeit J. Stingl (Beiträge zur Zeitgeschichte, Bd. 12). Berlin: Colloquium Verlag.

Bade, K. J. (1994). Das Manifest der 60. Deutschland und die Einwanderung. München: C.H. Beck.

Barwig, K., Franz, F., \& Müller, G. (Eds.). (1994). Vom Ausländer zum Bürger. Baden-Baden: Nomos.

Baumert, J. (2011), Ängstllichkeit regiert. Interview über Pisa Schock. Der Spiegel, 48, 40-41.

Baumert, J., Stanat, P., \& Watermann, R. (2006). Herkunftsbedingte Disparitäten im Bildungssystem: Differentielle Bildungsprozesse und Probleme der Verteilungsgerechtigkeit. Wiesbaden: VS Verlag.

Bommes, M. (2010). Migration research in Germany: The emergence of a generalised research field in a reluctant immigration country. In D. Thränhardt \& M. Bommes (Eds.), National paradigms of migration research (IMIS-Schriften 13, pp. 127-185). Osnabrück: V\&R Unipress

Borkert, M., \& Bosswick, W. (2007). Migration policy-making in Germany - Between national reluctance and local pragmatism? (IMICOE Working Paper No. 20).

Boswell, C. (2009). The political uses of expert knowledge. Immigration policy and social research. New York: Cambridge University Press.

Brettfeld, K., \& Wetzels, P. (2007). Muslime in Deutschland. Integration, Integrationsbarrieren, Religion und Einstellungen zu Demokratie und politisch motivierter Gewalt. Ergebnisse von Befragungen. Berlin: Bundesministerium des Inneren. 
Brubaker, R. (1992). Citizenship and Nationhood in France and Germany. Cambridge, MA: Harvard University Press.

Castles, S. (1984). Here for Good. Western Europe's New Ethnic Minorities. London: Pluto Press.

Diefenbach, H. (2010). Kinder und Jugendliche aus Migrantenfamilien im deutschen Bildungssystem. Erklärungen und empirische Befunde (3rd ed.). Wiesbaden: VS Verlag für Sozialwissenschaften.

Diehl, C. (2007). Gescheiterte Integration? Neue Befunde zur Eingliederung von Erwachsenen in Deutschland. Georgia Augusta Wissenschaftsmagazin, 5(2007), 86-93.

Diehl, C., \& Blohm, M. (2008). Die Entscheidung zur Einbürgerung: Optionen, Anreize und identifikative Aspekte'. Kölner Zeitschrift für Soziologie und Sozialpsychologie, special issue, 48, 437-464.

Esser, H. (1978). Wanderung, Integration und die Stabilisierung komplexer Sozialsysteme. Soziale Welt, 29(11), 180-200.

Esser, H. (1980). Aspekte der Wanderungssoziologie. Assimilation und Integration von Wanderern, ethnischen Gruppen und Minderheiten. Eine handlungstheoretische Analyse. Neuwied/Darmstadt: Hermann Luchterhand.

Esser, H. (2006). Sprache und Integration. Die sozialen Bedingungen und Folgen des Spracherwerbs von Migranten. Frankfurt am Main/New York: Campus Verlag.

Frindtke, W., Boehnke, K., Kreikenbom, H., \& Wagner, W. (2011). Lebenswelten junger Muslime in Deutschland. Berlin: Bundesminsterium des Inneren.

Gaugler, E. (1978). Ausländer in deutschen Industriebetrieben. Hanstein: Ergebnisse einer empirischen Untersuchung. Königstein im Taunus.

Gomolla, M., \& Radtke, F.-O. (2002). Institutionelle Diskriminierung. Die Herstellung ethnischer Differenz, in der Schule. Opladen: Leske und Budrich.

Hagedorn, H. (2001). Wer darf Mitglied warden? Einbürgerung in Deutschland und Frankreich im Vergleich. Opladen: Westdeutscher Verlag.

Hahn, D., Sauer, M., Schmidt, J., \& Stichs, A. (2012). Islamisches Gemeindeleben in Deutschland. Nürnberg: Bundesamt für Migration und Flüchtlinge.

Hailbronner, K. (1992). Einbürgerung von Wanderarbeitnehmern und doppelte Staatsangehörigkeit. Baden-Baden: Nomos.

Haug, S., Müssig, S., \& Stich, A. (2009). Muslimisches Leben in Deutschland. Im Auftrag der Deutschen Islam Konferenz. Nürnberg: Bundesamt für Migration und Flüchtlinge.

Heckmann, F. (1981). Die Bundesrepublik, ein Einwanderungsland? Zur Soziologie der Gastarbeiterbevölkerung als Einwandererminorität. Stuttgart: Klett-Cotta.

Heckmann, F. (1987). Theoretische Positionen der Forschung über Arbeitsmigration in der Bundesrepublik. Von der Gastarbeiterforschung zur Migrations- und Minoritätensoziologie?. In Deutsches Jugendinstitut (Ed.), Ausländerarbeit und Integrationsforschung. Bilanz und Perspektiven (Bundesweite Fachtagung München 15-17 April 1986. Reihe Materialien zur Ausländerarbeit). München: DJI Verlag Deutsches Jugendinstitut e.V.

Heckmann, F. (2003). From ethnic nation to universalistic immigrant integration: Germany. In F. Heckmann \& D. Schnapper (Eds.), The integration of immigrants in European societies. Stuttgart: Lucius \& Lucius.

Hill, P. B. (1984). Determinanten der Eingliederung von Arbeitsmigranten. Peter Hanstein: Königstein im Taunus.

Hoffmann-Nowotny, H.-J. (1970). Migration. Ein Beitrag zu einer soziologischen Erklärung. Stuttgart: Enke.

Hoffmann-Nowotny, H.-J. (1973). Soziologie des Fremdarbeiterproblems. Eine theoretische und empirische Analyse am Beispiel der Schweiz. Frankfurt am Main/New York: Campus.

Korte, H. (1980). Forschungsverbund "Probleme der Ausländerbeschäftigung”, gefördert vom Bundesminister für Forschung und Technologie. Rheda-Wiedenbrück: Erfahrungsbericht des Leitinstituts. Manuskript.

Korte, H., \& Schmidt, A. (1983). Migration und ihre sozialen Folgen. Förderung der Gastarbeiterforschung durch die Stiftung Volkswagenwerk 1974-1981. Göttingen: Vandenhoeck \& Ruprecht. 
Kristen, C. (2002). Hauptschule, Realschule oder Gymnasium? Ethnische Unterschiede am ersten Bildungsübergang. Kölner Zeitschrift für Soziologie und Sozialpsychologie, 54, 534-552.

Kristen, C. (2006). Ethnische Diskriminierung in der Grundschule? Die Vergabe von Noten und Bildungsempfehlungen. Kölner Zeitschrift für Soziologie und Sozialpsychologie, 58, 79-97.

Lüken-Klaßen, D., \& Heckmann, F. (2010). Intercultural policies in European cities. Dublin: European Foundation for the Improvement of Living Conditions.

Matzner, M. (Ed.). (2012). Handbuch Migration und Bildung. Weinheim \& Basel: Beltz Verlag.

Mehrländer, U., \& Hoffmann, R. (1981). Situation der ausländischen Arbeitnehmer und ihrer Familienangehörigen in der Bundesrepublik Deutschland - Repräsentativuntersuchung'80. Bonn: Bundesminister für Arbeit und Sozialordnung.

Beauftragte der Bundesregierung für Migration, Flüchtlinge und Integration. (Ed.). (2011). Zweiter Integrationsindikatorenbericht. Erstellt für die Beauftragte der Bundesregierung für Migration, Flüchtlinge und Integration. Köln/Berlin.

Beauftragte der Bundesregierung für Migration, Flüchtlinge und Integration. (2013). 9. Lagebericht der Beauftragten der Bundesregierung für Migration, Flüchtlinge und Integration über die Lage der Ausländerinnen und Ausländer in Deutschland. Berlin.

Mommsen, W. J. (1990). Die Idee der deutschen Nation in Geschichte und Gegenwart. Gewerkschaftliche Monatshefte 5/6, 263-273.

Musterd, S. (2005). Social and ethnic segregation in Europe: Levels, causes and effects. Journal of Urban Affairs, 27(3), 331-348.

Oberndörfer, D. (1994). Multikulturalismus in der Einwanderungsgesellschaft. In K. J. Bade (Ed.), Das Manifest der 60: Deutschland und die Einwanderung (pp. 133-148). Beck: München.

Schnapper, D. (1995). The significance of French immigration and integration policy. In F. Heckmann \& W. Bosswick (Eds.), Migration policies: A comparative perspective (pp. 99-112). Stuttgart: Enke.

Schneider, J. (2010). Modernes Regieren und Konsens? Kommissionen und Beratungsregime in der deutschen Migrationspolitik. Wiesbaden: VS Verlag für Sozialwissenschaften.

Scholten, P. (2009). The coproduction of immigrant integrations policy and research in the Netherlands: The case of the Scientific Council for Government Policy. Science and Public Policy, 36(7), 561-573.

Stanat, P. (2006). Schulleistungen von Jugendlichen mit Migrationshintergrund: Die Rolle der Zusammensetzung der Schülerschaft. In J. Baumert et al. (Eds.), Herkunftsbedingte Disparitäten im Bildungswesen: Diferenzielle Bildungsprozesse und Probleme der Verteilungsgerechtigkeit. Vertiefende Analysen im Rahmen von PISA 2000 (pp. 189-219). Wiesbaden: VS Verlag für Sozialwissenschaften.

Stanat, P., \& Christensen, C. (2006). Where immigrant students succeed. A comparative review of performance and engagement in Pisa 2003. Paris: OECD.

Sachverständigenrat Deutscher Stiftungen (SVR). (2010). Jahresgutachten 2010 mit Integrationsbarometer. Berlin: SVR.

Thränhardt, D. (2008). Rahmenbedingungen, Motive und Perspektiven des Erwerbs der deutschen Staatsangehörigkeit. Bonn: Friedrich Ebert Stiftung.

Tillman, K.-J. (2008). Leistungsvergleichsstudien und Systemsteuerung, oder: Was hat PISA zu bildungspolitischen Entscheidungen beigetragen? Vortrag auf dem Symposium zum Gedenken an Hermann Lange, 01.10.2088, Universität Hamburg. Online: http://www.gew.de/Binaries/ Binary38502/TillmannVortragHamburg 1008.pdf. Checked on 15.10.2012.

Treibel, A. (1988). Engagement und Distanzierung in der westdeutschen Ausländerforschung. Eine Untersuchung ihrer soziologischen Beiträge. Stuttgart: Enke.

Weinmann, M., Becher, I., \& Babka von Gostomski, C. (2012). Das Einbürgerungsverhalten von Ausländerinnen und Ausländern in Deutschland. Nürnberg: Bundesamt für Migration und Flüchtlinge.

Wilpert, C. (1984). International migration and ethnic minorities. New fields for post-war sociology in the Federal Republic of Germany. Current Sociology, 32(3), 305-352.

Wippermann, C., \& Flaig, B. B. (2009). Lebenswelten von Migrantinnen und Migranten. Aus Politik und Zeitgeschichte, 5(2009), 3-11. 
Wollenschläger, M. (1994). Migrationspolitik und Zuwanderungsrecht, Illegalität und Legalisierung, Integration und Staatsangehörigkeitsrecht'. In K. J. Bade (Ed.), Das Manifest der 60: Deutschland und die Einwanderung (pp. 198-212). Beck: München.

Worbs, S. (2008). Die Einbürgerung von Ausländern in Deutschland. Nürnberg: Bundesamt für Migration und Flüchtlinge.

Wunderlich, T. (2005). Die neuen Deutschen.Subjektive Dimensionen des Einbürgerungsprozesses (Forum migration 9). Stuttgart: Lucius und Lucius.

Zolberg, A. (2006). A nation by design. Immigration policy in the fashioning of America. Cambridge, MA: Harvard Universitiy Press. 


\title{
Chapter 12 \\ Research-Policy Dialogues in the Netherlands
}

\author{
Stijn Verbeek, Han Entzinger, and Peter Scholten
}

\subsection{Introduction}

The Netherlands was one of the first countries in Europe to formulate a coordinated national policy on migrant integration, in the early 1980s. In time this policy would become well known internationally as the Dutch multicultural model, because of its emphasis on the institutionalisation of cultural diversity and cultural emancipation of ethnic minority groups (see also Chap. 3). However, the history of Dutch migrant integration policy has been very dynamic. In the 2000s, the Netherlands was one of the first European countries to make a sharp 'assimilationist turn' (Joppke and Morawska 2003). More recently, Dutch policymakers have been withdrawing from this policy area, delegating responsibility for integration almost entirely to migrants themselves.

In the Netherlands migrant integration policy became politicised around the year 2000. Since then, political anti-migrant movements have gradually become stronger. Public perceptions of Muslims in particular have deteriorated significantly (SCP 2009: 29-30). Influential events in this regard were 9/11 and the killings of politician

\footnotetext{
S. Verbeek $(\square)$

Staff, Education Council of the Netherlands (Onderwijsraad), Nassaulaan 6, 2514 JS The Hague, Netherlands

Stijn Verbeek was previously associated with Erasmus University Rotterdam e-mail: s.verbeek@onderwijsraad.nl

H. Entzinger

Department of Sociology, Erasmus University Rotterdam, P.O. Box 1738, 3000 DR Rotterdam, Netherlands

P. Scholten

Department of Public Administration, Erasmus University Rotterdam, P.O. Box 1738, 3000 DR Rotterdam, Netherlands

e-mail: p.w.a.scholten@fsw.eur.nl 
Pim Fortuyn by an animal rights activist (2002) and film director Theo van Gogh by a fundamentalist Muslim (2004). Both were outspoken opponents of immigration, in particular from Muslim countries. Today, migrant integration issues are still high on the political and public agenda (Table 12.1).

At the same time, the extensive ethnic monitoring structure constructed in the 1980s and 1990s still exists (Guiraudon et al. 2005). Dutch policies still aim at socalled evenredigheid, i.e. proportional participation for comparable groups with or without a migrant background, though less explicitly than before (Dagevos 2012). Each year, either CBS (Statistics Netherlands) or the SCP (the Social and Cultural Planning Office, a governmental research organisation that provides data on social and cultural developments) still publishes an integration report on the progress made so far and on remaining challenges in various societal domains.

Table 12.1 Policy frames in Dutch migrant integration policy since the 1970s (Adapted from Scholten 2011)

\begin{tabular}{|c|c|c|c|c|c|}
\hline & $\begin{array}{l}\text { No } \\
\text { integration } \\
\text { policy } \\
<1980\end{array}$ & $\begin{array}{l}\text { Ethnic } \\
\text { Minorities } \\
\text { Policy } \\
\text { 1980-1994 }\end{array}$ & $\begin{array}{l}\text { Integration } \\
\text { Policy } \\
\text { 1994-2003 }\end{array}$ & $\begin{array}{l}\text { New Style } \\
\text { Integration } \\
\text { Policy } \\
2003-2010\end{array}$ & $\begin{array}{l}\text { Beyond } \\
\text { Integration } \\
\text { Policy }>2010\end{array}$ \\
\hline Terminology & $\begin{array}{l}\text { Integration } \\
\text { with } \\
\text { retention of } \\
\text { identity }\end{array}$ & $\begin{array}{l}\text { Mutual } \\
\text { adaptation } \\
\text { in a multi- } \\
\text { cultural } \\
\text { society }\end{array}$ & $\begin{array}{l}\text { Integration, } \\
\text { Active } \\
\text { citizenship }\end{array}$ & $\begin{array}{l}\text { Adaptation, } \\
\text { 'Common } \\
\text { citizenship' }\end{array}$ & $\begin{array}{l}\text { Individual } \\
\text { responsibility to } \\
\text { assimilate or } \\
\text { 'return home' }\end{array}$ \\
\hline $\begin{array}{l}\text { Social clas- } \\
\text { sification }\end{array}$ & $\begin{array}{l}\text { Immigrant } \\
\text { groups } \\
\text { defined by } \\
\text { national } \\
\text { origin and } \\
\text { framed as } \\
\text { temporary } \\
\text { guests }\end{array}$ & $\begin{array}{l}\text { Ethnic or } \\
\text { cultural } \\
\text { minorities } \\
\text { charac- } \\
\text { terised by } \\
\text { socio- } \\
\text { economic } \\
\text { and socio- } \\
\text { cultural } \\
\text { problems }\end{array}$ & $\begin{array}{l}\text { 'Citizens' or } \\
\text { 'allochto- } \\
\text { nen', } \\
\text { individual } \\
\text { members of } \\
\text { specific } \\
\text { minority } \\
\text { groups }\end{array}$ & $\begin{array}{l}\text { 'Non- } \\
\text { Western } \\
\text { allochtonen' } \\
\text { defined as } \\
\text { policy } \\
\text { targets } \\
\text { because of } \\
\text { socio- } \\
\text { cultural } \\
\text { differences }\end{array}$ & $\begin{array}{l}\text { Continuity: } \\
\text { 'non-Western } \\
\text { allochtonen' } \\
\text { defined as policy } \\
\text { targets because of } \\
\text { socio-cultural } \\
\text { differences }\end{array}$ \\
\hline $\begin{array}{l}\text { Causal } \\
\text { stories }\end{array}$ & $\begin{array}{l}\text { Socio- } \\
\text { economic } \\
\text { participation } \\
\text { and } \\
\text { retention of } \\
\text { socio- } \\
\text { cultural } \\
\text { identity }\end{array}$ & $\begin{array}{l}\text { Socio- } \\
\text { cultural } \\
\text { emancipa- } \\
\text { tion as a } \\
\text { condition } \\
\text { for socio- } \\
\text { economic } \\
\text { participation }\end{array}$ & $\begin{array}{l}\text { Socio- } \\
\text { economic } \\
\text { participation } \\
\text { as a } \\
\text { condition } \\
\text { for socio- } \\
\text { cultural } \\
\text { emancipa- } \\
\text { tion }\end{array}$ & $\begin{array}{l}\text { Socio- } \\
\text { cultural } \\
\text { differences } \\
\text { as obstacle } \\
\text { to } \\
\text { integration }\end{array}$ & $\begin{array}{l}\text { Mythical mass } \\
\text { immigration of } \\
\text { 'disadvantaged' } \\
\text { damages Dutch } \\
\text { society }\end{array}$ \\
\hline $\begin{array}{l}\text { Normative } \\
\text { perspective }\end{array}$ & $\begin{array}{l}\text { The } \\
\text { Netherlands } \\
\text { is not a } \\
\text { country of } \\
\text { immigration }\end{array}$ & $\begin{array}{l}\text { The } \\
\text { Netherlands } \\
\text { as an open, } \\
\text { multi- } \\
\text { cultural } \\
\text { society }\end{array}$ & $\begin{array}{l}\text { Civic } \\
\text { participation } \\
\text { in a de-facto } \\
\text { multicul- } \\
\text { tural } \\
\text { society }\end{array}$ & $\begin{array}{l}\text { Preservation } \\
\text { of Dutch } \\
\text { national } \\
\text { identity and } \\
\text { social } \\
\text { cohesion }\end{array}$ & $\begin{array}{l}\text { Limiting } \\
\text { immigration, } \\
\text { except some } \\
\text { high-skilled flows }\end{array}$ \\
\hline
\end{tabular}


The broader field of migrant integration research (i.e. the field of knowledge production) has changed significantly over the years. From a relatively small and coherent field in the 1980s, with a strong knowledge consensus (the 'minorities paradigm'), migrant integration research has evolved into a large and fragmented field, which is characterised by various 'schools of thought'. There has been a growing manifestation of knowledge conflicts amongst migrant integration scholars, often working from very different frames of migrant integration. Moreover, Dutch migrant integration research has internationalised rapidly, especially over the last decade or so. There has been a rapid proliferation of comparative studies.

Since the late of the 1980s, the positivist belief in the role of scientific research as a tool for societal engineering in this area has clearly declined (Scholten 2011). In fact, there appears to be a growing disenchantment about research-policy dialogues. The politicisation of migrant integration policies has at various moments led to public scepticism about the credibility of migration scholars (see also Scholten and Verbeek 2014), in Parliament as well as in the media, partly because of their deep involvement in previous policies that were so fiercely rejected later. The research-policy dialogue structure has become much more politicised and mediatised compared with earlier years when a strong mutual relationship pertained in official, but relatively private (non-mediatised) settings. Jan Rath coined the term 'technocratic symbiosis' to describe this earlier scenario (Rath 2001).

In the current literature on research-policy dialogues on migrant integration lots of attention has been devoted to politicisation but little to mediatisation. The DIAMINT project was also designed to address this gap. In DIAMINT, we took a broad perspective on research-policy dialogues: we did not only look at relatively direct communications between researchers and policymakers in formal and informal settings - but also at indirect communications via the mass media.

The Netherlands is a strategic case to explore the combined impact of politicisation and mediatisation of research-policy dialogues about migrant integration, because media attention for the topic reached unprecedented peaks in the 2000s, also in international comparison. ${ }^{1}$ As Vliegenthart (2007: 139) states: 'Research that tries to explain the recent changes in the Dutch debate on immigration and integration of minorities without taking the media factor into account is incomplete - at best' (see Uitermark 2010). In his longitudinal (1990-2004), large-scale content analysis of the political and media debates on immigration and integration in the Netherlands, Vliegenthart (2007: 136) concluded that the results resonated most strongly with a 'mediacratic conception of democracy'. In this conception, the media 'assert influence on both politics and public and are in that way most powerful in shaping political decision-making processes and public opinion' (Vliegenthart 2007: 135).

The next section gives the necessary context for the analysis by briefly describing the key issues in migrant integration and migrant integration policies in the

\footnotetext{
${ }^{1}$ See the FP7 project on 'Support and Opposition to Migration', http://www.som-project.eu/, accessed 24 Sept 2013.
} 
Netherlands. The third section summarises the existing literature on research-policy dialogues on migrant integration in the Netherlands, which is mainly devoted to their politicisation: as the issue became politicised, did research-policy dialogues become politicised as well? The fourth section explores the hypothesised mediatisation of research-policy dialogues, about which very little research is available yet. It 'zooms in' on the roles taken by individual scientists in different research-policy dialogue structures (mediatised and non-mediatised) and the possible consequences of these roles for the utilisation of their knowledge by policymakers. In agreement with the other country cases, three specific key topics were chosen to strengthen the comparative analyses at the international level: Islamic schools, educational segregation, and naturalisation. The concluding section suggests that the combined politicisation and mediatisation of research-policy dialogues on migrant integration may have created a new boundary, i.e. a boundary between mediatised and nonmediatised research-policy dialogues. Consequently, the old boundary between the 'two worlds' of 'research' and 'policy' may have lost some of its relevance.

\subsection{Migrant Integration and Migrant Integration Policies}

The recent history of immigration to the Netherlands and the immigrant presence in the country are not drastically different from those in neighbouring European countries (Entzinger 2010, Entzinger et al. 2011). Currently, about $11 \%$ of the Dutch population of 16.5 million people are foreign born and for that reason can be qualified as immigrants. One in five persons living in the Netherlands is either an immigrant or a child of an immigrant. Three communities (including the 'second generation') stand out in size: Turks, Surinamese and Moroccans, each numbering between 350,000 and 400,000. The Turkish and the Moroccan communities are legacies of the so-called 'guest worker' policies in the late 1960s and early 1970s. Most migrants from Surinam arrived in the 1970s, when this former Dutch colony acquired political independence. The end of the Cold War led to a significant growth of East European migrants, particularly since the accession of the new member states in 2004 and 2007, and of asylum seekers, some of whom later acquired refugee status. Besides, growing numbers of Dutch and foreign residents find their spouses in other countries. In recent years, the number of highly skilled migrant workers has also increased, although many of them do not settle for good. Meanwhile, family migration among the three largest communities, the Turks, the Surinamese and the Moroccans, is continuing, albeit at a much slower pace than before (Entzinger 2010).

Dutch integration policy, however, focuses only on specific categories of migrants. Unlike many other immigration countries in Europe, citizenship is not generally considered as the primary distinguishing factor between migrants and the native population (Entzinger 2010). Rather, ethnic origin tends to be more relevant 
in the public perception as a means of differentiating between them and us. The Dutch have even constructed a term for this: the Greek-based word allochtonen refers to those people whose ethnic roots lie outside the Netherlands and who, for that reason, can be differentiated from autochtonen, the native Dutch. The statistical category 'niet-westerse allochtonen' ('non-Western allochtones', just over onetenth of the population) includes both first-generation migrants and persons who were born in the Netherlands, but have at least one parent born in a 'non-western' country, i.e. in Africa, Central and South America, Asia (excl. Indonesia and Japan), or Turkey (Statistics Netherlands 2008). All other allochtonen are labelled 'Western' and are generally seen as more similar to the native Dutch - and therefore as less problematic. It should be noted that the term allochtonen is not uncontested and controversy surrounding the concept has led several municipalities to abolish it. One reason for this is that perceived integration problems no longer coincide so clearly with 'non-Western' origins (Ham and Van der Meer 2012).

The development of Dutch national integration policy is marked by discontinuity: the Minorities Policy in the 1980s had distinct multiculturalist traits; Integration Policy in the 1990s had more universalist traits; and finally the so-called New Style Integration Policy since 2002 has had distinct assimilationist traits (Scholten 2011: 75-76) (Table 12.1). In the latter frame, the dominant idea is that migrants are to blame for their slow integration, while efforts to step up this process should come from their side (Entzinger 2010). Some lip service is being paid to the idea that integration should be two-sided and that the established population should also leave some space to newcomers, but only a few concrete policy measures have pointed in that direction. Most of the new measures leave little or no room for public recognition of migrants' cultural identity (Entzinger 2010). The Dutch case seems to be exceptional in the sense that it exemplifies a radical turn from multiculturalism to assimilationism (Poppelaars and Scholten 2008: 339). In fact, although the Netherlands has long been celebrated for its multiculturalist policies, nowadays this multiculturalist approach is widely dismissed as a failure in Dutch public and political discourse (ibid.).

The 'assimilationist turn' (Joppke and Morawska 2003) in Dutch integration policies was less outspoken in the period 2007-2010, when the Labour Party was part of the national government. As distinct from the New Style Integration Policy of the preceding period, migrant integration was now connected to urban policy and to neighborhood policies, away from the more symbolic facets of national integration policies and issues of national identity. However, the Centre-Right coalition led by Prime Minister Rutte that came to power in 2010 again discursively promoted assimilation, national unity and 'Dutchness', as was to be expected given its political composition and the fact that the minority coalition needed parliamentary support from the anti-immigrant Freedom Party. Actually, however, it did not achieve much in this realm. At present, policymakers are withdrawing from this policy area, focusing instead much more on limiting immigration, with the exception of some high-skilled flows. This, however, is easier said than done, since most immigration now stems from other EU countries, and these flows cannot really be controlled. 


\subsection{Research-Policy Dialogues: A State of the $\mathrm{Art}^{2}$}

\subsubsection{The 1970s and the 1980s}

Research as well as policymaking on migrant integration had been virtually nonexistent in the Netherlands until the late 1970s, as the country did not consider itself a country of immigration (Entzinger and Scholten 2013). The settlement of growing numbers of post-colonial migrants since the 1950s and of 'guest workers' from Mediterranean countries since the 1960s was not recognised by the authorities as a permanent phenomenon. Thus specific policy efforts to promote their integration were not deemed necessary. Only the Ministry of Social Work (CRM) assumed a more proactive role, since it was the first to be faced with demands from immigrants and also encountered growing tensions between immigrant communities and the native population. The Ministry, however, had virtually no experience in these matters, and therefore turned to the social sciences. In those days the belief was widespread that social scientists could provide the necessary tools for social planning and engineering, and provide answers to the emerging challenges.

In this context several boundary organisations entered the scene. The Social and Cultural Planning Office (SCP) - established in 1973 and closely associated with the Ministry of Social Work - began to collect information on the position of immigrants in society. Mobilising data would be a first step towards raising awareness that new policy measures would be required. Taking this approach a step further, the Ministry of Social Work installed the Advisory Commission on Minorities Research (ACOM) in 1978. ACOM was meant to advise the Ministry on programming the research needed for the further development of policies in this area (Scholten 2011). This was not unusual in those days: so-called researchprogramming commissions were set up in several policy areas, in some cases because the area was too controversial for decision-making (e.g. demography, where birth control was still an issue), in other cases because it was too new and too little was known to enable sound policymaking (e.g. environmental issues, and also immigration). The ACOM membership was exclusively academic, and ACOM soon acted as a linchpin or archetypical boundary organisation between policymakers and the research community. After a few years, as other ministries began to be faced with the effects of continuing immigration, ACOM's advisory capacities were expanded to the entire government.

Another boundary organisation that played a pivotal role in the research-policy dialogue was the Scientific Council for Government Policy (WRR), a high-level governmental advisory body, set up in 1972 to advise the Dutch government on new developments in society and their potential relevance for policymaking (Scholten 2009). The WRR is an independent body, free to decide its own agenda, but administratively part of the Office of the Prime Minister. The government is obliged

\footnotetext{
${ }^{2}$ This section is partly based on Entzinger and Scholten (2013).
} 
by law to respond to its recommendations. The WRR has reported on migrant integration four times in the 40 years of its existence. The first report, called Etnische minderheden ('Ethnic Minorities'), was released in 1979 and set the scene for the initial multiculturalist approach to migrant integration adopted by the Dutch government. In fact, this report was taken as a direct basis for the first memorandum on migrant integration policies, the Nota Minderhedenbeleid ('Memorandum on Minorities Policy') of 1981, which was finalised in 1983.

These developments in the Dutch research-policy dialogue on migrant integration reflected the strong policy orientation of social scientists in this period. This was matched by a strong belief in rational societal steering amongst policymakers and politicians. Amongst policymakers there was little experience with migrant integration policies. Respondents in our fieldwork agree that a strong consensus prevailed that migrant integration should not be turned into a partisan issue. This led to a context of de-politicisation, which enabled social science research to provide an authoritative venue for policy formulation.

The research-policy dialogue also affected the development of migration research itself. By the early 1970s, only a handful of social scientists had been active in the area, largely inspired by the immense amount of knowledge that was developed over many decades by their US colleagues and, to a lesser extent, in the UK. In those days, dominant scholars in these two countries had begun to distance themselves from the classical idea that migrant integration would involve assimilation. The idea that immigration would lead to the formation of ethnic minorities, recognisable as such for at least several generations to come, had become the major paradigm in these more experienced immigration countries. The 'ethnic minorities' concept also appealed to many of the Dutch academics: several anthropologists, for example, were familiar with the concept of 'ethnicity' through earlier research in the Dutch colonies.

The construction of a direct dialogue structure between migration research and policymaking in the late 1970s and early 1980s not only led to the formation of an Ethnic Minorities Policy, but also facilitated the dominance of the ethnic minorities paradigm in early migration research. Rath observes that 'the development of political-economic theory on guest workers in the Netherlands was quite suddenly interrupted, precisely at the moment that the state incorporated researchers into the bureaucratic apparatus and initiated wide-scale funding for politically relevant research' (Rath 2001: 152). Similarly, Penninx, one of the key architects of the WRR's Ethnic Minorities report, observes that significant criticism existed towards ACOM, which 'in some circles of researchers (..) was seen as a biased group of advisors that functioned as gatekeepers for (..) research funding, and gave no or insufficient attention to certain topics or disciplines' (1988: 37). Thus, support for the ethnic minorities paradigm coincided with the dismissal of contending knowledge claims. This happened, for example, to those who were doubtful about the effects of mother tongue teaching for migrant children and also to adherents of the racism paradigm. The same happened to research initiatives that emerged, albeit very slowly, from within the ethnic communities themselves (Essed and Nimako 2006). 


\subsubsection{The 1990s}

Until well into the 1990s, the ethnic minorities paradigm remained the dominant paradigm in the Netherlands, both in policymaking and in research. Research in the area expanded rapidly, mostly financed by a growing number of Ministries that perceived a need for a sounder basis for their new policies. Slowly but surely the 'technocratic symbiosis' (Rath 2001) began to collapse. In an effort to strengthen the academic nature of immigration research, the Netherlands Organisation for Scientific Research (NWO) funded a special programme in which the need for more theory was emphasised. At several universities chairs in migration studies were established, while specialised research centres for migration and ethnic studies were set up at the Universities of Utrecht (ERCOMER) in 1993 and Amsterdam (IMES) in 1994. Gradually, other academic disciplines, less burdened with the minorities paradigm than sociology and anthropology, also took on an interest in this research area. In fact a second report by the Scientific Council for Government Policy (1989), on immigrant policy, had already punctuated the monopoly of the ethnic minorities paradigm. The Council's main argument for this was that its use had reinforced tendencies towards separation and increased the migrants' dependence on public services, rather than fostering their integration. As an alternative the Council proposed a policy of individual integration into mainstream institutions, such as labour and education, combined with facilities to improve the immigrants' knowledge of the Dutch language.

Partly as an effect of the second WRR report, awareness grew among policymakers that the minorities paradigm would not hold (see also Scholten and Timmermans 2010). Immigration continued and diversified, developing into a structural phenomenon following the fall of the Iron Curtain after 1989. Moreover, within the oldest migrant communities, a second generation born and raised in the Netherlands began to manifest itself. In 1994, Minorities Policy was officially relabelled as 'Integration Policy', and the migrant integration issue began to rise slowly on the political agenda. Policymaking had now reached a more mature stage, characterised by a growing number of policy instruments (e.g. the introduction of mandatory integration courses in 1998) and by stronger vested interests, also from civil society, including migrant organisations.

A gradual alienation between academics and policymakers occurred. ACOM, a strong defender of the minorities paradigm had rejected the 1989 WRR report as 'unscientific', thus trying to discredit the researchers involved (Scholten 2011). However, this effort to discredit the WRR failed largely, and ACOM was eventually dissolved in 1992. Migration research now became more fragmented, but also more pluriform. For the academic world this growing disconnection with policymaking did not mean that research funds became scarcer, as alternative funding sources gradually gained importance. The main change was that political agenda setting shifted from academia to policymakers, while the use of research outcomes became more selective. Governmental research organisations like CBS and SCP became more important partners for migrant integration policymakers. 
The de-institutionalisation of the research-policy dialogue structure of the 1980s and the first signs of politicisation in the early 1990s coincided with an increasing demand for less conceptual and more 'practical' types of research. Policymakers needed large-scale data, preferably based on surveys or derived from existing registration systems. To borrow Peter Hall's typology, this preference for quantitative data was oriented to first and second-order information (regarding policy instruments and settings of policy instruments) rather than third-order information (regarding the policy paradigm) (Hall 1993). Policymakers from the 1990s onwards were not inclined to use knowledge to reframe migrant integration policies. Several of our interviews indicate that the mobilisation of such data fulfilled a clear role in the interdepartmental coordination of migrant integration policies. The data produced by SCP and CBS allowed the coordinating Ministry of the Interior to organise its information position in relation to other ministries involved in migrant integration. This enabled it to monitor the implementation of policy measures by various departments, to identify potential deficiencies and to put issues on the agenda so that new policy measures could be developed. Also more evaluation studies were needed to assess the impact of earlier policies. Such studies were increasingly commissioned to research units within the respective ministries, like the Centre for Scientific Research and Documentation (WODC) of the Ministry of Justice, or to private consultancy firms.

\subsubsection{The 2000s}

In the context of the sharp politicisation of migrant integration in the early 2000s the role of research in policymaking declined even further (Scholten and Verbeek 2014). Some speak of the rise of 'articulation politics', or a form of politics aimed at gaining legitimacy by responding to 'the voice from the street' (Verwey-Jonker Institute 2004). This became manifest soon after the dramatic 2002 elections when the newly elected Dutch parliament adopted a motion asking for an investigation into 'why immigrant integration had failed', without even asking if it had failed. The Parliamentary Committee set up for this purpose commissioned the Verwey-Jonker Institute, an independent institute for social research, to study this state-of-affairs, mainly based on existing research (see also Chap. 5 on consultative commissions). Their final report was heavily criticised in parliament as well as in the media for being biased and overly sympathetic to left-wing ideologies. In these debates the credibility of the social researchers involved in this institute was openly put on the line. Social researchers were blamed for having been too involved in policymaking and for reflecting a multiculturalist bias. At the same time, policymakers and politicians who had been active in this area were blamed for lacking a clear political vision and for having delegated too much of the policymaking to researchers (Scholten 2011). The days of technocratic symbiosis were definitely over. Likewise, when the Parliamentary Committee itself came with its final report, concluding that 
immigrant integration had been relatively successful, it was also heavily criticised by many actors in both parliament itself and in the media.

Research on immigration and particularly on integration is now being initiated in many more disciplines than before, including law, economics, psychology, and medical sciences. It is also much less policy-oriented than in the early days and theoretically richer and broader. The growing availability of databases and their improved accessibility have led to a much larger number of quantitative studies. Numerous $\mathrm{PhD}$ dissertations have been written in this field, which in less than four decades has become one of the core specialisms, certainly in the social sciences. The growing availability of European research funds has led to a dramatic increase in comparative studies, thus making Dutch researchers less dependent on national funding sources, many of which have been drying up anyway. Moreover, as policymaking is becoming more decentralised, local authorities have been taking up an interest in funding research. They often cooperate closely with local universities. On a critical note, it has been argued that the reliance not only of governmental researchers but also of university researchers on official ethnic data in the Netherlands contributes to the continuous substantiation of 'the ethnic lens', which sees socio-cultural explanations for every societal problem (Ham and Van der Meer 2012). Similarly, producing and using data on so-called 'social-cultural distance' between allochtonen and autochtonen of course confirms the idea that something like 'social-cultural distance' exists.

Finally, the Dutch DIAMINT study has found that civil servants in the Netherlands nowadays work with a 'continuum of trustworthiness'. The trust worthiest source of expertise is considered SCP, because SCP investigates the questions that the Ministry is interested in by using the best-known sampling and statistical techniques. Somewhat halfway are researchers who are capable of meedenken, translatable as the ability to 'think like a' policymaker. The position of this middle group is a clear indication of how 'policy-relevant expertise' is constructed in the knowledge utilisation process itself: the expertise does not 'exist' beforehand (Caponio et al. 2014). The least trustworthy are scientists who in the perspective of the bureaucratic officials take extreme positions or who are unpredictable from a ministry's perspective. Put simply, the positions of these experts are either known beforehand - which means that it is not necessary to invite them to hear them repeat their point of view - or completely unknown beforehand, meaning that it is risky to invite them to participate in research-policy dialogues, because the expert may propose ideas that are totally at odds with current political realities.

\subsection{An Exploration of Three Subtopics in Research-Policy Dialogues}

The analysis in this section proceeds in three steps. In the Netherlands political and media attention is often focused on the three I's: immigration, integration, and Islam. Consequently, the subtopic 'Islamic schools' is an interesting case 
for exploring the combined politicisation and mediatisation of research-policy dialogues in migrant integration. With reference to Islamic schools, it is clear that policy dialogues have become not just strongly politicised but also mediatised, which will affect the nature of research-policy dialogues as well. The subsequent analysis of the research-policy dialogue on educational segregation, the second subtopic in this section, suggests that for that policy topic the impact of mediatisation has been more limited. The third subtopic, naturalisation, explores whether mediatised and non-mediatised research-policy dialogues on this politicised topic not only exist alongside each other, but whether they also constitute alternative communication channels between researchers and policymakers.

\subsubsection{Islamic Schools}

Most interviewees argued that after 9/11 the discussion about Islamic schools had changed - in fact, before $9 / 11$ it was hardly an issue at all. It was simply taken for granted that Muslims in the Netherlands were using their constitutional right to establish their own schools. Like the Catholics in the early twentieth century, this would probably facilitate their societal emancipation. Prime Minister Ruud Lubbers (1982-1994, a Christian Democrat), for example, had encouraged Muslims to take this route. In 2003, however, then Prime Minister Jan-Peter Balkenende (2002-2010, also a Christian Democrat) warned that Islamic schools should not become 'prisons of disadvantage' (cited by Karsten 2006). Yet at the national level, there have been no official policies against Islamic schools. Their number is 'not large': in 2008, there were 44 Islamic schools for primary education in the Netherlands (Herweijer 2009: 43). Only $6 \%$ of all pupils with a Moroccan or Turkish background were enrolled in them. Still, opponents have argued that Islamic schools worsen segregation and hinder integration (ibid.). Observations by some of the respondents confirm the argument by some scholars (Entzinger 2010; Sunier 2014) that the migrant integration debate in the Netherlands has 'Islamised', rather than the Netherlands itself (Fortuyn 1997). The mass media's obsession with 'Islam' sometimes comes to the fore in surprising ways, as it can affect the use of expert knowledge even in seemingly unrelated domains.

One respondent (interview with educational researcher), for example, recalls how his research (with colleagues) on homeschooling was received initially. Homeschooling in the Netherlands mainly involves a small number of traditional Christians, who feel that no school adequately reflects their religious beliefs. The researchers basically concluded that 'no dramatic' situations existed (interviews with several scholars), i.e. that the parents involved educated their children well and that their children participated in society in an adequate manner. Parliament and the Minister of Education decided that no (additional) law was needed to regulate homeschooling. Two months later, however, one Islamic school had to close down amidst fierce media attention due to concerns over quality, and some parents said that they would rather start homeschooling than send their children to a non-Islamic 
school. Suddenly media interest in research on homeschooling exploded (interview). The minister responsible was quick to announce that he would scrutinise the existing regulations for homeschooling to prevent the Muslim parents' homeschooling plans. In other words, the initial effect of the study was that policymakers concluded that they did not have to worry about the topic of homeschooling too much. No legislation process was started, even though the researchers had advised the introduction of additional laws to regulate homeschooling. Due to the publicity about the Muslim parents' homeschooling intentions, however, in the second instance policymakers seemed to draw different lessons from the study.

Can we conclude that the political primacy in research-policy dialogues, which we noted earlier, has been replaced in some sub-domains by something like "media primacy'? In the next section, a key episode in the research-policy dialogue on educational segregation in the Netherlands is analysed to illustrate the fact that migrant integration researchers sometimes play a very pro-active role in mediatised research-policy dialogues themselves. Neither policymakers nor individual experts are merely playthings of media forces.

\subsubsection{Educational Segregation}

The issue of educational segregation in the Netherlands, often referred to as the issue of 'black' versus 'white' schools, has been on the public agenda since the 1980s (Herweijer and Van den Brink 2011, p. 1). Educational segregation in the Netherlands can largely be explained by residential segregation, but it is also related to the Dutch system of free school choice (Herweijer 2009). Parents are not obliged to choose for their children a school in the area where they live. National policies to combat educational segregation have been virtually absent. Since 2006, though, 'school boards, municipal authorities and childcare providers have been required to consult with each other with a view to achieving a more balanced distribution of pupils across schools' (Herweijer 2009, p. 14). In the period 2007-2011, the national government also supported pilots in 12 cities 'intended to identify effective interventions at a local level to reduce segregation' (ibid.).

Overall, educational research in the Netherlands is a well-developed area, with most of the funds being controlled by the government directly or indirectly (via the Netherlands Organisation for Scientific Research, NWO). Several established research institutes compete for funding. For these institutes, and the individual researchers affiliated to them, being part of this network is essential. Researchers outside of this dialogue structure find it much harder to get their projects funded and to get direct access to policymakers. Nonetheless, one of the best-known of these 'solitary experts', Professor Jaap Dronkers of Maastricht University (formerly European University Institute Florence, 2001-2009), pro-actively uses the media to inform the public and, by extension, policymakers. 
In June 2010, Jaap Dronkers gave his inaugural lecture at Maastricht University, just after the success of Geert Wilders of the anti-immigrant Freedom Party in the national elections. Based on PISA data (in particular on reading skills of 15-yearolds), he argued that ethnic diversity in schools hampers educational achievements, also in primary education. In its press statement, Maastricht University emphasised certain 'newsworthy' elements of the lecture, but it did not mention that the data used pertained neither to the Netherlands nor to primary school pupils. The professor also pro-actively sought media attention himself and he received a lot of it (national TV news, several newspapers, including the front page of NRC Handelsblad). On its website, the largest newspaper of the Netherlands stated that 'Many races in classes leads to poor achievement' (de Telegraaf). ${ }^{3}$ For the first time in years, Jaap Dronkers was invited to give a lecture at the Ministry of Education, where he summarised his inaugural lecture. A couple of months later, the new Minister of Education, in a cabinet that depended on support from Geert Wilders, announced that the national government no longer aimed at reducing segregation in education.

On the one hand, this episode could be depicted as a clear example of how social scientists can influence public policies on controversial issues via the media. Such a storyline would reveal how his 'dramatic' ${ }^{4}$ contribution silenced the argument in favour of fostering ethnically mixed schools. It became the 'final blow' - or at least it gave ammunition to the Minister (interview with educational scholar). On the other hand, jumping to this conclusion would be paradoxical, because to a considerable extent this research-policy dialogue centred on whether Jaap Dronkers had behaved unscientifically, i.e. whether he had made 'rather definite and generalising statements on the basis of one study', 'especially in the media'. The DIAMINT fieldwork made clear that even in this case, mentioned by virtually all respondents as an example of an extremely mediatised research-policy dialogue, the expert did not 'force a political decision via the media'. Instead, his lecture was used to substantiate a pre-existing political preference, and party political dynamics offer a convincing explanation for this. In contrast, in 2007 - i.e. in a less contested political context - a similar critical research report was not used to abolish the national policy against educational segregation. Even more than before, fighting educational segregation was simply framed in an 'integration and citizenship'

\footnotetext{
${ }^{3}$ See the item 'Veel rassen in klassen leiden tot slechte prestaties', published on 17 June 2010, on http://www.telegraaf.nl/binnenland/20876778/_Diversiteit_zorgt_voor_slechte_prestaties_. html, accessed 24 September 2013.

${ }^{4}$ Zeki Arslan of FORUM Institute for Multicultural Affairs, cited in NRC Handelsblad, 'Ideaal van gemengde klas blijft overeind; Na kritisch onderzoek Dronkers', published on 23 June 2010.

${ }^{5}$ From the personal website of educational researcher Geert Driessen: see http://www.its-nijmegen. nl/medewerkers/expertise.asp?id=15, accessed 24 September 2013. For similar criticism see Prof. Guuske Ledoux, Scientific Director of the Kohnstamm Instituut, a knowledge and research centre in the field of education, during a workshop about the local pilots to counter educational segregation, 23 November 2010 (see the PDF entitled 'Uitwerking_Verslag\%20Pilotbijeenkomst_20101123' at the website of the City of Almelo, www.almelo.nl, accessed 19 August 2013).
} 
perspective instead of an 'educational achievements' perspective (interview). In other words: this extreme case shows that it is too simple to argue that 'experts can choose to influence policymakers via the media'. Instead, actual knowledge utilisation always seems to be the result of a complex interplay between political factors and factors related to the media.

The DIAMINT research also suggested that the success of Jaap Dronkers in getting media attention comes with certain costs. As noted above, some other researchers found his behaviour 'unscientific': they did not trust the validity of his claim. Furthermore, by taking a quite extreme position - which of course can partly explain why he received so much media attention - Jaap Dronkers also ran the risk of alienating rather than pleasing policymakers. ${ }^{6}$ These themes will be picked up in the following section on naturalisation.

\subsubsection{Naturalisation}

In the 1980s, access to formal citizenship was still seen as a useful step in the integration process. Nowadays most parties define it as its pinnacle, or the "first prize' as Rita Verdonk, Minister for Immigration and Integration in two centre-right cabinets (2003-2007), called it. In the past decade, research-policy dialogues on naturalisation mainly concerned the attempts by subsequent governments to make access to Dutch nationality more difficult. Several plans were introduced publicly, but were actually never put to a vote in parliament. Other attempts, however, succeeded (Van Oers 2013), for example when standardised naturalisation tests were introduced in 2003 (interviews).

Research on naturalisation in the Netherlands is scarce. It is mainly done by legal scholars, some of whom have been watching - and partly influencing - the developments in this domain for decades. The policy positions of these experts are generally less strict than those of politicians. They argue, for example, that immigrants should not have to denounce the nationality of their country of origin. Dual nationalities for them simply reflect the fact that people can have durable bonds with more than one state. However the manner in which they defend these positions (i.e. the tone of their message) is quite different. Furthermore - and crucially - different experts tend to use different channels to try and influence the policymaking process in this domain. Some have a very pro-active role in mediatised research-policy dialogues and regularly criticise the national government in public debate. This often involves using strong language. Others keep quite a low profile

\footnotetext{
${ }^{6}$ In a personal communication to the authors (9 June 2014), Jaap Dronkers noted that his inaugural lecture (2010) was later published as a book chapter (Dronkers and van der Velden 2013). Furthermore he noted that the lecture was first of a series of publications on ethnic diversity in education (see Braster and Dronkers 2013; Veerman et al. 2013, and Dronkers' personal website http://www.roa.nl/cv/dronkers/nw_dronkers.htm, accessed 15 June 2014).
} 
and hardly perform in the media at all. This does not mean, however, that the former have a stronger influence on policymakers (via the media) then the latter. 'Behind-the-scenes', that is in relatively unknown national and international legal advisory bodies or in private settings like informal lunches, the impact of individual experts can be 'quite substantial' (interview). However, it is important to distinguish between 'details and major issues': 'The political climate (...) is very important. (...) But okay, within that politicised framework one tends to listen to scientists and there is still some space, especially for legal advice' (interview).

This view on mediatised and non-mediatised research-policy dialogues on naturalisation is not only advanced by experts themselves. As a former top civil servant notes, some experts 'can be very cynical and sarcastic', always wanting 'to take some further steps'. Yet experts who are too 'vigorous' are 'a bit difficult to cite' (interview). Other experts give priority to taking 'into account the political field surrounding the issue at hand'.

Summing up, the fieldwork on naturalisation confirmed the hypothesis derived from the fieldwork on educational segregation that there are relations between the tone and content of the messages of experts, their media presence, and the usefulness of their expertise as perceived by policymakers. Crucially, direct (formal or informal) access to policymakers emerges as an important factor, rather than indirect access via the media. There are indications that experts who have no alternative channels choose more active roles in mediatised research-policy dialogue structures.

The roles taken by individual scientists in mediatised research-policy dialogues may also be connected with knowledge utilisation outcomes. Experts whose positions in the public debate are considered 'too radical' by policymakers may no longer receive commissioned research assignments, formal invitations to join advisory committees, or informal invitations to meet top officials and ministers. As Engbersen (2009) notes, the 'loyalty-option' implies some degree of 'political realism', i.e. conformity to the parameters perceived by the powers in office.

\subsection{Conclusions}

As noted in the theoretical framework of this book, orthodox approaches to researchpolicy dialogues take the 'two worlds metaphor' as their starting point. The idea that one can somehow separate 'science' from 'policy' is implied by the very concept of research-policy dialogues. One of the key findings of the project, however, is that research-policy dialogues on migrant integration are characterised by extreme 'role convergence', to use Hoppe's (2005) phrase (also see Wittrock 1991). Put simply, migrant integration policymakers do their own research and migrant integration researchers 'make policies', in various ways (Caponio et al. 2014). Very few scientists nowadays 'lock themselves up in the ivory tower'. In other words, the border region between science and policy is not a 'no man's land'. Furthermore, we can also see a very strong role convergence when it comes to behaviour in 
the mass media: there are both scientists and policymakers who try to use the media to their advantage and they use similar strategies. It is one of the hallmarks of contemporary politicised research-policy dialogues on migrant integration that public officials have most trust in those researchers who depend on them most. And they mistrust so-called 'independent scientists', notwithstanding peer-review mechanisms, because they feel that these people have a (hidden) political agenda and are interested in promoting their political ideals. ${ }^{7}$ The scientists after all may even propose certain measures on the basis of empirical research and call them 'evidence-based policies', while in reality the evidence is not so strong and the recommendations are mainly based on normative preferences. Of course, due to the direct financial links between for example SCP and the ministry it advices, the argument could also be made that SCP researchers are less 'objective' than seemingly untouchable professors at universities.

This chapter contended earlier that the current literature on research-policy dialogues in the Netherlands is primarily concerned with politicisation. The section on the three subtopics explored the role of mediatisation and tentatively concluded that more attention to this aspect is warranted. The empirical analysis suggests that mediatised dialogue structures differ from non-mediatised ones as opportunity structures for influencing migrant integration policy. In fact, there may be a new Boundary, which is the one between non-mediatised and mediatised research-policy dialogues. By this we mean that scientists who wish to have policy impact can take two routes nowadays. The first, more traditional route is to communicate with policymakers directly. In practice this mostly happens in private, i.e. without media coverage, in so-called 'boundary organisations' like committees, advisory bodies and think-tanks, at conferences, informal workshops, dinners, etc. The second route is to communicate with policymakers indirectly, via the media. In the project we have found numerous examples of public intellectuals who have developed media strategies to influence migrant integration policymaking. One interesting avenue for future research, we believe, is to find out whether the two routes 'add up', i.e. whether researchers have to choose or not. There is some evidence (also see the British case) that both routes are to a certain extent alternatives. This is because communicating via the media has a 'cost': put simply, scientists who choose the public route tend to take more critical positions and this decreases the likelihood that they also interact with policymakers directly in more private networks. There are relations between the tone and content of the researchers' messages, their media presence, and the usefulness of their expertise as perceived by policymakers. For example, some researchers see the world of newspapers as 'a totally different reality' (interview). Scientists who do not have direct, private access to policymakers feel

\footnotetext{
${ }^{7}$ This was mentioned as the very first troublesome aspect of research-policy dialogues in the domain of migrant integration by Mr. Heida, Head of the Migration Directorate of the Interior Ministry, in a speech at the Interior Ministry's national conference for $\mathrm{PhD}$ researchers working on migration (The Hague, 15 May 2012).
} 
that they have no other option but to write letters to newspaper editors or to appear on radio or television. They also want to have an impact - on policy positions, public opinion, or both - and believe that writing only academic publications will not suffice.

In summary, up until the early 1990s the Netherlands was characterised by a strongly institutionalised research-policy dialogue structure that prevented politicisation and promoted a monopolisation of the ethnic minorities paradigm. Politicisation in the 1990s, and even more so in the early 2000s, punctuated this symbiosis, allowed for more pluriformity in knowledge claims and also led to more open knowledge conflicts. In situations characterised by a multiplicity of frames, actors with different frames can have very different selections or interpretations of 'evidence'. The growing fragmentation in the field of migration research and also the more open manifestation of knowledge conflicts - in the mass media - seems to have contributed to this trend. Perhaps this trend reflects a more general trend in Dutch politics away from policymaking 'behind closed doors' (and thus in a non-mediatised setting), which has been fiercely criticised by populist politicians since the turn of the millennium. Hence the evolution of Dutch dialogues on migrant integration may have largely kept pace with more macro-institutional developments in research-policy dialogues in the Netherlands. Research-policy dialogues on migrant integration appear to have been significantly affected as Dutch political culture has been moving away from its traditional ploy of consensus building in private settings towards a more confrontational style of politics in public, mediatised settings.

\subsection{A Note on Methodology}

This chapter is based on a review of the literature, document analysis, analysis of newspaper articles, and semi-structured interviews with 33 respondents. The interviews (carried out between late 2011 and early 2013) lasted about $1.5 \mathrm{~h}$ on average. They were all recorded and transcribed. Most respondents were prominent researchers from universities (19) and (former) senior civil servants from the national government (6). Some respondents' key affiliation was with boundary organisations such as SCP and WRR (5). Finally, we also interviewed some key figures from the media realm (3). We would like to thank all respondents for their participation. Due to the sensitivity of the topic, however, they shall remain anonymous.

Open Access This chapter is distributed under the terms of the Creative Commons Attribution Noncommercial License, which permits any noncommercial use, distribution, and reproduction in any medium, provided the original author(s) and source are credited. 


\section{References}

Braster, S., \& Dronkers, J. (2013). De positieve effecten van etnische verscheidenheid in de klas op de schoolprestaties van leerlingen in een multi-etnische metropool. Sociologie, 9, 3-29.

Caponio, T., Hunter, A., \& Verbeek, S. (2014). De(constructing) expertise: Comparing knowledge utilisation in the migrant integration 'crisis'. Journal for Comparative Policy Analysis (Published online in 2014).

Dagevos, J. (2012). Structurele integratie en evenredigheid. In M. Gijsberts, W. Huijnk, \& J. Dagevos (Eds.), Jaarrapport integratie 2011 (pp. 29-32). Den Haag: Sociaal en Cultureel Planbureau (SCP).

Dronkers, J. (2010). Positive but also negative effects of ethnic diversity in schools on educational performance? An empirical test using cross-national PISA data. Maastricht: Maastricht University.

Dronkers, J., \& van der Velden, R. (2013). Positive but also negative effects of ethnic diversity in schools on educational achievement? An empirical test with cross-national PISA-data. In M. Windzio (Ed.), Integration and inequality in educational institutions (pp. 71-98). Dordrecht/Heidelberg/London/New York: Springer.

Engbersen, G. (2009). Fatale remedies. Over onbedoelde gevolgen van beleid en kennis. Amsterdam: Pallas Publications/Amsterdam University Press.

Entzinger, H. (2010). Immigration: Open borders, closing minds. In E. Besamusca \& J. Verheul (Eds.), Discovering the Dutch. On culture and society of the Netherlands (pp. 231-241). Amsterdam: Amsterdam University Press.

Entzinger, H., \& Scholten, P. (2013). The interplay of knowledge production and policymaking: A comparative analysis of research and policymaking on migrant integration in Germany and the Netherlands. Journal of Comparative Policy Analysis (Published online in 2013).

Entzinger, H., Scholten, P., \& Verbeek, S. (2011). AMICALL. Attitudes to migrants, communication and local leadership. Country context paper - The Netherlands. Oxford: COMPAS Centre on Migration, Policy \& Society, University of Oxford.

Essed, P., \& Nimako, K. (2006). Designs and (Co)Incidence: Public policy on immigrants/minorities in the Netherlands. International Journal of Comparative Sociology, 47(3/4), 281-312.

Fortuyn, P. (1997). Tegen de islamisering van onze cultuur: Nederlandse identiteit als fundament. Amsterdam: Bruna.

Guiraudon, V., Phalet, K., \& Ter Wal, J. (2005). Monitoring ethnic minorities in the Netherlands. International Social Science Journal, 57(183), 75-87.

Hall, P. A. (1993). Policy paradigms, social learning, and the state: The case of economic policymaking in Britain. Comparative Politics, 25(3), 275-296.

Ham, M., \& van der Meer, J. (2012). De etnische bril; categorisering in het integratiebeleid. Den Haag: Netherlands Interdisciplinary Demographic Institute (NIDI).

Herweijer, L. (2009). Making up the gap: Migrant education in the Netherlands. Den Haag: Netherlands Institute for Social Research (SCP).

Herweijer, L. \& van den Brink, Y. (2011, June 8-10). Etnische diversiteit en leerprestaties. Paper presented at the Onderwijsresearchdagen, Maastricht.

Hoppe, R. (2005). Rethinking the science-policy nexus: From knowledge utilisation and science technology studies to types of boundary arrangements. Poiesis \& Praxis: International Journal of Technology Assessment and Ethics of Science, 3(3), 199-215.

Joppke, C., \& Morawska, E. T. (2003). Toward assimilation and citizenship: Immigrants in liberal nation-states. London: Palgrave Macmillan.

Karsten, S. (2006). Freedom of education and common civic values. European Education, 38(2), $23-35$.

Penninx, R. (1988). Minderheidsvorming en emancipatie: balans van kennisverwerving ten aanzien van immigranten en woonwagenbewoners 1967-1987. Samsom: Alphen aan den Rijn. 
Poppelaars, C., \& Scholten, P. (2008). Two worlds apart: The divergence of national and local immigrant integration policies in the Netherlands. Administration \& Society, 40(4), 335-357.

Rath, J. (2001). Research on immigrant ethnic minorities in the Netherlands. In P. Ratcliffe (Ed.), The politics of social science research. Race, ethnicity and social change (pp. 137-159). New York: Palgrave.

Scholten, P. (2009). The Co-Production of Immigrant Integration Policy and Research in the Netherlands: The case of the Scientific Council for Government Policy. Science \& Public Policy, 36(7), 561-573.

Scholten, P. (2011). Framing immigrant integration: Dutch research-policy dialogues in comparative perspective. Amsterdam: Amsterdam University Press.

Scholten, P., \& Timmermans, A. (2010). Setting the immigrant policy Agenda: Expertise and politics in France, the UK and the Netherlands. Journal of Comparative Policy Analysis, 12(5), 527-543.

Scholten, P., \& Verbeek, S. (2014). Politicization and expertise: Changing research-policy dialogues on migrant integration in Europe. Science \& Public Policy (Published online in 2014).

Scientific Council for Government Policy. (1989). Allochtonenbeleid. The Hague: SDU.

SCP. (2009). Jaarrapport Integratie 2009. Den Haag: Sociaal en Cultureel Planbureau (SCP).

Statistics Netherlands. (2008). Jaarrapport integratie 2008. Den Haag/Heerlen: Centraal Bureau voor de Statistiek (CBS).

Sunier, T. (2014). Domesticating Islam: Exploring academic knowledge production on Islam and Muslims in European societies. Ethnic and Racial Studies, 37(6), 1138-1155.

Uitermark, J. (2010). Dynamics of power in Dutch integration politics. PhD-thesis, University of Amsterdam.

Van Oers, R. (2013). Deserving citizenship: Citizenship tests in Germany, The Netherlands and the United Kingdom. PhD-thesis, Radboud University Nijmegen.

Veerman, G.-J., van de Werfhorst, H. G., \& Dronkers, J. (2013). Ethnic composition of the class and educational performance in primary education in The Netherlands. Educational Research and Evaluation 19, 370-401.

Verwey-Jonker Institute. (2004). Bronnenonderzoek. Tijdelijke Commissie Onderzoek Integratiebeleid. The Hague: SDU.

Vliegenthart, R. (2007). Framing immigration and integration: Facts, parliament, media and antiimmigrant party support in the Netherlands. PhD-thesis, VU University Amsterdam.

Wittrock, B. (1991). Social knowledge and public policy: Eight models of interaction. In P. Wagner, C. H. Weiss, B. Wittrock, \& H. Wollman (Eds.), Social sciences and modern states: National experiences and theoretical crossroads (pp. 28-85). Cambridge: Cambridge University Press. 


\title{
Chapter 13 \\ Research-Policy Dialogues in the United \\ Kingdom
}

\author{
Alistair Hunter and Christina Boswell
}

\subsection{Introduction}

Of the countries featured in this book, Britain has the longest experience of policy interventions aimed at integrating migrants, beginning in the 1960s. The migrants at whom policy was primarily directed had arrived in Britain after World War II as British Commonwealth subjects, particularly from (former) colonies in the Caribbean (e.g. Jamaica, Bahamas and Barbados), and South Asia (India, Pakistan and present-day Bangladesh). Contrasting with the 'guest-worker' approach of neighbouring countries like the Netherlands and Germany, Britain's initial 'open door' policy was not primarily conceived as a state-run recruitment campaign to supply industry with cheap labour. Instead it was a diplomatic means by which Britain hoped to maintain favourable economic and political relationships within the Commonwealth (Banton 1985: 34).

A second specificity of the UK case is the long-standing British preference for viewing questions of migrant integration through the conceptual prism of 'race'. From the late 1950s, the perception grew that 'coloured' Commonwealth migrants to reproduce the language of the period - were settling in Britain, and hence competing with white working class communities for scarce resources such as housing and jobs (Banton 1985: 35). The government action that followed combined immigration control (the 1962 Commonwealth Immigrants Act) with integration measures (the 1965 Race Relations Act). Two subsequent Race Relations Acts

\footnotetext{
A. Hunter $(\bowtie)$

Alwaleed Centre, School of Literatures, Languages and Cultures, University of Edinburgh,

Edinburgh, UK

e-mail: alistair.hunter@ed.ac.uk

C. Boswell

Politics and International Relations, School of Social and Political Sciences, University of Edinburgh, Edinburgh, UK
} 
(1968 and 1976) steadily built on this initial effort to contain racial discrimination and maintain public order. The 1976 Act, by recognising indirect discrimination against racial groups, in addition to the direct discrimination against individuals which the first two Acts targeted, opened the door to the recognition of group rights which emerged in multiculturalist policies promoting diversity in the 1980s. However, a major break with multicultural race relations occurred after 2000 in response to incidents of rioting and terrorism in which ethnic minorities (and above all Muslims of South Asian heritage) were perceived to be implicated. Instead of promoting diversity, integration policy took a 'civic integrationist' turn, emphasising values held in common and promoting cross-community cohesion.

The British preference for conceptualising integration in ethnic terms requires a brief explanation, since in neighbouring countries policy frames have tended to distinguish between 'citizens' on the one hand, and 'migrants' (or 'foreigners') on the other. In Britain, racial terminology did not have the same associations with Nazism as it did in mainland Europe, and was familiar to policymakers due to the legacy of British colonial administration. Furthermore, the citizen-foreigner dichotomy was unusable in Britain given that most inhabitants of the country, Commonwealth migrants and non-migrants alike, shared a (nominal) universal status of citizenship (Joppke 1999). In this sense, integration policy in the UK was never originally migrant integration policy, as the boundary across which integration was supposed to occur (be it as a one-way process or a two-way process) was not framed as a migrant/host boundary but as a racial boundary separating people sharing the same (formal) citizenship status. The arrival of 653,000 Eastern European migrants in the UK between 2004 and 2011 (Vargas-Silva 2013), following the A-8 countries' accession to the European Union, would come to challenge this consensus. Thus far, however, integration policy - in the sense of integrating new arrivals - continues to be a neglected domain (Spencer 2011).

As will be discussed in greater detail below, social scientific research on integration has had a varied influence on the development of policy in this area, at times making a very considerable impact on broad policy frames and specific policy measures, while at other times having very little influence. This minimal influence is certainly not due to an absence of knowledge production in this area: social scientists have produced research on migrant integration for more than half a century. Equally, the influence of social scientific knowledge on policy is not our only focus since that relationship can also be two-way, with policymakers influencing the production of knowledge in this domain.

\subsection{Migrant Integration: Key Issues}

The foundation stone of integration policy in the UK was the series of Race Relations Acts passed in the 1960s and 1970s. These were 'path-breaking' measures at least in the European context - aimed at combating discrimination on racial grounds (Spencer 2011: 213) and ensuring that migrants (and their descendants) 
were treated equally, as their status as citizens required. Rejecting assimilation, Roy Jenkins - the Home Secretary who introduced these policies - defined integration as 'equal opportunity accompanied by cultural diversity, in an atmosphere of mutual tolerance' (in Rose 1969: 25).

Behind these lofty words lay a more pragmatic logic: public order was at risk if such principles were ignored, as a series of 'race riots' in the late 1950s had demonstrated (Favell 1998). As such, integration was a prerogative of the Home Office. In order to minimise the potential for public disorder, the 1965 Act banned racial discrimination in 'places of public resort' such as theatres, hotels, bars, restaurants, and public transport. A second Act in 1968 extended the reach of protection to other domains, such as employment and housing, after evidence emerged of widespread discrimination in these areas.

The first Race Relations Acts required new bodies with which to implement and police the legislation. At the national level, a newly instituted Race Relations Board (RRB) was the agency charged with enforcing the 1965 and 1968 Acts. The 1976 Act created a new super-agency responsible both for the negative duty of enforcing the anti-discrimination measures and for the positive duty of organising activities with the aim of promoting good race relations. This new body was named the Commission for Racial Equality (CRE), and it would continue as such until 2007 when a successor agency, the Equality and Human Rights Commission, was created. ${ }^{1}$

One of the most far-reaching consequences of the 1976 Act was its focus on indirect discrimination, 'creat[ing] a space for the language of group rights' which in turn helped open the door for the multiculturalist policies of the 1980s (Joppke 1999: 230, 235). A central feature of multiculturalism relates to the prospect of institutional adjustments on the part of the state, insofar as there is an implicit multiculturalist understanding that integration is a two-way process of adaptation, with both newcomers and host institutions adjusting their practices. In the UK, institutional adjustments included the legal recognition of minority ethnic and faith groups, such as in the collection of census data incorporating different group categories (from 1991). Minor changes in law have been made to accommodate cultural or religious practices espoused by different communities, for example in relation to dress codes, children's education, and ritual slaughter of animals. In 2000, responding to the Macpherson inquiry into police racism in a high-profile murder case, the race relations legislation again evolved, extending the scope of the 1976 Act to impose a duty on all publicly funded bodies, including the police, to eliminate discriminatory practices and to promote race equality.

In the summer of 2001, a series of focusing events prompted a reconsideration of multiculturalism by policymakers. Firstly, major street disturbances occurred in the northern English towns of Bradford, Burnley and Oldham, involving ethnic minority youths. The ethnic minorities involved in the 'milltown riots' - so-called due to the textile milling past of the three towns - were primarily of South Asian

\footnotetext{
${ }^{1}$ The CRE was active also in promoting academic research on race relations. The Journal of Ethnic and Migration Studies, now one of the leading international academic journals in the field, began life in 1971 as the CRE publication New Community.
} 
Muslim heritage. The subsequent 9/11 terrorist attacks in New York and Washington contributed to a further hardening of the discourse around Muslims as a community experiencing particular integration difficulties. Critiques of multiculturalism did not issue solely from the right of the political spectrum, but also emanated from prominent centre-left opinion makers (Alibhai-Brown 2001; Goodhart 2004). The driving focus of policy henceforth was on measures that placed emphasis on the cohesion of local communities and values that were shared in common, rather than celebrating diversity.

The last decade has witnessed a consolidation of the rhetorical backlash against multiculturalism. $^{2}$ The election of a Conservative-Liberal Democrat coalition in 2010 did not result in any major deviations from the previous government's focus on cohesion and shared values. An overarching theme is to shift responsibility for integration from central to local government. This shift began in 2006 when responsibility for cohesion policy was switched from the Home Office to the newly created Department for Communities and Local Government (CLG). The only integration-related role that the Home Office retains is responsibility for the integration of refugees and naturalisation policy. These changes have led to some observers denouncing an 'extraordinary lack of coherence across Whitehall and between central and local government' (Spencer 2011: 233), with new migrants potentially slipping through the resulting cracks. Similarly, the zeal of the government's localism drive is a cause of some concern (Katwala 2012), given the difficult financial situation many local authorities found themselves in after the 2008 recession. Statements such as 'government will act only exceptionally' imply a very minimalist approach, absolving Whitehall of any responsibilities in this area (CLG 2012: 9).

\subsection{Historical Overview of Research-Policy Dialogues on Migrant Integration}

In order to provide a comprehensive overview of science-society dialogues on migrant integration in the UK, three constitutive components of these dialogues will be studied. The first component refers to knowledge production about migrant integration as a research field. What types of actors (research institutes, experts, etc.) have emerged and what 'schools of thought' can be distinguished? Secondly, we recognise that not all researchers are engaged with policymakers, politicians, civil society and the media to the same degree. We use the term dialogue structures to designate the principal actors involved, and the venues where they come together. Finally, we ask how policymakers made use of the body of knowledge produced in Britain on the topic of migrant integration. In order to analyse these patterns of knowledge use, this chapter also follows Boswell's (see Chap. 2) distinction between instrumental, legitimising and substantiating knowledge utilisation.

\footnotetext{
${ }^{2}$ However, several academic observers argue that the substantive content of policy and discourse continues as before, just under a different heading, i.e. 'diversity.' See Meer and Modood (2009) and Vertovec and Wessendorf (2010).
} 
Table 13.1 Policy frames in British migrant integration policy since the 1960s

\begin{tabular}{|c|c|c|c|c|}
\hline & 'Race relations' frame & $\begin{array}{l}\text { 'Multicultural } \\
\text { race relations' } \\
\text { frame }\end{array}$ & $\begin{array}{l}\text { 'Community } \\
\text { cohesion' } \\
\text { frame }\end{array}$ & $\begin{array}{l}\text { Recent } \\
\text { developments }\end{array}$ \\
\hline & $1965-c .1980$ & c.1980-2000 & $2001-2010$ & $2010-2015$ \\
\hline $\begin{array}{l}\text { Normative } \\
\text { perspective }\end{array}$ & $\begin{array}{l}\text { To maintain public } \\
\text { order and promote } \\
\text { equality of } \\
\text { opportunity }\end{array}$ & $\begin{array}{l}\text { As previous, } \\
\text { plus: To } \\
\text { promote } \\
\text { cultural } \\
\text { diversity }\end{array}$ & $\begin{array}{l}\text { To promote a } \\
\text { sense of } \\
\text { shared values } \\
\text { and belonging }\end{array}$ & As previous \\
\hline Terminology & $\begin{array}{l}\text { Race; (indirect) } \\
\text { discrimination; } \\
\text { positive action }\end{array}$ & $\begin{array}{l}\text { Race; group } \\
\text { rights; } \\
\text { institutional } \\
\text { racism }\end{array}$ & $\begin{array}{l}\text { Cohesion; } \\
\text { bridging; } \\
\text { Britishness; } \\
\text { parallel lives; }\end{array}$ & $\begin{array}{l}\text { Integration; } \\
\text { localism; }\end{array}$ \\
\hline $\begin{array}{l}\text { Main } \\
\text { policy } \\
\text { measures }\end{array}$ & $\begin{array}{l}\text { Anti-discrimination } \\
\text { legislation; more } \\
\text { immigration } \\
\text { restrictions }\end{array}$ & $\begin{array}{l}\text { Ethnic question } \\
\text { in census; } \\
\text { accommodation } \\
\text { of religious } \\
\text { practices (dress, } \\
\text { diet, education); } \\
\text { Race Relations } \\
\text { Act } 2000\end{array}$ & $\begin{array}{l}\text { Changes to citizen- } \\
\text { ship/naturalisation; } \\
\text { focus on youth; } \\
\text { English language; } \\
\text { counter-extremism }\end{array}$ & $\begin{array}{l}\text { As previous, } \\
\text { but } \\
\text { coordinated } \\
\text { by local not } \\
\text { central } \\
\text { government }\end{array}$ \\
\hline $\begin{array}{l}\text { Institutions } \\
\text { involved }\end{array}$ & $\begin{array}{l}\text { Home Office; RRB; } \\
\text { CRE; local } \\
\text { authorities }\end{array}$ & $\begin{array}{l}\text { Home Office; } \\
\text { CRE; local } \\
\text { authorities }\end{array}$ & $\begin{array}{l}\text { CLG; Home } \\
\text { Office; local } \\
\text { authorities; } \\
\text { CRE / EHRC; }\end{array}$ & $\begin{array}{l}\text { Local } \\
\text { authorities; } \\
\text { CLG and Home } \\
\text { Office (but } \\
\text { 'only } \\
\text { exceptionally') }\end{array}$ \\
\hline
\end{tabular}

Source: Authors' own elaboration

Because knowledge production, dialogue structures and knowledge utilisation can be difficult to disentangle empirically, we shall not discuss them separately here but instead focus on their mutual inter-relations in a chronological manner. Table 13.1 provides an overview of four phases.

\subsubsection{0s to 1960s: The Emergence of the Race Relations Frame}

Sociological studies of migrant settlement and integration in the UK first date to the 1940s, some considerable time before any explicit integration policies had been devised by the authorities. Kenneth Little was the first to investigate 'race relations' with his work in port cities such as Cardiff, where many sailors from British colonies had settled (Little 1947). This direction of inquiry was continued by Michael Banton, whose early work was supervised by Little at Edinburgh (Banton 1955). In the 1960s, John Rex and Robert Moore undertook a major study of migrant housing in Birmingham, heavily influenced by Robert Park and the Chicago School of sociology (Rex and Moore 1967). 
At this time, there was little instrumental use of academic research in policymaking (Banton 1985). Where academics were most influential was in initially framing questions of integration in terms of 'race relations', with academic output inspiring 'policy learning' by politicians, civil servants, and the media (Bleich 2011). However, even here Bleich argues that ' $[\mathrm{s}]$ ocial research ( . . ) contributed directly to the formulation of eventual dominant frames in Britain, but it was one of a number of influences rather than constituting an overwhelming element' (Bleich 2011: 62). This situation corresponds most closely to what Weiss (1986) calls the 'enlightenment' function of knowledge.

In this earlier period, examples of specific policy adjustments in which use of integration research was central were more likely to be inspired by applied research conducted outside academia, in what would now be termed think-tanks. In this regard, an early and highly influential pioneer was the Institute of Race Relations (IRR), originally founded in order to study race relations in colonial and Commonwealth countries. By the early 1960s, however, its focus had shifted to race relations in Britain itself, strongly influenced by academic and political currents in the United States (Banton 2011a). In 1963 a major 5-year survey was launched by the IRR, led by Jim Rose. This survey was later written up in the influential report, Colour and Citizenship (Rose 1969). Another organisation, Political and Economic Planning (PEP; later the Policy Studies Institute), also had a great influence on policy, providing persuasive and incontrovertible evidence of discrimination.

However, such data was not used in an instrumental manner, to rationally adjust policy, but rather used to substantiate an already-taken policy position (Boswell 2009). The passage of the 1968 Act is a paradigmatic example of this, as Banton relates with regard to the commissioning of an influential PEP study in 1967. In Banton's view this study was 'a set-up' devised by Home Secretary Roy Jenkins, his friend (and chairman of the Race Relations Board) Mark Bonham Carter, and their contacts at PEP. Indeed Bonham Carter 'made it a condition of his appointment [to the Race Relations Board] that he should be able to put the case [for review of the 1965 Act] after only a year's operation' (Lester 2000: 28). As Banton recounts, 'The ' 68 Act was an aspiration and it became a reality thanks to the [PEP] research (...). The government wanted to get a bill through the House of Commons and it did' (interview with Banton). Such remarks confirm Joppke's depiction of an 'elite-crafted' race relations paradigm (1999: 225). This elite was constituted by London-based political, media and legal figures, rather than academics at provincial universities.

\subsubsection{0s: Fragmentation and Politicisation}

Two principal features of migrant integration research in the UK become apparent from 1970: simultaneously, the expansion of knowledge production in this area, and the politicisation of the research field, resulting in competing schools of thought. Academics such as Ambalavaner Sivanandan, Stuart Hall, Paul Gilroy and 
Robert Miles emerged who combined a Marxist perspective with a commitment to combating racism politically through their academic work (Favell 2001: 356). Their focus on racism (as opposed to race) put them at odds with sociologists such as Banton and Rex who maintained that the term race could be deployed as a neutral concept. The growing importance of the 'critical race studies' school ${ }^{3}$ is revealed by the 'capture' of the IRR by Sivanandan and his supporters in 1972. Another locus for this new paradigm was the Centre for Contemporary Cultural Studies (CCCS) at the University of Birmingham.

Given the anti-system tendencies of academics in the 'critical race studies' school, it is no surprise that their writings were of little use to policymakers. One might have expected more synergy between academia and policy in the official venues created for dialogue. However, the first academic centre sponsored by the Social Sciences Research Council (SSRC), ${ }^{4}$ led initially by Banton at Bristol (19701978), was set up explicitly for the purposes of generating fundamental sociological knowledge, not policy-relevant knowledge (Banton 2011b). Another attempt to initiate dialogue was the creation of a Home Office Advisory Committee on Race Relations Research (ACRRR) in 1969. The terms of reference for the committee were: 'To advise the Secretary of State on a programme of research likely to be relevant to the formulation of policy concerning the relations between people of colour, race or ethnic or national origins settled in Great Britain' (ACRRR 1975: iii). Despite its easy access to channels of power, this Committee was far from successful in influencing the policy agenda. The initiative failed, largely because policymakers were reacting to short-term problems rather than developing long-term visions for policy:

That was an attempt to set up a place for exchange, and it failed, I think, completely (...).

The trouble was that the Home Office people were having to respond to ministers ... And ministers only wanted something when there was a problem (interview with committee member).

\subsubsection{0s and 1990s: The Rise of Multiculturalist Thinkers}

Despite the differences of opinion between the orthodox 'race relations' scholars and the activist-academics of the critical school, common ground existed between them in two important respects. The first was the shared tendency to frame British experiences of ethnic diversity in relation to North American precedents. To this 'Atlanto-centrism', Tariq Modood (2012) adds a second 'secularist' bias. His contention is that earlier researchers neglected the religious identities and practices of post-Commonwealth immigrant communities in the UK, especially South Asian communities. With the exception of some anthropological work on the religious

\footnotetext{
${ }^{3}$ Other authors refer to a 'cultural studies school' (see Favell 2001).

${ }^{4}$ After 1983 the SSRC becomes the Economic and Social Research Council (ESRC).
} 
practices of South Asian migrants in Britain (Helweg 1979; Jeffery 1976; Werbner 1990), up until the 1990s there was little attention given to the influence of religion in processes of settlement and integration. It was only after the Rushdie Affair of 1989 that questions of accommodation of ethnic minority religions began to generate sustained academic interest. In opposition to the secularist bias of earlier research, multiculturalist thinkers emerged such as Modood, firstly at the Policy Studies Institute and latterly at Bristol, and Bhikhu Parekh at Hull.

Other important research centres were emerging at this time. The directorship of the government-funded SSRC unit transferred from Banton at Bristol to John Rex, first at Aston and then to the Centre for Research on Ethnic Relations (CRER) at Warwick. This centre became a launchpad for many researchers who have since gone on to influential positions, such as John Solomos (editor of the journal Ethnic and Racial Studies). This transfer of leadership also coincided with a shift from the SSRC's original emphasis on fundamental sociological research, moving to a 'greater emphasis [on] policy relevant research and politically relevant research' (Banton 2011b: 9). However, the pervading impression given by key informants and literature on the topic is that CRER had difficulties fulfilling its new mission. While CRER produced policy-relevant research (Favell 2001), the fact remains that this material was not widely drawn on by policymakers. Peter Ratcliffe, who was affiliated with CRER, admits that 'the overall impact in terms both of minority empowerment and in policy transformation was probably rather slight' (Ratcliffe 2001: 130).

One can speculate that CRER might have been more successful if successive Conservative governments had shown any interest in the race relations agenda. According to a senior civil servant at the Home Office who covered the race relations brief at the Home Office in 1978-1981 and then during the 1990s prior to retirement, there was very little proactive dialogue on integration matters during the years of Conservative rule (1979-1997). The race relations agenda was effectively 'frozen' at this time:

\footnotetext{
Direct systematic routine contact between academics to my memory did not exist at my level. (...) We had no political impetus behind us to search people out. (...) Thatcher set the tone ... It was a failure of imagination, a failure to see what the country - simply through demographics - was likely to become ... Whatever the reasons, it did take the political sea change of 1997 to bring it back into its right scale of importance (interview with a former senior Home Office official).
}

\subsubsection{7 and After: The Quest for Policy Impact}

The election of a Labour government in 1997 signalled a more proactive approach (at least initially) to questions of race and integration (Ratcliffe 2001), evident in the amendments in 2000 to the Race Relations Act, which introduced a new duty on all public authorities to promote equal opportunities. New Labour's election win also had implications for the use of expert knowledge, with calls from ministers for 
evidence-based policymaking. ${ }^{5}$ This technocratic turn is observable in immigration policy more generally (Boswell 2009), but in the integration field academics such as Parekh and Modood were also quite influential at this time, 'shaping that early New Labour multiculturalism' (interview with university researcher). However, this pro-diversity discourse was turned on its head by two focusing events in summer 2001: the 'milltown riots' in northern England, followed by 9/11. It is at this point that multiculturalist scholars begin to be sidelined. For example, while New Labour politicians continued to solicit policy advice from Modood on some topics after $2001,{ }^{6}$ Modood himself acknowledged that policymakers have taken other policy directions that he was not willing to follow:

I've become less central or have been marginalised over the last decade (...) People in Whitehall ... think I'm not sufficiently addressing the most important issues which are to do with terrorism, extremism, and so on, segregation, ghettoisation, separate communities (interview with Modood).

However, other features of research-policy dialogues in earlier periods continued in the 2000s. The key role played by think-tanks in dialogue structures on integration has already been flagged, and in the 2000s more and more such organisations became interested in this field. In addition to the Runnymede Trust and PSI, which have long focused on race issues, left-of-centre think-tanks such as IPPR, Demos and Policy Network, as well as Civitas and Policy Exchange on the right, have all undertaken research in this area. Think-tanks provide a platform for academics to broadcast their ideas in a way which is more likely to catch policymakers' attention. Think-tanks also act as bridge between academia and advisory positions within government, as the career paths of a number of prominent actors show. ${ }^{7}$

In terms of knowledge utilisation, the trend observed in the earlier period continues into the current timeframe. Once again there are not many examples of instrumental knowledge use. This would be less surprising were it not for a significant cultural change in academia, with a new willingness on the part of academics to work on applied policy problems. Favell sees this as a dramatic shift:

In reading the citizenship and multicultural theorists of the present day, we need constant reminding that they are not speaking from the same social location as the politicians, judges, and bureaucrats who actually make decisions and implement policies. (...) One by one, prominent academic voices have been incorporated into the wider, state-sponsored production of practical knowledge (Favell 2001: 354-5).

One recent factor reinforcing this desire of academics to seek influence through applied policy research is the clear shift that can be observed in the political economy of university research funding. Since 2008, the Economic and Social Research Council and the Higher Education Funding Council for England (HEFCE) have required applicants for funding to demonstrate the likely socio-economic

\footnotetext{
${ }^{5}$ Speech by Secretary of State for Education and Employment David Blunkett to the ESRC, 2 February 2000. 'Influence or Irrelevance: can social science improve government?'

${ }^{6}$ See Martínez 2013; also Government Equalities Office 2010.

${ }^{7}$ E.g. Sarah Spencer and Shamit Saggar.
} 
benefits of any proposed research. The same applies to the current nation-wide evaluation of university research, the Research Excellence Framework (20082014). Informants viewed this 'chase' after policy 'impact' as a key constraint. Furthermore, this trend is not limited to public funding, since the various charitable trusts that fund research in the UK, such as the Joseph Rowntree Foundation and Barrow Cadbury Trust, also encourage researchers to seek demonstrable policy impacts.

Funding from European Union sources has also acted as a significant influence in this field. Not only has it driven engagement with new policymaking audiences in the European institutions, it has also stimulated the growing internationalisation of knowledge production. More internationally oriented (and comparativist) scholars have begun to expose the deficiencies of analyses based on 'national models' of integration. The Centre on Migration, Policy and Society at Oxford (COMPAS) in particular has become the premier centre for migrant integration research in the UK following this shift to internationalisation, supplanting the now defunct CRER at Warwick.

Given this funding-driven growth in applied research, it is hardly surprising that political actors tend to take primacy in coordinating research-policy dialogues on migrant integration. One respondent commented: 'I don't think there is much deference to the status of academics, at all, from policymakers. It's certainly not the case that people listen when a distinguished professor [speaks]' (interview with university researcher). The idea that it was normal for policymakers to be 'on top' and academic experts to be 'on tap' (Scholten 2011: 51) was made very clear in the comments of Home Office officials, who decried the lack of policy-relevant research on migration and integration. Their position was that researchers should be willing to listen to policymakers in order to produce research which '[is] playing to the themes which ministers, and often the public, feel are important' (interview with Home Office official).

A final feature of science-society dialogues on integration in the UK case is the marked preference of policymakers to facilitate dialogues via one particular venue, namely independent commissions. This venue preference has been noted by a number of authors (Favell 2001; Scholten 2011). Ratcliffe finds commissions to be especially prevalent in the UK following focusing events such as 'race riots' (Ratcliffe 2001). Commissions engage a wider set of actors beyond those normally involved in policymaking, usually involving some combination of academics, practitioners, and representatives of civil society. As such, commissions are an ideal venue in which to study science-society dialogues, as we elaborate in the next section.

\subsection{Key Topics in Research-Policy Dialogues}

We chose to focus on three government-sponsored or -endorsed commissions reporting after 1999 that made recommendations across the three topics covered by the DIAMINT project - naturalisation, religious diversity, and primary and 
secondary education. The three commissions are: the Commission on the Future of Multi-Ethnic Britain in 2000 (CMEB); the Community Cohesion Review Team (CCRT) in 2001; and the Commission on Integration and Cohesion in 2007 (CIC). In what follows, we will consider the three integration topics in turn. For each topic we will briefly discuss the context of that policy area, before analysing one of the commissions in greater depth.

\subsubsection{Naturalisation}

In the second half of the twentieth century, British citizenship policy was not designed to address the integration of migrants already in the UK but was instead a means of immigration control, by limiting the categories of Commonwealth citizens permitted access to the colonial metropole (Karatani 2002). Furthermore, the process of acquiring British citizenship through naturalisation was marked by a laissez-faire and bureaucratic nature. During his time as Home Secretary (20012004), David Blunkett moved to change this, taking the view that the 'prize' of citizenship should be (i) something to commemorate symbolically, and (ii) used as a lever to encourage integration.

External policy advice was a key driver in this reinvention of UK naturalisation policy, with the recommendations of experts on the Community Cohesion Review Team (CCRT) being particularly influential. One of the two headline findings of the CCRT - established following the 2001 'milltown riots'- was the need to 'establish a greater sense of citizenship, based on (a few) common values which are shared and observed by all' (CCRT 2001: 9). The values deemed important by the CCRT included 'a universal acceptance of the English language', support for women's rights, and respect for people of diverse faiths and beliefs (CCRT 2001: 19). It was also suggested that in relation to naturalisation procedures, 'a clearer statement of allegiance, perhaps along the lines of the Canadian model, should be considered' (CCRT 2001: 20). These proposals were enthusiastically backed by ministers, both in the immediate response to Cantle's report (Home Office 2001) and in the government's white paper ${ }^{8}$ Secure Borders, Safe Haven (Home Office 2002). Naturalisation policy was re-conceived as a lever for integration, particularly with the requirement that new citizens should demonstrate knowledge of English language and British institutions (Home Office 2002: 32). Citizenship ceremonies, incorporating an updated oath of allegiance to 'reflect a commitment to citizenship, cohesion and community', were also legislated for (ibid: 34 ).

Intriguingly, Cantle and his team were not the first policy advisors to suggest that naturalisation should be reinvented as a means to promote a sense of belonging

\footnotetext{
${ }^{8}$ In UK policymaking, a 'white paper' is a document produced by the Government setting out proposed changes to policy in a particular area.
} 
among newcomers. One year earlier, the Commission on the Future of Multi-Ethnic Britain (CMEB) had stressed the importance of renewing the British model of citizenship. One measure proposed by the CMEB in this regard was to institute citizenship ceremonies, transforming the process of gaining British citizenship from a dull administrative process to a more symbolic "ceremonious form of welcome for new British citizens which might help everyone to reflect on the value of citizenship and to appreciate diversity' (CMEB 2000: 55). These proposals did not receive the same welcome from ministers as was accorded to the CCRT: in fact, the CMEB's recommendations were unceremoniously dropped. A closer analysis of the CMEB shows why this was the case.

The CMEB was conceived by its sponsor the Runnymede Trust as a wide-ranging state-of-the-nation sequel to the influential Colour and Citizenship report (Rose 1969), one of the founding texts of the British race relations paradigm. Chaired by the eminent political philosopher Bhikhu Parekh, the Commission included some of the leading academics in the race relations field, ${ }^{9}$ as well as expert practitioners in the fields of law, health, local government, education, and journalism. Although formally independent of government, the Commission had close ties to leading figures in the ruling Labour Party and received strong backing from the Home Secretary, Jack Straw, who presided at the launches of the Commission (January 1998) and its report (October 2000).

Ministers' attitudes changed however once it became apparent that media coverage of the report was overwhelmingly hostile. Journalists focused on one short passage in the 417-page text: 'Britishness ... has systematic, largely unspoken, racial connotations' (CMEB 2000: 38). Mis-construing the word 'racial' for 'racist', the Daily Telegraph led with a front-page story accusing commissioners of committing a racist slur against the British people, a criticism which was subsequently taken up by mass media across the ideological spectrum. The report quickly became a 'politically untouchable document' (McLaughlin and Neal 2004: 156), and Jack Straw was forced to publicly distance the government from endorsing the Commission's findings. The CCRT by contrast did have the support of government, and their recommendations on naturalisation were put into practice. Nonetheless, it appears clear that the government's initial inspiration to legislate in this area came from the CMEB: the language of the Secure Borders, Safe Haven white paper closely resembles the text of the CMEB report. ${ }^{10}$

\footnotetext{
${ }^{9}$ Academics on the commission included: Tariq Modood, Stuart Hall, Sarah Spencer, Sally Tomlinson and Muhammad Anwar.

${ }^{10}$ Compare paragraphs 2.12 and 2.20 of Secure Borders, Safe Haven (Home Office 2002: 32, 34) with paragraphs 4.33 and 4.34 of The Future of Multi-Ethnic Britain (CMEB 2000: 55).
} 


\subsubsection{School Reception Policies}

School-age education is considered to be a key arena of integration policy, applying both to young migrants and second-generation children born in Britain. In British statistical data, these two populations are collapsed into the category of black and minority ethnic (BME) pupils. Over the decades, the educational attainment of BME school-leavers has advanced significantly: overall BME pupils are close to attaining parity with, or even overtaking, their white counterparts on the standard measure of percentage of pupils attaining five passes at GCSE level ${ }^{11}$ (A-C grades). The national average is $76 \%$, compared with $80 \%$ for Asian pupils. ${ }^{12} 74 \%$ of black pupils achieve such grades.

Given these generally positive outcomes, socio-economic disadvantage and differential school attainment among ethnic groups have been less prominent in recent UK policy debates than in other countries studied in this volume. Instead, the integration focus in schools has primarily been on socio-cultural aspects, particularly educational segregation and the lack of contact between pupils of different ethnic backgrounds. In 2001, the influential Cantle report identified 'separate educational arrangements', such as faith schools or mono-ethnic schools, as a major factor behind the CCRT's diagnosis of 'parallel lives', since it was primarily young people who participated in the 2001 disturbances (CCRT 2001: 9).

In response, the CCRT recommended a number of measures in schools to promote cross-cultural bridging. A legal duty on schools was proposed to 'promote respect for, and understanding of, the cultures in the school and neighbouring areas' (ibid: 36). This recommendation was eventually implemented in the duty on schools to promote community cohesion, as legislated for in the Education and Inspection Act of 2006. 'School-twinning' initiatives enabling pupils from different schools (and ethnic backgrounds) to participate in shared lessons and sports activities were given enthusiastic backing by the Review Team, and extra funding was made available by government for this (Home Office 2001: 24).

What factors led to the CCRT being such a productive research-policy dialogue? Compared with the $\mathrm{CMEB}$, its remit was far narrower, even to the point of stipulating who should be consulted: commissioners were asked 'to obtain the views of local communities, including young people, local authorities and faith organisations $\ldots$ on the issues that need to be addressed in developing confident, active communities and social cohesion' (CCRT 2001: 5). Ted Cantle, a senior local government leader, was asked to chair the Review. His previous role at the Association of Metropolitan Authorities meant that several Labour ministers knew him as 'a "safe officer" type person, who was capable of writing a report and presenting findings' (interview with Cantle).

\footnotetext{
${ }^{11} \mathrm{GCSE}$ stands for General Certificate of Secondary Education. It is not possible to leave school before sitting these exams, usually at age 15-16.

${ }^{12}$ All the statistics given in this paragraph are drawn from a special report Race in Britain 2012 which appeared in the Independent on Sunday on 8 January 2012.
} 
The choice of the trusted Cantle as chair, the narrow terms of reference, and the appointment of practically minded commissioners with grassroots experience in local government and community organisations, indicate that ministers were keen for the Review to produce pragmatic and politically savvy recommendations which could be taken up by policymakers. In particular, a number of observers have contended that the CCRT was primarily a government-controlled vehicle to substantiate a shift in policy from multiculturalism to community cohesion (Robinson 2008: 17-19). Yet interviews conducted for the DIAMINT project suggest a more nuanced reading. With a 'safe pair of hands' as chair, ministers did not need to intervene:

It wasn't a nurse-maiding approach. There was certainly nothing about no-go areas, or nothing about 'you've got to do so-and-so.' I can imagine that does happen in other types of reviews, but in this one, I think we just struck lucky with Ted (interview with minister).

Furthermore, the CCRT went beyond merely supporting pre-given policies, with a number of detailed proposals which drew on members' knowledge of local government practices and which were subsequently taken up by national policymakers. Thus, the CCRT appears to have served both substantiating and instrumental functions. The report's largely positive reception in both right- and left-wing media, and praise for Blunkett's straight talking on the issue from right-of-centre journalists, signalled to government that there was an appetite for policy change among the public. Cantle's subsequent career shift to academia at the Institute for Community Cohesion, which enabled him to closely monitor implementation of the CCRT proposals, is a striking example of 'role swap' among knowledge users and producers (Caponio et al. forthcoming).

\subsubsection{Religious Diversity}

Migratory flows to the UK have long been characterised by religious diversity. After World War II, Caribbean migrants brought with them more evangelical forms of Christianity, while Hindu, Muslim and Sikh beliefs travelled with South Asian migrants. Until recently, accommodation of this migration-driven religious diversity was perceived by policymakers to be relatively unproblematic (e.g. provision of halal food, planning permission for places of worship, and dress-code exceptions for public sector workers), with accommodations being made primarily on the basis of race relations legislation (Abbas 2009). However, since the 1990s religion has been recognised as a group identity which requires firmer legal protection, in the wake of South Asian communities making claims on the basis of religious identity rather than race. This trend gained momentum following the controversy over BritishIndian novelist Salman Rushdie's book The Satanic Verses in 1989 (Asad 1990). However, the protection of religious 'difference' has been subject to critique in recent years. After 2000 the government felt that more actions should be taken to bring different faith groups together rather than encouraging single group identities. 
This was first proposed in Cantle's report following the 2001 'milltown riots', and was given considerable attention subsequently by the Commission on Integration and Cohesion (CIC) sponsored by the Department for Communities and Local Government (CLG) in 2006-2007.

While the experts on the CIC acknowledged that 'religious faith is profoundly important to those whose lives it shapes and is potentially a unifying force within society', they also noted its potential to be 'a factor that separates people from the wider community - for example, in many of the areas where 'parallel lives' are most in evidence' (CIC 2007: 86). One recommendation which aimed at reducing the divisive force of religion was the presumption against single group funding, (including of faith groups), in preference to awarding funds to promote inter-faith activities (CIC 2007: 137 and Annex D). This proposal was inspired by academic work on social capital, and in particular Robert Putnam's distinction between 'bridging' and 'bonding' types (Putnam 2000).

However, in CLG's response to the CIC, it was clear that policymakers had reservations about prohibiting single-group funding, noting that 'the thinking behind it has in some areas been misunderstood' (CLG 2008: 30). CLG also acknowledged fears from voluntary organisations that their funding would be cut, such as Muslim organisations engaged in preventing violent extremism. Eventually, the CIC's recommendation against single-group funding was watered down to leaving matters to the discretion of Local Authorities. More broadly, the Commission can be viewed as a failed attempt to shift the paradigm away from cohesion of established ethnic communities towards recognition of Britain as 'super-diverse', and the need for integration of new migrant communities. It is worth elaborating briefly on the reasons behind this failure.

The origins of the CIC lie in the government's initial response to the 7/7 London terrorist attacks in 2005. A commission to review the role of religion in Britain was announced by the Home Office in September 2005. However, a reorganisation of Whitehall in May 2006 led to the newly created Department for Communities and Local Government taking over the commission. Simultaneously, its remit shifted from religious diversity to an interest in 'how local areas can play a role in forging cohesive and resilient communities' (CIC 2007: 17). The lack of urgency and focus that characterised the commission's genesis indicates that it was designed as a 'delaying tactic' by ministers, a knowledge use function we term 'legitimising'. This is confirmed by the way the CIC report was disseminated and received by policymakers, with the substance of the report being less important than publicly signalling that a rigorous and authoritative review had taken place:

\footnotetext{
All of the news coverage of the report is on the day before the report, which talks about what's in the report without the report ever having been available. And it is not that it is a pack of lies, but it picks certain things and gives them high profile, forgets most of the report, in a very selective manner. And of course, by the time the report is out, the news is dead... the news cycle has moved on. So nobody's that interested in reading the report, paradoxically (interview with commissioner).
}

Once the brief flurry of media interest had abated, the Commission disappeared from the policy agenda quite quickly. In contrast to the government's rapid response to 
the Cantle and Parekh reports, eight months had elapsed before CLG fully assessed the report and revealed which recommendations it planned to take forward (CLG 2008). While the government's rhetoric was broadly supportive, few of the headline recommendations were implemented in practice: for example, the flagship proposal for a centrally funded Integration Agency was rejected following a feasibility study. This leads us to conclude that the CIC's policy advice primarily served a legitimising function for the commission's sponsors in government.

\subsection{Conclusions}

The early production of social scientific knowledge on the question of migrant integration in Britain was characterised by consensus, with an agreement that the approach to the question should focus on the concept of 'race relations'. In looking to North American concepts of race, British scholarship on integration was launched on a trajectory quite distinct from approaches in neighbouring European countries. Furthermore, scholarship on integration, broadly defined, appears to have emerged in Britain some years before academics in neighbouring countries began to study such issues. Nonetheless, in this early period there was little proactive dialogue between research and policy, with academics preferring to engage in fundamental rather than applied research. Academic research did however have an indirect influence on policymaking, with the 'race relations' frame gaining acceptance among politicians, journalists and civil servants (Bleich 2011). This boundary configuration can be characterised as one of 'enlightenment' (Scholten 2011). By contrast, research produced by think-tanks (but strongly influenced by ministers) fed directly into policymaking at certain important junctures, such as the passage of the 1968 Race Relations Act, indicating an intermittent 'engineering' boundary configuration (Scholten 2011).

The 1970s and 1980s were marked by a growing politicisation and fragmentation of the field, leading to the emergence of rival schools of thought. The "critical race studies' school was characterised by its politicised anti-racist perspective, set against the value-free position of earlier sociologists who sought to deploy race as a neutral concept. In the 1980s and 1990s, multiculturalism came to the fore, with its critique that earlier research had neglected the religious identities and practices of migrant communities, especially from South Asia. The impact of these emerging schools of thought on policy was limited, however, partly due to the anti-system tendencies of the Marxist scholars in the 'critical race' school, and partly due to the inactivity of successive Conservative governments regarding migrant integration.

In sum, the range of discourse coalitions and actors involved in UK sciencesociety dialogues has increased markedly. British academia has also opened up internationally. In part, the catalyst for this internationalisation has been the emerging political economy of research in the UK, and importantly also in the Europe Union, in which international recognition and collaboration is an indicator of esteem. In addition, an interesting feature of the UK case has been policymakers' 
long-standing preference for integration dialogues to take place in governmentsponsored commissions. Since the 1980s, such commissions have tended to be launched after significant focusing events, usually an outbreak of disorder or violence, be it race riots, racist murders, or acts of terrorism.

We developed this insight by suggesting that independent commissions are an ideal venue to study science-society dialogues, since they involve a wider set of actors than is normally included in policymaking, usually a combination of academics, practitioners, and representatives of civil society (see also Chap. 5 for a comparison between similar commissions in Germany and the Netherlands). Furthermore, evidence-gathering about complex social problems is a primary activity of commissions, and commissions therefore often draw upon social science data and deploy social research methods. Accordingly, we compared three commissions which reported in the 2000s: the Commission on the Future of Multi-Ethnic Britain in 2000 (CMEB); the Community Cohesion Review Team (CCRT) in 2001; and the Commission on Integration and Cohesion in 2007 (CIC).

The findings of the CCRT - most subject to government influence of the three were used for both instrumental and substantiating purposes. The choice of the trusted Cantle as chair, the narrow terms of reference, and the stress on 'making things happen', all indicate it was geared towardss substantiating the new policy paradigm of community cohesion. However, the commissioners drew up a number of detailed policy proposals, which exceeded policymakers' expectations, and these proposals subsequently contributed to policymaking in an instrumental fashion. The CIC, by contrast, is judged to fit most closely to what we term the 'legitimising' function of knowledge use. Its drawn-out launch and proceedings, its broad remit, and the lack of interest paid to its findings, meant that the commission's output was not used to rationally adjust policy instruments. Instead, the manner in which findings were disseminated via the media indicates that policymakers were anxious to signal to the public that action was being taken to address what was perceived to be an urgent problem, highlighted by the London bombings.

Interestingly, we also found that the amount and duration of media coverage is more important than whether such coverage is favourable or not. This is demonstrated by the history of the CMEB, which was launched not by government but by the Runnymede Trust think-tank (although with close backing from senior government politicians). The CMEB's composition and workings indicate a partly instrumental and partly legitimising role. On the one hand, its sponsors and supporters intended and expected that it would influence policy. Yet Runnymede's trustees and the commission's Labour backers also appear to be motivated by a desire to signal the commission's authority and significance. Interestingly, the initial media reaction to the CMEB report was extremely unfavourable. Yet the longrunning controversy that the CMEB report generated in the media meant that its various proposals were debated at length. Thus, the CMEB remained in the public spotlight, and therefore on the policymaking agenda. In time, many of its findings and recommendations were in fact implemented, corresponding to what Carole Weiss terms the 'enlightenment' function of knowledge. 
Open Access This chapter is distributed under the terms of the Creative Commons Attribution Noncommercial License, which permits any noncommercial use, distribution, and reproduction in any medium, provided the original author(s) and source are credited.

\section{References}

Abbas, T. (2009). United Kingdom and Northern Ireland. In J. S. Nielsen, S. Akgonul, A. Alibasic, B. Maréchal, \& C. Moe (Eds.), Yearbook of Muslims in Europe (pp. 363-373). Leiden: Brill.

ACRRR. (1975). Race relations research: A report to the Home Secretary. London: Advisory Committee on Race Relations Research.

Alibhai-Brown, Y. (2001). After Multiculturalism. Political Quarterly, 72, 47-56.

Asad, T. (1990). Multiculturalism and British identity in the wake of the Rushdie affair. Politics and Society, 18(4), 455-480.

Banton, M. (1955). The coloured quarter: Negro immigrants in an English city. London: Cape.

Banton, M. (1985). Promoting racial harmony. Cambridge: Cambridge University Press.

Banton, M. (2011a). The early years, 1940-1969: A memorandum for the BSA race and ethnicity study group. Retrieved from https://www.jiscmail.ac.uk/cgi-bin/webadmin?A2=BSA-RACEETHNICITY;ad0f0afd.1109. Accessed 25 Mar 2012.

Banton, M. (2011b). The challenging years, 1970-1997: A memorandum for the BSA race and ethnicity study group. Retrieved from https://www.jiscmail.ac.uk/cgi-bin/webadmin?A2= BSA-RACE-ETHNICITY;7d12f3e1.1112. Accessed Mar 2012.

Bleich, E. (2011). Social research and "Race" policy framing in Britain and France. British Journal of Politics and International Relations, 13(1), 59-74.

Boswell, C. (2009). The political uses of expert knowledge: Immigration policy and social research. Cambridge: Cambridge University Press.

Caponio, T., Hunter, A., \& Verbeek, S. (forthcoming). (De)constructing expertise: Comparing knowledge utilisation in the migrant integration 'crisis'. Journal of Comparative Policy Analysis. http://www.tandfonline.com/doi/abs/10.1080/13876988.2014.889902\#.VQbakKMx1OJ.

CCRT. (2001). Community cohesion: A report of the independent review team. London: Home Office.

CIC. (2007). Our shared future. London: Department for Communities and Local Government.

CLG. (2008). The Government's response to the commission on integration and cohesion. London: Department for Communities and Local Government.

CLG. (2012). Creating the conditions for integration. London: Department for Communities and Local Goverment.

CMEB. (2000). The future of multi-ethnic Britain: Report of the commission on the future of multiethnic Britain. London: Profile Books.

Favell, A. (1998). Philosophies of integration: Immigration and the idea of citizenship in France and Britain. Basingstoke: Palgrave.

Favell, A. (2001). Integration policy and integration research in Europe: A review and critique. In T. A. Aleinikoff \& D. Klusmeyer (Eds.), Citizenship today: Global perspectives and practices (pp. 349-399). Washington, DC: Carnegie Endowment.

Goodhart, D. (2004). Too diverse?. Prospect, 95, 30-37.

Government Equalities Office. (2010). An anatomy of economic inequality in the UK. Report of the National Equality Panel. London: Government Equalities Office.

Helweg, A. W. (1979). Sikhs in England. Oxford: Oxford University Press.

Home Office. (2001). Building cohesive communities: A report of the ministerial group on public order and community cohesion. London: Stationery Office.

Home Office. (2002). Secure borders, safe haven: Integration with diversity in modern Britain. London: Stationery Office. 
Jeffery, P. (1976). Migrants and refugees: Muslim and Christian Pakistani families in Bristol. Cambridge: Cambridge University Press.

Joppke, C. (1999). Immigration and the nation-state: The United States, Germany, and Great Britain. Oxford: Oxford University Press.

Karatani, R. (2002). Defining British citizenship: Empire, commonwealth and modern Britain. London: Frank Cass.

Katwala, S. (2012), Integration matters. Retrieved from http://www.britishfuture.org/blog/ integration-matters/. Accessed 20 Aug 2013.

Lester, A. (2000). The politics of the Race Relations Act 1976. In M. Anwar, P. Roach, \& R. Sondhi (Eds.), From legislation to integration? Race relations in Britain (pp. 24-39). Basingstoke: Macmillan.

Little, K. (1947). Negroes in Britain: A study of racial relations in English society. London: Kegan Paul.

Martínez, D. O. (2013). Intellectual biography, empirical sociology and normative political theory: An interview with Tariq Modood. Journal of Intercultural Studies, 34(6), 729-741.

Mclaughlin, E., \& Neal, S. (2004). Misrepresenting the multicultural nation. Policy Studies, 25(3), $155-174$.

Meer, N., \& Modood, T. (2009). The multicultural state we're in: Muslims, "Multiculture" and the "Civic Re-balancing" of British Multiculturalism. Political Studies, 57(3), 473-497.

Modood, T. (2012). Post-immigration "difference" and integration: The case of Muslims in Western Europe. London: British Academy.

Putnam, R. D. (2000). Bowling alone: The collapse and revival of American community. New York/London: Simon \& Schuster.

Ratcliffe, P. (2001). Race and ethnicity research in Britain: Key ethical and political considerations. In P. Ratcliffe (Ed.), The politics of social science research: 'race', ethnicity and social change (pp. 106-136). Basingstoke: Palgrave.

Rex, J., \& Moore, R. (1967). Race, community and conflict: A study of Sparkbrook. London: Institute of Race Relations/Oxford University Press.

Robinson, D. (2008). Community cohesion and the politics of communitarianism. In J. Flint \& D. Robinson (Eds.), Community cohesion in crisis: New dimensions of diversity and difference (pp. 15-33). Bristol: Policy Press.

Rose, E. J. B. (1969). Colour and citizenship: A report on British race relations. London: Oxford University Press.

Scholten, P. (2011). Framing immigrant integration: Dutch research-policy dialogues in comparative perspective. Amsterdam: Amsterdam University Press.

Spencer, S. (2011). The migration debate. Bristol: Policy Press.

Vargas-Silva, C. (2013). Migration flows of A8 and other EU migrants to and from the UK. Oxford: Migration Observatory.

Vertovec, S., \& Wessendorf, S. (2010). Introduction: Assessing the backlash against multiculturalism in Europe'. In S. Vertovec \& S. Wessendorf (Eds.), The multiculturalism Backlash: European discourses, policies and practices (pp. 1-31). London: Routledge.

Weiss, C. (1986). Research and policymaking: A limited partnership. In F. Heller (Ed.), The use and abuse of social science (pp. 214-235). London: Sage.

Werbner, P. (1990). The migration process: Capital, gifts and offerings among British Pakistanis. Oxford: Berg. 


\title{
Chapter 14 \\ Research-Policy Dialogues in Poland
}

\author{
Mikołaj Pawlak
}

\subsection{Introduction}

This chapter examines the attempts to institutionalise the production, exchange and utilisation of knowledge on the issue of immigrant integration in Poland. The chapter analyses three kinds of related actors - non-governmental organisations (NGOs), researchers and public authorities - and takes into account the context of institutional transformation after the fall of communism. Europeanisation is a very important context for this analysis. First of all, migration-related legislation in Poland was shaped by the acquis communautaire, i.e. Poland had to introduce legislation related to migration in accordance with legislation developed in the EU, including institutions and instruments for implementation as a condition for accession. Secondly, Europe is not only a source of funds and resources which 'fuels' NGOs working with migrants in Poland, but it is also seen as a reference point for best practices and patterns of action in a society defined as 'catching up'. Thirdly, research in the field has surged, stimulated by material support and ideational inspiration coming from old EU-countries.

Poland has one of the smallest rates of immigration of any EU member state. The phenomenon first appeared after the fall of communism, so Poland does not have much experience with long-lasting processes and consequences of immigration (such as the integration of second-generation children). The issue of immigration is much less visible in the public discourse than the issue of Polish workers migrating to old EU member states. Integration policies thus far have applied to refugees and asylum seekers, while other categories of immigrants are subject solely to

M. Pawlak (ه)

Institute of Social Prevention and Resocialisation, University of Warsaw, Warsaw, Poland e-mail: mikolajpawlak@uw.edu.pl 
integration programmes financed by European funds. There is, however, both a will and a growing need to develop a more comprehensive national integration policy: discussions about such a policy are currently taking place.

In this chapter, I will firstly introduce the context of dialogue between relevant actors: the transformation from a communist to a democratic order and a capitalist economy, and its consequences for the welfare system. I will then discuss the specific relations between the actors of the dialogue: public authorities, civil society and social scientists. The next section outlines the development of migration and integration policymaking in Poland thus far. The mechanisms and structure of an emergent dialogue are then illustrated by two cases involving three types of actors: public authorities, NGOs and researchers. In the first case, a scandal is used to exert pressure on policymakers to change the procedures for school admission of refugee children. The second case shows how the institutionalisation of public consultation in the policymaking process also provides new institutional scope for research-policy dialogues in Poland. Finally I draw some conclusions on the specific characteristics of the emergent policy-research-NGO dialogue in Poland.

\subsection{The Context for Research-Policy Dialogues on Migration and Integration}

\subsubsection{Post-1989 Transformations and the Migratory Situation}

In 1989, the communist regime in Poland collapsed. The first democratic government of Prime Minister Tadeusz Mazowiecki began the radical reform of state institutions that had been designed to control society. There was also an urgent need for economic reform as the communist planned economy was in a state of deep crisis. These reforms - dubbed 'shock therapy' - were designed by the Minister of Finance, Leszek Balcerowicz, a professor of economics who was very much under the influence of neo-liberal economic thought. Thanks to his reforms, the Polish economy recovered relatively quickly. However, other institutional systems did not undergo such radical changes (Szelenyi and Wilk 2010: 566).

For the last 20 years this transformation has been the main topic of discussion in Polish sociology and other social sciences (for a more detailed discussion see Kolasa-Nowak 2010). Nearly all phenomena in Poland are explained in the context of the transformation of the communist regime, which is seen as an element in the process of modernising the state and society (Morawski 2010).

One point of relevance in the context of Polish integration policy is specifically the structure of the welfare system and the changes therein. As François Bafoil claims, 'the soviet-style welfare state, based on the promotion of labor, extensive paternalism, and clientelism, remained unchanged in the initial years, whereas financial constraints had tightened fiercely' (Bafoil 2009: 68). Thus, during the turbulent economic reforms the welfare system changed at a very slow pace in order to maintain social peace and sustain support for reforms that were painful for large portions 
of society. Szelenyi and Wilk conclude that there is 'fundamental inconsistency in the logic of [Central European] economic and welfare institutions. [...] neo-liberal economic institutions coexist with outdated, malfunctioning distributive institutions, which are fundamentally socialist in nature' (Szelenyi and Wilk 2010: 583).

Democratic institutions were introduced in the welfare systems, such as for example the institution of social dialogue in employer-employee relations. However, the so-called tripartite forums were very often perceived as a 'talking shop' and not as a real institution of participation (Bafoil 2009: 75). This is a bad omen for dialogues on the integration of migrants: if the most rudimentary institutions of social dialogue are considered inefficient and weak, the ones for migrants cannot be expected to function better.

Bafoil (2009) proposed to apply a 'path dependence' approach to the analysis of the welfare systems in Central Eastern Europe (see Putnam 1993: 179), since continuity is very visible in the social security systems of post-communist states. The Polish scholar Dariusz Zalewski takes a similar approach. In his opinion, the organisations of social policy in Poland have retained important characteristics of the old model (Zalewski 2005: 9). He also believes that the current welfare system in Poland is unsuccessful in helping clients stand on their own feet (which is the recognised aim of integration measures). However, it is able to cope effectively with crisis situations (Zalewski 2005: 142).

The liberalisation of the border regime was one of the first changes in the transformation process in Poland. As a consequence of economic reform, many Polish employees lost their jobs and for many groups in society, emigration became a rational strategy for improving well-being. These emigrants thus profited from this liberalisation. On the other hand, Poland started to develop and the big cities ${ }^{1}$ especially began attracting labour from other regions of the country and abroad. The majority of labour immigrants came to Poland from Ukraine, a neighbouring state whose economy seems to be in permanent crisis since the collapse of the Soviet Union.

The democratisation of Poland is also evident in the fact that Poland started accepting refugees. The ratification of the Convention Relating to the Status of Refugees (Geneva Convention) in 1991 was one of the instances where Poland was internationally recognised as a democracy. For a long time, accepted obligations towardss refugees were the most important reason for the creation of an integration policy targeting this particular category of immigrants (see below).

\subsubsection{State, Civil Society and Science in the New Poland}

The centralised character of the Polish state is a legacy of communism, although in the last 20 years much has been done to decentralise it. Municipalities have become

\footnotetext{
${ }^{1}$ Concerning immigrants one has to note that they often take up seasonal jobs in agriculture (Bieniecki and Pawlak 2009).
} 
independent actors, yet they often lack sufficient funds to build up bold policies on their own. In the communist era, all actions of state agencies were 'planned', the 'plan' usually being ignorant of reality, and never based on evidence or scientific expertise. There is no tradition of commissioning research and to add to this, despite ideological declarations stating otherwise, the social sciences themselves are not accustomed to providing applicable research results. The public administration and its officials remain procedure-oriented rather than goal-oriented. All these features of the state may be presented here with a certain dose of simplification and exaggeration, yet these broad brush strokes quite adequately depict the conditions for dialogue on certain issues in Poland.

When it comes to civil society in Central Eastern Europe, there are three factors of weakness (as compared to the West) according to Howard (2003): (1) illegitimacy and distrust towardss forms of collective association, which often were obligatory in the communist period; (2) strong bonds of family and groups based on friendship which render formal forms of association less relevant; and (3) increased individualism caused by a disappointment with corrupt and inefficient collective action (Howard 2003). Similarly, Bafoil lists the following features of non-governmental organisations in Central Eastern Europe: 'they are more widespread in urban than in rural areas; they are able to mobilise only a small number of voluntary workers (in comparison with the figures for Western Europe); they are particularly short of funds [...]; and their relations with the public authorities are often difficult' (Bafoil 2009:174-5). Non-governmental organisations are not perceived as partners by public authorities, but rather as providers of services. According to Bafoil, mistrust between the state and non-governmental organisations in many sectors has actually risen since the fall of communism, as governments did not wish to share their prerogatives. Howard and Bafoil's observations need to be supplemented with a reference to the Polish historical context that goes further back than communism: the perception of the state as oppressive originates in the nineteenth-century occupation of parts of Poland by the Russian Empire, and in the feudal social systems before that.

The mistrust between public officials and NGO activists hinders constructive dialogue and cooperation. However, such mistrust also seems to institutionalise specific forms of dialogue, such as scandals and symbolic conflict. Non-governmental organisations in Poland have been significantly strengthened recently thanks to the hitherto unknown possibility of acquiring European funds, which provide resources unattainable through private donors or authorities.

As mentioned, social scientists in Poland are generally not familiar with applied research for policymaking, despite occasionally expressed ambitions to advance social engineering. Applied research is perceived by some scholars as less prestigious than 'pure' scientific inquiry. But even scholars interested in social policy often develop indicators that are not applicable by policymakers. Expertise provided to authorities is often perceived as decorative in nature by researchers themselves. In relation to public authorities and non-governmental organisations, social scientists often behave like 'supporters' of NGOs. In the case of research on refugees in Poland it has been shown that authors of publications assume beforehand that NGOs act in favour of refugees, while public organisations are tools of exclusion and discrimination (Pawlak 2012). 
Leopold Gluck noted that research quite often was used as a cover and reinforcement for decisions already taken (Gluck 1973: 59): in Boswell's terms, having a symbolic function of substantiating already-decided policies (Boswell 2009: 73). Jerzy Mikułowski-Pomorski has pointed to the problem of communication between decision makers and researchers in similar terms to the metaphor of two communities (Mikułowski-Pomorski 1972).

Władysław Markiewicz and Witold Morawski closely analysed the influence of social sciences on political decisions in Poland in the 1980s. According to the authors, there was only an indirect influence on decision makers. Researchers were informing society and thus shaping public opinion (Markiewicz and Morawski 1991: 209-214). In the 1980s, the authorities launched an enormous project aimed to design a national strategy for Poland's development called 'Polska 2000'. Researchers who were amenable to the communist authorities were invited to provide expertise to feed into the strategy. According to Frieske and Regulski the submitted reports were just opinions from the intellectual elite and were not very grounded in systematic scientific inquiry (Frieske and Regulski 1984: 73).

To sum up the foregoing, one could claim that there is an institutionalisation of very specific research-policy relations. Researchers did not expect that their knowledge was going to be used instrumentally (Boswell 2009: 29), so two modes of research production were developed. The first mode was knowledge that was to be used symbolically as just an intellectual exercise, without needing to be very methodologically grounded. The second mode referred to knowledge addressed to the public and not to the policymakers, which often used exaggeration, the dramatisation of narratives and rhetorical recommendations. Thus, there is a strong tradition of an absence of direct dialogue and a lack trust between policymakers and researchers.

After the fall of communism, significant development occurred in the evaluation research sector in Poland. The European Union's requirements to evaluate policy programmes served as an important catalyst in the growth of the evaluation research industry. However, evaluation research is very often used symbolically.

The most important analyses of relations between research and policymakers in Poland stress the importance of the indirect impact of knowledge on public officials, as in Carole Weiss' enlightenment model (1979). It is claimed that the enlightenment of both public opinion and decision makers is one apparent contribution of Polish social science (Frieske 1990; Kwaśniewski 2002; Markiewicz and Morawski 1991).

In conclusion, using the language of Christina Boswell (2009) and Peter Scholten (2011), it could be said that there is an institutionalised symbolic use of knowledge by policymakers and there is also a strong tradition of indirect transmission of this knowledge from researchers to policymakers. In this indirect transmission, the use of scandalising and dramatised narratives is one of the ways to attract attention and achieve assumed goals through 'dialogue'. I would argue that there is no direct institutionalised mechanism for coordinating the two fields of research and policymaking, so one cannot talk about either enlightenment or bureaucratic models (Scholten 2011: 49). The discourses of administration and research are parallel rather than intersecting. These parallel discourses, in my opinion, 
make researchers' recommendations useless, because they are incompatible with administrative structures of decision-making. If communication between decision makers and researchers exists, it is informal and very often mediated through the engagement of researchers in non-governmental organisations' activities. The symbolic use of research is achieved by inviting recognised scholars to serve as policy advisors, and more recently by commissioning evaluation research (usually from consulting agencies rather than academic institutions).

\subsection{Emerging Migration and Integration Policies: An EU-Dominated, External Project}

\subsubsection{The Europeanisation of the Legal and Institutional Structure of Migration Policy}

The run-up to Poland's accession to the European Union in 2004 was a period of intense modifications to Polish legal acts in order to live up to the acquis communautaire, which was a condition for Poland to become a member state. In many ways it was also an occasion to implement changes in the legal and institutional structure of the state, which were not obligatory but perceived by policymakers as needed in order to modernise the state apparatus. These non-obligatory changes were usually also shaped according to so-called 'European' patterns. The Polish policy towards foreigners is one case of this process, which is analysed very well by Agnieszka Weinar (2006). According to her, the implementation of 'European' institutions was a very strong legitimising factor. In 2003 two new acts were enacted: Ustawa o cudzoziemcach (Act on Foreigners) and Ustawa o udzielaniu cudzoziemcom ochrony na terytorium Rzeczypospolitej Polskiej (Act on granting protection to foreigners within the territory of the Republic of Poland). Before 2003 all the issues regarding foreigners in Poland were regulated by one act. Splitting the regulations into two separate acts, one on asylum seekers and one on all other foreigners, was suggested but not requested by the European Commission (Weinar 2006: 97). Also, the Office for Repatriation and Aliens was instituted by the new Act on Foreigners (in 2007 the name of that institution was changed to The Office for Foreigners). The Office for Repatriation and Aliens was shaped along the lines of immigration departments found in the majority of European national administration systems (Weinar 2006: 95).

During the legislation process there were no cases of research-policy dialogues, although actors outside the administration or parliament were consulted about these acts. These consultations took place at the Helsinki Foundation (which also played an advisory role during the proceedings of the Act on Aliens in 1997), and at the local bureau of the United Nations High Commissioner for Refugees. The legal expertise of these two actors was based on their experience with advising asylum 
seekers, and - according to Weinar - they influenced the final formulation of the Act on granting protection to foreigners within the territory of the Republic of Poland to some extent (Weinar 2006: 97).

It must be noted that the Europeanisation of Polish legal and institutional structures was perceived as an aspect of modernisation and progress; therefore during this period reforming any institution or reformulating a legal act in the name of 'customisation according to European requirements' was strongly legitimising.

\subsubsection{The Administrative Structure Responsible for Migration and Integration Policies}

The responsibility for migration and integration policies is dispersed over different administrative bodies. The Ministry of Interior is responsible for coordinating migration policy, and has a Migration Policy Department to perform these tasks. The Migration Policy Department coordinates the cabinet actions regarding issues of migration and deals especially with issues of citizenship and repatriation policy. Within the Ministry of Interior, there is an Office for Foreigners that deals with admissions, decisions on expulsions and asylum matters. This Office coordinates the centres for asylum seekers and is responsible for providing them housing during the asylum process. Thus, the Ministry of Interior is an important institutional actor in the policy field of migration. The issues connected with the integration of immigrants, however, are a responsibility of the Ministry of Labour and Social Policy, which is also responsible for the regulations dealing with labour migration. Within the Ministry of Labour and Social Policy these issues are split between two departments: regulations dealing with labour migration are under the supervision of the Labour Market Department, and integration issues are under the supervision of the Department of Social Assistance and Integration. The Department of Social Assistance and Integration is also the responsible authority for implementing the European Fund for the Integration of Third-country Nationals (EIF) in Poland.

Two things must be noted when it comes to the significance of immigrant integration in this institutional setting. Firstly, the Department of Social Assistance and Integration is responsible for all issues regarding the social assistance system in Poland and for counteracting social exclusion. The system of social assistance in Poland has an estimated two million clients. Among them immigrants (specifically refugees) constitute a relatively small group of less than 10,000 clients. Policies targeting these latter clients are proportionally a lesser priority for the Department.

Secondly, since 2005 the ministers of Labour and Social Policy have been members of a smaller party (with minor exceptions) in the cabinet coalitions. Such ministers have less power. Furthermore, the reform of the social assistance system is relatively low on the agenda of policymakers in Poland. These two factors support the statements quoted above from Szelenyi and Wilk (2010) on the relations between the economy and social assistance in Central Eastern Europe. 
Another important actor is the Implementing Authority for European Programmes, which runs the European Refugee Fund (ERF) and European Fund for Integration of Third-country Nationals (EIF). As a delegated authority it cooperates with the different ministries responsible. In the case of integration of immigrants it cooperates with the Ministry of Labour and Social Policy and in the case of refugees it cooperates with the Ministry of Interior.

The institutional setting is recognised as quite complicated (for a deeper analysis see: Lesińska et al. 2010) and what is most striking is that the responsibilities are dispersed. The Ministry of Interior strongly emphasises that although it coordinates migration policy, the integration issue is beyond its competence. For the Ministry of Labour and Social Policy, the integration of immigrants is low on the agenda. The Department of Labour in the same ministry also emphasises that its competence is restricted to labour regulations. The issue of integration of immigrants can therefore be characterised as a 'hot potato' - units of central government try not to have it included among their tasks.

\subsubsection{The Strategic Shaping of Policies in Poland}

In recent years, we can observe a turn to more goal-oriented and strategy-driven policymaking in Poland. This is surely connected with the Europeanisation of the Polish administration, which since EU accession, has tried to shape its actions according to strategic documents aimed at modernising the state. In recent years, all of the ministries and the cabinet have launched an enormous effort to create a large body of strategic documents (around 300). In many domains, the strategies were designed to fit EU requirements, such as the Lisbon Strategy, or its successor, the Europe 2020 Strategy, or to create a larger scope of opportunities to absorb European Funds by different types of actors (central administration, local and regional administration, non-governmental organisations, enterprises).

One might hypothesise that the logic behind creating strategic documents is changing: from being a means of achieving certain goals to becoming an end of administration in itself (March and Olsen 2006). The way in which the final document 'Polish Migration Policy - current situation and postulated actions' was created illustrates that process. It was initiated at a time of massive production of strategic policy documents. The Department of Migration Policy in the Ministry of Interior (then the Ministry of Interior and Administration) was responsible for coordinating the work and took the lead in the Inter-ministerial Team on Migration, which was working on the document. The Department of Social Assistance and Integration in the Ministry of Labour and Social Policy, which according to the division of competences should have been responsible for the chapter on integration (one of ten chapters), played a subordinate role. External actors, such as non-governmental organisations and also researchers who were calling for an explicit statement on Polish migration policy (Lesińska et al. 2010: 201-209), were marginalised during the production of the document. The process of document creation was closed to the 
broader public. A few scholars from the Centre of Migration Research were invited as advisors but they were not specialists on integration issues (but rather were more experienced in economic processes of labour migration) and they did not have any influence on the integration chapter.

\subsubsection{Institutionalisation of Public Consultation}

Nonetheless, NGOs and researchers did get a somewhat unexpected chance thanks to the public consultation process. Regulations on public consultations in the policy process and on the assessment of the consequences of regulations do not regard strategic documents as objects for consultation: only acts or ordinances are subject to such regulations. Consulting or commissioning ex-ante evaluations of strategic documents is only recommended by the government but is not an obligation. Nevertheless, the government decided to have consultations on this policy document. As one of the officials from the Ministry of Interior commented: 'There was no legal basis for the consultation - we were just driven by a desire to know [non-governmental organisations' and researchers'] opinion.' So the mode of consulting about the 'Polish Migration Policy' strategy was discretionary.

On the other hand, there was a considerable pressure on the government to run consultations, and not doing so would have met with strong criticism. And even officials working on the document openly admitted that the integration chapter especially needed to be consulted upon because there was 'simply no good idea how to design it' (informal interview with an official from the Ministry of Labour and Social Policy). The result of all this was that consultations were launched for a 30-day period according to the procedure for public consultations on normative acts.

\subsection{Migration Research After 1989}

The fall of communism in Poland totally changed the migratory situation of the country. Under the communist regime, certain groups of foreigners settled in Poland, such as Greek communists in the 1940s, students from so-called 'developing countries' (especially Vietnam), as well as waves of immigration by ethnic Poles (just after World War II and in 1956). The transition to democracy (implying liberalisation of the border regime) and to a capitalist economy (increasing the attractiveness of its labour market) significantly increased the influx of foreigners to Poland.

In their discussion of the relations between politics and migration policies in Poland, Kępińska and Stola concluded that in general migration to Poland was not a big political issue and that the relevant legislation caused few controversies (Kępińska and Stola 2004: 162). That said, they did point out three exceptions: (1) the legislation on repatriation; (2) the case of introducing visas for Ukrainians in 
2003; and (3) the engagement of NGOs in the consultations on the 1997 Alien Act. Although these issues do not pertain to integration directly, they are illustrative of the development of migration policies in Poland.

Firstly, legislation on repatriation was introduced in order to aid the 'return' of ethnic Poles living in Central Asia. ${ }^{2}$ The solutions adopted in Poland were very similar to the Aussiedler policies in Germany (Kępińska and Stola 2004: 170). However, as time passed they failed to meet ethnic Poles' expectations: unlike the situation in Germany, local municipalities were not able to finance the resettlement of these repatriates.

Secondly, in the case of introducing visas for former USSR states (a condition for Poland's accession into the EU), Polish public opinion was reluctant to introduce visa controls. While positive sentiments - especially towardss Ukrainians - were strong, pressure from the EU proved stronger (Kępińska and Stola 2004: 171). Visas were introduced, but Ukrainian citizens could acquire them without much trouble.

Thirdly, Kępińska and Stola highlight the role of legal experts from the Helsinki Foundation in providing advice in view of the proposed Alien Act in 1997 (Kępińska and Stola 2004: 162). The authors add, however, that this is in fact the only example of a successful dialogue between civil society and public bodies on issues connected to migration.

The above points, argue Kępińska and Stola, give support to their thesis that Polish migration policies were often an outcome of the priorities of other governments (Kępińska and Stola 2004: 162). In their view, 'the emerging migratory regime has lacked clear objectives; migration policies have been reactive and lack long-term goals and guidelines' (Kępińska and Stola 2004:173).

Kicinger \& Weinar, in their 'State of the Art of Migration Research in Poland' (2007), state that in the 1990s, migration research in Poland was in an exploratory phase - new phenomena were described by researchers of different backgrounds, interested in different scientific problems and research issues. In the twenty-first century, research became more explanatory, analysing the general situation and statistical data on the daily lives of specific groups of migrants, at macro- and micro-levels (Kicinger and Weinar 2007: 38). Kicinger \& Weinar also stress - and it is difficult to disagree - that the research agenda for migration studies in Poland was mostly set by western scholars seeking comparative data (Kicinger and Weinar 2007: 38). Polish research was influenced by theories developed in the West, and the inclusion of Polish researchers in research proposals and funded projects was thanks mainly to western scholars.

In Poland there is a strong tradition of studying emigration: without much exaggeration it may be stated that emigration was at the heart of the development of sociology in Poland, such as the seminal works of Thomas and Znaniecki (1918). Emigration studies became institutionalised, an example of which is the Institute of Polish Diaspora and Ethnic Studies at the Jagiellonian University in Kraków. By contrast, the studies on immigration mentioned above were the products of

\footnotetext{
${ }^{2}$ Their ancestors were deported there during the Stalinist era.
} 
individual scholars, not an effort by institutionalised research centres. The Centre of Migration Research (CMR) at the University of Warsaw, the most recognised and strongest scientific institution on migration in Poland, is the result of Professor Marek Okólski's efforts and leadership in the field of migration research in Poland to build a team of scholars and create an institute. Its institutionalisation in 1993 was a result of the support of international agencies and research grants seeking data from Central Eastern Europe (Okólski 2008: 1). Another centre worth mentioning is the Central European Forum for Migration and Population Research (CEFMPR) established in 2002, financially supported by the Swiss Foundation for Population, Migration and Environment. Recently, a new institute was established at the Adam Mickiewicz University in Poznań: the Centre for Migration Studies (CeBaM). $\mathrm{CeBaM}$ also became active thanks to European financial resources. Kicinger and Weinar underline that Polish research on migration policy did not aim to provide a basis for policymaking (Kicinger and Weinar 2007: 59) and that 'the dynamic development of migration policy research in Europe, with many international research projects in the field, proved to be the most important accelerator for migration policy research in Poland' (Kicinger and Weinar 2007: 61). Ironically, this is also the case with this chapter.

As Kicinger \& Weinar contend in their 'State of the Art', studies about the issue of integration have treated this notion as self-explanatory and seldom discussed the meaning of or measures for the process of integration. They express doubts about whether it is possible to examine integration in Poland, as immigrants reside in Poland for only a short period of time and suggest the term 'adjustment' of immigrants in Poland as more applicable (Kicinger and Weinar 2007: 44).

Since the publication of Kicinger \& Weinar's 'State of the Art' in 2007, two significant books have appeared: a collection of theoretical papers on integration (Grzymała-Kazłowska and Łodziński 2008) and a multi-dimensional analysis of the integration policy towardss refugees in Poland (Frelak et al. 2007). The former work discussed the theoretical aspects of research on integration of immigrants. The latter research focuses on the so-called 'programmes of individual integration for refugees' and more generally evaluated the system of integration of refugees in Poland put in place in 2000 thanks to changes to the Social Assistance Act. The general conclusion of the study by Frelak and colleagues is that the evaluation of integration policy is difficult, as most of its target audience do not wish to reside long-term in Poland and plan to eventually migrate to Western Europe. At the same time the volume provided several detailed recommendations for policymakers: one of the most important was the inclusion in integration programmes of forced migrants who had not acquired Geneva refugee status, but instead had been granted so-called 'tolerated stay' status (similar to German 'Duldung'). Soon after the book's publication, the Social Assistance Act was rewritten and broader categories of forced migrants were included in the integration programmes. One should note, however, that for this particular change in legislation the voice of the researchers was just one among many: social workers from local social assistance centres, representatives of NGOs, and officials of The Office for Repatriation and Aliens also supported it. The necessity for change seemed obvious to all actors and required no additional discussion. 
Another conclusion drawn from the research was that the individual programmes of integration did not have any aims or goals set. Social workers assisted refugees in increasing their knowledge of the Polish language, aided in job seeking and encouraged contact with the local community, but the programme was terminated after 1 year, regardless of its outcomes. Thus, it could be concluded that the mean ('to integrate') is the aim of the policy, not a particular end (to achieve some sort of level of integration or at least adjustment of a refugee). This could be called the logics of appropriateness, because actions are taken not because the ends are needed, but because it is appropriate (or legitimised) to apply the mean (March and Olsen (2006).

Frelak and colleagues' study of integration policies (2007) is illustrative with regard to dialogues involving NGOs, researchers and policymakers in Poland. The research project was conducted by the Institute of Public Affairs (an independent think-tank) in cooperation with a pro-bono organisation of lawyers, financed by the European Social Fund. The Ministry of Labour and Social Policy (responsible for the integration of immigrants in Poland) was also invited to be a partner. This scenario is typical in the Polish setting - civil society initiates, European funds facilitate, and public institutions are co-opted. However, the latter seldom use the resulting recommendations.

Polish migration policymaking is viewed as a product of the pressures of the Europeanisation process. This is the case for the legislation created to meet the requirements of the acquis communautaire (Weinar 2006; Kicinger et al. 2007). It is also expressed by the support of norms and institutions recognised as 'western' by practitioners (Pawlak 2011; Łodziński and Grzymała-Kazłowska 2011). Yet Kicinger disagrees with this view, arguing that there are certain fields of migration policy that are 'more Poland-oriented' (Kicinger 2009: 80). In her opinion these areas include: the visa policy for Eastern neighbours (noted above), the 'policy of silent tolerance towardss the irregular employment of foreigners in Poland', repatriation policy (also noted above), and emigration. In Kicinger's opinion the tolerance of irregular employment of Ukrainians in Poland (mostly in agriculture, construction and domestic work) is deliberate (Kicinger 2009: 87). On the other hand, she believes that the refugee protection regime in Poland is the most Europeanised, since what was most at stake here was to prove that Poland was a liberal democracy (Kicinger 2009: 91).

In the case of refugee protection, especially the policies concerning the integration of refugees in Polish society, one could claim (although there is not sufficient conclusive evidence) that elements of this policy are deliberately weak. Referring to the concept of strategic decoupling (Hirsch and Bermiss 2009: 265), one can interpret the deliberate ineffectiveness of refugee integration policies (noted by NGOs) as a means to avoid attracting greater numbers of asylum seekers. According to this interpretation, the Polish state would be achieving two contradictory goals: (1) running the refugee protection regime according to western standards (legitimation); and (2) discouraging the arrival of new asylum seekers and settlement of those already present (the interest of the Polish state). 
Some studies include policy recommendations as part of their conclusions. It seems, however, that they often serve a rather superficial, cosmetic function: researchers express their views (which are often critical towardss the current situation) but the 'recommendations' are not compatible with policymakers' logics of action.

\subsection{Processes of Research-Policy Dialogue: Two Examples}

\subsubsection{NGO-Initiated Research as a Lever for Dialogue: Refugee Children and Education}

In 2005 and 2006 the Association for Legal Intervention (SIP) conducted a survey in centres for asylum seekers regarding school enrolment of refugee children. SIP's primary field of operation is non-profit legal advice, but the organisation also comments on legal acts and lobbies for changes in legislation, favouring individuals in danger of exclusion or marginalisation. Although refugees and migrants are not SIP's only clients, they are one of the most important and the lawyers from this NGO specialise in immigration law, especially the application procedures in order to attain refugee status.

SIP activists sent questionnaires to all refugee centres in Poland - nearly 20 at the time. The officials from the centres were supposed to provide the number of children living in the centre, the number of children attending school, and a description of the results of tests assessing children's knowledge of Polish, as well as their educational attainment. This was important in the case of children who did not possess school certificates or those who had been educated in incomparable education systems.

The results confirmed the NGO's suspicions that a very large group of refugee children was not even enrolled in schools. Half of the children had not sat the educational attainment test and, as a consequence, did not attend school at all. Also, some children who according to the test results had poor command of Polish did not attend school as well. In the SIP report the authors stressed that the organisation of such tests was required by regulations (Jasiakiewicz and Klaus 2006). However, as in some locations such tests were organised only once a year, many children who arrived after the beginning of the school year were simply excluded from the education system, which - as the authors stressed - is in fact illegal. In many cases social workers from the refugee centres explained the low attendance among refugee children by pointing to parents' lack of interest in school enrolment. This stance is in breach of regulations on compulsory education in Poland. The report also makes note of the low evaluation of the level of Polish language classes and educational support for children provided in the refugee centres. Many of these problems have been revealed previously, for example in the first Polish edition of the annual 'Age, Gender and Diversity Mainstreaming' survey conducted by the regional UNHCR office for Central Europe (UNHCR 2005). 
The outcomes of the SIP research were strongly publicised: the final report was published in full on the Internet, and a shorter version appeared as a policy paper. Furthermore, a conference on the topic of the education of refugee children was organised. This case is therefore illustrative of a specific form of dialogue between civil society and public institutions in Poland. The evidence gathered by the NGO by means of a simple but accurate methodology was used to put pressure both on the Office for Repatriation and Aliens (which at the time managed the centres for asylum seekers and ruled on asylum applications) and on local educational authorities to improve their practices. The situation was presented as scandalous and the need for finding quick solutions was highlighted.

Measures were swiftly taken after the publication of the report: in particular, the practices regarding the educational attainment test were changed (they are presently organised more frequently), and more attention was devoted to assisting refugee pupils in the centres for asylum seekers. The biggest problem for the Office for Repatriation and Aliens was to create effective incentives for parents to send their children to schools, particularly for Chechen parents. ${ }^{3}$ As many of them had plans to leave Poland soon, they did not see much point in their children pursuing education in Poland. The solution that was finally implemented was to pay a sum of money directly to parents: this sum was equivalent to the meal costs saved by asylum seeker centres when children were away in school. This solution revealed the dual purpose of the measure. The first is direct and obvious: refugee parents need money to feed their children. The second one is indirect, but silently accepted by both refugees and the Office for Repatriation and Aliens: the money is perceived by many as a source of income and thus even the ones not willing to stay in Poland become interested in enrolling their children in school.

Since 2006 all children residing in centres for asylum seekers have been enrolled in schools, but the real problems with their education and further integration into the school system remain unresolved. Refugee children are in danger of exclusion, and while the enrolment rate is easily assessed from raw data, it is much harder to monitor the process of their integration. Owing to the research and engagement of NGOs in 2006, a first step was made and the school system was effectively opened for refugee children. However, their educational achievements and participation in school life remain a problem.

In summary, in this case we see that local educational authorities and the public institution responsible for refugees (The Office for Repatriation and Aliens) did not take any action to monitor the school enrolment of children residing in centres for refugees. Action was started by an NGO in the form of a survey to expose this situation. The survey could not have been completed, however, without full cooperation from social workers and officials from the centres that are run by the state agency: they provided detailed data. The results were publicised by the $\mathrm{NGO}$, which was strongly critical of the current situation, resulting in the quick

\footnotetext{
${ }^{3}$ In the 2000s, Chechens constituted the majority of asylum seekers in Poland.
} 
implementation of (somewhat ambiguous) measures to formally solve the problem. This was recognised as a mutual success, but was also just the first step in facilitating integration in schools. Other aspects of the process remained problematic.

\subsubsection{The European Integration Fund as a Lever for Future Policy?}

Poland's migrant integration policy has so far focused exclusively on refugees and asylum seekers. In 2009, however, Poland became eligible for accessing the European Fund for the Integration of Third-Country Nationals (EIF). This situation is paradoxical because the projects granted by the Fund should complement actions taken on a national level, according to a Decision of the Council of the European Union, (article 6, 2007/435/EC). However in the case of Poland and some other Eastern European countries (i.e. Hungary), such actions cannot complement any national integration policy, because no such policy exists. ${ }^{4}$

Since the beginning of 2009 over 40 organisations in Poland have received financial support for their projects from the EIF. This has resulted in a boom in activities by NGOs in the field of migrant integration. It is worth noting that, in the case of Poland as a new EU state, the Fund could cover up to $75 \%$ of a project's budget. Additionally, organisations may apply for national support for another $10 \%$. As a result, even small organisations with limited resources could launch activities for immigrants.

In the eyes of experts and practitioners in the field, neither the authority implementing the programme (Władza Wdrażająca Programy Europejskie) nor the Ministry of Labour and Social Policy (which is responsible for migrant integration) are qualified to manage the EIF (Bieniecki and Pawlak 2010). As the field in Poland is relatively small, the amount of money claimed in proposals filed for 2009 was smaller than the total funding available. ${ }^{5}$ As a consequence of this absence of competition, and the implementing authority's lack of capacity to evaluate project proposals, the actions that were financed were extremely incoherent. They often overlapped with or duplicated existing actions, as in the case of handbooks for immigrants, while other issues were not covered at all.

One of the EIF's priorities was research on the situation of third-country nationals and their integration needs. Several research projects were carried out, but only one was conducted by an academic institution, plus a few others which were coordinated by independent research institutes with appropriate research experience. However the majority were conducted by NGOs lacking sufficient

\footnotetext{
${ }^{4}$ National integration policy might exist without being institutionalised (a lack of policy is also a policy), but the European Fund is supposed to be complementary to institutionalised and explicit policy.

${ }^{5}$ In 2009 organisations could apply for the 2007 and 2008 EIF allocations.
} 
methodological and professional expertise. Academic institutions faced great difficulty in applying for research grants from the EIF, since EIF's procedures and requirements as well as academic bureaucracy were highly incompatible. In the EIF's defence, the Polish implementing authority lacked sufficient knowledge to review research proposals: decisions were made by officials based on their own reasoning rather than on peer review.

Research reports from the projects financed by the EIF were supposed to provide policy recommendations, but this requirement is highly problematic in the absence of explicit national policies. Evaluation studies and surveys show that NGO-run projects often displayed a lot of enthusiasm, yet - hindered by lack of research experience - did not provide useful data. Many of their recommendations are not realistic as the activists do not fully understand the mechanisms of the administrative implementation of policies, or overestimate the funds available to national and local authorities for dealing with issues that are not recognised as important in public discourse. On a more positive note, one might expect that this body of knowledge might be used in the near future to develop policy recommendations from civil society.

In terms of content, it is to be noted that the requirements of the EIF, and its definitions and practices, shape the views of practitioners from the field of migrant integration. Symptoms of both coercive and normative isomorphism can be observed (DiMaggio and Powell 1983: 150): firstly, organisations apply structures and reproduce practices that are set by the bureaucratic standards of the fund; and secondly, both activists and employees of organisations are in a process of professionalisation. 'Integration' becomes their professional ideology and this is a source of pressure for normative isomorphism (Pawlak 2011). These phenomena shape expectations for future Polish integration policies.

In the near future, integration policy appears certain to be extended to cover more than forced migrants. While the scope of the actions outlined in the official document on 'Polish migration policy' prepared by the government is very general, it seems that it is going to be 'reactive' to the actions financed by the EIF during the past years.

The debate on the integration issue has only recently started in Poland. Thanks to the fact that immigration is not a politicised topic, it is not influenced by democratic impatience (Penninx 2009) ${ }^{6}$; instead it is shaped by the EIF's agenda and categorisations, which are in many respects linked with the problems recognised in western countries with longer immigration traditions. This caused the abovementioned pressures for coercive and normative isomorphism regarding actions to integrate immigrants, which in turn shaped the expectations of participants in the debate regarding national integration policy. This process - along with legal changes connected to EU accession and the requirements of the acquis communautaire - is yet another aspect of Europeanisation of Polish integration policy.

\footnotetext{
${ }^{6}$ It can be said however that the integration policy introduced thus far, with the help of the EIF, suffers from 'project impatience': actions are not sustainable, and finish when funding stops at the end of a project.
} 
The discussions over the 'Polish Migration Policy' document (especially with regard to its chapters on integration) can be viewed as a preliminary attempt to set (new) standards in the Polish dialogue between civil society and policymakers. Caritas Poland (one of the biggest charities in Poland connected to the Catholic Church and active in assistance to immigrants) has taken the lead in trying to organise actors in the NGO and research fields into putting pressure on governmental agencies to improve integration policy. The first means to do this is Caritas' initiative to review EIF projects and their outcomes in Poland, in order to identify which knowledge could be included in integration policies, and also to scrutinise the standards of NGO services. Caritas, recognising its lack of authority to evaluate other NGOs or public bodies, facilitated the creation of a team of experts with backgrounds in public administration (local and national), NGOs and research institutions. Representatives from the field then discussed the analysis of completed integration projects provided by this expert team. The second means by which to exert pressure on government is to organise conferences and bring practitioners and experts together to lobby for better integration policies.

The 30-day period of public consultation on the 'Polish Migration Policy' document was a time of mobilisation for civil society. NGO activists wanted to provide evidence-based provisions for the document - not only to improve policy, but also to prove their accountability to governmental officials. Governmental officials needed to listen to civil society partners, knowing that after the shortcomings in utilisation of EIF money thus far this was the only way to gain legitimisation for future policy. There were 19 submissions during the consultation period: one by the leading migration research institute (the Centre of Migration Research), five by governmental institutions (not included previously during the document's preparation), two by leading trade-unions, two by international organisations (UNHCR and IOM), and eight by NGOs plus the submission by the expert team formed by Caritas Poland (some of the representatives of the eight NGOs were also members of this coalition but wanted to also send their separate official opinions). Specifically regarding the integration chapter, more than 40 corrections proposed during the consultation period were inserted in the final version of the document adopted by the Prime Minister in July 2012. One of the Ministry of Interior officials admitted that the team of experts formed by Caritas Poland could be regarded as a co-author of the chapter (informal interview with Interior Ministry official).

\subsection{Conclusions}

To conclude, the government is not an active participant in shaping migrant integration policy: its approach is rather reactive. The most important reason for this state of affairs is that the immigration issue is not a topic of wide public debate, so there is no pressure from the political parties to design an integration policy. Instead, the institutional framework was shaped by pressure from outside. Poland had to accept the acquis communautaire as a condition of EU accession in 2004, 
and the availability of EIF funding opened up opportunities for the mobilisation of the civil sector. At the same time, the research agenda of scholars was shaped by European research interests and theories. Introducing the European framework for the policy was not just obligatory, but also perceived as appropriate. Drawing and borrowing from institutions and structures that have a longer experience with immigration legitimised Polish policymakers. For the Polish actors, the European framework seemed to be 'the most rational' model to be adopted.

The consequences for actual policy practices can be considered in a positive light. If it were not for the external pressures and financial resources described above, integration polices in Poland would not have developed. Nonetheless, there is a risk that structures and institutions will be adopted superficially in order to gain legitimacy, without much impact on daily practice in administrative agencies or in social welfare organisations. In organisational sociology, such an effect is termed 'decoupling' (Meyer and Rowan 1977). However, this will not occur if a strong set of professional norms emerges among those who implement integration policies.

Research-policy dialogues in Poland are not institutionalised. This chapter has instead shown that currently it is more accurate to speak of policy-research-NGO dialogues. This means that the transmission of knowledge is rather indirect, and the forms of this transmission often contain scandalising, exaggeration or purely rhetorical policy recommendations. NGOs use research and research methods to legitimise their authority in the dispute over the future direction of integration policy. When dialoguing with policymakers, they often join forces with researchers. The most important constraint encountered in developing dialogues is distrust between policymakers on one side and civil society and researchers on the other. There is no tradition of evidence-based policymaking in Poland and a public debate on integration in Poland is largely absent: the issue is not perceived as important. Finally, evidence and recommendations provided by researchers are often not compatible with the logics of action of public institutions. The dialogue, as far as it exists, is facilitated by the forces of Europeanisation at many levels: legislative; organisational standards and procedures; political legitimisation; and normative attitudes held by participants in policy-research-NGO dialogues.

NGOs and researchers are becoming a stronger party in dialogues thanks to external forces like EU funds and frameworks for integration practices. Furthermore, the models of civic participation in policymaking and use of expertise that already exist in the EU also influence the perception of how dialogues should be guided. The growing trend in Poland for government to initiate strategy documents and public consultations, and to commission evaluation studies, will certainly influence the institutionalisation of future dialogues. Yet the possibility exists that this is going to have only a symbolic character.

The first case study showed that in a context of relatively less institutionalised relations, scandalising the integration issue is one way of exerting pressure on policymakers. However, it appears that this mode of dialoguing between policymakers and researchers is unlikely to be effective on an institutionalised, day-to-day basis. The second case study indicated that there is a possibility to adjust research-policy dialogues to fit institutional channels of communication through mechanisms like 
public consultations. It should be noted that in the case of the 'Polish Migration Policy' document, launching the public consultation was a discretionary decision of policymakers. However, the pressure to initiate a consultation on the document came both from new trends in government practice and from the expectations of non-governmental organisations.

Open Access This chapter is distributed under the terms of the Creative Commons Attribution Noncommercial License, which permits any noncommercial use, distribution, and reproduction in any medium, provided the original author(s) and source are credited.

\section{References}

Bafoil, F. (2009). Central and Eastern Europe. Europeanisation and social change. Basingstoke: Palgrave MacMillan.

Bieniecki, M., \& Pawlak, M. (2009). Strategie przetrwania. Adaptacja ukraińskich migrantów zarobkowych do polskiej rzeczywistości instytucjonalnej. Warszawa: Instytut Spraw Publicznych.

Bieniecki, M., \& Pawlak, M. (2010). Laboratoria integracji. Obserwacje i notatki praktyczne. Gliwice: Caritas Polska.

Boswell, C. (2009). The political uses of expert knowledge: Immigration policy and social research. Cambridge: Cambridge University Press.

DiMaggio, P. J., \& Powell, W. W. (1983). The iron cage revisited: Institutional isomorphism and collective rationality in organisational fields. American Sociological Review, 48(2), 147-160.

Frelak, J., Klaus, W., \& Wiśniewski, J. (Eds.). (2007). Przystanek Polska. Analiza programów integracyjnych dla uchodźców. Warszawa: Instytut Spraw Publicznych.

Frieske, K. W. (1990). Socjologia w dziataniu: Nadzieje i rozczarowania. Warszawa: Wydawnictwa Uniwersytetu Warszawskiego.

Frieske, K. W., \& Regulski, J. (1984). Studia nad metodologią ekspertyz naukowych Polska 2000. Biuletyn ,Polska 2000”, 1, 1-104.

Gluck, L. (1973). O niektórych problemach współdziałania decydenta i eksperta. In J. Kubin \& A. Podgórecki (Eds.), Stosowane nauki społeczne w praktyce (pp. 49-64). Wrocław/Warszawa/Kraków/Gdańsk: Zakład Narodowy im. Ossolińskich Wydawnictwo Polskiej Akademii Nauk.

Grzymała-Kazłowska, A., \& Łodziński, S. (Eds.). (2008). Problemy integracji imigrantów. Koncepcje, badania, polityki. Warszawa: Wydawnictwa Uniwersytetu Warszawskiego.

Hirsch, P. M., \& Sekou Bermiss, Y. (2009). Institutional "dirty" work: preserving institutions through strategic decoupling. In T. B. Lawrence, R. Suddaby \& B. Leca (Eds.), Institutional Work. Actors and agency in institutional studies of organisations (pp. 262-283). Cambridge: Cambridge University Press.

Howard, M. M. (2003). The weakness of the civil society in post-communist Europe. Cambridge: Cambridge University Press.

Jasiakiewicz, A., \& Klaus, W. (2006). Realizacja obowiazku szkolnego przez matoletnich cudzoziemców przebywających w ośrodkach dla uchodźców. Raport z monitoringu. Warszawa: Stowarzyszenie Interwencji Prawnej.

Kępińska, E., \& Stola, D. (2004). Migration policy and politics in Poland. In A. Górny \& P. Ruspini (Eds.), Migration in the New Europe. East-west revisited (pp. 159-176). Basingstoke: Palgrave Macmillan.

Kicinger, A. (2009). Beyond the focus on Europeanisation: Polish migration policy 1989-2004. Journal of Ethnic and Migration Studies, 35(1), 79-95. 
Kicinger, A., \& Weinar, A. (Eds.). (2007). State of the art of the migration research in Poland (CMR Working Papers 26/84). Warsaw.

Kicinger, A., Weinar, A., \& Górny, A. (2007). Advanced yet uneven. The Europeanisation of polish immigration policy. In T. Faist, A. Ette, \& M. Baumann (Eds.), The Europeanisation of national immigration policies (pp. 181-200). Basingstoke: Palgrave Macmillan.

Kolasa-Nowak, A. (2010). Zmiana systemowa w Polsce w interpretacjach socjologicznych. Lublin: Wydawnictwo Uniwersytetu Marii Curie-Skłodowskiej.

Kwaśniewski, J. (2002). Socjologia stosowana. In Encyklopedia socjologii (pp. 80-84). Warszawa: Oficyna Naukowa.

Lesińska, M., Stefańska, R., \& Szulecka, M. (2010). Migration policy considerations. In A. Górny, I. Grabowska-Lusińska, M. Lesińska, \& M. Okólski (Eds.), Immigration to Poland: Policy, employment, integration (pp. 197-209). Warszawa: Wydawnictwo Naukowe Scholar.

Łodziński, S., \& Grzymała-Kazłowska, A. (2011). Koncepcje, badania i praktyki integracji imigrantów. Doświadczenia polskie w europejskim kontekście. Studia Migracyjne - Przegląd Polonijny, 2, 11-39.

March, J. G., \& Olsen, J. P. (2006). The logic of appropriateness. In M. Moran, M. Rein, \& R. E. Goodin (Eds.), The Oxford handbook of public policy (pp. 689-708). Oxford: Oxford University Press.

Markiewicz, W., \& Morawski, W. (1991). The influence of social sciences on political decisions in Poland. In P. Wagner, C. Hirschon Weiss, B. Wittrock, \& H. Wollmann (Eds.), Social sciences and modern states: National experiences and theoretical crossroad (pp. 207-220). Cambridge: Cambridge University Press.

Meyer, J. W., \& Rowan, B. (1977). Institutionalised organisations: Formal structure as myth and ceremony. American Journal of Sociology, 83(2), 340-363.

Mikułowski-Pomorski, J. (1972). Socjologia w świetle doświadczeń jej praktycznego stosowania. In A. Podgórecki (Ed.), Socjotechnika. Style działania (pp. 385-412). Warszawa: Książka i Wiedza.

Morawski, W. (2010). Prometeusz spętany? Próby analiz instytucjonalnych polskiej modernizacji. In W. Morawski (Ed.), Modernizacja Polski. Struktury, agencje, instytucje (pp. 90-123). Warszawa: Wydawnictwo Akademickie i Profesjonalne.

Okólski, M. (2008). Od założyciela OBM Profesora Marka Okólskiego. Biuletyn Migracyjny, 20, $1-1$.

Pawlak, M. (2011). Termin „integracja” jako narzędzie legitymizacji. Neoinstytucjonalna analiza uprawomocniania działań w polu organizacyjnym obsługi i pomocy imigrantom w Polsce. Studia Migracyjne - Przeglad Polonijny, 2/2011, 59-80.

Pawlak, M. (2012). Asymetrie i klisze pojęciowe w analizach uchodźstwa w Polsce. Studia Migracyjne - Przeglad Polonijny, 2/2012, 163-185.

Penninx, R. (2009). Decentralising integration policies. Managing integration in cities, regions and localities. London: Policy Network.

Putnam, R. (1993). Making democracy work: Civic tradition in Modern Italy. Princeton: Princeton University Press.

Scholten, P. (2011). Framing immigrant integration: Dutch research-policy dialogues in comparative perspective. Amsterdam: Amsterdam University Press.

Szelenyi, I., \& Wilk, K. (2010). Institutional transformation in European post-communist regimes. In G. Morgan, J. L. Campbell, C. Crouch, O. Kai Pedersen, \& R. Whitley (Eds.), The Oxford handbook of comparative institutional analysis (pp. 565-585). Oxford: Oxford University Press.

Thomas, W. I., \& Znaniecki, F. (1918). The Polish Peasant in Europe and America. Monograph of an immigrant group. Boston: Richard D. Badger.

UNHCR. (2005). Listening to refugees: Report on the gender, age and diversity roll-out in Hungary, Poland, the Slovak Republic and Slovenia. Budapest: UNHCR Regional Representation for Central Europe. 
Weinar, A. (2006). Europeizacja polskiej polityki wobec cudzoziemców 1990-2003. Warszawa: Scholar.

Weiss, C. H. (1979). The many meanings of research utilisation. Public Administration Review, 39(5), 426-431.

Zalewski, D. (2005). Opieka i pomoc społeczna. Dynamika instytucji. Warszawa: Wydawnictwa Uniwersytetu Warszawskiego. 


\title{
Chapter 15 \\ Research-Policy Dialogues in Denmark
}

\author{
Martin Bak Jørgensen
}

\subsection{Introduction}

The Danish integration and immigration policies are among the most restrictive of their kind within Western Europe. As in other countries integration is a highly contested policy-domain and a salient policy issue. It is also one of the policydomains most subject to change over the last two decades. This can raise the question of what has driven this development - new types of problems or the scope of the problem, political convictions or evidence-based research? It can be argued that the utilisation of external expert knowledge at national level has been minimal and the research-policy relationship can perhaps best be considered as a 'pickand-choose' model where politicians and policymakers have employed the research that supports the hegemonic policy-frame of integration and definition of problems. Research thereby serves a legitimising function rather than an instrumental function (Jørgensen 2011). This characterisation at the same time stands in contrast to the importance and emphasis given to evidence-based policymaking. Subsequently, this situation may lead to disenchantment about research-policy dialogues. While the use of external research arguably has been limited there has in contrast been a proliferation of in-house research institutions within the political system itself, although often with limited budgets.

This chapter examines the role and impact of the scientific community on integration- and immigration policymaking. This analysis will be elaborated by three cases investigating, first; the 'Workgroup on Burkas and other Similar Clothing', which reported in 2009-2010 secondly; the development of the Action

\footnotetext{
M.B. Jørgensen ( $\square)$

Department for Culture and Global Studies, Aalborg University, Aalborg, Denmark

e-mail: martinjo@cgs.aau.dk
} 
Plan against Extremism and Radicalisation of Youth from 2008/2009, and thirdly; the policy plans on social housing and segregation from 2004 onwards - in a Danish context termed 'strategies against ghettoisation'. In all three cases the relationship between external and in-house research institutions will be discussed and taken together this will facilitate an outline of the prevailing research-policy dialogues in Denmark today. It is argued that particular research-policy infrastructures have consequences affecting not only policymaking and research-policy dialogues but also shaping perceptions of the research field itself and what it can contribute in policy processes.

The sources used for the analysis draw on a range of different materials. These include legislative texts, action plans, policy documents, newspaper articles, evaluations, political statements and speeches as well as six formal and informal interviews conducted for this piece of research.

\subsection{Migrant Integration: An Overview}

The following section gives an overview of the immigrant integration policies in Denmark over the last 40 years. The overview and following analysis draw on a policy-frame analytical approach (Benford and Snow 2000).

\subsubsection{The Genesis of Danish Migrant Integration Policies}

Until the end of the 1970s, Denmark had an extremely homogeneous population, with rather moderate immigration flows. The trajectory of Danish migration policy resembles that of many other European countries. In the late 1960s and early 1970s, substantial numbers of predominantly male migrant workers arrived in response to private employers' demands.

Henceforth the main policy-frame was a frame building on the notions of 'temporariness' and 'guest workers'. This frame was championed by both political actors and private employers who saw no need to introduce measures of integration, such as language acquisition, as the workers were there to work and not to talk. Both Danish society and many migrants themselves envisioned this stay as temporary. However, by the time of the oil crisis in 1973, many migrant workers had earned the right to stay, to state support, and to family reunification, making permanent settlement in Denmark a more attractive option than the often insecure economic conditions in countries of origin. Where previously male migrants had paid taxes but made little demands on the welfare state, recession and labour market restructuring gradually marginalised many of the original migrant workers. High levels of unemployment among unskilled workers created increased demands for public funds and services. 
This created the basis for a new policy-frame as issues of integration (or rather disintegration, see Geddes 2003), became an increasingly political matter, raised particularly by the Social-Democrats in the early 1980s. This situation continued into the 1990s but was mainly set on the agenda by political actors. In 1994 a number of social-democratic mayors from suburbs of Copenhagen (Ishøj, Brøndby and Hvidovre) and Århus (all cities/areas with large concentrations of immigrants and real or perceived social problems) lost patience and brought the immigrant issue to the top of the agenda, through demands for quotas and dispersal of immigrants nationwide.

Following a commissioned study (Indenrigsministeriet 1997), the first Danish Act of Integration based on this new policy-frame was implemented in 1999 by the Social-Democratic and Social-Liberal government. The new act initiated a 'tougher' line with regards to integration and centralised authority over such matters, which previously had been delegated to local authorities and the private sector. The overall framing was based on a representation of immigrants as lacking the necessary human capital to achieve parity with the majority society. In this representation, self-sufficiency and autonomy were held to be valued characteristics which migrants were likely to lack. The focus on socio-economic integration inevitably led to a shift of burden towardss the immigrant, where integration first and foremost became the responsibility of the individual. The main instrument therefore was restrictions and the Minister of the Interior Thorkild Simonsen, responsible for the new Act stated: 'I find it hard to see what the right-wing parties can implement in an orderly manner that would be more restrictive than what we are proposing here (Jastrup 1999).'

\subsubsection{The New Era of Immigration and Integration Policies - From 2001 Onwards}

The change of government to a right-wing coalition supported by the anti-immigrant Danish People's Party in 2001 initiated a new era of migration and integration policymaking based on a policy-frame of assimilation and cultural adaptation. The new integration policy-frame was and is based on an overtly socio-economic representation of integration. The primary focus was therefore to keep people in employment in order to be able to maintain welfare services. The main claim was that 'we must integrate those who already reside in the country'. This legitimated the restrictions in access to Denmark, especially targeted at inflow coming through family reunification and asylum seekers (Regeringen 2002). Integration policy thus was linked to general immigration policy.

Integration from then on was defined as active participation in the labour market and contribution to the welfare state. The key policy document for the new Danish integration policy was the action plan En ny chance til alle [A new chance for everybody] (Regeringen 2005) itself linked to the government strategy paper Noget for noget [Quid pro quo] published in 2004 (Regeringen 2004a). These programmes 
are the basis of policy today, but have been amended in different - often more restrictive - ways since, not least with the significant changes introduced in 2010 (Regeringen 2010a).

During the 2000s the political opposition was in an ambiguous position. There was a general support for the restrictive turn and 'new realism' within the population and, despite voicing critique of the policies, the opposition promised a continuation of existing policies. The government changed once more in 2011, and is now constituted by the Social Democrats and Social Liberal Party. The change in government also led to a shift from a predominantly centralised Ministry for Immigration and Integration towardss decentralised coordination, leading to the abolishment of the Ministry of Integration and a division of competences between different ministries. The government launched a new Integration policy in 2012 consisting of seven goals. These goals resemble the goals and strategic action plans of the past government and point to a large degree of path dependency in terms of policy goals (Regeringen 2012).

The policy trajectory initiated in 2001 evolved into a new frame that emphasises cultural adaptation to the host society and emphasises that integration should lead to a specific form of national identity. This is in line with the reframing of assimilation as the guiding principle for policy developments and provides an exclusivist mechanism that is used to legitimise especially 'harsh' political actions that are used to combat social phenomena that are described as 'un-Danish'. This logic informs many of the policy initiatives relating to terrorism, radicalisation and ghettoisation, as will be discussed below.

\subsection{Boundary Relations and Division of Labour}

In the following section I will discuss and outline the boundary relations between research and policy. I will argue that the Danish boundary relations resemble an engineering model and will outline the features of the Danish model. This is followed by a concluding section on the roles of external research institutions in the Danish case.

\subsubsection{An Engineering Model}

With the realisation that migrants were settling permanently in Danish society, migrant integration emerged not only on the political agenda but also on the research agenda in the 1980s and 1990s.

Integration research initially reflected the fact that immigrants came as labour migrants and gradually turned into a perspective on immigrants as constituting social problems demanding political solutions. Research was diffuse and came mainly from papers and essays from specific educational institutions and/or as 
(local) reports with a focus on practical issues originating in concrete immigrant projects. During the 1980s socio-economic issues gained prominence alongside an increase in studies on marginalisation and inequality. Structural labour market explanations are prominent in describing the immigrants' position. From the 1990s research is polarised between two main types. Firstly, studies focusing on immigrant behaviour and attitudes to immigrants; and secondly, evidence-based mapping studies seeking to generate facts about immigrants and performance in relation to language, education and work.

Especially in the 1990s there was also an increased utilisation of expert knowledge for policy-formulation. A good example is the reports by the sociologist, and later politician, Eyvind Vesselbo for the municipality of Ishøj in 1990. In the report Vesselbo shows how the population of Turkish newcomers grew from 145 people in 1969/1970 to 1,824 in 2000 (Vesselbo 2000). The report has been much cited in the Danish parliament and has been used as an example of how things can get out of control (see Jørgensen 2011). The research was not used instrumentally but was used to substantiate, i.e. lend authority, to the new emerging policy-frame coupling immigration, human capital and socio-economic integration.

However, for a large part the focus on restrictions, and the political ambition to bring down the number of immigrants arriving in the 1990s stand in stark contrast to the dominant Danish research agenda on immigration at the time. This finding lends support to the 'two communities' thesis, which claims that there is a gap between the worlds of researchers and policymakers, making it difficult to translate research into policy (Wehrens 2013). The central research institution in the 1990s was the Danish Centre for Migration and Ethnic Studies (DAMES) established in 1995 in Esbjerg by the University of Southern Denmark (SDU). Its main task was to coordinate and strengthen Danish immigration research. Contrary to the political agenda its main conclusion was that Western societies including Denmark indeed needed migrants and should focus on how to manage migration and avoid social marginalisation (see Jørgensen 2011). The research coming from DAMES was unsurprisingly - not utilised in policymaking. The relation between politics and science in the period from the arrival of the migrant workers in the 1960s until the late 1990s can be characterised as a pick-and-choose model resembling the 'engineering' model outlined by Hoppe (2005). Knowledge was mobilised for the service of the state when needed and here it first and foremost served a symbolic function by substantiating the policy-frame being developed by politicians at the time.

Thus, research-policy relations in Denmark resembled an engineering model of boundary relations, and to some extent continue to do so today. Several features in particular resemble this engineering model. The first important feature was the establishment of the Ministry of Refugee, Immigration and Integration Affairs bringing together all tasks and competences relating to immigration and integration in one ministry. Of course there were overlaps with other ministries such the ones for education, social affairs or employment, but the main responsibility for policymaking within this field was laid down in this ministry until its abolition in 2011. The ministry contained different departments and different in-house research 
institutions. It also provided secretariat support and steering responsibility for the commissioned- and think-tank research that was contracted to inform policymaking in this field. The in-house bodies have become more important over the years and play a decisive role in defining policy problems and developing policy-frameworks.

The emergence of new departments was established more from political will than from the belief that there was a lack of research; at a minimum it can be said that the timing was without doubt based on political interests. The establishment of the Office for Democratic Community and Prevention of Radicalisation in 2008 definitely owed its existence to political interest in the topic at that particular time. It is a good example of a new type of in-house research institution, very often being a small unit with a department leader and a (small) number of researchers. The influence on policy-formulation of these units should not be underestimated however. They often cooperate with cross-ministerial groups in formulating policy and action plans. The question that follows is how such units interact with external research institutions in the policymaking process. Here a tendency is that the workgroups from the ministries can choose to engage external research institutions or commission specific research but are not obliged to include these results. Very often this research is indeed not utilised at all or mainly used in a legitimating way to show that the ministry has sought expert opinions or alternatives to a given policy problem and thereafter chosen to stick to the already preferred policy-frame. The various departments and sections of the Ministry of Integration developed libraries and databases containing state of the art research on the particular area of interest, e.g. radicalisation and terrorism. The commissioned studies also were listed among these. It can be difficult however, to see if these extensive knowledge bases were utilised in any way; there are few references to such information. First and foremost they had a legitimising function showing that the department in charge indeed had knowledge of research.

The second feature is that some research institutions had - and in certain cases still have - a privileged position. One of the most influential research bodies was the Think-Tank on Integration. It was established in 2000 and terminated in 2007. It illustrates a preference for experts with economic and statistical backgrounds, which is perfectly in line with the preferred socio-economic perspective on integration. The Think-Tank served as a research unit to gather data on trends in migration and integration. The Think-Tank's reports were designed to guide legislators in developing new and coherent integration policies, as well as presenting international comparisons. The Think-Tank's perspective was based on the same economically oriented backdrop as prevailing governmental understandings of integration (Tænketanken 2001). It also ordered research from other research institutions to guide its conclusions. The normative backdrop of the Think-Tank nevertheless was convergent with the position taken by the government and the Think-Tank's findings were used to legitimate both previous and future policies. It was given the particular task of presenting reports on the state of integration in Denmark, but was not used to provide research on specific problems. Hence the research presented by the Think-Tank was not used instrumentally but rather symbolically, in both legitimising and substantiating ways to support the government policies 
already defined and implemented. The Ministry therefore had a great interest in disseminating the results from the Think-Tank and emphasising the congruence between the 'two communities'.

The third feature of boundary relations and use of expert knowledge relates to the utilisation of external research. Here the relations definitely illustrate the primacy of politics when it comes to influence on policymaking. Generally we find a situation where external (but state-funded) research has very little impact on policymaking. The most important research initiative in the 2000s, the Academy for Immigration Studies in Denmark (AMID), has had very little influence on later policymaking if we compare the research results and suggestions coming from AMID with actual policy developments (Jørgensen 2011). AMID incorporated the economic angle, but also developed an innovative inter-disciplinary approach that included researchers from political science, anthropology, sociology and other disciplines. One of its ambitions was to facilitate dialogue between researchers, practitioners, policymakers and, to some extent, immigrants themselves. Basically AMID tried to influence the research-policy dialogue in a two-way model where both sides acknowledged the competences of the other. AMID has not been actively engaged in policymaking however, and the ambition has rather been to frame the issue of integration and to highlight gaps in research and in political instruments. In 2002 AMID released a publication providing a state-of-the-art review of research on integration between 1980 and 2002. This publication concluded by providing 40 concrete recommendations on areas where there was a profound lack of research that also had consequences for future policymaking on these particular issues (AMID 2002). But since these recommendations were made, almost nothing has happened to address them; the changes following from the 2010 revision of the Foreigners Act stand in particular contrast to these recommendations. It is still too early to tell if the change of government will lead to radical changes in the policy path. ${ }^{1}$

There have been other research institutions besides AMID of course, and since its closure in 2007, we find a number of research initiatives emerging across the country, as well as the original consortium partners comprising AMID at the time. These external institutions also include independent self-funded research units such as the Rockwool Foundation, which since 1999 has had a special task-group working on immigration and integration (see www.rff.dk/en). A common feature across all these initiatives is that their results may or may not be used. In short the main tendency has been that studies using policy-frames which conflict with those of the government most often have been ignored, while research supporting government policies has been highlighted. This does not necessarily imply that relations between politics and research are 'bad'. For example, the research institution Social Cohesion and Ethnic Diversity (SOCED) had a good relationship with the Ministry of Integration, which acts as a partner, pointing to a fruitful research-policy dialogue.

\footnotetext{
${ }^{1}$ There have been some changes, for instance in relation to the conditions for asylum-seekers, access to permanent residence, and re-introduction of mother-tongue education (on an experimental basis), but these revisions cannot be described as a new policy approach as such.
} 
The discrepancy between the interest in external research and actual utilisation of this is also reflected in the attitude of a research employee in the former Ministry of Integration whom I interviewed, who stated that 'the employees at the Ministry certainly take account of research results but at the moment there is no room for changing the path taken.' ${ }^{2}$ The truth may also be that the research provided by universities lacks the applicability that civil servants ask for when assessing usability (cf. Boswell 2009).

\subsubsection{The Role of External Research Institutions}

External research institutions have different roles to in-house research institutions: I will point to four main roles. Firstly, in the policy-formulation process they are engaged rather late and most often asked to provide assessment of a given policy proposal alongside a long list of state agencies, NGOs and interest-holders. These consultation statements are often rather short and liable to be lost among all the others. As already stated they are given at a stage in the process when the policyproblem is already formulated. This particular form of involvement in the policyprocess has more to do with the formal rules of the democratic decision-making process than utilisation of knowledge.

Secondly, external research institutions may be commissioned to provide a specific type of research, most often in an open competition. Here the frame is decided beforehand but not the outcome. The risk is that the research knowledge provided is not utilised later. This obviously leads to disenchantment about researchpolicy dialogues on the part of the researchers when this happens. Besides the risk of being ignored the researchers involved in commissioned research become open targets for political critique when working on politically contested issues.

Thirdly, external research institutions are often involved in evaluations of existing policies. Here the key task exactly is evaluating and not formulating policy. Such contributions may be emphasised if they support government actions, or ignored and bypassed in silence if they provide conclusions going against the preferred policyframe or if they are undertaken in a policy-area where there is consensus, because there is not any real political interest in the outcome.

The fourth feature of the utilisation of expert knowledge has to do with the perception of research and knowledge itself, and hence decisive for research-policy dialogues. During the 2000s there was primacy for policymaking based on 'values', which was situated in the so-called 'value-struggle' initiated and championed by the right-wing government and Danish People's Party. It legitimised firm actions bordering on the discriminatory and undemocratic, and emphasised that social problems may become so intractable that the required solutions may be invented from case to case and be based on moral conviction rather than knowledge. This

\footnotetext{
${ }^{2}$ Interview with civil servant at the Ministry of Integration May 2009.
} 
understanding gained strength with a controversial New Year Address at the end of 2001, in which the Danish Prime Minister Anders Fogh Rasmussen at the time stated that:

We do not need experts and 'arbiters of taste' to decide on our behalf. [...] There is a tendency towardss an expert tyranny that risks suppressing free public debate. [...] Experts can be useful in submitting factual knowledge. But when we have to make personal choices we all are experts.

This understanding has been repeated several times since and used as the guiding principle for policymaking. Basing policymaking on ideological convictions cannot but distort research-policy dialogues, as rational arguments and research evidence may be ignored and may lead to dissatisfaction from researchers and hence strengthen the gap between the scientific and policy communities.

\subsection{Key Issues in Research-Policy Dialogues}

In the following three sections I will analyse the specific boundary relations and research-policy dialogues in the mentioned cases. The three cases represent different aspects within the integration policy domain: the first case on burkas concerns a much contested and politicised issue where methodological issues gained special prominence; the second case on radicalisation likewise represents a much politicised policy issue which here has links to issues of integration, extremism and security and involves different sets of actors; and the third one on ghettoisation relates to an issue where so far there has been more consensus between policy and research communities.

\subsubsection{Burkas}

One example of research-policy dialogues in Denmark involves the commissioned research of the 'Workgroup on Burkas and other Similar Clothing'. The work group was appointed by the government in summer 2009 after a political debate started by the Conservative party which suggested banning the burka. The work group consisted of members from the Ministries of Internal and Social Affairs, of Employment, of Integration and of Justice. The backdrop was the government's intention to combat the repressive 'view of human nature and women' that the burka illustrates (Indenrigs- og socialministeriet 2009). A very normative backdrop one can add. The problem was that nobody knew the scope of the problem, so the work group decided to commission a report on the use of the niqab and burka.

The task went to a group of researchers from the Department of Cross-cultural and Regional Studies at Copenhagen University who delivered the report in November 2009 (Rapport om brugen af niqab og burka 2009). The report was 
based mainly on qualitative methods and included interviews with Muslim leaders and organisations and the conclusion was that their best estimate was that there were around 100-200 women wearing the niqab in Denmark and very few wearing burka. Interviews with seven of these women moreover indicated that they did so by their own choice and did not feel forced to do so. It is difficult to say if the results were valid but they were definitely not what the government had expected. The report was leaked to the news but was subjected to a secrecy clause so Copenhagen University or the researchers could not respond to the debate that followed.

The report was criticised by almost all political parties. Naser Khader then member of the Conservative Party stated 'I cannot believe that people on campus can bring themselves to make such a report. It's embarrassing (Agger 2010)', and Pia Kjærsgaard, then leader of Danish People's Party, stated: 'I am considering reporting the researchers to The Danish Committee on Scientific Dishonesty. This is really far out (Brix 2010a).' Both Khader, who suggested the burka ban originally, and Kjærsgaard, who was and is against all signs of 'Islamism', had strategic reasons in criticising the report, but other politicians also made similar statements and criticised the methodology used in the report and thereby questioned the very foundations of that particular research. Some researchers supported this critique while most other researchers and Copenhagen University supported the validity and methodology of the report, especially because the researchers only had four weeks to finish the report and were given a very modest budget (Brix 2010b). Nevertheless, the critique was repeated in the final white paper of the government's Legal Committee where it is claimed that the report is 'on the "edge" of good research (Retsudvalget 2010)', despite the support from large swathes of the scientific community. The white paper concluded with a sentence again emphasising the 'right' of policymakers to base policymaking on moral convictions rather than evidence.

The proposed ban did not go through, however, and the proposers had to settle with an amendment of the penal code making it an offence to force others to wear the burka and similar clothing, punishable with up to 4 years in prison. In the proposal for the new bill the methodology and quality of the expert knowledge (i.e. the Copenhagen University report) was again emphasised and based on these presumed shortcomings the work group concluded: 'Given this background, it can in the work group's opinion not definitely be ruled out that some women are forced to wear burka, niqab or similar clothing (Lovforslag nr. L 181 Folketinget 20092010).' The example of the burka report shows that there are risks involved when the research-agenda is influenced by different interests. It leads to greater gaps between the policy and research communities and to increased dissatisfaction for both parties. The politicians could not understand that the researchers could not provide the evidence they needed to legitimise the bill banning the use of the burka; and the researchers, who were two $\mathrm{PhD}$ students, could not stand the harsh critique following the report and the attacks on their professionalism. This dispute also spread to other scientific venues polarising the research camps between quantitative and qualitative researchers. Finally it probably shows that there may be heavy costs when engaging in research on heavily politicised topics. 


\subsubsection{The Strategy on Radicalisation}

The struggle against terrorism and various forms of extremism and radicalisation has gained much attention in many countries. Spurred by international developments as well as the Muhammed cartoons in 2005, attention for radicalisation in Denmark increased both in politics and in research. However, increased political attention and research does not tell us anything about the boundary relations as such or about how that research is used in policymaking. The main dispute here has been about the definitions supporting the policy-frame. Here we find a discrepancy between government, ministry and in-house research institutions and almost all external actors. The action plan En falles og tryg fremtid [A Common and Safe Future] adopted in January 2009 describes the main actions and attention in this field (Regeringen 2009). The process leading to the action plan included research to different degrees and there has been a clear political intention to gain more knowledge on how and why people become 'radicalised'.

The development of this plan has a longer story though. In 2005 the government's action plan on combating terrorism identified a need to strengthen research on radicalisation and recruitment. The government thereby set the initial research agenda. Concretely two different projects were funded with 1.3 million euros each. The Danish Institute for International Studies (DIIS) received one of the grants and the other went to the Ministry of Defence who used the money to open an independent research centre, the Centre for Studies in Islamism and Radicalisation (CIR) based at Aarhus University's Institute for Political Science. Both projects ran until the end of 2009 and were designed to cover gaps in knowledge and inform policymaking.

The same message was repeated after the publication of the proposal for the new action plan in 2008. The proposal was created by a cross-ministerial work group led by the aforementioned Office for Democratic Community and Prevention of Radicalisation, but did not include researchers. In the proposal outlining the action plan it is stated that: 'Research from both projects will in future make important contributions to develop, qualify and target strategy in preventive work (Ministeriet for Flygtninge, Indvandrere og integration 2008: 61).' However, the proposal was subject to a 'dialogue-process', which consisted of three meetings, one with representatives from the scientific communities and the other two with educational institutions, civil organisations and municipalities. Here the use of expert knowledge was used in a very symbolic manner, inviting researchers to participate, which legitimated the policy proposal but did not change anything in the policy proposal as such. The proposals were a combination of security and social control-based initiatives and instruments known and used from the integration policy. The end result was not so much a comprehensive policy plan, as an overly broad policy plan.

The Danish Security and Intelligence Service's Department for Preventive Security and the Center for Terror Analysis (CTA), which both conduct in-house research as well as hands-on projects, have been central actors in the policymaking 
process and framing of radicalisation. Their presence definitely forefronts the security dimension, which obviously is a crucial dimension when investigating causes for terror, but it champions some policy solutions and disregards other. There is also a tendency to pick-up definitions and solutions in countries with more or less the same approach and it is no coincidence that the Dutch actions against radicalisation have been a great inspiration for the Danish policymakers. The consultation statements submitted by the scientific community more or less point to the same issues. Most acknowledged interesting and well-grounded ideas but almost all criticised the definitions of radicalisation, being too broad and encompassing too many potential radicals compared to what research results show. The policy plan pointed to the 'many' while research pointed to the 'few'. If support for Hamas in the Palestinian-Israeli conflict was defined as radicalisation, as the policy proposal contended, such 'support' would most likely qualify the majority of Muslims in Denmark as radicalised, making the definition somewhat useless. The proposed initiatives were felt as stigmatising and generalising and in reality made all Muslims seem part of the problem rather than the solution. The very strong security aspect was mentioned as a problem for overall framing. The concept of radicalisation itself originates from the political debate and not from research and there might be risks in making such a concept the basis for future research (see hearing statements on Fakta om høringen 2008).

However, the problem was also based on the fact that most researchers were unable to provide knowledge that policymakers needed (e.g. who, when, how many, what can we do, how can we detect?). The in-house research institute responsible for the action plan had fewer problems in this and proposed a model based on different stages and phases of radicalisation, which was used in the final action plan published in 2009. Such a model, in theory, provides something to look for and indicates when actions should be taken to literally prevent the 'bomb from exploding'. This did not stop the critique from other scientific venues but it is at the same time an example of instrumental use of research but here originating from an in-house institution. The scientific criticism is mentioned and acknowledged in the final action plan but it is difficult to spot any profound changes in the definitions and aims from the first 2008 proposal. Moreover the plan created a policy-frame prioritising the focus on radicalisation as a guiding principle for policymaking in other (integration) related fields. It is for instance coupled explicitly to the 2010 bill on housing policy and prevention of segregation. As a consequence, segregation is framed as potentially leading to radicalisation, for which certain solutions are prescribed, in contrast to framing segregation as marginalisation or poverty where other solutions are proposed. Hence, popular policy definitions are diffused to other policy areas basically because there is a political will to focus on this particular issue.

The utilisation of external expert knowledge pertaining to radicalisation can be characterised as legitimating. The CIR for instance published an investigation showing that very few were potential 'radicals'. The researchers had problems with the definitions but did attempt to operationalise them and most importantly pointed to the action plan's negative consequences, potentially leading to discrimination and 
marginalisation (Kühle and Lindekilde 2009). The investigation got a lot of media attention but the ministry and policymakers ignored the main points of critique. The authors also had problems recognising their own findings in the dominant radicalisation frame set up by both politicians and media, and gradually decided not to cooperate with the media. ${ }^{3}$ In order to present their findings and what they understood as the main contributions they wrote a feature to a weekly newspaper and a web-portal for science (Kühle and Lindekilde 2010).

\subsubsection{Ghettoisation}

Segregation as it pertains to housing is framed as ghettoisation in the Danish context. It has been a very politicised and much contested area, like many other integration related issues we could add, but the scope and visibility of this problem has put it high on both the media and political agenda. The same can be said for the research agenda. It is one of the aspects of migration and integration policies that have generated a very developed research literature. This is due to the relations to other policy fields and research fields such as urban development, gentrification, social policies, and housing policies and so on.

The urban neighbourhoods now being defined as ghettos by the former LiberalConservative government were not perceived as problems when they were developed of course. On the contrary they were seen as the solution to the housing problems that immigrants faced when settling in Denmark. However high concentrations of different immigrant groups, social problems, low levels of labour market participation and general perceptions of higher levels of crime and lack of security gradually developed into a new policy-frame of ghettoisation. The first policy plan using this policy frame and addressing these questions is the Strategy against Ghettoisation in 2004. The main problem is that people with better socioeconomic resources move away from these areas, which in turn attract people with poorer resources, thus laying the basis for segregation. This focus is also recognised by research in the field. The main framing is that ghettoisation sets up a serious barrier for integration and therefore the government needs to develop instruments to combat this development (Regeringen 2004b). Ghettos are thereby described as a problem pertaining to immigrants particularly. In contrast, this story is not supported by the existing research (e.g. Skifter Andersen 2010). The 2004 plan did not involve any research initiatives explicitly or refer to the literature. It did however draw up a new division of labour. It set down the so-called Programbestyrelse [Program Committee] that was to create the framework in which to implement the initiatives in the strategy plan. The committee itself does not have any members from the scientific community but consisted of members from municipalities, housing associations and with practical experiences in the issues at stake.

\footnotetext{
${ }^{3}$ Interview with participating researcher Oct 2010.
} 
In the same period public funding supported a large research project titled Segregering, Lokal Integration og Beskaftigelse (SLIB) [Segregation, Local Integration and Employment] which was an advisory group in connection with a strategic research programme for welfare research lead by Professor John Andersen. The advisory group formed a governance network comprising members from housing associations, municipalities, Ministries, consultants and experts. It is perhaps an example of a dialogue-based relationship between researchers and policymakers, and follows similar previous practices at local levels.

SLIB had the original purpose of building a better knowledge base for integration in vulnerable urban and residential areas, i.e. ghettos. This is basically consistent with instrumental use of expert knowledge and deviates from the otherwise dominant engineering model. SLIB cooperated with another important research institute, The Danish Building Research Institute (SBi) and the aforementioned Skifter Andersen. SBi has a broad research agenda looking at all technical aspects of buildings as well as the surrounding environment, and therefore also the social spaces defined as 'ghettos'. One of the members describes the dialogue-process as productive not least due to innovative civil servants with actual interest in the field. ${ }^{4}$

In the final report on employment in segregated areas the group was asked to move from analysis to policy recommendations and invited to present the preliminary findings and suggestions at different meeting with the relevant ministries. This created some tension however, as the Ministry of Employment would not support the suggestions and the researchers on the other hand would not change them. As a result, the research-policy dialogues are characterised less by mutual dialogue and more by the 'two communities' thesis. The same conclusion is drawn by another participating researcher who maintains that the infrastructure for dialogue is there and there are good formal relationships between researchers and actors from the ministries and municipalities, but in the end it is not the civil servants who make the final decisions about policy goals and expert recommendations are rarely followed. ${ }^{5}$ Thus research is decoupled from the final policymaking stage.

Without going into details about the research undertaken by either research institute it should be emphasised that SLIB and SBi as units and as individual researchers have contributed massively to the existing research on this field. ${ }^{6}$ SLIB was originally scheduled to cease work in 2010 but it was decided by the previous government to continue the unit with the task of assessing specific policies and interventions in vulnerable areas, and evaluations of interventions. This is interesting as the researchers attached to SLIB have been openly critical of the new action plan against ghettoisation presented in 2010. While researchers and research

\footnotetext{
${ }^{4}$ Interview with Professor in Sociology John Andersen, member of SLIB Nov 2010.

${ }^{5}$ Interview with Senior Researcher Hans Skifter Andersen, member of SLIB Nov 2010.

${ }^{6}$ For a list of SLIB publications see:

www.nyidanmark.dk/da-dk/Integration/by_og_bolig/slib/publikationer.htm
} 
units in other integration policy fields are sidetracked - as the discussion on the radicalisation strategy illustrated - researchers in this particular field are kept in the dialogue.

Until 2011 there was no ministry for housing or housing policies in Denmark and the policies were therefore made through cooperation between different ministries, with the Ministry of Integration holding a central role. In 2011 the new government established the Ministry of Housing, Urban and Rural Affairs, which now holds responsibility for segregated urban areas. In October 2010 the government launched a new action plan, which led both to political discussions and also to an increasing discrepancy between the policy and research communities (Regeringen 2010b).

Framing ghettos more as a cultural problem than a social problem situated the ghetto-problem in a value-based policy area as distinct from evidence-based or research-informed policymaking. The action plan provides the first actual definition of the problem based on three criteria: a high proportion of residents without labour market attachment $(<40 \%)$; a high proportion of immigrants and their descendants from non-Western countries $(<50 \%)$; a high proportion of residents with criminal records $(<270$ convicted out of 10,000 residents) (Regeringen 2010b). If an area was characterised by two out of three markers it was by definition a ghetto. Making ethnicity and culture the basis for ghetto problems implied that the traditional sociopolitical measures couldn't be of any use here. Moreover the solutions mentioned focused mainly on control, law enforcement and demolition of parts of the ghettoes, dismantling the physical space, and less on changing the composition or social space.

John Andersen contends that two minor proposals followed the recommendations of the SLIB group; a proposal for preventative removal of families with serious social problems and a proposal on employment initiatives in the segregated areas. Both suggestions were framed differently from SLIBs suggestions however, and overall the policy instruments and solutions outlined in the action plan were not aligned with previous suggestions and recommendations. More problematic, however, is the ghetto definition itself as it is difficult to see the valid causality between unemployment, ethnic composition and crime rates. John Andersen describes the action plan as driven by ideological reasons rather than research findings. ${ }^{7}$ It overemphasised the explanatory power of ethnicity and thereby stood in stark contrast to SBi's findings.

Generally most experts in the field are critical of the new strategy (Lehmann and Møller 2010) and their recommendations on how to deal with the problem of segregation are very different from the governments' strategy (Møller 2010). The former chairman for the Program Committee Jørgen Nue Møller tried to rearticulate the old policy-frame on integration and criticised the government for being too passive and not following the recommendations of the Committee (JyllandsPosten 11 February 2010; Programstyrelsen 2008). Nonetheless, the situation was closer to

\footnotetext{
${ }^{7}$ Interview with Professor in Sociology John Andersen, member of SLIB Nov 2010.
} 
the two communities' thesis than the close relations between research and politics that characterised the policy-field during the 2000 s and perhaps still so at municipal level.

The new government from 2011 initially followed the same definition and revised the ghetto-list in 2012 and insisted on maintaining the word 'ghetto' as well. However, in 2013 the Ministry of Housing, Urban and Rural Affairs added two additional criteria (level of education in the target area and level of income in the area). It remains to be seen how expert knowledge will be used in the new policy setting. Research-policy dialogues previously characterised by informative and instrumental knowledge use and evaluation could change, with ideological and value-based policymaking leading to a more symbolical role for expert knowledge.

\subsection{Conclusions}

The institutional arrangements between decision makers and scientific communities are complex and vary in different policy fields. While this is a very simple and also unsatisfactory conclusion, it is nevertheless difficult to identify a single model to describe these arrangements. The role of research and utilisation of expert knowledge is closely related to how a given policy issue is debated in the political and public agenda. If the government or ministries have sought to promote a specific policy-frame, research has been used in symbolic ways to support the proffered policy-frame. That is, by substantiating a predefined policy-frame or by lending authority to and thereby legitimising a given frame.

In the analysis of the Danish case as presented in this chapter I have argued that the boundary relations resembled Hoppe's 'engineering' model with diffuse demarcations but primacy lying in politics where knowledge is mobilised for the service of the state. The different examples of commissioned research projects support this conclusion. However, researchers at the same time enter the policymaking process at a later stage when policy goals and definitions have already been defined or are left out in the final phases. The discussion of definitions was crucial for the researchpolicy dialogue on radicalisation. In Denmark, the issue of integration has been defined first and foremost by politicians, and research has been used to back up their perspectives in a bureaucratic pick-and-choose model. Hence, there may be different models at different times or indeed at the same time relating to different aspects. That finding is justified considering the three cases analysed. The value of such case studies when seeking to understand the overall boundary arrangements and uses of expert knowledge is exactly that it makes it possible to outline the complexity. Researchers working on issues of urban segregation definitely have been involved more closely in the policymaking process and provided knowledge that was used more instrumentally than research dealing with citizenship and naturalisation for instance. Consequently research-policy dialogues may be more balanced in some policy issues, but characterised by disenchantment in other aspects of the same policy-domain. 
The analysis also shows that there is a difference between the roles ascribed to in-house research institutions and external research units. We have seen that commissioned studies have been ignored when their results were presented. There can be several explanations for this. The results may deviate from the policy-frame and therefore be ignored. They may be difficult to translate into policymaking, due to being too ambiguous ('on the one hand...' etc.). Commissioned studies may also have an alternative role, insofar as they give importance not to findings but rather to de-politicising effects, i.e. a policy controversy is to be elaborated by an external research unit that is given money and time, and when they finally present their results most politicians have lost interest. In other situations research is ordered and included first and foremost to show that specific angles have been investigated but the results will not be decisive for policymaking.

If we look at in-house research institutions their mark on policy has been easier to identify. The understanding of radicalisation was developed by an in-house research group. Again, it cannot be regarded as surprising that internal research is utilised differently to external research. Nevertheless, it shows that different lines are drawn for the boundary relations between science and policy, and signals a greater distance between internal and external scientific venues than between science and policy as such. Hence the two communities' thesis can be confirmed in some situations and policy areas but not in others.

Research-policy dialogues in Denmark have changed over the last decades. The development of the research field and the growth in both external research institutions and in-house research institutions has changed the nature of these dialogues. The research field over the years has become more polarised and the policy field has utilised research in a pick-and-choose model. The relationships between policy and research take different forms according to the particular topic at stake. This has led to productive dialogues in some cases but disenchantment and frustration in other cases. One may conclude that the more a given topic is politicised, the less there is room for dialogue.

Open Access This chapter is distributed under the terms of the Creative Commons Attribution Noncommercial License, which permits any noncommercial use, distribution, and reproduction in any medium, provided the original author(s) and source are credited.

\section{References}

Agger, C. (2010). Politikere kritiserer burka-rapport. Kristeligt Dagblad, January 19, 2010.

AMID. (2002). Integrationsforskningen i Danmark 1980-2002. København: INM.

Benford, R. D., \& Snow, D. A. (2000). Framing processes and social movements: An overview and assessment. Annual Review of Sociology, 26, 611-639.

Boswell, C. (2009). The political uses of expert knowledge. Cambridge/New York: Cambridge University Press.

Brix, S. M. (2010a). Naser K og Pia K pukker på burka-professor. Universitetsavisen, January 10, 2010. 
Brix, S. M. (2010b). Er burka-rapport god videnskab? Universitetsavisen, January 19, 2010.

Department of Cross-cultural and Regional Studies at Copenhagen University. (2009). Rapport om brugen af niqab og burka. KU: København.

Fakta om høringen. (2008). https://www.borger.dk/Lovgivning/Hoeringsportalen/Sider/Fakta. aspx?hpid=2146000244

Geddes, A. (2003). The politics of migration and immigration in Europe. London: Sage.

Hoppe, R. (2005). Rethinking the science-policy nexus: From knowledge utilisation and science technology studies to types of boundary arrangements. Poiesis and Praxis, 3, 199-215.

Indenrigsministeriet. (1997). Betankning afgivet af det af indenrigsministeren nedsatte Integrationsudvalg. Betænkning nr. 1337. København.

Indenrigs- og socialministeriet. (2009). Regeringen nedsatter hurtigt arbejdende arbejdsgruppe om burka og anden lignende bekladning. København.

Jastrup, M. (1999). Udlændingeloven er strammet fire gange, Information, 24 December 1999.

Jyllands Posten. (2010). Ghettoplan er slået fejl. Jyllands Posten, 11 February 2010.

Jørgensen, M. B. (2011). Understanding the research-policy nexus in Denmark and Sweden: The field of migration and integration. British Journal of Politics \& International Relations, 13(1), 93-109.

Kühle, L., \& Lindekilde, L. (2009). Radicalisation among Young Muslims in Aarhus. Aarhus: CIR.

Kühle, L., \& Lindekilde, L. (2010). Tid til revurdering: Stærkt brændbart. Weekend Avisen, 15 January 2010: 4 sektion, 4.

Lehmann, C., \& Møller, T. (2010). 10 eksperter: Drop den kortsigtede og barske ghettoindsats. Information, 22 October 2010.

Lovforslag nr. L 181 Folketinget 2009-10. Forslag til Lov om andring af straffeloven og retsplejeloven.

Ministeriet for Flygtninge, Indvandrere og integration. (2008). En falles og tryg fremtid. København: INM.

Møller, T. (2010). De 10 eksperters råd for ghetto-problematikken. Information, 21 October 2010.

Programstyrelsen. (2008). Fra udsat boligområde til hel bydel.

Regeringen. (2002). En ny udlandingepolitik. København.

Regeringen. (2004a). Noget for noget. København.

Regeringen. (2004b). Regeringens strategi mod ghettoisering. København.

Regeringen. (2005). En ny chance til alle - regeringens integrationsplan. København.

Regeringen. (2009). En faelles og tryg fremtid - Handlingsplan om forebyggelse af ekstremistiske holdninger og radikalisering blandt unge. København.

Regeringen. (2010a). Aftale mellem regeringen og Dansk Folkeparti, 15. marts 2010: Nye regler for at få permanent opholdstilladelse og serviceeftersyn af udlandinge- og integrationspolitikken. København.

Regeringen. (2010b). Ghettoen tilbage til samfundet - Et opgør med parallelsamfund i Danmark. København.

Regeringen. (2012). En styrket integrationspolitik. København.

Retsudvalget. (2010). Betankning over Forslag til folketingsbeslutning om forbud mod at bare burka og niqab $i$ det offentlige rum (Til beslutningsforslag nr. B 11).

Skifter Andersen, H. (2010). Spatial assimilation in Denmark? Why do immigrants move to and from multi-ethnic neighbourhoods?. Housing Studies, 25(3), 281-300.

Tænketanken. (2001). Udlandinges integration i det danske samfund, - Tanketanken om udfordringer for integrationsindsatsen i Danmark. INM: København.

Vesselbo, E. (2000). I går i dag i overmorgen - Indvandrerrapport III (Ishøj).

Wehrens, R. L. E. (2013). Beyond two communities. The co-production of research, policy and practice in collaborative public health settings. Rotterdam: University Medical Center Rotterdam. 


\title{
Chapter 16 \\ Research-Policy Dialogues in the European \\ Union
}

\author{
Andrew Geddes and Marthe Achtnich
}

\subsection{Introduction}

\begin{abstract}
Migrants actively contribute to the economic, social and cultural development of European societies. Their successful integration into society in the host country is the key to maximising the opportunities of legal migration and making the most of the contributions that immigration can make to EU development. Although the EU is not responsible for integration, it is supporting national and local policies with policy coordination, exchange of knowledge and financial support. ${ }^{1}$
\end{abstract}

This quote, taken from the website of the European Commission's Directorate General for Home Affairs, provides insight into the conceptual and empirical issues that are encountered when analysing science-society dialogues (SSDs) on migrant integration at EU level. As Scholten (2011: 42) notes 'the social construction of problems is considered inherently related to the institutional setting within which framing takes place'. Of particular relevance is that the EU is not responsible for migrant integration and does not possess or promote a particular migrant integration framework or paradigm. What it does promote, as this chapter shows, are two things. First, knowledge exchange on migrant integration and, second, the stimulation of applied scientific research on issues associated with integration. It is important to

\footnotetext{
${ }^{1}$ Statement on the European Commission Directorate General for Home Affairs webpage dealing with immigrant integration: http://ec.europa.eu/home-affairs/policies/immigration/ immigration_integration_en.htm
}

\author{
A. Geddes $(\bowtie)$ \\ Department of Politics, University of Sheffield, Sheffield, UK \\ e-mail: a.geddes@sheffield.ac.uk \\ M. Achtnich \\ School of Anthropology and Museum Ethnology, University of Oxford, Oxford, UK
}


recognise these limits. Organising meetings or funding research does not amount to the propagation of some kind of EU model or framework. There is the possibility that these may reify and/or refine existing national approaches rather than fuel the hunt for some kind of EU alternative. Obviously and necessarily, integration issues are best dealt with at a local and national level. This does not mean that the EU has no role to play, but that it's role is rightly circumscribed by the practical nature of the issues. The chapter's main empirical focus is on two types of EU activity that exemplify the kinds of co-ordination, knowledge exchange and knowledge stimulation that the EU can promote. We explore the role of the European Migration Network (EMN) as a predominantly member state driven way of sharing ideas and information about migration, including issues related to integration. We also examine the role of the Migrant Integration Policy Index as a monitoring exercise led by a Brussels-based NGO, the Migration Policy Group. ${ }^{2}$ This means that the chapter has a rather different focus to the national case studies because the accommodation of religious pluriformity, naturalisation of newcomers and reception policies for immigrant children in primary and secondary education are not EU competencies. These are and will very likely remain the responsibility of member states. The EU does, however, claim a role for itself in coordinating policies and, significantly in the context of this analysis of SSDs, exchanging knowledge. That said, the chapter shows that EU dialogue takes the form of a more restricted policy dialogue that involves a network of actors united by their expertise in relation to this area of policy. There is little evidence to suggest that EU action specifically in this area has spilled over into wider public debate in the member states.

The word 'exchange' used in the quote at the beginning of this chapter is relatively neutral and says little about institutional processes or framing effects. This chapter takes exchange as a synonym for dialogue and looks at dialogue structures and their content. The EU could merely reflect the policy pre-occupations of member states; alternatively it could re-shape the preferences and identities of actors and make them think differently about migrant integration. It may also have particular effects on some member states compared to others (newer compared to older member states or newer compared to older immigration countries, for example). It can also involve the EU in calling for research on aspects of migrant integration. This chapter shows the active stimulation of research on migrant integration that does include religion, naturalisation and education, and also demonstrates how boundary organisations such as think-tanks play an active role in policy debate at the EU level, occasionally having close relationships with EU institutions. There is, however, little evidence of broader public debate. The EU addresses a 'specialist public' of migrant and pro-migrant organisations, think-tanks and other civil society organisations.

In terms of broader comparison and in relation to the production of knowledge, its utilisation and to dialogue structures, there are clear distinctions between the

\footnotetext{
${ }^{2}$ One of this chapter's authors (Geddes) was involved in the first two iterations of the MIPEX project, but has had no involvement since 2007.
} 
EU and the national cases. The most important aspect of this distinction is that the EU is not a state, does not have a 'national paradigm of migration research' and does not fund research centres and institutes in a comparable way to what happens in some of the other case countries within this book. This does not mean that there is a complete absence of EU competencies. Since 1999, the EU has established a range of 'harder' (essentially meaning with legal effect) governance mechanisms, including two directives on anti-discrimination, plus directives on family reunification and the rights of long term residents that contain provisions on integration measures. The EU is, thus, relevant to the study of dialogues on immigrant integration in Europe; but the task is to establish why, how and with what effects this relevance has been established, has become evident, who the key players are, and how the dialogues have been structured. The chapter shows how dialogues on migrant integration are embedded within and enabled by an EU context with its own distinct source of legal, social and political power. Any attempt to characterise EU dialogue on migrant integration needs to be attuned to this EU context and its development without exaggerating its effects but aware of its activities and their implications (both actual and potential) for the development and exchange of knowledge about migrant integration in Europe.

\subsection{Migrant Integration: Key Issues}

Time and timing are always important when studying problem structures in particular policy areas. The debate about migrant integration is linked to the broader debate about EU immigration and asylum policy that was given significant impetus in the 1980s and 1990s by three fundamentally important events in this history of European integration. The first was the creation of the Schengen Area in 1985 by a smaller, vanguard group of member states (Belgium, France, Germany, Luxembourg and the Netherlands). The aim was to move more quickly to the attainment of free movement objectives by creating an area within which people would be able to move freely with 'compensating' internal security measures. As of 2011, Ireland the UK remained outside Schengen while non-EU members Iceland and Norway participated as observers. Schengen does not deal with migrant integration, but does play a role in shaping the EU's institutional setting. Immigration and asylum became issues that were largely populated by officials from interior ministries and internal security agencies. The relevant frame here was the security setting within which a rights-based conceptualisation of the economically mobile citizen existed.

The second key event was the Single European Act (SEA) of 1986, which had as its core objective the creation of an internal market for all member states which would be an area without internal frontiers within which the free movement of people, services, goods and capital would be assured. The SEA marked a progressive extension of earlier market-based liberalisation that had occurred on the basis of the Treaty of Rome and had led to the creation of the Common Market in the 1960s. The important point to bear in mind for the discussion of immigrant 
integration is that market-based integration created certain understandings of rights. For example, the Treaty of Rome (1957) contained provisions outlawing discrimination on the grounds of nationality and on the grounds of gender. The 1976 directive (76/207/EEC) on the implementation of the principle of equal treatment for men and women related to access to employment, vocational training and promotion, and working conditions. An understanding of market citizenship developed that linked mobility within the EU to the attainment of economic objectives. In the context of debates about the welfare state (within which, of course, much discussion of immigrant integration resides) the EU's objective wasn't so much to 'decommodify' people (to reduce their reliance on the market) but to allow new opportunities for commodification in an economically integrated and market-driven EU.

The third key event was the end of the Cold War and its implications for immigration policy, particularly for a re-focused debate about security with a move from 'national' to 'societal' security with an attendant focus on the construction of new security threats, such as irregular migration. Inter-state cooperation on migration at EU level was greatly impelled by the end of the Cold War, with increased concerns about a range of internal security issues, including immigration and asylum. These concerns were based on largely unfounded fears about largescale migration; but, as is often the case in immigration, big numbers and dramatic projections can often have a big impact on debate.

By the mid-1990s, 'Schengenland' was being developed outside of the formal treaty framework within which key features of the EU immigration paradigm were being developed and operationalised; single market integration was providing an impetus to notions of market-based citizenship; and, the Maastricht Treaty moved immigration and asylum into informal modes of inter-state cooperation with a strong intergovernmental bias. These can all be characterised as macro events that were to have specific implications for the definition of migrant integration as an EU issue and the attendant problem structure. The implications were as follows: notions of security in post-Cold War Europe and market-based citizenship for the economically useful configured the EU's institutional setting; member states were the key actors with supranational institutions such as the Commission, European Parliament and European Court of Justice largely excluded; and the Treaty was 'silent' on immigrant integration.

The development of a common response to migrant integration is documented more fully in Sandra Pratt's contribution to this volume. From its formal inception in Title IV of the Treaty of Amsterdam (agreed in 1997 and entered into force in 1999) developments in the area of migration have been characterised by a complex, multi-speed process resulting in different competences and styles of policy- and law-making. The scope of this legal and policy development on immigration can be characterised as partial, limited, asymmetric and flexible. Partial in the sense of applying to some but not all aspects of migration policy - admissions policy is a notable exception. Limited in the sense that, until recently, the involvement of institutions such as the European Parliament and European Court of Justice was severely constrained. Asymmetric in the sense that the effects on member states can 
differ. And flexible in the sense that the UK, Ireland and Denmark have opt-out arrangements from Title IV provisions and their subsequent development.

The most important EU directives related to migrant integration are those on anti-discrimination (agreed in June and November 2000), the rights of long-term residents (2003) and the right to family reunion (2003). Both the directive on family reunion and the directive on the rights of long-term residents contain 'integration measures'.

\subsubsection{The Racial Equality (2000/43/EC) and Employment Equality Directives (2000/78/EC)}

The Racial Equality Directive defines and proscribes direct and indirect discrimination and harassment, and provides for positive action to be taken to ensure full equality in practice. It also requires each member state to set up an organisation to promote equal treatment and assist victims of racial discrimination. Similar in many ways to the Racial Equality Directive, the Employment Equality Directive requires equal treatment in employment and training irrespective of religion or belief, disability, age or sexual orientation.

The Commission reported on the implementation of the directives in 2006 and 2008 (COM (2006) 643 final and COM(2008) 225 final), launched infringement proceedings against around half of all member states for non-compliance; and made a 'renewed commitment' to complete the task with the proposal of a new directive.

\subsubsection{Family Reunification (Council Directive 2003/86/EC of 22 September 2003)}

The EU family reunion directive determines the conditions under which legally resident third-country nationals (TCNs) can exercise the right to family reunification. It also 'aims to highlight' the need for integration policy to grant TCNs rights and obligations comparable to EU Citizens. The EU directive on family reunification was agreed in June 2003 after a negotiating period of 3 years and after three different Commission proposals. Denmark, Ireland the UK are not covered by its provisions. The long negotiating period indicates that the Commission encountered resistance from member states and was forced to temper some of the more progressive aspects of the original proposals that would have impinged more directly on member states' admissions policies. Throughout the negotiation it became clear that a core group of states - with Austria, Germany and the Netherlands to the fore - would insist on EU measures that did not place additional constraints on their capacity to regulate admission of family members. 
The EU directive determines: the right to family reunification of TCNs who reside lawfully in the territory of an EU member state; the conditions under which family members can enter into and reside in a member state; and the rights of the family members (once the application for family reunification has been accepted) regarding, for example, education and training. The Directive also recognises the rights of member states to impose conditions on family migration and gives them margin to do so in relation to factors such as the definition of the family, waiting periods and integration measures.

\subsubsection{Long-Term Residence (Council Directive 2003/109/EC of 25 November 2003)}

The legitimation for EU action extending mobility rights to legally resident TCNs after 5 years of residence was represented as a way for the EU to attain its 'marketmaking' objectives linked, for example, to the Lisbon Process that proclaimed the aim of making the EU the world's leading knowledge-based economy by 2010. The economic impulse to economic and political integration in Europe dating back to the Treaty of Rome provided by the four freedoms (freedom of movement for people, services, goods and capital) is a basic, founding principle. The rights of long-term residents were developed in this context, but here too we see a focus on 'integration measures' as member states seek to ensure that if legally resident TCNs were to move from one state to another, then there would be some scope for member states to insist on application of any relevant integration measures in their national laws.

The directive concerned the status of third-country nationals who are long-term residents and was generally considered less controversial than the directive on family reunion. It establishes rights and freedoms for long-term TCNs to be granted after 5 years of continual residence. These rights include access to employment and self-employed activity; education and vocational training; social protection and assistance; and access to goods and services. The directive also gives the right to move and reside in another member state. As with the directive on Family Reunion, during the Council negotiations a clause was inserted in Article 5 (conditions for acquisition of secure status) to include 'compliance with integration conditions provided for by national law'. This has been criticised because it allows member states wide discretion to use mandatory integration requirements (for example passing an integration test and covering its financial costs) before getting access to the benefits and rights conferred by the status of long-term resident. Again it was the Netherlands, Austria and Germany who were the driving forces behind the insertion of this extra clause.

\subsubsection{Soft Governance Mechanisms}

The key point about soft measures is that they are non-binding. This does not mean that they are without effect, but it does mean that it can be more difficult 
Table 16.1 The 'common basic principles on immigrant integration', adopted by the Justice and Home Affairs Council of 19 November 2004

1 - Integration is a dynamic, two-way process of mutual accommodation by all immigrants and residents of member states

2 - Integration implies respect for the basic values of the EU

3 - Employment is a key part of the integration process

4 - Basic knowledge of the host society's language, history and institutions is indispensable for integration

5 - Efforts in education are critical for preparing immigrants to be more successful and active

6 - Access for immigrants to institutions, as well as to public goods and services, on a basis equal to national citizens and in a non-discriminatory way is an essential foundation

7 - Frequent interaction between immigrants and member state citizens is a fundamental mechanism

8 - The practices of diverse cultures and religion as recognised under the Charter of

Fundamental Rights must be guaranteed

9 - The participation of immigrants in the democratic process and in the formulation of integration policies, especially at the local level, supports their integration

10 - Integration policies and measures must be part of all relevant policy portfolios and levels of government

11 - Developing clear goals, indicators and evaluation mechanisms to adjust policy, evaluate progress and make the exchange of information more effective is also part of the process

Source: Council of the European Union, 2618th Council Meeting Justice and Home Affairs, Brussels, November 192004

to detect effects. So, for example, there is a network of National Contacts Points on Integration at member state level; the member states agreed to the Common Basic Principles on integration; there is a network of largely interior minister officials known as the European Migration Network (EMN); there is a think tankled monitoring exercise, the Migrant Integration Policy Index (MIPEX); funds for research have been provided by various funds; and finally there is the ubiquitous website. There have also been attempts to influence the agenda - for example the European Programme for Integration and Migration (EPIM). These various softer governance mechanisms don't bind the member states, but can provide a forum for knowledge exchange and the development of new knowledge.

The Common Basic Principles on Immigrant Integration (CBPI) are shown in Table 16.1. Fuller discussion of the origins of the CBPI can be found in Sandra Pratt's contribution to this volume. They emerged as a result of discussion and reflect the changing focus of European integration policies. They were formally agreed during the Dutch Council Presidency in the second half of 2004.

We now move on to assess institutional roles arising largely from the extension of competence to supranational institutions as a result of the gradual communitarisation of immigration policy since the Amsterdam Treaty came into force in 1999. This has included a growing role for the European Parliament (EP) through the application of what is known as the Ordinary legislative procedure (OLP) and enhanced powers for the Court of Justice of the European Union (CJEU) since the Lisbon Treaty came into force in 2009. It then identifies the wider constellation of actors present in this policy field. 
Within the EU system, power has tended to reside with the Council comprised of member states. This has given an intergovernmental focus to policy development and decision-making. However, there is a growing role and influence for supranational institutions. Indeed, following the Lisbon Treaty (2009) migration and asylum became fully communitarised policy areas, which means co-decisionmaking between the Council and European Parliament and full jurisdiction in this policy area for the Court of Justice.

The Commission took on a stronger role after the Amsterdam Treaty came into force in 1999. Following a decision made by the Heads of Government in June 2003, National Contact Points on Integration were established. The Commission was also asked to present annual reports on Migration and Integration. In its 2003 Communication on Integration and Employment the Commission set out its approach to integration. In June 2004, the Common Basic Principles on Integration (CBPI) were agreed and in November 2004 a Handbook on Integration for Policymakers and Practitioners was published (written by the Migration Policy Group, MPG). Funding mechanisms were created through the establishment of Preparatory Actions for the integration of TCNs (INTI). The 2007-2013 budget created a European Fund for the Integration of Third-country Nationals. After 2004, the Commission has concerned itself with how to put the CBPI into effect. In its 2005 Communication on a Common Agenda for Integration (CEC 2005), the Commission broke-down the CBPI to identify more focused areas for development. Many of the proposed areas for development were clearly identified as areas for national action. The EU did, though, specify areas in which EU action could be developed, such as: supporting transnational actions, campaigns or events; supporting pilot projects and studies to explore new forms of Community cooperation in the field of admission and integration; raising public awareness; monitoring impact of national reform programmes on labour market integration of TCNs; encouraging the development of labour market integration policies; monitoring the application of the antidiscrimination and long-term residents directives; stimulating transnational actions such as exchange of good practice, joint development of programmes and common dissemination of results; supporting innovative training programmes; initiating a mapping exercise on the level of TCNs' rights and obligations; and exploring the value of creating a concept of civic citizenship as a means of promoting the integration of TCNs.

In the areas of education, three potential EU activities were identified. First, incorporating integration objectives into the Commission's various educational programmes. Second, promoting the education of TCNs through the 'Education and Training 2010 Work Programme'. Third, developing a transparent system for the recognition of qualifications. On religious pluriformity, the Commission proposed to develop the EU integration agenda so as to facilitate intercultural and interreligious dialogue at EU level, and further develop the Commission's dialogue with religious and humanist organisations. On naturalisation, the Commissions' development of the CBPI was somewhat vague and called for the promotion of research and dialogue on identity and citizenship questions. 
The key point about the Commission Communication is that it established priorities and had a framing effect on dialogue structures at the EU level.

One area of interest was the development of indicators (CEC 2005: 11). The CBPI had called for the development of clear goals, indicators and evaluation mechanisms. In 2003, the Justice and Home Affairs Directorate commissioned research on the use of benchmarks in immigrant integration policy (Entzinger and Biezeveld 2003). This report looked at opportunities and problems associated with measuring the impact of integration policies in the socio-economic, cultural, legal and political realms. It also considered attitudes towards immigrants. This report identified various indicators that could be used in each field and assessed their reliability and utility. It was noted that basic impediments were the lack of shared definitions and of comparable data.

Sitting between the EP and the Commission is the European Migration Network (EMN), which was established through Council Decision 2008/381/EC to provide up-to-date, objective, reliable and comparable information on migration and asylum, with a view to supporting policymaking in the EU. In each member state is a National Contact Point who liaises with a wide range of relevant 'stakeholders', including academic researchers and think-tanks. Essentially, the EMN brings together national information on a wide range of migration and integration related issues and then, on the basis of national reports, develops a synthesis report. The EMN's role is assessed in more detail below.

Between 2007 and 2013 the EU established the General Programme 'Solidarity and Management of Migration Flows' with a total allocation of $€ 4032$ million. Within this was created the European Fund for the Integration of TCNs with an allocation of $€ 825$ million for the 6 year period. The general objective of the fund is to 'support the efforts made by the member states in enabling TCNs of different economic, social, cultural, religious, linguistic and ethnic backgrounds to meet the conditions of residence and to facilitate their integration into European societies'. The particular focus would be on newly arrived TCNs. This would involve:

Facilitating the development and implementation of admissions procedures relevant to and supportive of the integration of TCNs;

Develop and implement the integration process of newly arrived TCNs

Increase the capacity of member states to develop, implement, monitor and evaluate policies and practices for the integration of TCNs;

Exchange information, best practices and cooperation in and between member states in developing, implementing and evaluating policies and measures for the integration of TCNs.

Between 2007 and 2009, 78 programmes were funded with a total commitment of $€ 223.1$ million. The five main beneficiaries were Spain (€34.7m); UK (€34.3m); Germany $(€ 33.6 \mathrm{~m})$ and Italy $(€ 30 \mathrm{~m})$. Together with France $(€ 18.2 \mathrm{~m})$, they received more than $68 \%$ of the total amounts allocated to national programmes in 2007-2009 (CEC 2011). In addition to grants, funding was also used for several public procurements: a European Integration Forum was set up as a discussion forum and has met twice a year since 2008. A European website on integration 
was created to provide extensive information about immigrant integration. ${ }^{3}$ Three versions of the European Handbook on Integration for Policymakers and Practitioners have now been produced. The most recent in April 2010 was written for DG JHA by the MPG think-tank.

\subsection{Research-Policy Dialogues: A State of the Art}

This section identifies key EU-level actors and examines three main components of science-society dialogues. Firstly in relation to 'knowledge production', it considers whether there are 'schools of thought' about migrant integration at EU level. It then identifies the institutional nexus at EU level that relates knowledge production to more formalised institutional competencies and policymaking. This can be thought of as 'knowledge utilisation'. This relationship between knowledge production and knowledge utilisation is mediated by 'boundary organisations'. Such organisations can include think-tanks such as the MPG, Centre for European Policy Studies, Migration Policy Institute and European Policy Centre. There are also a large number of research projects funded by specific DGs that relate to issues of migrant integration, including during the period 2007-2013 within the European Integration Fund. In addition, DG Research funds Europe-wide consortia (previously within its 'Framework' Programmes, and now in Horizon 2020) to undertake scientific research applied to particular Europe-wide policy challenges that including aspects of migrant integration and citizenship as 'problems of Europe' requiring a concerted European response. Finally, the section makes a distinction familiar to other chapters of this book by looking at the ways in which knowledge can inform evidence-based approaches to policymaking (an instrumental view of the role of knowledge), but can also serve to legitimate institutional roles and/or substantiate existing policy choices (which could be understood as 'policy-based evidence making') (Little 2012). To assess these issues the chapter pays particular attention to the role and importance of two instances of knowledge production, utilisation and dialogue. The first of these is the European Migration Network (EMN) that brings together (primarily) state actors to exchange knowledge and share ideas about migrant integration. The second is the Migrant Integration Policy Index (MIPEX), which is a think-tank- and civil societyled evaluation exercise, with a key role also played by the British Council. The European Commission has also provided funding. MIPEX benchmarks performance in all EU member states, plus some non-EU member states such as Australia and Canada.

Knowledge production has occurred within 'softer', non-binding and informal networks, which will be analysed more closely when the role of the EMN and MIPEX are assessed. However, a key feature of the EU system is that key institutions, particularly the Commission, have played a key role in knowledge

\footnotetext{
${ }^{3}$ European Website on Integration, http://ec.europa.eu/ewsi/en/
} 
production by, for example, funding research or sponsoring particular initiatives. This emphasises the importance of understanding interactions within the political setting at EU level. There is intense interchange between EU institutions and thinktanks and civil society organisations. One reason for this is that the EU is a relatively small organisation that has traditionally drawn heavily on outside expertise to inform policy development and evaluation. This suggests an instrumental role for knowledge, i.e. the Commission gathering more and better data to support policy. However, it is also the case that the Commission has sought to shape knowledge production to legitimate its own role in this policy area. Through the EMN, we can also see how the active involvement of member states in knowledge production means that the EU becomes a venue within which national policy choices are substantiated with the effect that an EU migrant integration agenda is set by the form taken by such policies at national level. We have seen that this was evident in the cases of the directives on family reunion and the rights of TCNs who are long-term residents.

How, then, is the relationship structured between knowledge production, utilisation and related dialogue structures? There is little evidence of a broader science-society dialogue at EU level because there is little evidence of wider public debate. Instead, there are more specific policy dialogues that involve a restricted and specialist community of actors (including national governments, EU institutions, think-tanks, academic researchers and private sector consultancies). It also needs to be re-stated that the EU does not exercise competence for the naturalisation of newcomers, the reception policies of immigrant children in primary and secondary education, or the accommodation of new religious pluriformity. These are all matters for the member states. The EU does, however, constitute a new political setting within which a European migrant integration frame is established that can have effects on member states. A final contextual point is that the focus of this chapter's analysis is on EU level developments. The chapter does not assess how and with what effects these EU competencies may feed into national debates, although the variable effects of the EU on particular countries may be evident in the country case study chapters in this book.

Two key EU-level dialogue structures are assessed in order to specify the ways in which knowledge about migrant integration is produced at EU level, the ways in which it is used and how policy dialogues mediate this relationship. The two cases that will be explored in more detail are EMN and MIPEX.

The EMN's development can be traced to the 1990s. In 1996, the Commission undertook a feasibility study for the creation of a European Migration Observatory, although this was not established. The Laeken summit of 2001 called for a system of information exchange on migration. In 2003 the EMN was launched as a pilot project and then, between 2004 and 2006, as a 'Preparatory Action' during which participation was voluntary. At this time, the EMN was run from a research centre in Germany. The first topic that the EMN reported on was the ambitious question of the Impact of Immigration on European Societies. The report was controversial and delayed and led to a re-evaluation of the EMN's role with a greater emphasis placed on work of a more technical nature (Boswell 2009). 
The subsequent development of the EMN had a strong focus on interactions between member states. The Hague Programme for Justice and Home Affairs covering the period 2005-2010 included a plan for a Green Paper on the future of the European Migration Network. On the basis of the Green Paper the Commission in August 2007 proposed to the Council the creation of a legal basis for the EMN, which was agreed by Council Decision 2008/381/EC. The decision to more formally constitute the EMN also gave it a stronger intergovernmental base as most of the national correspondents, or National Contact Points (NCPs) as they are known, are based in interior ministries. According to the Council Decision the purpose of the EMN 'is to meet the information needs of Union institutions and of member states' authorities and institutions on migration and asylum by providing up to date, objective, reliable and comparable information on migration and asylum with a view to supporting European policymaking in these areas [by] ... collecting, exchanging and updating data; analysing data and providing it in readily accessible forms; contributing to the development of indicators; publishing periodic reports; creating and maintaining an internet based information exchange system to provide access to relevant documents'. The EMN is coordinated by the Commission (DG Home Affairs), which is supported by two private sector contractors that assist with the exchange of information and with the development of the technology to support interchange. The network is centred on NCPs in all EU member states (except Denmark, but including Norway) with at least three experts, one of whom is the national coordinator. These national coordinators are mainly from ministries of the interior and justice but also involve research institutes, NGOs and international organisations (for example, the International Organisation for Migration is the NCP for 3 countries). The intention to promote social learning as well as the EMN's intergovernmental orientation was emphasised by an interviewee from an international organisation:

There is still a learning and exchange process that comes with that network. There is some kind of network effect to it, it's hard to put the finger on it, it's not a network that produces some ground-breaking new evidence that changes the course of policies, but that rather informs the policymakers and these people largely come from the institutions that also set the policy course .... (Representative of international organisation, March 2013)

MIPEX has a different history. It is coordinated by a Brussels-based think-tank, the Migration Policy Group (MPG), which has worked with the British Council, civil society organisations and academic researchers to develop MIPEX while also securing financial support during its existence from the European Commission. MIPEX began life as the European Civic Citizenship and Inclusion Index (reflecting a discursive focus at that time within the EU on so-called civic citizenship) and sought to develop ways of benchmarking migrant integration policies in all EU member states. Policies were benchmarked against a normative framework derived from existing EU legislation and also from other standards such as those of the Council of Europe. MIPEX could be understood as a form of international policy learning. However, MIPEX is one intervention - albeit an important one - in the Brussels migrant integration 'field' within which there are also other actors present 
such as politicians, bureaucrats and other think-tanks. In such a situation where there are a range of possible 'teachers' for policy learning then learning is more likely to arise as a result of bargaining and social interaction (Dunlop and Radaelli 2013). Indeed, as will be shown, bargaining and interaction do seem to be two key aspects of knowledge use arising from the MIPEX exercise.

The two most recent MIPEX iterations $(2007,2011)$ have produced comprehensive assessments and rankings and were linked to extensive EU-wide dissemination. Coverage has also been expanded to cover non-EU countries such as Australia, Canada and the USA. In addition to MIPEX, the MPG has a strong track record of work at EU level in the field of migration and anti-discrimination policy and has, at times, worked closely with the Commission. For example, MPG produced the Integration Handbook and 'integration modules' for the Commission. The 2007 iteration of the MIPEX indicators was partly funded by the Commission's DG for Justice and Home Affairs through what were known as INTI funds (the predecessor of the European Integration Fund).

What the EMN and MIPEX have in common is that they are both modes of 'softer' governance that seek to share information and ideas with the potential to feed into national policy systems, reshape policy, and reconfigure the relationship between research and policy. Both also place great emphasis on the exchange of information, the sharing of ideas and the pursuit of 'best practice'. In both cases, knowing (understood as a process of social learning) can be linked to softer, nonbinding governance mechanisms. Likewise, the role and use of information and knowledge are central in MIPEX and EMN. However, the pursuit of information can also become associated with organisational pathologies, as more and more information is demanded with the result that people feel that they don't have enough time to process the data and to make sense of it. Put another way, there can be an 'over-interest in and underuse of information' (Alvesson and Spicer 2012: 1201). An interviewee working in an EU institution provided insight into information overload:

Reading all the reports in their entirety is wishful thinking. We have our priorities set in terms of our agenda ... we receive all the information, we file it, we know where it is and we access it when this is needed.

Migrant integration is a policy area in which great emphasis has been placed on the gathering and sharing of information and on the development of social processes designed to support policy learning. Within this EU setting, the meaning and value of 'expertise' is very important. An interviewee cautioned that it would be wrong to assume that even this category is straightforward, particularly in an area as contentious as migration policy:

Who is an expert? Even, who is an academic? The problem we are seeing not only in DG Home, but also in the European Parliament is the same. So that you have an academic ... issuing a paper ... basically serving a certain political interest ... and this is something that is developing more and more. (Interviewee from think-tank, March 2013)

EU institutions, particularly the Commission, have been long been seen as reliant on expertise to support the development of policy, but also to legitimate institutional roles and substantiate policy choices (Zito and Schout 2009; Boswell 2009). 
Both the EMN and MIPEX can be understood as forms of social learning that, in different ways, seek to break down barriers between the domestic and the international. Both are located within the EU field and address 'problems of Europe'. They can also be understood as displaying characteristics of what have been called 'communities of practice', which are 'groups of people who share a concern or a passion for something they do and learn how to do it better as they interact regularly' (Wenger 2010). Participating in a community of practice is an essential element of learning as it is the 'social container' that brings people together by a sense of joint enterprise, mutual engagement and a shared repertoire of communal resources (Wenger 2010: 229). The social definition of learning that is central to the operation of a community of practice has two components (competence and personal experience) combining with three modes of belonging (engagement, imagination and alignment). Competence is historically and socially defined: 'To be competent is to be able to engage with the community and be trusted as a partner in these interactions' (Wenger 2010: 229). Competence and experience are not necessarily congruent but when they are in close tension and either starts pulling the other then learning takes place. A practical example of this dynamic in the context of learning about migrant integration policies within the EU would be between older/new member states/countries of immigration with asymmetries in experience that affect the historical and social definition of competence.

The three modes of belonging are typically seen as co-existing. Engagement involves people working together in ways that can shape experience. An imaginative leap can also be required to think of oneself as a member of a community of practice and to see some basis for shared membership. This leap may be large if the community is big (a national community) and members don't all meet, but is not such a large leap if members do meet on a regular basis (as they do in both the cases that are analysed in this chapter). The third mode of belonging is alignment, understood as a mutual process of coordinating perspectives that may, at first glance, appear quite pluralistic, but will be embedded within social structures that do not evenly distribute resources.

A community of practice has three key characteristics. First, a shared domain of interest as membership implies a commitment to the domain. Second, the existence of a community as evidenced by joint activities, discussions and information sharing. Third, a community of practice is also a community of practitioners with a 'shared repertoire of resources - experiences, stories, tools, ways of addressing recurring problems - in short a shared practice' (Wenger 2010: 229). Practices can develop through problem solving, requests for information, seeking experience, reusing assets, coordination and synergy, discussing developments, documentation projects, visits, mapping knowledge and identifying gaps (Wenger 2010). All these are evident in the EMN and MIPEX.

Boundary interactions can then be stimulated by individuals acting as brokers across boundaries while 'boundary objects' such as the development of data and information can also facilitate boundary interactions as comparable data can also help to generate a sense of shared meaning (Star and Griesemer 1989). 
Although they are differently constituted and have a different type of participation both the EMN and MIPEX seek to make migrant integration a more tractable issue by defining it as a 'problem of Europe'. They both place emphasis on social learning with potential implications for the boundaries between national policy frameworks, the scope and content of policy, and for the relationship between research and policy. For example, referring to the work of the EMN an interviewee from an international organisation put it as follows:

We should not look at it [the EMN] only judging the quality of the reports that come out of there, because it's not the point. The point is to have government officials to sit together on a regular basis and discuss those issues that are political priority, to have a mechanism in which they can request information from their peers. (Representative of international organisation, March 2013)

The EMN lays great emphasis on networking. This can take various forms:

- Regular meetings of NCPs (12 in 2009, 7 in 2010 and 7 in 2011);

- EMN Studies drawing from information from all participants of which there are usually 3 each year;

- An annual EMN conference;

- Training sessions on technical or administrative issues;

- Twinning and collaboration meetings;

- Studies addressing specific themes;

- Annual reports from all participants that feed into the Commission's Annual Report on Migration and Asylum;

- The development of a glossary and thesaurus as the basis for improved comparability to develop common understanding of terms with the aim of harmonising policy concepts;

- An information exchange as a repository with a search function;

- Ad-hoc requests.

Ad-hoc requests are particularly interesting as ways of sharing information about practices. Around 400 or so Ad-hoc queries were made between 2008 and 2012 (of which more than 260 were made public). An interviewee from an international organisation highlighted the role of Ad-hoc requests as follows:

My impression .... is that the EMN in particular has become important through its more kind of research gathering, the Ad-hoc queries. There is an enormous amount of queries that are circulated and that are requested on a state basis ... that really has become an important mechanism of policy learning .... Member states who have an interest to make or change a policy on a particular issue, sometimes on very specific issues... even if it's just six or seven member states replying to that, it's still something that you don't have, or something that individual member states don't have the capacity to deliver in the same way. It's much more difficult for individual member states to use their own contacts ... to get that kind of information in that timeframe. (Representative of international organisation, March 2013)

Two representatives of think-tanks both highlighted a strong intergovernmental dynamic, but also the way in which the strategic context for national policymaking has changed: 
It serves intergovernmental needs because it allows member states to ask their Ad-hoc queries...they are very politically motivated... you can match almost every query to a national policy debate or national policy process... it allows them to then make the comparative claim themselves ... In the UK there was a green paper restricting family reunification, with many proposals .... and they were then using comparisons, you know, saying ... other countries do this... and then they would give certain examples. Whereas they only chose very few countries in Europe that do this, not noting that all other countries do not do this. (Brussels think-tank March 2013)

Ad-hoc queries are surprisingly useful because they tend to be linked to one particular member states' deliberations at a given moment .... last year when the Dutch were thinking about the integration of EU citizens, they had an Ad-hoc query ... and they got a wealth of information back and it really helped them to think through what the key issues were... (Brussels think-tank, March 2013)

Ad-hoc queries are grouped under various headings, one of which is queries made with regards to immigrant integration. Table 16.2 shows the 11 requests that have been made publicly available and provides information on the specific content of the request, the country making the request and the number of other network members that responded.

The EMN is a state-centred network that displays the characteristic features of a community of practice: domain, information sharing, joint practices. The social

Table 16.2 Ad-hoc queries to the European Migration Network National Contact Points on the theme 'immigrant integration'

\begin{tabular}{|c|c|c|c|}
\hline Date of request & Theme & Requested by & No. of respondents \\
\hline Nov 2009 & $\begin{array}{l}\text { Integration agreements and } \\
\text { language examination for foreign } \\
\text { citizens }\end{array}$ & Italy & 16 \\
\hline November 2009 & $\begin{array}{l}\text { Allocation of refugees to } \\
\text { municipalities for integration } \\
\text { programmes }\end{array}$ & Latvia & 13 \\
\hline July 2010 & $\begin{array}{l}\text { Media use in language training } \\
\text { courses }\end{array}$ & Germany & 16 \\
\hline February 2011 & Citizenship tests & Finland & 23 \\
\hline October 2011 & $\begin{array}{l}\text { Legislative regulation for health } \\
\text { insurance of TCNs }\end{array}$ & Czech Republic & 19 \\
\hline December 2011 & $\begin{array}{l}\text { Organisation and management of } \\
\text { legal assistance provided to } \\
\text { foreigners in EU member states }\end{array}$ & Poland & 17 \\
\hline December 2011 & $\begin{array}{l}\text { Foreign resident registration for } \\
\text { municipal/local elections }\end{array}$ & Luxembourg & 19 \\
\hline January 2012 & $\begin{array}{l}\text { Legal status of the 'second' } \\
\text { generation }\end{array}$ & Greece & 7 \\
\hline April 2012 & Citizenship tests & Austria & 20 \\
\hline May 2012 & Dual citizenship & Estonia & 21 \\
\hline July 2012 & $\begin{array}{l}\text { Programmes for linguistic } \\
\text { integration of immigrants }\end{array}$ & Germany & 18 \\
\hline
\end{tabular}

Source: EMN 
legitimacy of the EU as 'teacher' (or learning facilitator) is also high. The EMN thus corresponds with what Dunlop and Radaelli (2013) characterise as 'learning in the shadow of hierarchy', with an institutional environment that is strongly structured both by the formal institutional context at EU level (the acquis), but also by the repertoires and resources that are associated with national ways of doing things. The EMN has not fundamentally rethought the precepts upon which migrant integration policies are based, as it has tended to reflect domestic priorities at the EU level. Since 2006, the EMN has had a stronger focus on technical questions and the mobilisation of 'official knowledge' from national ministries. Scientific research has tended more to follow this agenda than to shape it.

The MPG as the driving force behind MIPEX can be understood as a policy entrepreneur investing resources in the hope of a future return. They advocate migrant integration as a 'problem of Europe' requiring stronger and more effective action at EU level. There is a different dynamic underpinning MIPEX compared to the EMN as it arises from a civil society- and think-tank- initiative and draws-in academic researchers (mainly legal scholars) to produce its evidence base. Similarly to the EMN, MIPEX can be understood as a community of practice creating a domain with some sense of shared commitment, information sharing and exchange, and a focus on practice. The MIPEX indicators are based on detailed countrylevel assessment against a wide range of indicators. A key advantage of MIPEX as a 'boundary object' was identified by an interviewee from an international organisation:

MIPEX is a clear tool that helps to initiate a discussion... 'my country ranks really badly, let's talk about it'.... Is it an invitation to speak about it or maybe an invitation for complacency? There are different ways to look at it and I think not everyone who looks at those tools has a clear understanding of what this actually means, the data that comes out on the screen and what else you need to do to put it in the right context.

MIPEX focuses very squarely on identifying areas in which countries could improve their performance. The network of civil society organisations that underpin this work then provide the context for national debates that bring together Communities of Practice at national level, but expose them to a wider European debate. The impact of MIPEX is then very carefully monitored with credible evidence that changes in law and policy have arisen as a result of poor performance in the MIPEX rankings.

The MPG is a highly credible actor at EU level, MIPEX is without doubt a much-used tool, and there is evidence of changes in law and policy as a result of MIPEX findings. Where MIPEX has been more effective is in relation to more conditional forms of learning where actors encounter know-how and other ways of doing things. However, MIPEX is also an 'outsider' (civil society) intervention in a policy area where national governments are strong and, in particular, where the executive branches of these national governments have been key players. 


\subsection{Conclusions}

This chapter has surveyed the development of dialogue structures on migrant integration at EU level. The EU does have a growing relevance to these discussions because of the development of its common migration and asylum policy, which does include provisions, albeit weak, on migrant integration. To reiterate the point made at the start, the EU does not have a strong legal basis for action in this area and there is neither an EU paradigm nor is one likely to emerge. Quite rightly and logically, these will remain local and national issues. The EU's role lies more in the areas of the gathering and exchange of knowledge, the sharing of ideas, the monitoring of practices and the development of what were referred to as 'boundary objects'.

The chapter assessed both the structures of knowledge production and the utilisation of knowledge while also looking at the dialogue structures that mediate the relationship between the two. In particular, close attention was paid to the roles of the EMN and MIPEX. As noted from the outset, these are different kids of activity, but they also exemplify both the possibilities and limits of EU action. The EMN is largely state-led network and seeks to exchange information and ideas between member states while generating frequent interaction between officials from the member states. MIPEX is a civil society network that seeks to intervene in debates about migrant integration and, in particular, to make the case via monitoring for stronger and more effective EU-level action. Both were understood as having the characteristic features of communities of practice within which understandings can be developed and shared with attendant social and communicative processes of policy learning. These occur in quite specialised and EU-centric forums with very little evidence of spillover into public debate about the EU's role in migrant integration.

In both of these cases, the production and utilisation of knowledge went beyond the instrumental use that is more familiarly referred to as evidence-based policymaking. In the case of MIPEX there has at times been close interaction with EU institutions such as the Commission and the European Parliament. For example, MIPEX has secured funding from the European Commission's funding INTI programme. In such a situation, we can see how the development of a programme of research with a civil society focus was also consistent with the idea to develop a greater EU role in this area of policy and thus with attempts to legitimate the role of the European Commission as an actor in the area of migrant integration policy. This is not simply a process of co-option because the relationship between civil society and the Commission is more complex. Yet there is a mutual dependence between institutions such as the Commission and think-tanks such as MPG, leading to a close relationship between the production and use of knowledge and the role that this can play in legitimating policy choices and institutional roles, in particular the argument for a stronger role for the EU in the area of migrant integration.

The case of the EMN was somewhat different because of the strong state-led focus on its activities. However, the EMN can also be understood as a community of practice that changes the nature of the relationship between the production and 
utilisation of knowledge because of the relatively intense EU level interactions that now occur between national level actors. However, it is also the case that the EMN tends to serve as a forum for the representation of member states' policy concerns rather than for the transmission of EU priorities. While it would be wrong to argue that the flow of ideas is entirely one way because it is necessarily more complex, it is the case that the EMN tends to be used as an arena for the substantiation of existing policy choices.

In the cases of both the EMN and MIPEX we can see the production of knowledge, its utilisation and also the role played by dialogue structures. We can also see that this goes beyond the instrumental use of knowledge to also include knowledge-use as a form of institutional legitimation and as a way of substantiating existing policy choices. Finally, what is also very clear about the EU level dialogue is that it is relatively closed and specialist, with little evidence that EU action has spilled over into wider public debate.

Open Access This chapter is distributed under the terms of the Creative Commons Attribution Noncommercial License, which permits any noncommercial use, distribution, and reproduction in any medium, provided the original author(s) and source are credited.

\section{References}

Alvesson, M., \& Spicer, A. (2012). A stupidity-based theory of organisations. Journal of Management Studies, 49(7), 1194-1220.

Boswell, C. (2009). The political uses of expert knowledge: Immigration policy and social research. Cambridge: Cambridge University Press.

CEC. (2005). A common agenda for integration: Framework for the integration of third-country nationals in the European Union. $\operatorname{COM(2005)~} 389$ final.

CEC. (2011). European agenda for the integration of third country nationals. $\operatorname{COM(2011)~} 455$ final.

Dunlop, C., \& Radaelli, C. (2013). Systematising policy learning: From monolith to dimensions. Political Studies, 61(3), 519-699.

Entzinger, H., \& Biezeveld, R. (2003). Benchmarking in immigrant integration. Report written for the European Commission. Rotterdam: Erasmus University Rotterdam.

Little, A. (2012). Political action, error and failure: The epistemological limits of complexity. Political Studies, 60(1), 3-19.

Scholten, P. (2011). Framing immigrant integration: Dutch research-policy dialogues in comparative perspective. Amsterdam: Amsterdam University Press.

Star, S., \& Griesemer, J. (1989). Institutional ecology, "Translations" and boundary objects: Amateurs and professionals in Berkeley's museum of vertebrate zoology, 1907-39. Social Studies of Science, 19(3), 387-420.

Wenger, E. (2010). Conceptual tools for CoPs as social learning systems: Boundaries, identity, trajectories and participation. In C. Blackmore (Ed.), Social learning systems and communities of practice (pp. 125-143). Dordrecht: Springer.

Zito, A., \& Schout, A. (2009). Learning theory reconsidered: EU integration theories and learning. Journal of European Public Policy, 16(8), 1103-1123. 
Part III

Comparison and Conclusions 


\title{
Chapter 17 \\ Research-Policy Dialogues on Migrant \\ Integration in Europe: Comparison and Conclusions
}

\author{
Peter Scholten, Han Entzinger, and Rinus Penninx
}

\subsection{Introduction}

The aim of this book has been threefold: first, to describe the evolution of research-policy dialogues on migrant integration in Europe at different levels the local, the national and the EU level; secondly, to find patterns of convergence and divergence in this development; and third, if we see such patterns, to explain why these appear. In our search for patterns and explanations, we come back to the conceptualisation discussed in the introductory chapter. There we formulated three basic empirical questions: (1) What forms of research-policy dialogues do we find empirically? (2) What type of knowledge is brought into these dialogues? (3) What use is made of that knowledge?

We are also interested in the interrelationship between our three major concepts: research-policy dialogue structures, knowledge utilisation and knowledge production. These influence one another, and this generates questions such as: how do specific dialogue structures affect knowledge utilisation, and vice versa? Do certain forms of knowledge utilisation lead to specific dialogue structures? What are the effects of dialogue structures on knowledge production, and do certain forms of knowledge production lead to specific dialogue structures? And to what extent are

\footnotetext{
P. Scholten $(\bowtie)$

Department of Public Administration, Erasmus University Rotterdam, P.O. Box 1738, 3000 DR Rotterdam, Netherlands

e-mail: p.w.a.scholten@fsw.eur.nl

H. Entzinger

Department of Sociology, Erasmus University Rotterdam, P.O. Box 1738, 3000 DR Rotterdam, Netherlands

R. Penninx

Institute for Migration and Ethnic Studies, University of Amsterdam, Nieuwe Achtergracht 166, 1018 WV Amsterdam, Netherlands 
these modes of utilisation and production of knowledge a result of, and embedded in, national traditions of research-policy relations - or, more broadly, in dialogues between science and society?

One specific question was added to each of the foregoing ones: has the politicisation of migrant integration, which seems to have occurred in many parts of Europe over the last decade or so, had an impact on dialogue structures, knowledge utilisation and knowledge production and their interrelationships? And, if so, what has been the nature of that impact?

\subsection{Forms of Dialogue Structures, of Knowledge Use and Knowledge Production}

\subsubsection{Forms of Research-Policy Dialogue Structures}

The 15 preceding chapters brought together empirical studies of research-policy dialogues from a variety of contexts. In Part I of this book several specific forms of dialogue and their functions have been analysed, such as the use of statistics by policymakers, the role of knowledge production inside government institutions, the impact of national integration models on research and policymaking, and the role of expert committees in shaping integration policy. Most of these phenomena have been studied on a comparative basis, which has revealed similarities, but also differences between European countries in their ways of handling the interrelationships between knowledge production and knowledge utilisation, between research and policymaking. As the role of the European Union in this field of policymaking has become more prominent recently, three chapters in Part I were dedicated to researchpolicy dialogues at the European level, including one dealing specifically with local policymaking and the role the EU has been playing here.

Part II of the book includes analyses of research-policy dialogues in a number of 'old' immigration countries (Austria, Denmark, Germany, the Netherlands and the United Kingdom), as well as Italy as a relatively 'new' immigration country, and Poland as a country that has only just begun to experience immigration, after having witnessed much more sizeable emigration and transmigration. This part of the book also includes an analysis of the increasingly relevant research-policy dialogues at the EU level.

All chapters indicate that the emergence, development and effects of researchpolicy dialogues are very diverse. Long-standing forms of dialogue structures, both at the national and the local level, have often changed significantly over the last decade, but in different ways and at different paces. New dialogues have emerged, particularly, but not exclusively at the EU level. All of this has added undeniably to the diversity of the interrelationships between knowledge production and knowledge utilisation, of research-policy structures, and, even more broadly, of science-society dialogues. It has also become clear that integration policies increasingly are a multilevel issue of governance. Not only the role of the EU has become more prominent, 
but also that of local government. This again has contributed to more diversity in research-policy dialogues and to the development of new coalitions, for example between the European Commission, cities and NGOs.

\subsubsection{Knowledge Utilisation}

The empirical cases brought together in this book all draw on Boswell's distinction between instrumental and symbolic modes of knowledge utilisation (Boswell 2009; see also Chap. 2 in this book). Instrumental knowledge utilisation refers to the use of knowledge directly in order to rationally adjust policy outputs, as is assumed in the term 'evidence-based policymaking'. This function of knowledge is found regularly in different phases of the policy cycle: either at the stage of conceptualising and framing new policies, or, more often, in developing concrete instruments for existing policies and in monitoring and evaluating policy action. In recent years, this instrumental and evaluative use of research has become clearly visible at the EU level. This may be to compensate for the fact that the European Commission has only limited competences in this policy area, so that its credibility depends on its ability to mobilise relevant knowledge and instruments. The same phenomenon may be observed at the local level, where a systematic exchange of experience and good practice in using policy instruments has become a major element of knowledge utilisation.

Nevertheless, the other mode distinguished by Boswell, symbolic knowledge utilisation, appears to have gained in importance. This refers to more indirect ways of using knowledge, either in substantiating already-decided policy choices or in legitimising policy actors. The chapters on countries that do have a longer policy tradition in the field of migrant integration confirm such symbolic use of knowledge. This becomes evident, for example, in the selective use of research-policy dialogue structures and their products by policy actors, as a good number of governmentinitiated expert commissions have experienced (see also Boswell and Hunter 2014). Such specific use of knowledge can be facilitated by specific structures that produce knowledge, for example within ministries that set up their own in-house research departments. Local authorities may do the same.

Some of the contributions to this book suggest that we should go beyond Boswell's conceptualisation, for two reasons. First, Boswell's distinction between instrumental and symbolic use of knowledge suggests that these two exclude each other. In reality, however, the same input of knowledge may have an instrumental and a symbolic function at the same time, or such input may have a symbolic function initially, and later become instrumental as well. This has been observed in the analysis of several consultative expert commissions in the UK, Germany and the Netherlands.

Secondly, Boswell's dichotomy seems to exclude a situation where no use at all is being made of knowledge, even if it is produced at the request of policymakers and funded by them. In her chapter on Austria Borkert observes the phenomenon 
of 'knowledge shelving', whereby knowledge is stored for possible later use. This phenomenon can also be found at the European level. The European Commission has invested significantly in research on migration and integration (through the Framework Programmes of DG Research, but also through the European Refugee Fund, the European Integration Fund and the European Social Fund), but with little direct use. Much of what is produced does not filter through into EU policy, partly due to the European Commission's lack of competencies in this field.

\subsubsection{Knowledge Production}

The third concrete empirical question in this book relates to changes in knowledge production and developments within the field of migration research itself. From all historical observations in this book it is clear that, initially, research was strongly embedded in national contexts. Consequently, the central issues and concepts are framed rather differently from one country to another, as a comparison of different chapters illustrates. In the UK, for example, the 'Race Relations' and, later, the 'Community Cohesion' frames have dominated the research field. In Germany this was the case for the 'Guest Worker' frame, in the Netherlands for the 'Ethnic Minorities' frame, while the 'Republican' frame was dominant in French research. In exceptional cases, when policies were first being developed, researchers, policymakers and the general public shared such a framing, at least for a certain period. Under such conditions a 'co-production of models' could develop: the same model was then used as an analytical tool by scientists and as a conceptual tool in policymaking (see also Entzinger and Scholten 2014). In most cases, however, the framing by researchers within one country was more diverse, also reflecting different scientific and methodological traditions. If there was a dominant concept at all in research it did not necessarily correspond with the way policymakers had framed the issue. As a general rule we may say that the closer the contacts between researchers and policymakers the more likely they are to use shared frames of analysis. Under such circumstances research activities often tend to be directly funded by the government or other stakeholders, and less so by universities or research councils.

Comparing our case studies, a general picture of the development of researchpolicy dialogues over time emerges. Roughly until the turn of the millennium, migration and integration research was strongly embedded within national contexts, not only in terms of the framing of questions, but also in the selection of questions to be researched, and in terms of funding. In the 1990s, research institutes dealing specifically with migration and integration began to emerge in many West European countries, mainly (but not exclusively) within universities. Initially, most of these institutes were primarily oriented towards the national context. How relations between research and policies developed in such national contexts differed significantly. Usually, however, politics and policy were the partners that defined and developed the relationship, if there was any, and not academia. 
Later this picture began to change. The most important development has been the entrance of the European Union, and specifically the European Commission, as a policymaker and a funder of research. The European Commission has commissioned an increasing number of studies since international migration was declared a topic of communitarian policymaking in the Amsterdam Treaty of 1997. The field of integration followed in 2003 after the Commission's Communication on Immigration, Integration and Employment had been politically accepted (see Chaps. 3 and 7 for a more complete overview of EU involvement in this research area).

Partly anticipating this development at the EU-level and partly in its wake, the research world started to organise itself across national borders (but clearly within the EU, or rather the European Economic Area). The IMISCOE Network of Excellence (2004-2010), funded by the European Commission, and its independent successor the IMISCOE Research Network, are the most prominent examples of this. IMISCOE's programme is predicated on systematic cross-national comparative research, beyond 'methodological nationalism' (see Penninx et al. 2006). Some observers, however, wonder if the heavy reliance on EU-funding does not introduce a new dependency of researchers on the definition of migrant integration as a European problem (see Geddes and Scholten 2014).

\subsection{The Effects of Politicisation}

In the introductory chapter we formulated a number of hypotheses about the effects of politicisation on (the development of) dialogue structures, knowledge utilization and knowledge production. These assumptions speak to a broader literature on the role of science in contemporary late-modern society. Various scholars have argued that society is moving beyond the traditional model of 'science speaking truth to power', based on a powerful belief in the rational use of scientific knowledge (Wildavsky 1979). After the 'scientification of politics' that characterised this rational approach to policymaking, the late-modern or risk society is experiencing a simultaneous 'politicisation of science' in which science's credibility is put on the line and scientific disagreements increasingly surface (Beck 1992; Gieryn 1999; Weingart 1999).

We have taken migrant integration as a case study for testing such presumed transformations. Migrant integration is increasingly perceived as a social risk and has become strongly politicised in many European countries. Throughout Europe, immigration and migrant incorporation have risen on national political agendas. Multicultural policies - whatever these may entail - have been discarded as a failure in many places, even in places where they have never existed at all. This (perceived) failure of rational efforts to establish a multicultural society and the political saliency of migrant integration have made this issue one of the most challenging social risks in the eyes of many Europeans (Scholten and Verbeek 2014).

Our first hypothesis, based on a review of the literature on migrant integration research and policymaking, was that the politicisation of migrant integration would 
contribute to a de-institutionalisation of existing research-policy dialogues. This speaks to a broader debate in the migration literature on the strongly policy-oriented nature of research, especially in the early years of the development of this field. Favell (2003), for example, pointed to a policy-oriented habitus of research and the consequences thereof. He argued that such an orientation would favour certain types of research and ignore others. Scholten (2011) showed that, especially in the Netherlands, a strongly institutionalised relationship between researchers and policymakers persisted for a long period: researchers were often directly involved in policymaking, but as a consequence they were also dependent on the policy context. In the science studies literature, this type of relationship has been described as the technocratic mode of research-policy dialogues (Weiss 1977; Hoppe 2005), with direct relations between researchers and policymakers and often also a central role for these researchers in policymaking. Elaborating this line of thinking, more recent work has argued that the politicisation of the debate on migrant integration in many countries has challenged this technocratic model and re-established a firm political primacy (see, for instance, Scholten and Verbeek 2014). In various countries this renewed political primacy has been associated with controversy over the involvement of researchers in this area, as in France where ethnic statistics are contested, or in the Netherlands where a public debate has taken place on the credibility of migration scholars. So, our first hypothesis assumes that politicisation leads to a de-institutionalisation of research-policy relations, which will become less direct, more open to diverse participants and more ad-hoc. By contrast, institutional relations will persist in places with a relatively low level of politicisation.

Our second hypothesis focuses on knowledge utilisation. Whilst instrumental knowledge utilisation involves the direct use of knowledge in policy formulation and political decision-making - as in 'evidence-based policymaking' - symbolic knowledge utilisation refers to more indirect functions of knowledge for policymakers, either to substantiate already-decided policy choices or to legitimise policy actors. Following Boswell's analysis of knowledge utilisation in the UK, Germany and the EU (2009), we expect that politicisation generates more symbolic forms of knowledge utilisation.

The third and final hypothesis refers to the effect of research-policy dialogues on developments within the field of migration research itself. In the science studies literature this has been conceptualised as the 'co-evolution' or 'coproduction' of scientific knowledge (Ezrahi 1990; Jasanoff 2013). For migration studies in particular, a rich literature has evolved in this context, both supporting (Brubaker 1992; Koopmans and Statham 2000) and criticising (Vasta and Vuddamalay 2006; Bertossi 2011; Favell 2003; Thränhardt and Bommes 2010) national models of integration. This has largely been an empirical debate on whether integration policies are framed in distinct national settings, or whether scientists should take a more dynamic, multilayered, but also more contested approach to how integration is framed. As Chaps. 4 and 5 in this volume indicate (see also Favell 2003; Bertossi 2011), this debate also speaks to how relationships between researchers and policymakers affect processes of knowledge production. This has structural implications since such a relationship may have an impact, for example, on the financing of specific research centres, but 
it also has cultural effects because privileging specific frames of migrant integration affects the way the general public perceives this process (see also Entzinger and Scholten 2013). Such symbioses between integration research and policymaking in Europe have often been criticised for favouring specific knowledge producers and knowledge claims while ignoring others, thus reproducing specific national models of integration (Thränhardt and Bommes 2010; Duyvendak and Scholten 2011). Turning this argument around, in this book we expect the opposite to happen when migration and integration become politicised. Developments such as the de-institutionalisation of research-policy dialogues and the internationalisation of academia challenge the container view of 'national models of integration', and can be expected to contribute to academic fragmentation (see also Favell 2003; Thränhardt and Bommes 2010).

In the following sections we assess the evidence for each of the three hypotheses on the basis of what has been brought forward in this book. We do so firstly by comparing the historical development of knowledge production, knowledge utilisation and research-policy dialogues around migrant integration, in different countries and at different levels. After that we look in more depth at how researchpolicy dialogues have evolved around three core themes in the integration debate: naturalisation, education and religion, basing our comparisons and conclusions on the much more detailed information collected in the rest of this volume. To assist the reader who is interested in more detail, we make direct reference to the relevant chapters in Part I of this book. Conversely, in order to keep the text readable, we make no references to the individual country chapters in Part II. All information, however, on specific countries as well as on the EU can be traced back to the corresponding case studies in that part of the book.

\subsubsection{Changing Structures of Research-Policy Dialogues?}

Concerning the first hypothesis on the relationship between politicisation of migrant integration and de-institutionalisation of research-policy dialogue structures, we find mixed evidence when comparing the findings from the various cases. Generally speaking, we have found evidence of changes in the institutional set-up of researchpolicy dialogues, rather than a clear de-institutionalisation of dialogue structures. In short, politicisation changes rather than impedes research-policy dialogues. Interestingly, in some cases we found evidence that institutionalisation followed after a period of politicisation, as in Germany and Austria. It seems as if in these cases politicisation first created a sense of urgency, which later, when the political climate had calmed down again, was translated into an institutionalisation of research-policy dialogues.

Only in the Netherlands, Italy and Denmark did we find modest direct evidence in favour of the original de-institutionalisation hypothesis. In the Netherlands the strongly institutionalised technocratic research-policy nexus that had been built around the Ethnic Minorities policy in the 1980s was indeed dismantled in the 1990s and 2000s, in a context of increasing politicisation. However, this 
de-institutionalisation was also spurred by developments within the research community. Furthermore, it led to a re-institutionalisation of a different type of nexus, of a more bureaucratic nature, that focused not so much on conceptual research but rather on data-driven studies, carried out by the Social and Cultural Planning Office (SCP) and Netherlands Statistics (CBS), two government agencies. In Italy attempts were made to institutionalise research-policy dialogues in the 1990s, particularly by setting up a Commission on the Integration of Migrants. However, given the politicisation of migration at that time, that commission did not have a great impact and it was dismantled. In Denmark researchers were directly involved in the genesis of policies in the 1980s and 1990s, but less so thereafter. However, as in the Dutch case, a certain re-institutionalisation of research-policy dialogues also took place in Denmark, though different in character.

Importantly, we found that in various cases, including Germany as the most prominent example, the politicisation of migrant integration may have spurred the establishment of research-policy dialogues rather than having impeded them. In contrast to other cases studied here, such as the Dutch case, the development of migration research in Germany followed a more autonomous path with very little dialogue between researchers and policymakers, especially at an institutional level. The politicisation of migrant integration at the end of the 1990s and in the early 2000s provided various opportunities for researchers to become more actively engaged in policymaking and in political debate. This led to the establishment of various 'boundary structures' (Entzinger and Scholten 2013), such as the Council for Migration and the Expert Council for Migration and Integration. The Austrian case, reflecting to some extent the German experience, even reveals evidence of efforts to institutionalise research-policy relations in the aftermath of politicisation. In Austria, at the end of the 2000s, the grand coalition between the People's Party (ÖVP) and the Social Democrats (ÖVP) involved researchers and research-based commissions as well as NGOs and other stakeholders in formulating a National Action Plan for Integration (NAPI). At the same time, more informal dialogue structures emerged in Austria, outside institutional channels.

The more bureaucratic dialogue structure that emerged in the Netherlands in the late 1990s, with a preference for statistics-driven research oriented towards specific government policy priorities, also emerged in other countries. In Germany, the Federal Institute for Migration and Refugees (BAMF) performs a role in policymaking that is very similar to that of the Dutch SCP. As Boswell (2009) shows, the BAMF plays a key role by producing data that help to legitimise national policies, promote policy learning (both nationally and internationally) and monitor and identify areas for policy intervention at the national, regional and local levels. A similar process can be identified in Denmark: Bak Jørgensen (2011) describes the development of in-house research facilities at the Ministry of Refugees, Immigration and Integration Affairs, bringing together knowledge and information that is important for policy coordination.

One case that clearly seems to defy the hypothesis on politicisation and deinstitutionalisation of research-policy dialogues is the EU case, which is distinctive in two ways. The first aspect concerns timing: the EU entered this policy area rather 
late, at a moment when politicisation of the issue was thriving in much of Europe. In this respect it resembles the Polish case, where the emergence of a policy could not lead to any form of de-institutionalisation for the simple reason that no relevant institutions had been set up yet. The Polish case differs from the EU, however, because thus far the issue has never been politicised.

A second reason why the EU case differs from all others is that the EU's position in the multi-level governance system is completely different from that of national governments. In the absence of direct competencies in the field of migrant integration, mobilising research has proved to be one of the few strategies the EU possesses to influence policies in this domain. Geddes and Achtnich (Chap. 16) as well as Pratt (Chap. 7 of this volume; see also Geddes and Scholten 2013) show how a selective mobilisation of research has provided a tool for the soft-governance of migrant integration in a European setting. In particular this has led to a number of comparative studies of migrant integration policies aiming to facilitate horizontal policy learning between European countries. It has also led to more systematic efforts to measure integration policies so as to monitor compliance with EU policy frameworks (for example the Migrant Integration Policy Index, MIPEX). This latter strategy to promote horizontal learning by comparing policies and instruments has recently emerged at the local level as well, leading to some very specific researchpolicy dialogues in networks of European cities, such as Cities for Local Integration Policies, Integrating Cities and Intercultural Cities (see Chap. 6).

What stands out in the national cases in terms of dialogue structures is the central role of ad-hoc and often government-sponsored commissions at critical junctures in the policy process (see also Boswell and Hunter 2014). In Germany, Italy, the UK, and the Netherlands such commissions were put in place in the aftermath of focusing events in order to create a temporary platform for researchpolicy dialogues. Such commissions, however, often are highly selective in opening up to researchers and in their knowledge claims. This suggests that creating adhoc commissions should be seen as a political reflex in the face of immediate and intractable policy controversies rather than as an effort to engage in critical reflection based on research. Furthermore, though their public profile was often high, the policy impact of the work of these commissions was not always very direct. In fact, commissions in the UK (for example the Community Cohesion Review Team, led by Ted Cantle), the Netherlands (the Temporary Parliamentary Investigative Commission on Integration Policy, led by Stef Blok), and to a lesser degree also Germany (the Commission on Immigration, led by Rita Süssmuth) show how easily the knowledge claims selected by these commissions can lead to public controversy and to contestation of the commissions' authority.

Furthermore, several of the cases suggest that the media play an increasingly important role in opening up dialogue structures to a broader set of actors and to the public. Dialogue structures in the rational policy model were mostly restricted to a relatively small network of scholars and policymakers. The traditional route was to communicate with policymakers directly, for instance in private without media coverage, in commissions, boundary organisations, or at conferences, informal dinners, and so on. Another route we have observed, especially in the Dutch, 
German, and British cases, involves communicating with policymakers indirectly, via the media. In the DIAMINT project we found numerous examples of public intellectuals who seek media attention in order to influence policymakers in this domain.

Finally, what can be observed in many countries, as well as at the EU level, is the growth of dialogue structures for purposes of policy monitoring. The German BAMF and the Dutch SCP can be considered as the most institutionalised versions of this type of dialogue structure. This also applies to MIPEX, though it monitors policy compliance rather than policy performance. A key rationale for dialogue structures of this type, which we will discuss further in the next section, is that they help identify areas for policy action and provide coordinating ministries with tools to mobilise policy intervention by other ministries and institutional bodies that possess 'hard governance' tools that enable them to act more directly in a specific policy area where such intervention is deemed necessary.

\subsubsection{Towards More Symbolic Knowledge Utilisation?}

Our comparative analysis provides strong support for the second hypothesis on the increasingly symbolic character of knowledge utilisation. Our analysis shows that politicisation does not impede knowledge utilisation, but rather changes its nature. All national cases show that the use of knowledge became increasingly symbolic in the 2000s. This includes forms of substantiating knowledge utilisation, where research is used to support already-decided policy choices, as well as forms of legitimising use, where research is used to boost the authority of specific policy actors.

Some of the cases, such as the British case in the 1950s and the Dutch case in the 1980s, indeed show how research initially provided a direct stimulus for policy development, thus accounting for instrumental forms of knowledge utilisation. This was also the case in Sweden, which was not included as a case study in this book (Hammar 2004). The other countries studied do not provide such clear evidence: generally we have found only incidental cases where individual academics may indeed have had an impact on policy development at key moments, as did the Vesselbo report in Denmark. This challenges the assumption in the literature that migrant integration research originally had a strong policy orientation. In fact, countries like Germany and Denmark, and to some extent also Italy and Austria, show a largely autonomous development of migration research and policymaking alongside each other, but with very little interaction.

Most of the cases examined reveal intriguing examples of symbolic knowledge utilisation. In the originally more instrumental cases of the Netherlands and the UK the use of knowledge claims clearly became more selective around the year 2000 , aimed at substantiating policies formulated in the political arena. In the UK, for example, research was utilised (at least partly) to substantiate the Community Cohesion frame that emerged in politics after the 'milltown riots' of 2001. In the 
Netherlands research-policy dialogues virtually came to a halt after the political developments of the early 2000s, with government only selectively using outcomes of carefully commissioned research for purposes of policy monitoring. Similarly in Austria, there is broad consensus over the selective use of knowledge, mainly driven by the development of in-house research facilities at the Ministry of Interior. In Denmark the state supported the Academy for Immigration Studies (AMID), thus legitimising its policy position. However, it hardly ever drew on the findings and recommendations of AMID studies.

Very specific forms of legitimising knowledge utilisation were found in Germany, the Netherlands, and also at the EU level. As has been mentioned earlier, the German and Dutch governments rely rather heavily on data produced by governmental research agencies such as BAMF and SCP. In both countries the choice of indicators for which data are being collected is made in collaboration with these government agencies. As such, these institutes provide 'mandated truths' (Salter 1988) that are used in the complex inter-departmental and multi-level governance of migrant integration. They provide ammunition to raise problem awareness and to trigger policy interventions by other actors. This confirms what Boswell has already observed: even in an extremely politicised domain such as migrant integration policymakers are keen on upholding "the myth of instrumental use" (Boswell 2009: 249). However, the German case in particular also shows how knowledge utilisation can be symbolic and legitimising, but at the same time also instrumental, particularly when the development of more concrete policy plans and measures and their implementation are at stake. The important differentiation to be made here is that this instrumental use is found primarily in relation to secondary policy aspects, whereas on the level of more fundamental policy premises it is much more difficult to discern.

The cases of the EU and European cities (see Chap. 6) demonstrate a different dynamic. The EU case shows that precisely because of the specific setting in which it operates and the absence of concrete policy measures, the mobilisation and more symbolic use of knowledge provide important tools for the soft-governance of migrant integration policies. At first, the EU initiated comparative research to facilitate 'horizontal policy learning' between member states. Very often this involved comparisons at the local level, possibly because local government often plays a crucial role in migrant integration. This EU approach can be interpreted as a legitimising form of knowledge utilisation, since such comparisons and the policy convergence at which they are aimed provide a basis for EU policy intervention. The Migrant Integration Policy Index (MIPEX) can be seen as a primary example of such legitimising forms of knowledge utilisation, as it monitors the compliance of member states with EU policies, and thus further legitimises EU policy intervention.

This has evolved into more substantiating forms of knowledge utilisation. And indeed, the EU is increasingly mobilising research based on specific EU policy priorities, as formulated in the Common Basic Principles of Integration, adopted in 2004, and the Stockholm Common Integration Agenda of 2009. At the same time, one may also observe a growing role for Eurostat, the EU's statistical agency, in data collection and in prescribing what data national statistical agencies in the member 
states should collect (see Chap. 3). This can be considered an indirect manner of agenda setting for the member states, comparable to the role agencies like BAMF and SCP play at a national level.

European cities have yet another position in the increasingly complex multi-level governance of migrant integration. Until 2003, their strategies and research-policy dialogues were largely determined by the question whether or not national integration policies existed at all, as illustrated by Dutch versus Swiss cities and their use of research (see Chap. 6). The very specific dialogue structures for horizontal learning that the networks of European cities have established since 2004, with strong support from the European Commission, are certainly novel. It is not clear whether the function we should attribute to these structures is primarily instrumental or symbolic. They seem to fulfil both.

In some cases, politicisation has also contributed to a growing contestation of research at large. This applies in particular to the case of Italy, traditionally characterised by a certain distrust toward social-scientific knowledge. To some extent it also applies to the Dutch case, where the credibility of migration scholars involved in policymaking in the 1980s and 1990s was openly put on the line in the 2000s; they were blamed for introducing a multiculturalist bias into Dutch policies. This reinforced a mode of 'articulation politics' characterised by clear political primacy, an orientation towards popular - if not populist - views and distrust, especially of research on a conceptual level. This speaks to Caponio et al. (2014) analysis of expertise being constructed not only before but also during the knowledge utilisation process. This underlines the social nature of processes of knowledge utilisation, whereby the knowledge that is potentially utilised is not 'out there waiting', but actively and constantly under construction and an object of on-going contestation. Many different actors - policymakers, experts, but also the media - are likely to be involved in the process, implying (partly) converging roles irrespective of their labels. As observed in our case studies, such role convergence stems from actors' common interest in increasing the 'epistemic authority' of some knowledge claims and claimants while decreasing the authority of other claims and claimants (ibid.).

\subsubsection{Knowledge Production: Beyond National Models of Integration}

Our analysis of knowledge production clearly shows how migration research has vastly expanded over the past decades, not just in the 'old' immigration countries in Europe, but increasingly also in the 'new' immigration countries. Undoubtedly the ongoing nature of immigration and the continued growth of migration-driven diversity in European societies have contributed to this growth. In terms of our third hypothesis on the diversification of knowledge claims and the rise of knowledge conflicts, our comparative analysis provides partial support. We indeed observe a 
decreasing relevance for researchers of so-called national models of integration in the various cases that have been examined. However, this seems to be related not just to politicisation and changing research-policy dialogues in these national settings, but also to broader developments such as the growing involvement of both the EU and local authorities, and the internationalisation of the migrant integration research community.

Whereas research in Austria, Germany and Italy was fragmented even before the issue had become more politicised, the Dutch and British cases indeed show a more gradual fragmentation. Before politicisation, migration scholarship in these countries was characterised by a relative consensus within their respective national contexts, leading to what have been framed as distinct 'national models of integration': the Dutch 'Ethnic Minorities' model and the British 'Race Relations' model. Following politicisation (which occurred much earlier in the UK than elsewhere), these national models became fragmented and contested. Both the UK and the Netherlands also reveal many instances of knowledge conflicts amongst scholars. In other countries, for example in Germany, migration scholarship has always been more fragmented, possibly even because of the absence of an institutional relationship to policy that could have sustained a single national model of integration. In Germany distinct schools of thought can be identified that co-evolved over the past decades, in particular an ethnic-minority approach, a socio-historical approach and a rational-choice approach. However, it is fair to say that in Germany, but also in other countries, such as Austria and Italy, knowledge claims have become even more diversified meanwhile, also along disciplinary lines.

The EU case again appears to be different, due to its recent genesis: there was simply no pre-existing unity against which a possible fragmentation could have taken place. Research initiated and supported by the EU has always had a special, comparative character.

Interestingly, the fragmentation of knowledge paradigms at the national level goes hand in hand with a growing alignment of knowledge paradigms between countries. Whether an indirect effect of EU involvement in this research area or just a symptom of a broader internationalisation of the academic world - exemplified by the development of various international networks such as IMISCOE - the growth of international and comparative research generated at the EU level has no doubt had an impact on national and local research as well. Knowledge paradigms seem to be increasingly developing along the lines of academic disciplines (political science, economics, sociology, anthropology, law) and this occurs in very similar ways in the various countries that we have examined.

Finally, our analysis also shows that, contrary to what has been suggested in the literature for specific cases (Favell 2003; Scholten 2009), the development of migrant integration as a research field has not necessarily been driven by 'co-production' or 'co-evolution' with the policy context. We do indeed see evidence of research-policy coordination in some countries, especially the Netherlands and less so in the UK. By contrast, however, Germany and Denmark, but also Italy and Austria, have witnessed a largely autonomous development of research and policy. In Italy and Austria government interest in research emerged long after 
a (national) research field had been established. In Germany migration research evolved relatively autonomously within various institutions strongly embedded in academia. In Denmark DAMES (the Danish Institution for Migration and Ethnic Studies) spurred the development of migration research as well as its international orientation without having a significant policy orientation.

\subsection{Research-Policy Dialogues on Naturalisation, Religion and Education}

In order to obtain a more detailed view of how research-policy dialogues take shape around concrete topics in the integration debate, each of our DIAMINT case studies also provides a more in-depth analysis of three core themes: naturalisation, education and the management of religious diversity. The selected themes not only represent three core issues in integration debates throughout Europe, but they also illuminate very different dimensions of migrant integration: the politico-legal, the socio-cultural, and the socio-economic dimensions respectively.

Naturalisation, as a theme closely associated with citizenship, and with significant implications for migrants' rights and entitlements, has been on the agenda in most countries before as well as after the politicisation of migrant integration.

The accommodation of new religious diversity in practically all cases primarily revolves around the growing salience of Islam in European society. This is one of the themes that has emerged more centrally on the agenda since the politicisation of migrant integration, though at different paces and to different degrees in the various cases.

Finally, reception policies for migrant children in primary and secondary education were chosen as a theme in the socio-economic field. The inclusion of newly-arrived migrants and their children in existing educational arrangements has also been on the agenda in all countries studied since the early days of immigration, but, as we will see, in very different ways. In what follows we will analyse what our studies of these three core themes have contributed to our understanding of dialogue structures, knowledge production and knowledge utilisation.

\subsubsection{Dialogue Structures: Differences Between Themes and Between Countries}

Our analysis reveals important differences in how research-policy dialogues are organised for the three chosen themes, both between and within the countries under study. Of these three, accommodating new religious diversity appears to be the most contested theme and it is not really surprising that the shape of researchpolicy dialogue structures on this issue differs significantly between all cases. In 
the Netherlands an informed dialogue between researchers and policymakers on religious pluriformity in general and Islam in particular has been largely absent. The same applies to Germany, although there the 'Islam Conference' provides opportunities for academics to exert indirect influence on policymakers. The British, Italian and Austrian cases all appear to be different again. In Austria we do see clear efforts to institutionalise a dialogue structure around this topic, via the increasingly influential 'Dialogue Forum Islam', in which there is also some room for knowledge production. In the UK, religion - and Islam in particular - has been central to the three government-sponsored commissions that have reported in the past decade (though with very different knowledge claims involved). However, even though these commissions have had great influence in many areas, their influence on policies relating to religion has been limited. In Italy, a special Scientific Committee has played a key role in drafting a charter on Values of Citizenship and Integration that includes a clear view on the role of religion in society.

On the theme of primary and secondary education for migrant youth, more systematic dialogue structures have emerged from our comparative analysis. Education is one of the areas where the collection of data and statistics (often governmentsponsored) plays a central role in the monitoring, evaluation and mobilisation of policy initiatives. This is perhaps best exemplified by the Dutch case where data collection by the Social and Cultural Planning Office (SCP) has been an important tool for policy coordination. Those data have been used, for instance, to monitor policy performance in different sectors and, if needed, to mobilise policy intervention by the relevant Ministries.

Our analysis shows that research and statistics can also play a role beyond that of policy evaluation and monitoring. The Programme for International Student Assessment (PISA), initiated by the OECD, for example, not only revealed a relatively modest overall educational performance in certain countries by comparing these to others, but it also indicated that young people of migrant background often perform well below the national average. In some countries, particularly in Austria and Germany, the PISA studies have had a great impact on national policymaking in the area of migrant integration, setting educational performance firmly on the political agenda and spurring a range of policy initiatives.

Finally, as regards naturalisation pronounced differences have emerged between the different cases examined. In the UK, academics and other experts played a central role in the revision of naturalisation policies, for example in the Commission for the Future of Multi-Ethnic Britain, the Community Cohesion Review Team and the Advisory Board on Naturalisation and Integration. Likewise in Italy the Commission for the Integration of Immigrants has had an important effect on the reform of legislation on naturalisation. In the Netherlands the role of academics on this theme has been less institutionalised, but academics nevertheless did exert influence on societal and political debates by advocating more liberal policies. In other countries, for example in Austria, naturalisation has been treated primarily as an issue for legal experts within the government, and at best some informal dialogue has taken place externally, often also involving other actors such as NGOs. 
What has also emerged from all examined cases is the role the media may play in shaping the debate between researchers, policymakers and other stakeholders on each of the three themes. Take, for instance, the key role of the media in enhancing the impact of the PISA scores in Germany and in encouraging public debate on this. We have also come across several examples of media actors who actively position themselves as participants in research-policy dialogues, which then broaden up to science-society dialogues. Certain media actors have more or less explicit political agendas, be it for opportunistic reasons or for ideological ones. In the UK, the Netherlands and Italy, for example, it is clear that some newspapers favour strict naturalisation policies and have a securitised view on Islam. We have also found examples of academics and 'public intellectuals' who use the media as a platform not only to communicate the outcomes of their research to a wider audience, but also to pursue political or ideological goals. This, of course, is perfectly legitimate in a democracy, but it can also be interpreted as interfering with the direct flow of ideas from science to policy (the transmission of 'truth to power'). Seeking media access enables some critical experts to get a 'public voice'. If it were not for the presence of open media outlets, policymakers might never hear some of these experts at all.

\subsubsection{Conditions for Instrumental and Symbolic Knowledge Utilisation}

In terms of knowledge utilisation, the DIAMINT cases reveal a complex interaction between knowledge producers, the (party-)political context and the media in all three thematic areas that we have analysed in depth. It is often hard to predict whether research outcomes will be used at all, and if so whether their use will be instrumental or symbolic. Political interests and media attention may certainly act as catalysts here, as with the 'PISA shock' in Germany, described earlier. There can be little doubt that the overwhelming and long-lasting media attention that PISA received convinced politicians of the need to act. Yet our more detailed analyses show that the process of knowledge utilisation is seldom clear-cut. In the UK, for example, ministers' attitudes towards the report by the Commission on the Future of Multi-Ethnic Britain changed from positive to negative once it had become apparent that media coverage of the report was overwhelmingly hostile. Still, in the final instance the report clearly inspired new legislation in the area.

Moreover, we tentatively conclude that there is greater potential for instrumental knowledge utilisation in relation to primary and secondary education than on the two other themes we have studied. Very often, however, research in the field of education appears to be unable to influence relevant policies at the policy paradigm level. In Austria, for example, the area of education is marked by the active role of boundary actors facilitating dialogue and a request for applied science with regard to teaching German as a second language. While the benefits of intercultural education or plurilingualism at school are widely recognised by scientists, NGOs, 
and policymakers, the current Austrian system is predominantly run under the monolingual 'submersive' school model.

As in Germany, the PISA project on education has also had some impact in Austria. In the area of education, the Italian case highlights the importance of the personal commitment and interest of policymakers in a specific issue. Furthermore, prior governmental influence also emerges as an important factor: dialogue contributions directly solicited by the government seem to stand a better chance of being used instrumentally, that is to modify existing policies or legislation. This, however, does not rule out symbolic uses.

From a comparison of all DIAMINT case studies we may conclude that symbolic knowledge utilisation is most prevalent with regard to the theme of accommodating new religious diversity. In comparison to naturalisation and education, religious diversity is also the theme most frequently covered by the media and where the influence of media is strongest. This is not surprising. All over Europe religious diversity is closely associated with the growing presence of Islam. This is a very sensitive and highly politicised issue that leaves little room for serious consideration of research outcomes.

With regard to naturalisation, the Austrian case signals a lack of willingness to use the outcomes of international research, particularly if these are not in line with national ideas on policymaking. This phenomenon is by no means unique to Austria. If knowledge produced by third parties, for example by international bodies, is unwelcome, governments may argue that the organisation that commissioned the research, such as the EU or the OECD, holds no responsibility for the policy area at stake and is therefore not qualified to pronounce on national policies. It is again the PISA example that shows the limited validity of such arguments.

Finally, it should be noted once more that academics sometimes actively seek to engage in research-policy dialogues via the media, thus following their own 'symbolic' interests, such as the wish to reproduce their expert status or to secure the relevance of their academic work or their specific organisation. This not only occurs at the level of individual researchers, but also at an institutional level. In the UK and the Netherlands in particular we found universities and research funders to be quite keen on generating media attention for their projects. Some researchers experience this pressure as an annoying side-effect of their work, whereas other scientists have developed close ties with journalists and co-create news stories with their media contacts on a regular basis.

\subsubsection{Knowledge Production: Knowledge Conflicts}

Moving to knowledge production, the various cases reveal clear conflicts between researchers on how to classify the three themes selected for our in-depth analysis. Not all stakeholders necessarily share our analytical categorisation of 'naturalisation', 'religion', and 'education' as politico-legal, socio-cultural and socio- 
economic issues. Differences exist among and between academics, politicians and others in the way they problematise and frame some major issues. Nowadays, for example, issues related to Islam are more often framed as security issues in both the political arena and the media.

In the Netherlands and Germany, for instance, the so-called 'radicalisation' of Muslim youth has been a key concern in the past decade. As a consequence, funding for research on this particular topic has been made available rather generously. The effect of this may be that in the perception of policymakers and the general public 'combating radicalisation' runs the risk of becoming a proxy to 'accommodating religious diversity'. In fact, in the Netherlands one of the earliest research projects into Islamic schools was carried out by the secret service AIVD, as reported by the Blok Committee (2004). It was also found in several cases that the public debate with regard to Islam has been quite different in tone and substance from the debate on other 'new' religions 'imported' by newcomers.

In the UK the Commission on the Future of Multi-Ethnic Britain noted that "[a]ggressive hostility to Islam is expressed in ways unthinkable in relation to other beliefs" (CMEB 2000: 10). As time went by, however, this Commission's proposal to improve the legal protection against discrimination of Muslims was adopted (ibid.). In other words, the Commission framed the issue of "new religious pluriformity' not as a problem of socio-cultural 'self-separation' of immigrant groups or even as 'backwardness' of Islam, as Pim Fortuyn did in the Netherlands around the same time - but as a challenge for the receiving society to uphold its own preexisting liberal democratic principles, which already protected Jews and Sikhs.

In the dialogues on naturalisation, social scientists and legal experts often adopted more liberal positions than policymakers did. In the Netherlands and Germany, for example, academics have advocated the acceptance of dual citizenship and presented naturalisation as an instrument in the integration process rather than as its end stage. Conversely, public opinion and media analysis reveal that having a single passport is perceived as a proxy for loyalty to the 'host nation'; thus securitisation processes are at work here as well. Several of our case studies also indicate that concrete empirical evidence on the relationship between naturalisation and integration (measured, for example, as labour market participation) is very scarce (see OECD 2011). As a consequence, the contribution of scientists to the naturalisation debate often focuses on philosophical and normative arguments rather than empirical arguments, as, for example, in Germany.

The main fault line in the domain of education centres on the question whether education should be approached as a socio-economic issue, which calls for emphasising equal opportunities for migrant children in the national educational system, or rather as a cultural issue. In the latter frame, for instance, reducing educational segregation is seen as an end in itself irrespective of the effects of such segregation on educational achievements of individual pupils. Another example of cultural framing came when Dutch and Austrian politicians denounced mother tongue teaching to migrant children on the grounds of principle, irrespective of the potentially positive long-term effects that teaching other languages may have on the educational careers of migrant children and on their integration in society. 
The framing of issues and differences in policy objectives and priorities have consequences for the kind of knowledge required. From the policymakers' perspective the production of such knowledge is not necessarily a purely academic affair. We have observed repeatedly that, as the area of migrant integration has become more politicised, governments become more selective in the types of research they use and support, while they also prefer to produce their own data more often. In specific cases this may lead to a dissension of opinions when it comes to generating and using comparable data on migrant integration at the European level. Not surprisingly, the EU's efforts to develop common indicators for integration have been only partially successful so far (see Chap. 3).

\subsection{Conclusions}

Our analysis has revealed profound changes in the dialogue structures associated with the research-policy nexus in the domain of migrant integration, rather than a clear de-institutionalisation of these dialogues, as we had initially expected. On the one hand, we have found that dialogue structures have become more ad-hoc, often established in response to distinct political events or to specific problems. A striking similarity between the countries involved in this study is the establishment of ad-hoc government commissions to channel research-policy dialogues at critical junctures in policy development. On the other hand, we have also found that politicisation has not thwarted all efforts to develop more institutionalised dialogue structures between producers and users of knowledge. 'Going technical' or mobilising specific types of research should not always be seen as a tactic of depoliticisation, but can also represent a strategy of 'politics by different means'.

Additionally, we found that in all cases studied here research-policy dialogues have gradually become more open. Though it is difficult to establish a clear relationship with politicisation here, we can speak of a gradual evolution from 'research-policy dialogues' to broader 'science-society dialogues'. In all countries analysed several new actors have emerged as participants in these science-society dialogues. In the British case this can be illustrated by comparing the composition of three independent commissions created to advice the government at different moments in the past decade. The membership of these commissions not only consisted of academics, but also included expert practitioners in areas such as law, health, local government, education, and journalism. Interestingly, the most influential of these commissions (the Community Cohesion Review Team led by Ted Cantle) left out academics altogether. In the Netherlands, the role of 'public intellectuals' in research-policy dialogues has increased noticeably; relevant names here are Paul Scheffer and Jaap Dronkers. From the Italian case study it becomes apparent how important (primarily faith-based) NGOs can be in providing knowledge to policymakers. The Austrian case study documented a central role for social partners alongside the very dominant Ministry of Interior. In Germany it was found that civil society initiatives, such as the Academies, were very open to 
diverse actors, playing an important stabilising role in research-policy dialogues on nationality legislation and on Islam. In all cases the DIAMINT researchers showed that the media should be conceptualised both as a platform for research-policy dialogues and as an important participant in such dialogues.

In the rational model of governance knowledge utilisation has traditionally been assumed as being direct and instrumental. Our analysis provides clear evidence that more symbolic forms of knowledge utilisation prevail in practically all cases. Knowledge is being used primarily not in an instrumental manner, but rather to legitimise government institutions or to substantiate government policies. This required, amongst other things, the mobilisation of specific data to be used as soft-governance tools for policy coordination (for instance through institutions such as BAMF, SCP, MIPEX) as well as the establishment of expert commissions to substantiate policy frames (such as the 'Community Cohesion' frame in the UK) or to justify abandoning existing frames (as the 'Germany is not an immigration country' frame in Germany). At the same time we can observe that, particularly in the Netherlands and Denmark - both older immigration countries that witnessed a substantial shift in their dominant policy approaches around 2000 - research-policy dialogues on the more conceptual level of policy framing have virtually come to a halt.

Furthermore, most cases provide evidence of the growing role of the media in processes of knowledge utilisation. Academics wishing to have a policy impact can basically opt for two routes. The first, more traditional route is to communicate with policymakers directly. In practice this mostly happens in private, without media coverage, in so-called 'boundary organisations' like advisory bodies, special commissions and think-tanks, and it also happens at conferences and informal workshops. A second route is to communicate with policymakers indirectly via the media. In this project we have found numerous examples of academics and public intellectuals who have developed media strategies to influence migrant integration policymaking. There is some evidence (particularly from the British and Dutch cases) that to a certain extent these two routes can be considered mutually exclusive. This is because communicating via the media has a 'cost': put simply, scientists who choose the public route tend to take more critical positions and this decreases the likelihood that they also interact with policymakers directly in more private networks. There is a link between the tone and content of researchers' messages, their media presence, and the usefulness of their expertise as perceived by policymakers.

Finally, our analysis has revealed a sharp increase in both the quantity and diversity of knowledge production and knowledge dissemination over the past decades in all cases examined. This makes it more complicated than in the past to identify or to construct a distinct research-policy nexus. Nowadays, many centres for knowledge production exist. Some are more academic and mono-disciplinary, while others are more akin to boundary organisations, deriving expertise from different disciplines involved in this area. Some use primarily quantitative methods, while others specialise in qualitative research. Some focus on comparative research, while others are more nationally or even locally oriented. It is beyond doubt that this has also facilitated a more selective use of knowledge claims within specific policy 
settings. It also signals, however, the maturing of migrant integration as a research area, in which room has developed both for more policy-oriented and for more theory-oriented schools.

Interestingly, this expansion and diversification appears to have taken place in the 'old' as well as in the 'new' immigration countries. This is not just an endogenous effect of all countries being increasingly confronted with migration and diversity, but it has also been provoked by the internationalisation of academic research as such. The European Union has played a dominant role in this process by facilitating the comparative research needed to support its growing involvement in this policy area. In addition, the research community itself has also been active in reaching out across national borders. IMISCOE, for example, one of Europe's largest research networks in the domain of migration and integration has fulfilled an important role in incorporating Central and East European scholars into the international research community.

Furthermore, our analysis provides evidence of how knowledge production and knowledge utilisation may influence one another. The changing nature of dialogue structures and new forms of knowledge utilisation have eroded nationally-oriented framings and models of migrant integration in those relatively few cases where these had come into existence. This evolution of dialogue structures and knowledge utilisation has provoked a fragmentation of migrant integration research in terms of numbers of institutes involved and it has also led to a diversification of knowledge paradigms. As an academic field of study migrant integration has come of age.

Open Access This chapter is distributed under the terms of the Creative Commons Attribution Noncommercial License, which permits any noncommercial use, distribution, and reproduction in any medium, provided the original author(s) and source are credited.

\section{References}

Bak Jørgensen, M. (2011). Understanding the research-policy nexus in Denmark and Sweden: The field of migration and integration. British Journal of Politics \& International Relations, 13(1), 93-109.

Beck, U. (1992). Risk society: Towards a new modernity. London: Sage.

Bertossi, C. (2011). National models of integration in Europe: A comparative and critical perspective. American Behavioral Scientist, 55(12), 1561-1580.

Blok Committee. (2004). Bruggen Bouwen. Eindrapport van de Tijdelijke Parlementaire Onderzoekscommissie Integratiebeleid. The Hague: SDU.

Boswell, C. (2009). The political uses of expert knowledge: Immigration policy and social research. Cambridge: Cambridge University Press.

Boswell, C., \& Hunter, A. (2014). The political functions of independent commissions: Comparing UK commissions on migrant integration and cohesion. Journal of Comparative Policy Analysis, published online 2014.

Brubaker, R. (1992). Citizenship and nationhood in France and Germany. Cambridge, MA: Harvard University Press.

Caponio, T., Hunter, A., \& Verbeek, S. (2014). (De)constructing expertise: Comparing knowledge utilisation in the migrant integration 'crisis'. Journal of Comparative Policy Analysis, published online 2014. 
CMEB. (2000). The future of multi-ethnic Britain: Report of the commission on the future of multiethnic Britain. London: Profile Books.

Duyvendak, J., \& Scholten, P. (2011). Beyond the Dutch "multicultural model". Journal of International Migration and Integration, 12(3), 331-348.

Entzinger, H., \& Scholten, P. (2013). The interplay of knowledge production and policymaking: A comparative analysis of research and policy-making on migrant integration in Germany and the Netherlands. Journal of Comparative Policy Analysis, published online September 2013.

Entzinger, H., \& Scholten, P. (2014). The interplay of knowledge production and policymaking: A comparative analysis of research and policy-making on migrant integration in Germany and the Netherlands, Journal of Comparative Policy Analysis.

Ezrahi, Y. (1990). The descent of Icarus: Science and the transformation of contemporary democracy. Harvard: Harvard University Press.

Favell, A. (2003). Integration nations: The nation-state and research on immigrants in western Europe. Comparative Social Research, 22, 13-42.

Geddes, A., \& Scholten, P. (2014). Policy analysis and Europeanization: An analysis of EU migrant integration policy-making, Journal of Comparative Policy Analysis, published online 2014.

Gieryn, T. F. (1999). Cultural boundaries of science: Credibility on the line. Chicago: University of Chicago Press.

Hammar, T. (2004). Research and politics in Swedish immigration management. In M. Jandl \& I. Stacher (Eds.), Towards a multilateral migration regime. Special Anniversary Edition dedicated to Jonas Widgren (pp. 11-34). Vienna: ICMPD.

Hoppe, R. (2005). Rethinking the science-policy dialogue structure: From knowledge utilisation and science technology studies to types of boundary arrangements. Poiesis \& Praxis, 3(3), 199-215.

Jasanoff, S. (2013). States of knowledge: The co-production of science and the social order. London: Routledge.

Koopmans, R., \& Statham, P. (2000). Migration and ethnic relations as a field of political contention: An opportunity structure approach. In R. Koopmans \& P. Statham (Eds.), Challenging immigration and ethnic relations politics. Oxford: Oxford University Press.

OECD. (2011). Naturalisation: A passport for the better integration of immigrants? Paris: OECD.

Penninx, R., Berger, M., \& Kraal, K. (Eds.). (2006). The dynamics of international migration and settlement in Europe. A state of the art. Amsterdam: AUP.

Salter, L. (1988). Mandated science: Science and scientists in the making of standards. London: Kluwer.

Scholten, P. (2009). The co-production of immigrant integration policy and research in the Netherlands: The case of the scientific council for government policy. Science \& Public Policy, 36(7), 561-573.

Scholten, P. (2011). Framing immigrant integration: Dutch research-policy dialogues in comparative perspective. Amsterdam: Amsterdam University Press.

Scholten, P., \& Verbeek, S. (2014). Politicization and expertise: Changing research-policy dialogues on migrant integration in Europe. Science \& Public Policy, published online 2014.

Thränhardt, D., \& Bommes, M. (2010). National paradigms of migration research. Göttingen: V\&R Unipress.

Vasta, E., \& Vuddamalay, V. (2006). International migration and the social sciences: Confronting national experiences in Australia, France and Germany. Basingstoke: Palgrave Macmillan.

Weingart, P. (1999). Scientific expertise and political accountability: Paradoxes of science in politics. Science and Public Policy, 26(3), 151-161.

Weiss, C. (1977). Research for policy's sake: The enlightenment function of social research. Policy Analysis, 3(4), 531-545.

Wildavsky, A. (1979). The art and craft of policy analysis: Speaking truth to power. London: Macmillan. 


\section{Appendices}

\section{Appendix I: Biographies of Authors}

Marthe Achtnich is a doctoral candidate in Social Anthropology at the University of Oxford studying at the Centre on Migration, Policy and Society (COMPAS) and the Institute of Social and Cultural Anthropology. Her doctoral research examines sub-Saharan African migrants in Libya and Malta. Marthe holds an MPhil in Migration Studies from the University of Oxford. Before working on the DIAMINT project, she worked for Foresight, the UK Government Office for Science, on a project on migration and global environmental change. She also worked with the International Organization for Migration (IOM) in Geneva and Malta.

Martin Bak Jørgensen - Associate Professor (male), has a PhD in Migration Studies. Works within fields of sociology, political sociology and political science. $\mathrm{He}$ has recently launched the book series 'Political and Social Change' with Peter Lang. Has co-edited volumes such as Irregular Migration in a Scandinavian Perspective, and special issue of Migration Letters 'Civil society and immigration - New ways of democratic transformation'. Has published, among others, in International Migration Review, JIMI and has contributed to edited volumes for Ashgate and Routledge. Vice-Chair of Nordic Migration Research. Co-Director of Nordic/Baltic node in the International Network on Migration and Development (INMD).

Christophe Bertossi is Director of the Centre for Migrations and Citizenship at the French Institute for International Relations in Paris; his research concerns citizenship and the roles of Muslims in the French military, gendarmerie, and hospitals. His most recent publications are As Cruzadas da Integracao na Europa (2012) and European States and their Muslim Citizens (Cambridge University Press, 2013, with John R. Bowen, Jan Willem Duyvendak, and Mona Krook). 
Maren Borkert holds a Doctorate in Sociology with a specialisation in migration and interethnic relations from the Universities of Bamberg (DE) and Padova (IT). Her main fields of research include migration and integration policies and regimes in Europe, transnationalisation and transformation as well as the nexus between ICTs and migration. Maren published and edited numerous reports, studies and book publications on immigration and immigrant related issues such as The Making of Migration and Integration Policies in Europe: Processes, Actors and Contexts in Past and Present (with G. Zincone and R. Penninx) and The Local Dimension of Migration Policies (with T. Caponio).

Christina Boswell is Professor of Politics and Co-Director of the Centre for Science, Knowledge and Policy at the University of Edinburgh. She has written extensively on questions of UK and European immigration and asylum policy, and the uses of knowledge in policy-making. Recent books include Migration and Mobility in the EU (co-authored with Andrew Geddes, Palgrave, 2011) and The Political Uses of Expert Knowledge: Immigration Policy and Social Research (Cambridge University Press, 2009).

Tiziana Caponio, Ph.D. in Political Science, is assistant professor of Dynamics and Policies of Migration at the Department of Cultures, Politics and Societies of the University of Turin. She is research affiliate at Collegio Carlo Alberto and collaborates with FIERI. She is co-chair of the Imiscoe Standing Committee "The Multilevel Governance of Migration", and member of the Council for European Studies at Columbia University. Among her recent publications: '(De-)Constructing expertise: Comparing knowledge utilisation in the migrant integration "crisis" (with Alistair Hunter and Stijn Verbeek), Journal of Comparative Policy Analysis, 2014 , in course of publication.

Jan Willem Duyvendak has been Distinguished Research Professor in Sociology at the University of Amsterdam since 2003, after having been director of the Verwey-Jonker Research Institute for Social Issues (1999-2003) and Professor of Community Development at the Erasmus University Rotterdam. His latest books include The Politics of Home. Nostalgia and Belonging in Western Europe and the United States (Palgrave Macmillan, 2011); Crafting Citizenship. Negotiating Tensions in Modern Society (Palgrave Macmillan, 2012, co-authored with Menno Hurenkamp and Evelien Tonkens); European States and Their Muslim Citizens (Cambridge University Press, 2014 co-edited with John Bowen, Christophe Bertossi, Mona Lena Krook); and New York and Amsterdam. Immigration and the New Urban Landscape (NYU Press, co-edited with Nancy Foner, Jan Rath and Rogier van Reekum, 2014).

Han Entzinger has been Professor of Migration and Integration Studies at Erasmus University Rotterdam since 2001. From 1986 to 2001 he held a similar chair at Utrecht University, and before that he worked inter alia for the Scientific Council for Government Policy (WRR) in The Hague and the International Labour Office 
in Geneva. He has published extensively on international migration, integration and multiculturalism and has consulted local and national governments and international organisations on these issues. He is the former president of the Research Committee on Migration of the International Sociological Association and currently is the deputy chair of the Scientific Committee of the European Union Agency for Fundamental Rights (FRA) in Vienna.

Andrew Geddes is a Professor of Politics at the University of Sheffield. Publications include, as author, Immigration and European Integration: Beyond Fortress Europe? (Manchester University Press, 2008) and, as co-author with Christina Boswell, Migration and Mobility in the EU (Palgrave, 2011). For the period 20142019 he has been awarded an Advanced Grant by the European Research Council for a project on the drivers of global migration governance.

Friedrich Heckmann is director of the european forum for migration studies (efms) and professor of sociology (em.) at the University of Bamberg. He received his academic education in sociology, history and economics at the Universities of Münster, Kiel, Lawrence (USA) and Erlangen-Nürnberg. Following research on socialisation and the history of sociology Heckmann has specialised in the sociology of migration and integration. He has been a co-founder of the Committee on Migration of the German Sociological Society and of the efms. Heckmann has been a consultant to the EU, the German Parliament, to federal states and cities and to foundations.

Alistair Hunter is currently a research fellow at the University of St Andrews. His research interests are migrant integration and transnationalism, with a special focus on older people. Previously he was involved in the DIAMINT project as a research fellow in the School of Social and Political Science, University of Edinburgh, where he also completed his PhD. Alistair will shortly be commencing a 3-year British Academy Postdoctoral Fellowship at the Alwaleed Centre, University of Edinburgh (2015-2018).

Albert Kraler has a background in political science and African studies. Since 2011, he has been programme manager of ICMPD's research department, which he first joined as a junior researcher in 2001. He also held fellowships at the Centre for Migration Research at the University of Sussex (UK, 2003-2004) and the Department of Political Sciences, University of Vienna (2005-2006). He has widely published on migration statistics and migration statistics policy, irregular migration, regularisation, family related migration, and migration policy. He also published on global and African migration patterns, migration and development and politics in peripheral states.

Mikołaj Pawlak, $\mathrm{PhD}$ is assistant professor of sociology at the Institute of Social Prevention and Resocialisation, University of Warsaw. His research interests cover new institutional theory, migration studies and sociology of knowledge. Mikołaj Pawlak applies the new institutional perspective in organization studies to the 
problem of emerging policies of immigrant integration in Poland. He is also engaged in civic activism in favour of immigrants - he used to lead the research group at Caritas Poland and now serves as a member of the supervisory board of the Foundation for Social Diversity.

Rinus Penninx has been involved in the field of migration and settlement of immigrants in several capacities. His report Ethnic Minorities (1979) formed the starting point for integration policies in the Netherlands. From 1978 to 1988 he worked in Dutch ministries in research and policy making on integration of immigrants in the Netherlands. He founded the Institute for Migration and Ethnic Studies at the University of Amsterdam in 1993 and was its director until 2005. From 1999 to 2009 he was co-chair of the International Metropolis project. He was coordinator of the IMISCOE Network of Excellence (2004-2009) and the IMISCOE Research Network (2009-2014).

Sandra Pratt was an official in the European Commission from 1988 to 2007. In 1999 she joined the Immigration and Asylum Unit of the newly established Directorate General for Justice and Home Affairs and became its Deputy Head in 2003. She was responsible for the conception of the common EU immigration policy and the development of its integration strand in the immediate post-Tampere period. Her work included maintaining relations with international and other organisations and with the academic community in the EU concerned with immigration and asylum issues.

David Reichel has a sociology background, with a specialisation on quantitative methods. Since 2014 he has been working as a research officer in the Statistics and Surveys Sector at the Freedoms and Justice Department of the European Union Agency for Fundamental Rights (FRA). Before joining FRA, he was a researcher at the International Centre for Migration Policy Development and an external lecturer at the University of Vienna. His areas of work include survey methodology and statistical data analysis with special focus on the international context. His publications cover topics of migration and integration statistics, irregular migration, discrimination and naturalisation of immigrants.

Jan Schneider is Head of the Research Unit of the Expert Council of German Foundations on Integration and Migration. He holds a doctoral degree in Political Science (University of Giessen) and his research is focussed on migration/integration issues and the politics of policy advice. Jan has worked as Researcher for the European Migration Network within the German Federal Office for Migration and Refugees (BAMF) and taught migration policy at the Universities of Halle-Wittenberg and Erlangen-Nuremberg. He is also a Research Fellow at the Hamburg Institute of International Economics (HWWI) and serves as Editorial Board Member to the European Website on Integration. 
Peter Scholten is Associate Professor Public Policy \& Politics at the Erasmus University Rotterdam. His research focuses on themes of intercultural governance, migration and integration policies, and the relationship between knowledge and power. Peter is editor in chief of Comparative Migration Studies and, since 2014, associate director of IMISCOE, Europe's largest research network in the field of migration, integration and social cohesion studies.

Ann Singleton is the Head of the Centre for the Study of Poverty and Social Justice at the School for Policy Studies, University of Bristol and Co-Chair of the Statewatch Trustees. Ann specialises in asylum and international migration policy and statistics in the UK and the European Union, focusing on the use of international migration data in policy development. She has advised the European Commission, European Parliament, Council of Ministers and EU Presidencies and collaborates with many NGOs. Between 2002 and 2004 Ann was responsible for policy on statistics in the European Commission's then Directorate-General for Justice and Home Affairs.

Stijn Verbeek studied political science at the University of Amsterdam (UvA) and the Free University of Berlin. His Ph.D. thesis on Diversity Policies and Ethnic Minority Representation was written at the Sociology Department of the Erasmus University Rotterdam. In the DIAMINT project, he formed part of the international coordinating team and the Dutch team. Stijn published (with others) in journals such as Journal of Comparative Policy Analysis, Personnel Review, Review of Public Personnel Administration, Science and Public Policy, and The International Journal of Human Resource Management. Stijn currently works as a senior policy advisor for the Education Council of the Netherlands.

Delia Wiest is a sociologist (Dipl.-Univ.) and has specialised in the sociology of migration and inter-ethnic relations. She studied sociology, demography, empirical research and cultural geography at the University of Bamberg and the Università degli Studi di Roma I "La Sapienza". She was a researcher at the european forum for migration studies (efms) from 2010 to 2012. Her main research activities focused on migration and integration policies in Germany and Europe. Currently Delia Wiest is completing an interdisciplinary master's programme on urban planning at the HafenCity University of Hamburg. 


\section{Appendix II: Publications of the DIAMINT Project/IMISCOE Standing Committee on Research-Policy Dialogues}

\section{Publications}

- Scholten, P. and Verbeek, S. (2014). Politicization and Expertise: Changing research-policy dialogues on migrant integration in Europe. In: Science \& Public Policy.

- Boswell, C. and Hunter, A. (2014). The Political Functions of Independent Commissions: comparing UK commissions on migrant integration and cohesion, in Journal of Comparative Policy Analysis, published first online.

- Geddes, A. and Scholten, P. (2014). Policy Analysis and Europeanization: An analysis of EU migrant integration policymaking. In Journal of Comparative Policy Analysis, published first online.

- Caponio, T., A. Hunter and S.R. Verbeek (2014). (De)constructing expertise: comparing knowledge utilisation in the migrant integration 'crisis.' In: Journal of Comparative Policy Analysis, published first online.

- Entzinger, H. and Scholten, P. (2014) The interplay of knowledge production and policymaking: A comparative analysis of research and policy-making on migrant integration in Germany and the Netherlands. In: Journal of Comparative Policy Analysis, published first online.

- Scholten, P. and Van Nispen, F. (2014). Policy analysis at times of crises: windows of opportunity for policy learning? In: Journal of Comparative Policy Analysis, published first online.

- Boswell C., Geddes A. and Scholten, P. (2011). States, Knowledge and Narratives of Migration: The Construction of Immigration in Migration Policy-Making in Europe. British Journal of Politics and International Relations, 13:1.

- Boswell, C. (2011). Migration control and narratives of steering. The British journal of politics \& international relations, 13(1), 12-25.

- Scholten, P. (2011). Framing immigrant integration: Dutch research-policy dialogues in comparative perspective. Amsterdam: Amsterdam University Press.

- Bleich, E. (2011). Social research and 'race' policy framing in Britain and France. The British Journal of Politics \& International Relations, 13(1), 59-74.

- Jørgensen, M. B. (2011). Understanding the research-policy nexus in Denmark and Sweden: The field of migration and integration. The British Journal of Politics \& International Relations, 13(1), 93-109.

- Scholten, P. (2011) Constructing Dutch immigrant policy. Research-policy relations and immigrant integration in the Netherlands. In: British Journal of Politics and International Relations, 13:1.

- Penninx, R. (2005). Bridges between research and policy? The case of post-war immigration and integration policies in the Netherlands. International Journal on Multicultural Studies, 7(1), 33-48. 


\section{Reports}

- Borkert, M. and Leipold, M. (2012). DIAMINT: state of the art report on Austrian science-society dialogues. Working paper.

- Boswell, C. and Hunter, A. (2012). DIAMINT: state of the art report on UK science-society dialogues. Working paper.

- Caponio, T. and Quirico, M. (2012). DIAMINT: state of the art report on Italian science-society dialogues. Working paper.

- Geddes, A. (2012). DIAMINT: state of the art report on EU science-society dialogues. Working paper.

- Heckmann, F. and Wiest, D. (2012). DIAMINT: state of the art report on German science-society dialogues. Working paper.

- Verbeek, S., Scholten, P., Entzinger, H. (2012). DIAMINT: state of the art report on Dutch science-society dialogues. Working paper.

- Penninx, R., \& Scholten, P. (2009). Research-policy dialogues on migration and integration in Europe. IMISCOE Policy Brief.

\section{Events}

- Joint IMISCOE-ICPA symposium 'Policy Learning at times of Crisis', Erasmus University Rotterdam, 23-24 November 2013.

- DIAMINT Project Conference, 26-27 September 2013, Erasmus University Rotterdam.

- Panel on 'Science-society dialogues on migrant integration in Europe' at the CES Conference Amsterdam, 25-27 June 2013.

- IMISCOE panel on 'Science-society dialogues on migrant integration in Europe', Amsterdam 28-29 August, 2012.

- IMISCOE Conference 'Research-policy dialogues on migrant integration in Europe', University of Twente, 22-23 May 2008. 